\title{
MATING SYSTEMS AND INFANT CARE OF COOPERATIVELY BREEDING BLACK-FRONTED TAMARINS (LEONTOCEBUS NIGRIFRONS)
}

\author{
DISSERTATION \\ FOR THE AWARD OF THE DEGREE \\ „DOCTOR RERUM NATURALIUM“(DR. RER. NAT.) \\ OF THE GEORG-AUGUST-UNIVERSITÄT GÖTTINGEN \\ WITHIN THE DOCTORAL PROGRAM BIOLOGY
}

OF THE GEORG-AUGUST UNIVERSITY SCHOOL OF SCIENCE (GAUSS)

SUBMITTED BY

DARJA SLANA

FROM PTUJ, SLOVENIA

GÖTTINGEN, 2019 


\section{$\underline{\text { Thesis committee }}$}

Prof. Dr. Eckhard W. Heymann

Behavioral Ecology \& Sociobiology, German Primate Center, Göttingen

Prof. Dr. Julia Fischer

Cognitive Ethology Laboratory, German Primate Center, Göttingen

Prof. Dr. Julia Ostner

Department of Behavioral Ecology, Johann-Friedrich-Blumenbach Institute for Zoology and Anthropology, University of Göttingen

\section{Members of the Examination Board}

Reviewer: Prof. Dr. Eckhard W. Heymann

Behavioral Ecology \& Sociobiology, German Primate Center, Göttingen

Second Reviewer: Prof. Dr. Julia Ostner

Department of Behavioral Ecology, Johann-Friedrich-Blumenbach Institute for Zoology and Anthropology, University of Göttingen

\section{Further members of the Examination Board}

Prof. Dr. Julia Fischer

Cognitive Ethology Laboratory, German Primate Center, Göttingen

PD Dr. Christian Roos

Primate Genetic Laboratory, German Primate Center, Göttingen

Prof. Dr. Matthias Waltert

Conservation Biology/ Workgroup on Endangered Species, University of Göttingen

Prof. Dr. Margarete Boos

Georg-Elias-Müller-Institut for Psychology, Department of Social and Communication Psychology, University of Göttingen 



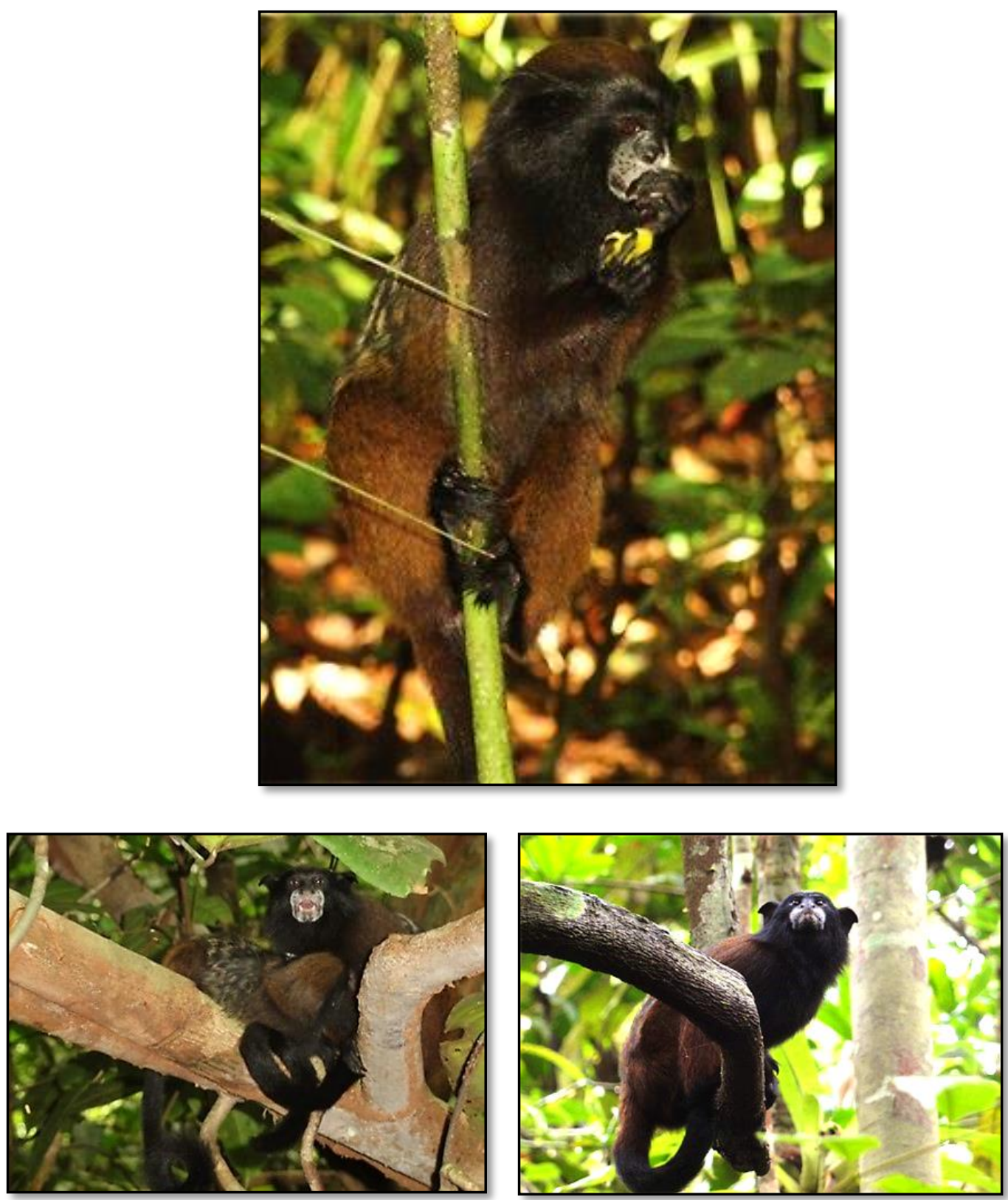



\section{Table of Contents}

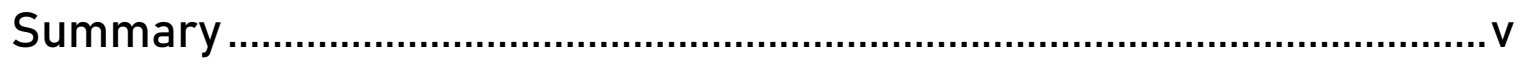

Zusammenfassung .................................................................................

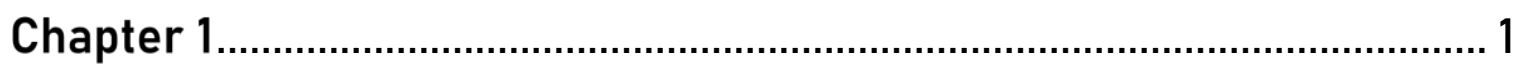

General introduction

Chapter 2

Study species

Chapter 3

General methods

Chapter 4

Mating systems and infant care in a co-operatively breeding primate Leontocebus nigrifrons, in single- and multi-female breeding groups

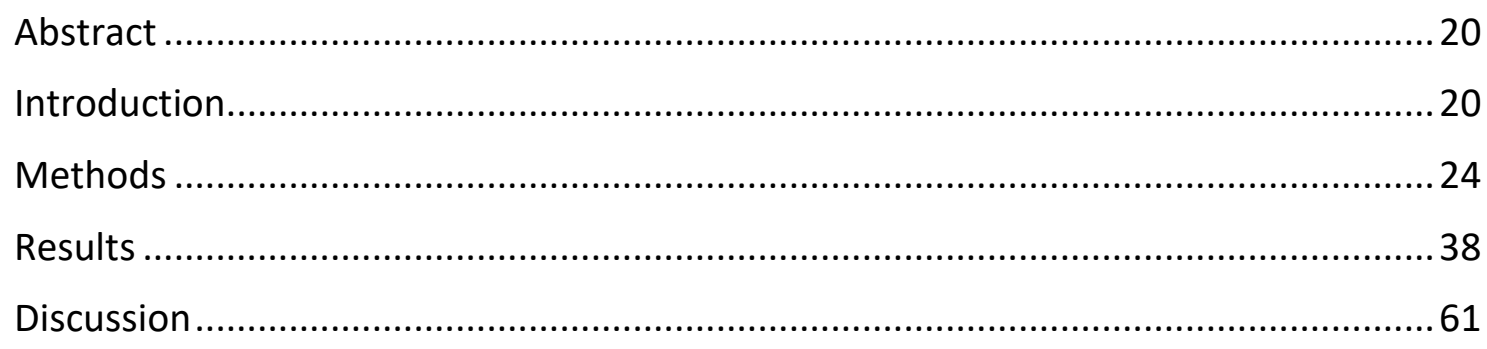

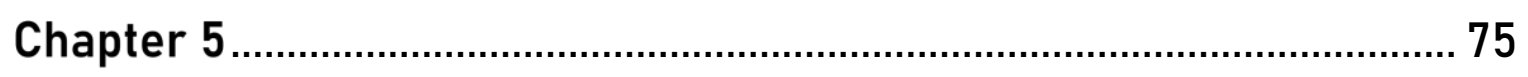

Activity budget changes while carrying infants in a co-operatively breeding primate

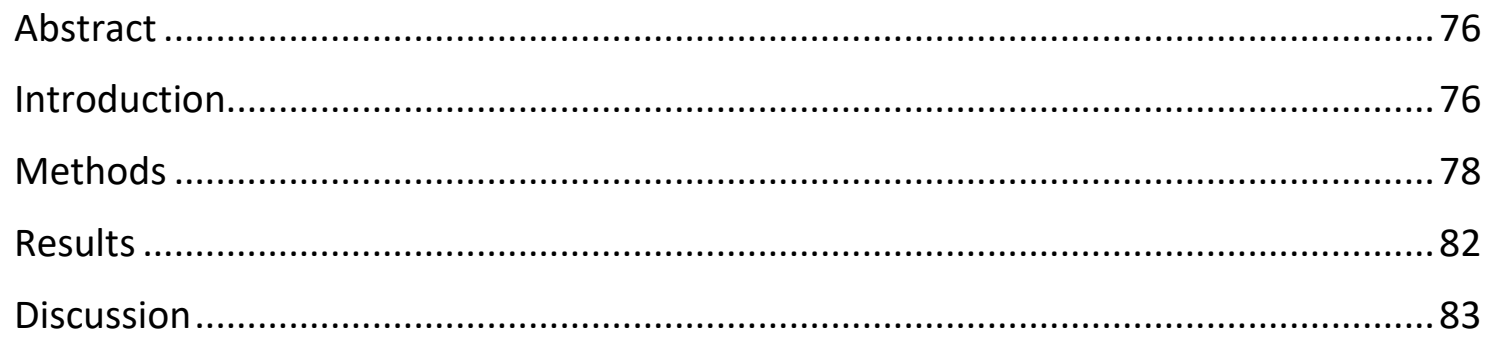


Chapter 6 .

Is infant care associated with physiological stress in a cooperatively breeding wild primate?

Abstract 1

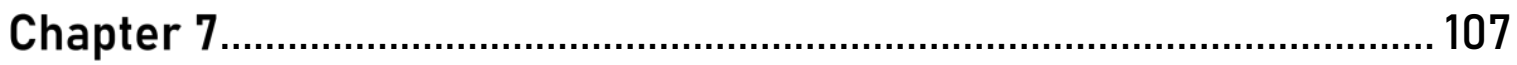

General discussion

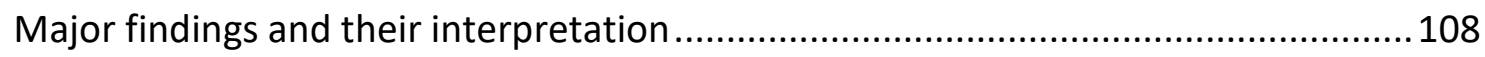

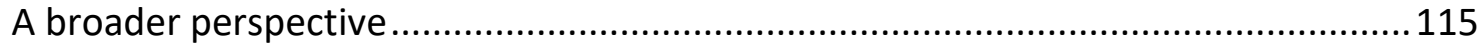

Strengths and limitations of this thesis, and future recommendations ......................124

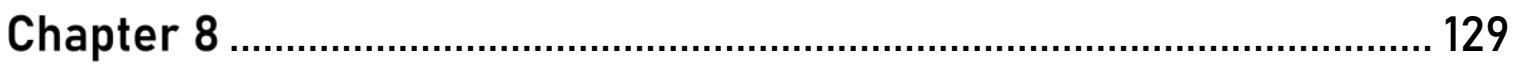

Conclusions

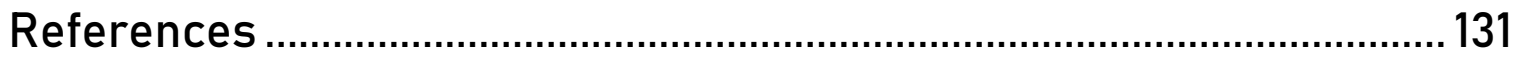

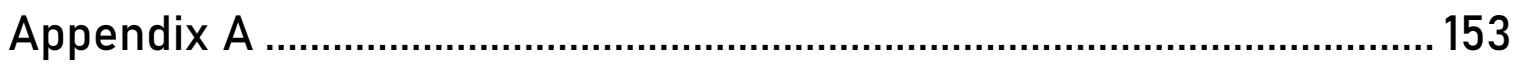

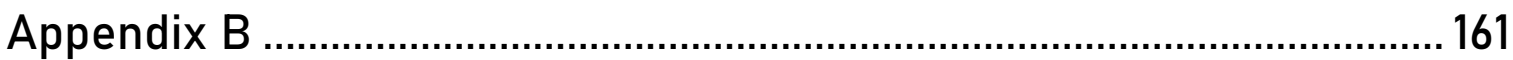

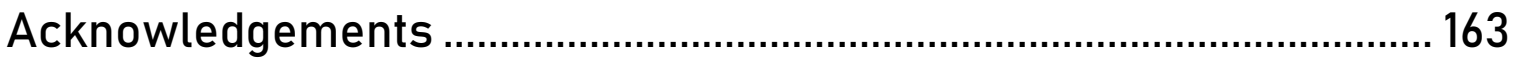

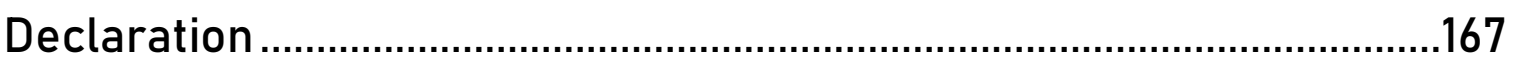

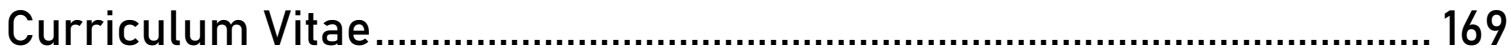


Table of Contents 

In animal societies, individual fitness partly depends on a decision on whether or not to provide parental care, and the number of mating partners. The later defines a social mating system, whereas consequences of copulations, namely breeding, define a genetic mating system, which may or may not be the same, i.e. monogamous, polyandrous, polygynous or promiscuous. Copulations and breeding are means to produce offspring, whereas parental care is a means to ensure offspring survival and ultimately its reproduction. In terms of fitness, parental care benefits the parents but can also incur costs, e.g. mobility constraints, increased risk of predation, higher energy expenditure. These costs may provoke a stress response, i.e. activated HPA axis and results in increased glucocorticoids in the blood. Short-term HPA axis activation ensures availability of additional energy and may be beneficial for coping with short-term stress, whereas longterm HPA axis activation may lead to damaging consequences, e.g. in health, reproduction and it may alter behavior. Whether or not parental care costs results in increased glucocorticoid production, parental care cost are especially high in female mammals, due to obligatory gestation and lactation, and even more so for primate mothers, because they often transport their infants alone. On the contrary, primate males are not equally constrained. One of the parental care costs are reduced additional mating opportunities, thus a compromise between parenting effort and copulations must be reached. Infant care can be monoparental, biparental, or extended to other group members, nonreproductive adults and subadults or so-called helpers. The latter is a characteristic of a cooperatively breeding system, which can be found within only a small percentage of animal species, including birds, mammals, fish, and insects. Within primates, only one family is classified as cooperative breeders: family Callitrichidae (marmosets and tamarins). In addition, callitrichids have flexible reproductive strategies, with the prevailing polyandry, particularly high amount of paternal care and normally only one breeding female per group, which usually gives birth to twins - dizygotic chimers. Callitrichid infants are heavy, regularly fed and carried for approximately three months, and caring for these infants is energetically costly. 
In this thesis, I aimed to understand why some individuals, especially adult males, contribute more to infant care than others, and how does infant care relate to mating systems. For this reason I tried to identify mating systems, I measured infant-directed behavior, activity budgets while carrying or not and fecal cortisol metabolites (FCM) in relation to carrying and time periods - carrying or non-carrying. Adult males were the focus of this study because they are often the main carriers in callitrichids. I studied five wild groups of black-fronted tamarins (Leontocebus nigrifrons) from lowland Amazonia. I found that infant care shifts activity budgets: decrease feeding and foraging time yet increased time spend in vigilance. I suggest that these shifts are due to mobility constraints of carrying heavy infants, which are likely to contribute to behavioral modifications of predator avoidance strategies. Moreover, these changes are likely to incur energetic costs, implying that infant care may be stressful. Nonetheless, I found no increase in FCM levels in relation to infant care, thus I suggest that infant care is not physiologically stressful, potentially due to infants acting as a stress buffer. Females are likely to base their infant care contribution on whether they are breeders or not. Males are likely to base their infant care contribution on their physical fatigue, but most of all on their level of paternity certainty, which depends on the social system of a mother whether a male copulated with her and whether other males also copulated with her. Shared paternities of twin litters, limited monopolization of paternities (only within a one twin litter) and extra-group copulations may be due to consorting males not sensing the entire female fertile period. I suggest that extra-group copulations are an important breeding strategy and that callitrichid mating system definitions cannot be limited to within a group description. Taken together, these complex relations are likely to relate to monogamy not being a modal mating system in callitrichids. 


\section{Zusammenfassung}

Bei gruppelebenden Tieren hängt die individuelle Fitness teilweise davon ab, ob man elterliche Brutpflege leistet und mit wie vielen Partnern man sich paart. Letzteres definiert das soziale Paarungssystem, während die Konsequenz der Kopulationen, nämlich die erfolgreiche Fortpflanzung, das genetische Paarungssystem definiert. Diese Paarungssysteme, Monogamie, Polyandrie, Polygynie und Promiskuität, können, müssen aber nicht übereinstimmen. Kopulationen und Fortpflanzung sind Wege um Nachwuchs zu erzeugen, während Brutpflege dazu dient das Überleben des Nachwuchses zu sichern und letztendlich dessen eigene Fortpflanzung. Elterliche Brutpflege wirkt sich positiv auf die inklusive Fitness der Eltern aus, aber hat gleichzeitig negative Auswirkungen auf ihre individuelle Fitness, wie zum Beispiel eine eingeschränkte Mobilität, ein erhöhtes Prädationsrisiko und ein höherer Energieverbrauch. Diese negativen Effekte können eine Stressreaktion auslösen, sodass die HPA-Achse aktiviert wird, was zu einem Anstieg der Glucocorticoide im Blut führt. Eine kurzzeitige Aktivierung der HPA-Achse gewährleistet die Verfügbarkeit von zusätzlicher Energie und kann vorteilhaft für die Bewältigung von kurzzeitigem Stress sein. Im Gegensatz dazu kann eine langfristige Aktivierung der HPAAchse negative Konsequenzen haben, z.B. für Gesundheit und Fortpflanzung, und sie kann das Verhalten verändern. Unabhängig davon, ob die Fitnesskosten von elterlicher Brutpflege eine erhöhte Produktion von Glucocorticoiden nach sich ziehen, die Kosten der Brutpflege sind besonders für weibliche Säugetiere durch Trächtigkeit und Säugen hoch. Insbesondere gilt das für Primaten, da hier die Mütter auch nach der Geburt oftmals allein für den Transport der Jungtiere verantwortlich sind. Im Gegensatz dazu sind männliche Primaten nicht in vergleichbarer Weise eingeschränkt. Eine der negativen Auswirkungen der Brutpflege ist die geringere Zahl an zusätzlichen Paarungsmöglichkeiten, sodass Tiere einen Kompromiss zwischen Brutpflege und weiteren Kopulationen eingehen müssen. Die Brutpflege kann von einem oder beiden Elternteilen übernommen werden, oder sie kann sich auf weitere Gruppenmitglieder verteilen. Diese sogenannten „Bruthelfer“ sind subadulte Tiere oder Adulte, die sich selbst nicht fortpflanzen. Bruthelfer sind ein 
Merkmal von kooperativer Brutpflege, die nur bei wenigen Arten von Vögeln, Säugetieren, Fischen und Insekten vorkommt. Innerhalb der Primaten kommt kooperative Brutpflege nur in der Familie der Callitrichidae (Marmosetten und Tamarine) vor. Die Callitrichidae haben zusätzlich flexible Fortpflanzungsstrategien, wobei Polyandrie vorherrscht; außerdem betreiben sie eine besonders aufwändige Brutpflege und normalerweise gibt es nur ein reproduktives Weibchen in einer Gruppe, welches meist Zwillinge gebärt, die dizygotische Chimären sind. Die Jungtiere der Callitrichidae sind schwer, werden regelmäßig gefüttert und circa drei Monate lang getragen; sie zu versorgen kostet daher viel Energie.

In dieser Dissertation versuchte ich zu verstehen, warum manche Individuen, insbesondere adulte Männchen, mehr zur Brutpflege beitragen als andere und wie Brutpflege mit dem Paarungssystem zusammenhängt. Um diesen Fragen nachzugehen versuchte ich Paarungssysteme zu identifizieren, protokollierte das Verhalten gegenüber Jungtieren und Aktivitätsbudgets sowie fäkale Cortisolmetabolite (FCM) in Zeiträumen, in denen Individuen Jungtiere trugen oder nicht. Adulte Männchen waren der Fokus der Studien, da sie bei den Callitrichidae oft die wichtigsten Träger sind. Ich erforschte fünf frei lebende Gruppen von Schwarzstirntamarinen (Leontocebus nigrifrons) im Amazonastiefland. Ich konnte zeigen, dass Brutpflege das Aktivitätsbudget beeinflusst: Die Zeiten für Nahrungssuche und -aufnahme nahmen ab, währen die Zeit der Wachsamkeit zunahm. Vermutlich gehen diese Verschiebungen darauf zurück, dass das Tragen von schweren Jungtieren die Mobilität eines Individuums einschränkt, was wahrscheinlich die Anpassung von Strategien zur Prädationsvermeidung mit sich bringt. Zusätzlich bringen diese Veränderungen wahrscheinlich energetische Kosten mit sich, was impliziert, dass Brutpflege Stress verursacht. Nichtdestotrotz fand ich keinen Anstieg der FCM im Zusammenhang mit Brutpflege, was darauf hindeutet, dass Brutpflege nicht physiologisch belastend ist, eventuell weil Jungtiere als Puffer gegen Stress wirken. Bei Weibchen hängt der Beitrag zur Brutpflege meist davon ab, ob sie sich selbst fortgepflanzt haben. Bei Männchen hängt der Beitrag zur Brutpflege auch von der physischen Erschöpfung ab, aber vor allem wird er durch den Grad der Gewissheit der Vaterschaft bestimmt. Dieser hängt vom sozialen Paarungssystem der Mutter ab - davon, ob das Männchen mit ihr kopuliert hat und ob noch andere Männchen mit ihr kopuliert haben. 
Geteilte Vaterschaften der Zwillingswürfe, beschränkte Monopolisierung der Vaterschaft (nur innerhalb eines Zwillingswurfs) und Kopulationen außerhalb der Gruppe gehen eventuell darauf zurück, dass die paarungswilligen Männchen nicht die gesamte fruchtbare Zeit der Weibchen wahrnehmen. Meine Ergebnisse legen nahe, dass Kopulationen außerhalb der Gruppe eine wichtige Fortpflanzungsstrategie sind und dass Definitionen der Paarungssysteme der Callitrichidae sich nicht auf eine Beschreibung innerhalb der Gruppe beschränken lassen. Insgesamt rühren diese komplexen Beziehungen wohl daher, dass Monogamie nicht das vorherrschende Paarungssystem der Callitrichidae ist. 



\section{Chapter 1}

\section{General introduction}

A simple life cycle. Two cells merge to form a zygote that may or may not survive to adulthood. As an adult, it may mate, produce offspring and the cycle begins anew. Differences in fitness among individuals, i.e. to survive and reproduce, may arrive from differences at any of these life stages. Animal fitness partly depends on individual strategies, including decisions on whether or not to provide parental care, and the number of mating partners. The latter defines the mating systems: one mating partner defines monogamy, more than one mating partners define polygamy. Further division of polygamy depends on the sex-ratio: if a male mates with more than one female, that constitutes polygyny, if a female mates with more than one male, that constitutes polyandry and if more than one female mates with more than one male, that constitutes promiscuity. Another important aspect of mating systems is that includes two components, social and genetic. Social mating systems are defined by a specific type of interaction, namely copulations, whereas genetic mating systems are defined by the consequences of copulations, namely breeding (Clutton-Brock 1991; Kappeler and van Schaik 2002; Smiseth et al. 2012).

Copulations and breeding are means to produce offspring, whereas parental care is a means to ensure offspring survival and ultimately its reproduction. Parental care is defined as any parental trait that increases offspring fitness (Clutton-Brock 1991; Kappeler and van Schaik 2002; Orr 2009; Smiseth et al. 2012). Parental traits vary considerably, starting with gamete provisioning (Williams 1994, birds; Fox and Czesak 2000, arthropods), up to the care of mature offspring (Surbeck et al. 2011, Pan paniscus). Parental care can be viewed as direct and indirect care. Behaviors like infant carrying and 
food transfer are considered direct parental care because they are immediately beneficial for the offspring. Behaviors like territorial defense and vigilance are considered indirect parental care because they would be performed regardless of an offspring's presence, still, they might benefit an offspring (Muller and Emery Thompson 2012). In this thesis, I am concerned with social and genetic mating systems and direct infant care ${ }^{1}$.

Parental care benefits the parents but can also incur costs. Offspring survival and reproduction represent the benefits, whereas the costs are often linked to constraints in mobility, increased risk of predation, and higher energy expenditure (Clutton-Brock 1991; Smiseth et al. 2012). If energetic costs represent challenging, aversive and arousing situations they may provoke a stress response (Moberg and Mench 2000). In vertebrates, stress is usually detected through increased glucocorticoid output, such as the hormone cortisol (Sapolsky et al. 2000) that can be measured in blood, urine or in feces (Moberg and Mench 2000). Cortisol is created in the adrenal glands and controlled by the hypothalamic-pituitary-adrenocortical (HPA) axis system, which is typically regarded as the body's primary stress-responsive neuroendocrine system. Within a few minutes after exposure to a stressor the HPA axis increases secretion and circulating levels of glucocorticoids in the blood (Hennessy et al. 2009, review). Depending on a stressor, HPA axis activation can be short- or long-term. Exposure to long-term stress, results in prolonged and repeated HPA axis activation and may lead to damaging consequences (Moberg and Mench 2000), e.g. in health, reproduction and it may alter behavior. But exposure to short-term stress activates the HPA axis for only a short time and the amount of released glucocorticoids is adaptive for coping with the short-term stressors (Sapolsky et al. 2000, review). What happens is that the HPA axis response promotes the reallocation of resources from energy consuming systems, like immunity and reproduction. Thus, short-term HPA axis activation ensures availability of additional

\footnotetext{
${ }^{1}$ In this thesis I interchangeably use the terms "parental care" and "infant care". Infant care is equivalent to the term parental care, but with one difference. Parental care includes only parent-offspring dyad, whereas infant care involves any caretaker-offspring dyad, including parents, in regards to providing care for offspring.
} 
energy that may help to ease damaging effects of short-term stressors (Willner 1993; Wingfried and Sapolsky 2003), such as carrying infants.

Whether or not parental care costs results in increased glucocorticoid production, i.e. stress, due to obligatory gestation and lactation, parental care costs are especially high in female mammals. For primate mothers the parental costs are even higher, because they often transport their infants alone (van Noordwijk 2012). On the contrary, primate fathers are not equally constrained: they cannot provide the two most energy consuming parental traits, (gestation and lactation) (Oftedal 1984). Thus whether to care for offspring and to what degree is a fundamental question of male reproductive strategies. One of the parental care costs are reduced additional mating opportunities, thus a compromise between parenting effort and copulations must be reached (Trivers 1972; Maynard Smith 1977; Muller and Emery Thompson 2012). Primate males show a variety of combinations, including both sides of the extremes: polygynous males with little or low parental care, e.g. chimpanzees and gorillas (Muller and Wrangham 2004a, Pan troglodytes; Harcourt and Stewart 2007, Gorilla gorilla), and social monogamy and high infant investment, e.g. Azara's night monkey (Rotundo et al. 2005, Aotus azarae), but also males who occasionally care for unrelated infants, supposedly to gain access to the mother, e.g. olive baboons (Smuts and Gubernick 1992, Papio anubis). Overall, in comparison to other mammals, the number of primate taxa that provide paternal care is high (Kleiman and Malcolm 1981; Whitten 1987).

Thus, infant care can be monoparental, i.e. provided by one parent, biparental, provided by both parents, but it can also extend to other group members, non-reproductive adults and subadults or so-called helpers ${ }^{2}$. The latter is a combination of parental and alloparental care and is in addition to strong ecological constraints on dispersal or

\footnotetext{
2 With the term "helpers" I refer to non-breeding individuals who help to rear offspring. In callitrichids all group members, i.e. parents and helpers contribute with infant care (summarized in Garber et al. 2016). However, most of the data on callitrichids does not provide with the parental information, especially about who the father is. Therefore, it is often impossible to make a clear distinction within adult males, in terms of who the father is and who the non-breeding helper is. Thus, whenever the callitrichid parentage status is unclear, I refer to the helping individuals with a more neutral term, i.e. "caretakers".
} 
independent breeding (Hatchwell 2009) a characteristic of a cooperatively breeding system (Solomon and French 1997; Koenig and Dickinson 2004). In terms of fitness in cooperative breeders, the role of a breeder is usually more profitable than the role of a helper. Helper's infant care investment often trades off against helper's own residual reproduction. Therefore, the cooperative breeding systems embody a major puzzle in evolutionary theory "how can altruistic behavior be favored by natural selection?", and they embody an evolutionary conflict, which arises whenever the participants in an interaction cannot achieve their optimum fitness outcome simultaneously. Thus, cooperative breeding systems are an excellent model to investigate behavior ecology and the consequences of this evolutionary conflict, including effects on mating, breeding and parental care strategies (Cant 2012). Only a small percentage of animal species can be classified as cooperative breeders: around $9 \%$ of birds ( 852 species), $2 \%$ of mammals, less than $0.5 \%$ of fish ( 20 - 38 species) and hundreds of insect species. Some mammal representatives of cooperative breeders are arctic foxes, meerkats, banded mongoose, red wolves, Ethiopian wolves (Kullberg and Angerbjörn 1992, Alopex lagopus; CluttonBrock et al. 1998, Suricata suricatta; Nichols et al. 2010, Mungos mungo; Sparkman et al. 2010, Canis rufus; Kesteren et al. 2013, Canis simensis), and among primates, only the family Callitrichidae (marmosets and tamarins). Callitrichids are small-bodied (100-650g) New World primates. Reproductive traits of callitrichids are unique: in addition to cooperative breeding, they produce dizygotic chimeric twins and have the potential to produce two litters per year (summarized in Garber et al. 2016). What is more, callitrichids have flexible reproductive strategies, including monogamy, polygyny, promiscuity, and the prevailing polyandry (Goldizen 1988) and a particularly high amount of paternal care (summarized in Garber et al. 2016). These traits combined constitute callitrichids as an outstanding and extremely complex model for studying mating systems in combination with infant care.

Callitrichid caretakers provide infants with food transfer and carrying, normally on their backs. For the first $2-3$ months infants are carried in all group movements, and are provided with food for a few months more (Epple 1975; Terborgh and Goldizen 1985; Pryce 1988; Goldizen 1989; Tardif et al. 1992; Huck et al. 2004a). Although all group members help, the main carriers are usually adult males (Savage et al. 1996; Garber 1997; 
Yamamoto et al. 2009). It was suggested, that infant care is a male tool to court a female. According to a courtship strategy, a male that is a better caretaker would gain access to (more) copulations (Price 1990, cotton-top tamarins, Saguinus oedipus; Smuts and Gubernick 1992, olive baboons, P. anubis) but also see Tardif and Bales (1997, captive common marmosets, Callithrix jacchus, cotton-top tamarins, S. oedipus). Another explanation for "why males help" is based on female polyandrous mating: i.e. males are likely to help because polyandrous mating provides males with a chance of being a father and males could be helping their own litter (Huck et al. 2004a). This may be plausible, if helping is not a form of altruism (Hamilton 1964), but instead is based on increasing own fitness (Huck et al. 2004a). If it's the latter a mere chance for reproduction, like access to copulations, may result in increased infant care by males. In cooperative breeders, helper's trade-off against own residual reproduction whereas breeder's actually trade-off in favor of their own reproduction (Cant 2012). Thus we would expect that the breeders contribute more than the non-breeding helpers, and if males have any information on their paternity certainty level they might adjust their infant care effort accordingly.

Callitrichids may have various reasons that trigger participation in infant care, nonetheless carrying is energetically demanding, due to heavy infants. Callitrichids routinely produce twins that at birth together weight $\sim 15-20 \%$ of the maternal body mass (Tardif 1994). This makes infant carrying so costly that, even under captive conditions with unlimited food access, carrying fathers and helpers, experience loss in body mass (Sánchez et al. 1999, S. oedipus; Achenbach and Snowdon 2002, S. oedipus). The body mass loss implies on several non-excluding options. First, physical fatigue should occur and result in carrying reduction. Second, energetic costs of carrying imply that changes in the activity budget should occur. Carrying imposes constraints on the type and speed of locomotion and thus carrying may also effect foraging maneuvers (Schradin and Anzenberger 2001a; Caperos et al. 2012). Animal prey is a considerably high component in wild tamarin's diet and thus prey foraging is one of the main daily activities (Soini 1987; Garber 1988; Porter 2001). A reduction of foraged prey may lead to lower energy intake. In addition, studies on captive callitrichids suggest an effort to reduce the predation risk, i.e. carriers spend more time in concealed areas (Price 1992). Captive studies also show that carriers spend less time in locomotion, socializing, foraging, feeding, have lower energy intake and are less likely to 
be vigilant (Price 1992; Sánchez et al. 1999). Vigilance is an important part of anti-predator strategy (Stojan-Dolar and Heymann 2010, Saguinus mystax), yet the two studies on activity budget of wild carrying tamarins did not include vigilance (Goldizen 1987b; Huck et al. 2004a). However these two studies report decreased time spent feeding and increased time spent resting while carrying infants. Still, both studies were based on very small sample sizes (one or two infant care periods, respectively) and did not distinguish feeding from prey foraging. Third, energetic costs of infant care are likely to create physiological stress and would result in increased glucocorticoid levels. However, wild callitrichid males show no change in cortisol levels over the course of the year (Huck et al. 2005b, S. mystax) or when compared between the breeding and infant care season (Bales et al. 2006, Leontopithecus rosalia). These two studies however did not focus on or include the carrying effort or infant care in general into their analysis. Captive studies did but nonetheless they showed no effect of carrying (da Silva Mota et al. 2006, C. jacchus) or they even showed lower cortisol levels in carriers (Nunes et al. 2001, Callithrix kuhlii). Diverse arguments suggest that cortisol levels in adult males are likely to be influenced by previous experience in infant care, interaction with pregnant females, and infants themselves (Nunes et al. 2001; Ziegler et al. 2004; da Silva Mota et al. 2006). The apparent lack of information from wild populations enhances the unclearness of a link between infant care, stress and cortisol in callitrichids.

In addition, callitrichids are characterized by single-female breeding groups, yet multifemale breeding groups can occur (summarized in Garber et al. 2016). More infants in the group are likely to raise the costs of infant care, therefore we can assume that helping individuals would make a choice: which infants to help and to what degree. Multi-female breeding have been observed in several tamarin species: Saguinus geoffroyi, Leontocebus weddelli, S. oedipus and S. mystax (detailed review in Garber et al. 2016) and Leontocebus nigrifrons (Tirado Herrera et al. 2000). Limiting factors on the number of breeding females in a group are resource availability and high energetic demands of infant care (Goldizen et al. 1996, L. weddelli). Nonetheless, multi-female breeding may result in allonursing (Smith et al. 2001, S. mystax) but potentially due to infanticide also lower infant survival (Tirado Herrera et al. 2000, L. nigrifrons; Culot et al. 2011, S. mystax). Callitrichids routinely produce dizygotic twins which may result in shared paternities of twins, but also in 
monopolization of paternities within the twin litter and across the litters (Huck et al. 2005a, wild S. mystax; Suárez 2007; Díaz-Muñoz 2011, S. geoffroyi). The comprehensive complexity of callitrichid mating systems enhances the research question of this thesis: how does individual infant care investment relate to copulations and (non-) breeding status, especially in a multi-female breeding situation?

In this thesis I studied how infant care relates to mating systems, activity budgets and fecal cortisol metabolite levels (FCM). I aimed to understand why some individuals, especially adult males, contribute more to infant care than others, and how does infant care relate to mating systems. I studied wild black-fronted tamarins (L. nigrifrons). In chapter 4 I examine how differences in their social and genetic mating systems affected patterns of infant care. I found two occurrences of multi-female breeding, thus I compared groups with single-female and multiple-female breeding. I predict to find both, monopolization of paternities within a group and multiple paternities within a twin litter. I predict that breeders (mother and father) will contribute more to infant care than nonbreeding helpers. Regarding male help, I test three hypotheses: 1) paternity certainty, where I predict that males with a higher level of paternity certainty will help more, 2) physical fatigue, where I predict male carrying reduction for the second consecutive litter in the multi-female breeding cases, and 3) pay to copulate, where I predict that males who copulate more help more. In this chapter I present group composition, parentage, mating behavior, infant-directed behavior on individual level and on the study population level, i.e. in relation to age, sex and parentage. In chapter 5 I examine activity budgets when carrying or not carrying infants. I test the following hypothesis: infant care causes changes in the activity budget. Here I predict that infant carrying strongly reduces the time spent foraging for prey and the time spent feeding. In contrast, I predict that the time spent being vigilant will increase. An increase in vigilance might be compensation to limited mobility while carrying infants, because limited mobility implies higher risk of predation. Nonetheless, whether carrying or not, while travelling through home ranges any individual has to keep up with its group. Therefore I predict no differences in time spent in locomotion. In chapter 6 I examine how infant care behavior relates to stress hormone output in the carriers. Specifically, I examine differences in FCM levels in relation to carrying effort, and carrying and non-carrying period. My focus was on main carriers, i.e. 
adult males (Savage et al. 1996; Garber 1997; Yamamoto et al. 2009). However since subadults, regardless of sex, can also make a significant contribution to infant care (Goldizen 1987b; Huck et al. 2004a), I have included them in the study. Due to energetic costs of infant carrying (Sánchez et al. 1999, S. oedipus; Achenbach and Snowdon 2002, S. oedipus) I predict FCM levels of adult males and subadult helpers increase during periods of infant carrying and that an increase in FCM levels is proportional to the carrying effort. 


\title{
Chapter 2
}

\section{Study species}

\author{
Kingdom: Animalia \\ Phylum: Chordata \\ Class: Mammalia \\ Order: Primates \\ Suborder: Haplorhini \\ Infraorder: Simiiformes \\ Parvorder: Platyrrhini \\ Superfamily: Ceboidea \\ Family: Callitrichidae \\ Genus: Leontocebus
}

Species: Leontocebus nigrifrons

Black-fronted tamarins (Leontocebus nigrifrons), locally known as "pichico común", is one of the several tamarin species that in addition to the marmoset species, belong to the family Callitrichidae of Neotropical primates (Rylands et al. 2016). Callitrichids are known for their small body size, claw like nails, the ability to cling on to a vertical support, the ability to produce young twice a year, reproductive twinning, high litter weight, high levels of cooperative infant care with extensive male involvement and flexible mating systems with the prevailing polyandry (summarized by Garber 1993). Most tamarin groups are likely to be extended families, adult female-male pair with their adult and immature offspring. They often exhibit only one breeding female, although multi-female breeding does occur (Garber et al. 2016). The peak birthing time is between December and March, 
which is the early half of the rainy season (Snowdon and Soini 1988). Both sexes migrate, with females usually as single individuals and males in pairs (Garber et al. 1993, 2016).

Genus Leontocebus occupy a large terrain of the Amazonian basin, west from the Rio JiParaná in Brazil, east of the Andes to about $16^{\circ} \mathrm{S}$ in Bolivia, south from the rivers Caquetá, Caguán and Orteguaza in Colombia, and south through Ecuador and Peru (Rylands et al. 2016). Saddleback tamarins (former Saguinus fuscicollis: the study species of this thesis was considered to be a one of the 14 sub-species (Hershkovitz 1977; but see Rylands et al. 2016) populate tropical lowland humid forests, but can also be found in secondary forests and seasonally flooded forests and its patches (Snowdon and Soini 1988). The widespread geographic distribution of saddleback tamarins and a tendency to form stable long-lasting associations with other callitrichid taxa, (Saguinus mystax, Saguinus labiatus, Saguinus imperator, and Callithrix argentata), has contributed to the extensive studies on saddleback tamarins (summarized by Garber 1993). Saddleback tamarins are the smallest among the tamarins, with a body mass of about $350 \mathrm{~g}$ (summarized by Garber 1993). Females are slightly heavier and bigger than males, even though the sexual morphism is not obvious (Snowdon and Soini 1988). They reach sexual maturity at the age of around two years, although they do not reproduce for an additional year (Epple and Katz 1980; Goldizen and Terborgh 1989).

The study species of this thesis, L. nigrifrons, live in groups of approximately 5 individuals, often with more adult males than adult females (Heymann 2001). They are diurnal primates, which are active from shortly after dawn till late afternoon when they retire for the night in a palm or a tree (Heymann 1995). The predominant mode of locomotion of $L$. nigrifrons are trunk to trunk leaps (Garber 1991; Nyakatura and Heymann 2010). Home range size is $30-40$ ha with $23-30 \%$ home range overlap and $1849 m$ mean day range (summarized by Garber 1993). They have 0.69 intergroup encounters per day (Heymann 2001) which can be aggressive, although extra-group copulations do occur (Lledo-Ferrer et al. 2011). Markings - anogenital, suprapubic and sternal - seem to be an important way of communication: likely to exchange information with neighboring groups, and allomarking may even function as a chemical mate guarding of a consorted female (Heymann 2001; Lledo-Ferrer et al. 2010, 2011). 
L. nigrifrons primary diet component is ripe fruits, followed by plant exudates, nectar and arthropods. Occasionally they also prey on amphibians, reptiles (Knogge and Heymann 2003; Nadjafzadeh and Heymann 2008) and small vertebrates, e.g. infant rats (Slana, personal observation). Temporary nutritional content depends on seasonal availability, distribution and habitat location of these resources (summarized by Garber 1993). Tamarins themselves are under high predation pressure, mostly from avian species raptors, but also snakes and ground mammals. This is due to their small body size (Moynihan 1970; Terborgh 1983; Goldizen 1987a; Heymann 1987; Oversluijs Vasquez and Heymann 2001; Shahuano Tello et al. 2002; Lledo-Ferrer et al. 2009), although for the same reason they are not hunted by humans, instead are kept as pets (Slana, personal observation). At the EBQB study site, L. nigrifrons live sympatrically with another callitrichid species, moustached tamarins (S. mystax). They form mixed-species troops, although there is a vertical segregation between the species: S. mystax occupy higher parts of the canopy, whereas L. nigrifrons are mostly found on 10-15 m height (Heymann and Buchanan-Smith 2000). 



\section{Chapter 3}

\section{General methods}

The study was carried out at the biological field station Estación Biológica Quebrada Blanco (EBQB) (Fig. 3-1, Fig. 3-2). The station is situated the north-eastern Peru, in the primeval Amazonian lowland rainforest, on the right bank of the river Quebrada Blanco, which is an affluent of the river Rio Tahuayo. It is positioned about $120 \mathrm{~m}$ above sea level, with coordinates $4^{\circ} 21^{\prime} \mathrm{S}$ and $73^{\circ} 09^{\prime} \mathrm{W}$ (Heymann, 1995). I studied five groups of habituated black-fronted tamarins (Leontocebus nigrifrons). Three groups (Gr1, Gr2, Gr3) had already been habituated: Gr1 since May 1999, Gr2 since January 2000 and Gr3 since 2001, and were routinely monitored every month by the field assistants. Another two groups $(\mathrm{Gr} 5, \mathrm{Gr} 6)^{3}$ were known to exist in the area, however, Gr5 has only been habituated since August 2012 and Gr6 since December 2012, and only for the purpose of this thesis. The position of the study groups is presented in Fig. 3-3. The habituation process of both groups started in May 2012 and was completed by the end of July 2012 for Gr5 and at the end of November 2012 for Gr6.

\footnotetext{
${ }^{3}$ Numbering of groups at EBQB is based on the sympatric moustached tamarins (S. mystax) with which the black-fronted tamarins generally form mixed-species groups (Heymann and Buchanan-Smith 2000). Group $4(\mathrm{Gr} 4)$ which had been named before the onset of this study included only moustached tamarins.
} 


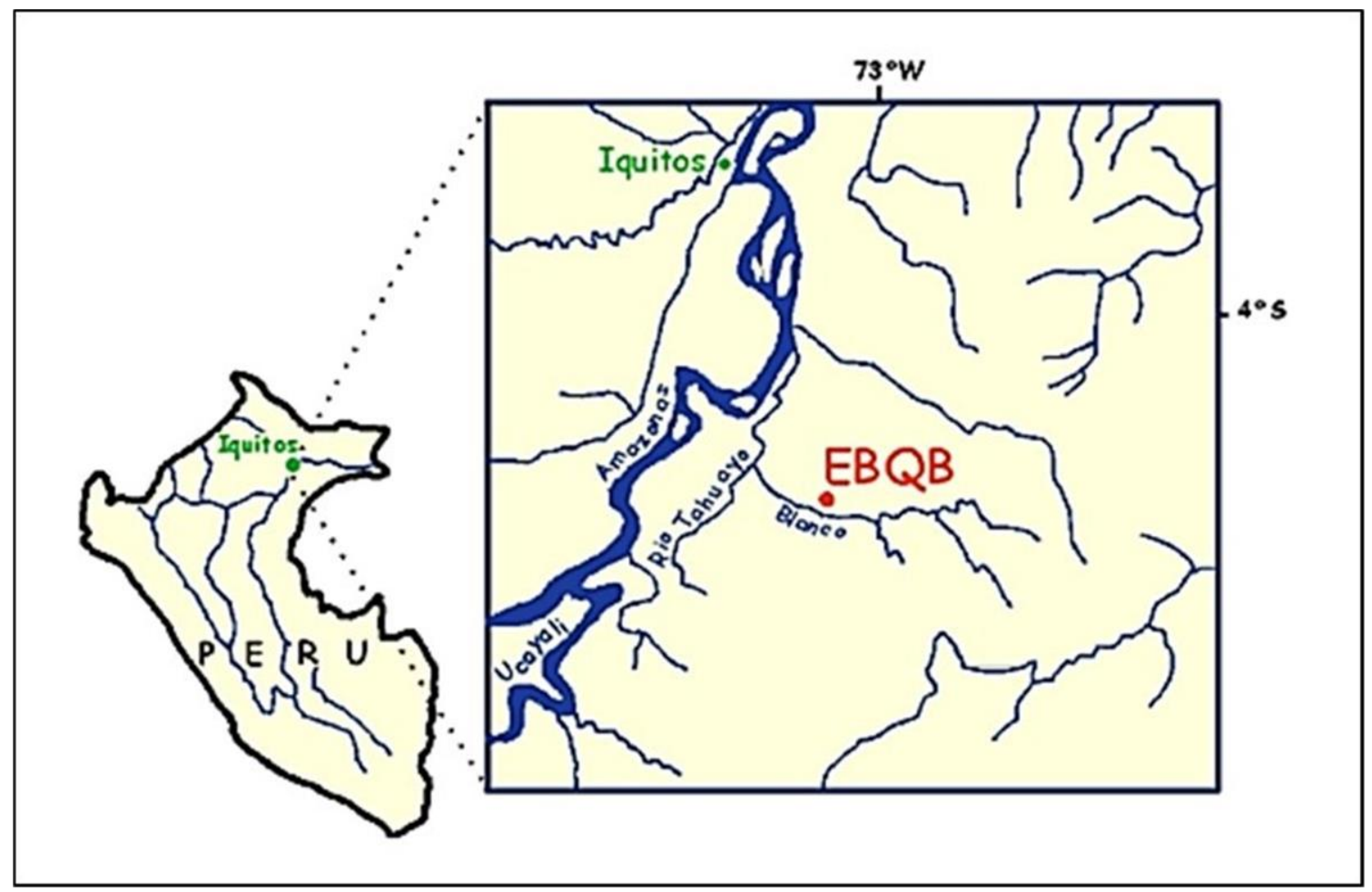

Fig. 3-1: The location of the Estación Biológica Quebrada Blanco. Illustrated by Ulrike Walbaum.
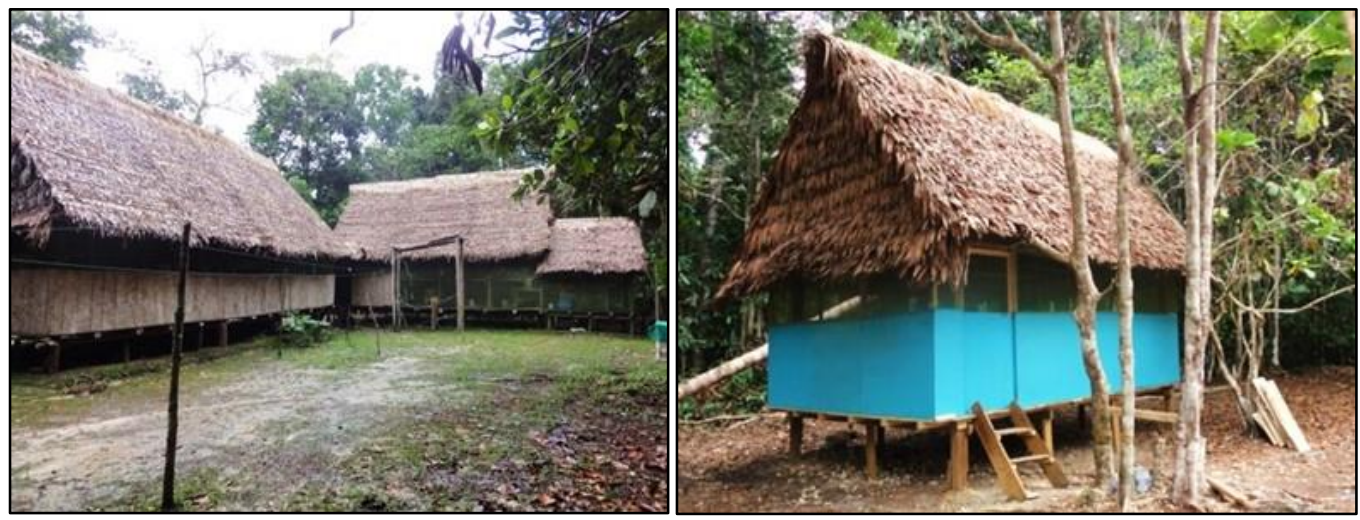

Fig. 3-2: Estación Biológica Quebrada Blanco: the housing and the working area. Illustrated by Darja Slana. 


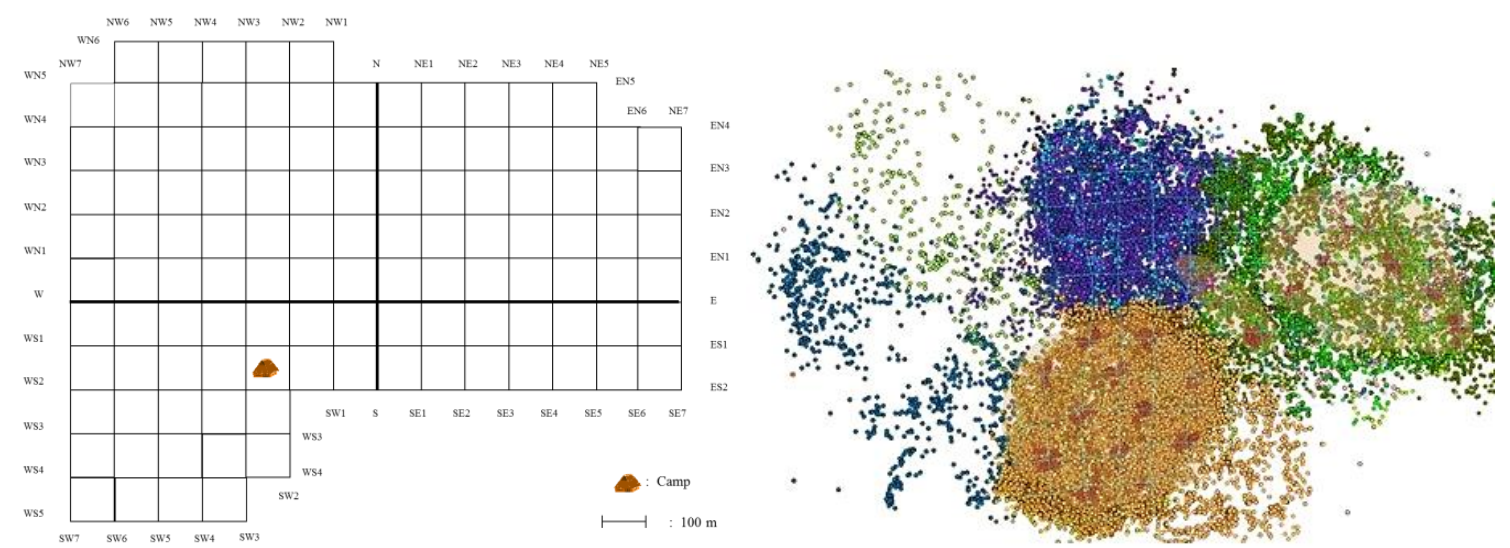

Fig. 3-3: Study area at the EBQB: A) approximate path grid of the EBQB; B) more exact path grid of the EBQB with the territory locations of the five study groups. Each dot represents a GPS location and most of them represent locations of the groups, taken several times per day when with the group. Yellow dots bellow represent Gr1; green dots on the right represent Gr2; violet, pink and light blue dots in the middle up represent Gr3; dark blue dots on the left represent Gr5; bright green dots on the left represent Gr6. (Figure A was illustrated by Eckhard W. Heymann; figure B was illustrated by Tiziana Gelmi.)

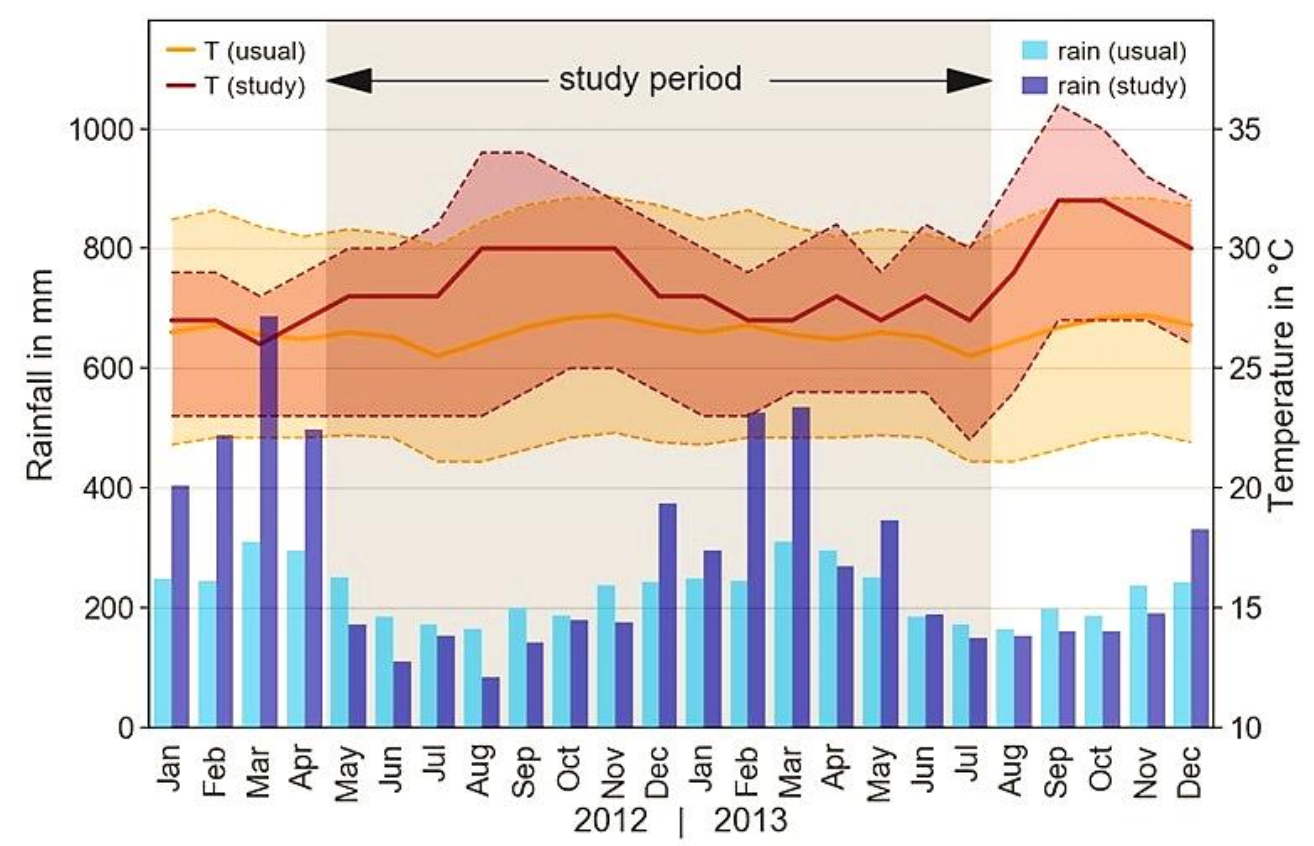

Fig. 3-4: Climate data of the Tamshiyacu weather station, located approximately $30 \mathrm{~km}$ from the research station. The diagram shows data from the relevant years 2012-2013 (WorldWeatherOnline.com 2018) and long-term climate diagram data (Climate-data.org 2018) as a comparison. The gray-shaded area marks the study period. Bars represent monthly rainfall (left scale), where dark blue bars show the years 2012 and 2013, while light blue bars show long-term climate data as a comparison. Solid lines represent monthly average temperatures (right scale), where the dark red line shows the years 2012 and 2013, while the lighter orange line shows long-term climate data as a comparison. Shaded bands around the respective lines indicate monthly minimum and maximum temperature values. 
In the two-month preparatory period, March to April 2012, we started following three study groups (Gr1, Gr2 and Gr3). The purpose was to become familiar with the surroundings, the study animals and the methods of data collection. Finally, the study period started in May 2012 (Gr1, Gr2, Gr3), in August 2012 (Gr5) and in December 2012 (Gr6) until the end of July 2013 (Fig. 4-1). We identified the individual animals through natural markings, like genital size and shape, body size, fur pattern and tail shape (Fig. 3-5). The individuals were assigned to age categories (infant: 0-3 months; juvenile: 4-11 months; subadult: 12-23 months; adult: $\geq 24$ months) based on known age or on the size and the stage of genital development (Goldizen 1989; Goldizen et al. 1996). The latter was assessed by experienced field assistants. The study groups consisted of $1-4$ adult males, $1-2$ adult females, $0-3$ subadults, $1-2$ juveniles and $0-3$ infants. Further details of group composition are given in Table 4-1. Observations and data collection were conducted by eight people - five field assistants (Ney Shanuano Tello, Camilo Flores Amasifuen, Migdonio Huanuiri Arirama, Gabriel Cartitimari Arirama, Carlos Cartitimari Arirama), two biology students (Judith Jacira Achong Sánchez, Allison Licett Núñez Levy) and myself - working in groups of two, simultaneously collecting data on three study groups.
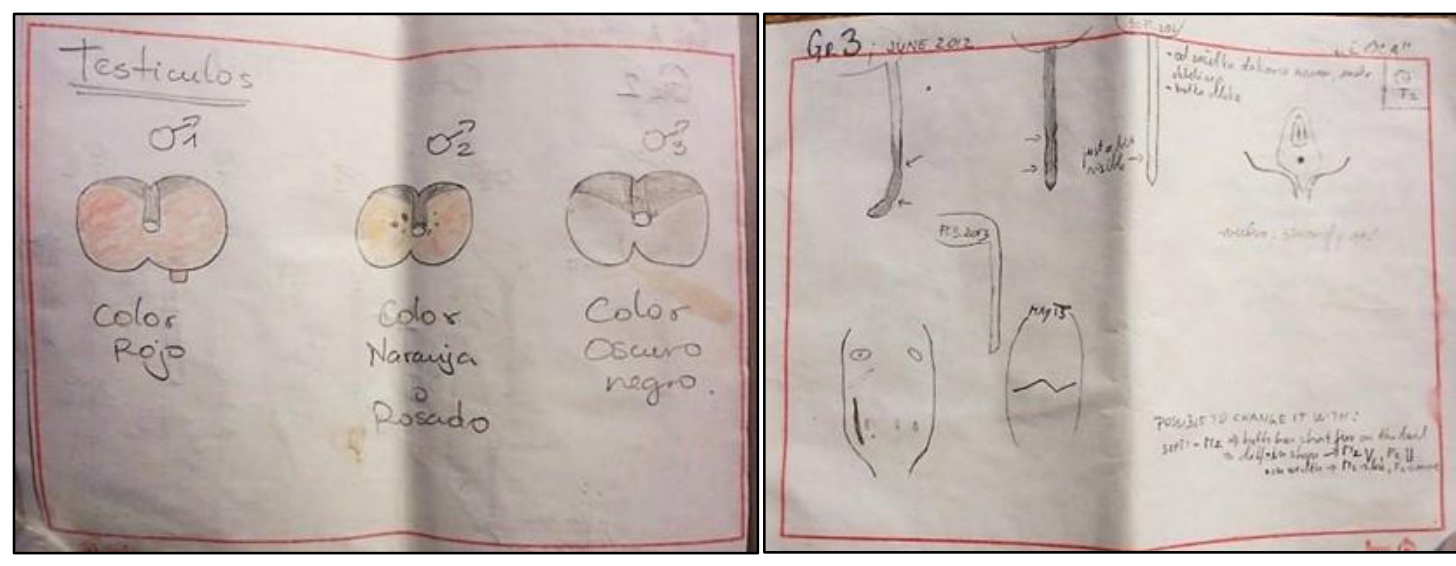

Fig. 3-5: Drawings of natural markings of animals, to help with the individual identification. Illustrated by Ney Shahuano Tello and Darja Slana.

We followed the five study groups daily, from the time they left the sleeping site, between 5:30 - 8:30 hour and until they entered the sleeping site, between 15:00 - 17:00 hour. We observed each group on average for 7.5 days per month and 8.5 hours per day. We observed Gr1 for 966.8 hours, Gr2 for 938.9 hours, Gr3 for 870.7 hours, Gr5 for 673.1 hours and Gr6 for 419.3 hours, yielding a total of 3868.7 hours of observation. We 
collected behavioral data by a) continuous behavior sampling for interactions, markings and rare behavior, like tongue flicking, b) scan sampling, which was conducted on every half an hour for two minutes, to access the differences in individual visibility and their activity budget, and c) 10-minute focal protocol for adults and subadults. In addition to the behavioral data we collected fecal samples from all individuals, for the purpose of genetic and hormonal analyses. The sampling methods are explained in greater detail in the respective chapters.

The genetic analyses of the fecal samples were performed by me, under the instructions and supervision of technical assistants Christina Glaschke and Christiane Schwarz. I extracted the nuclear DNA from fecal samples, amplified it with PCR and used it for microsatellite analyses. The method is explained in greater detail in chapter 4 . Considering hormonal analyses, the first part of the laboratory analyses - the extraction of hormones for evaluation - was conducted in the field station EBQB, by myself and the two biology students, Judith Jacira Achong Sánchez and Allison Licett Núñez Levy. The second part the enzymeimmunoassay (EIA) technique - was performed in the laboratory by the technical assistant Andrea Heistermann. The method is explained in greater detail in chapter 6 . The statistical analyses were executed by myself (chapter 4), and together with statistician Holger Sennhenn-Reulen (chapter 5, chapter 6). The methods are explained in greater detail in the respective chapters. Overall supervision of genetic part was done by Christian Roos, overall supervision of hormonal part was done by Michael Heistermann and overall supervision of the thesis was done by Eckhard W. Heymann. 



\section{Chapter 4}

\section{Mating systems and infant care in a co-operatively breeding primate Leontocebus nigrifrons, in single- and multi-female breeding groups}

Authors: Darja Slana', Judith Jacira Achong Sánchez ${ }^{2}$, Allison Licett Núñez Levy², Christian Roos $^{3}$, Eckhard W. Heymann ${ }^{1}$

${ }^{1}$ Verhaltensökologie \& Soziobiologie, Deutsches Primatenzentrum - Leibniz-Institut für Primatenforschung, Göttingen, Germany

${ }^{2}$ Facultad de Ciencias Biológicas, Universidad Nacional de la Amazonía Peruana, Iquitos, Peru

${ }^{3}$ Primatengenetic, Deutsches Primatenzentrum - Leibniz-Institut für Primatenforschung, Göttingen, Germany

Author contribution, listed by sections: design of the study by DS and EWH; field data collection by DS, JJAS and ALNL; laboratory analyses by DS; statistical analyses by DS; writing the manuscript by DS and EWH; supervision by $\mathrm{CR}$ and $\mathrm{EWH}$. 


\section{Abstract}

In animal societies with cooperative breeding parents and helpers contribute to caring for offspring. In Neotropical callitrichid primates - tamarins and marmosets - infant care consists of carrying and food transfer. Infant care mediates changes of activity budgets and results in loss of body mass in carriers and thus affect helpers' direct fitness. Therefore, individuals must decide whether to contribute in infant care or not, and to which extent, especially if caretakers are confronted with more than one litter. Callitrichid have a flexible mating system with a high degree of polyandry. Therefore, it has been suggested that male callitrichid help to increase their direct fitness. Here we present data on infant care in relation to group composition, mating patterns and parentage in three single- and two multi-female breeding groups of wild black-fronted tamarins, Leontocebus nigrifrons. We suggest monogamy and promiscuity as a social mating system within a group. Due to incomplete genetic results and extra-group paternities, we suggest genetic mating systems on individual levels - monogamy, polygyny, polyandry. We conclude that callitrichid mating system definitions cannot be limited to within a group description. Based on our multi-female breeding cases we provide evidence for a link between the level of paternity certainty, copulations, physical fatigue, and male infant care. We argue that a male's infant care investment is based on a social mating system of the mother whether she copulates with that male and also with other males - which influences the level of paternity certainty. Finally, we argue that in the case of a high level of paternity certainty, physical fatigue is of lesser importance for the male carrying investment.

Keywords: Callitrichidae; infant care; mating system; parentage

\section{Introduction}

A wide variety of strategies ensure the direct and indirect fitness of individuals. This includes decisions on the number of mating partners and whether or not providing parental care. The number of mating partners defines the mating systems which include a social and genetic component. Social mating systems are defined by only one type of interaction, namely copulations, whereas genetic mating systems are defined by reproductive consequences of copulations, i.e. breeding. Copulations and breeding are 
means to produce offspring, whereas parental care is defined as any parental trait that increases the offspring fitness (Clutton-Brock 1991; Kappeler and van Schaik 2002; Smiseth et al. 2012). Parental care can be viewed as direct care - behaviors that are immediately beneficial for offspring, e.g. carrying, and indirect care - behaviors that might benefit offspring, but would also be performed in the absence of infants, e.g. territorial defense (Muller and Emery Thompson 2012). In this study we are concerned with direct care.

Parents exhibit benefits and costs of parental care. Benefits are shown in the offspring survival and reproduction, whereas costs often include higher energy expenditure, constraints on mobility and increased risk of predation (Clutton-Brock 1991; Smiseth et al. 2012). Mammals have especially high costs, females more so than males: due to obligatory gestation and lactation. The transportation of infants increases these costs and burdens the primate mothers even more, because they often transport the infants alone (van Noordwijk 2012). In contrast, primate fathers are not equally constrained, therefore whether to care for offspring and to what degree, is a fundamental question to male reproductive strategies. Caring males might gain a reproductive advantage but there is a trade-off in parental care costs, like energetic expenses and most of all additional mating opportunities (Trivers 1972; Maynard Smith 1977; Muller and Emery Thompson 2012). Compromises between copulations and parenting effort are diverse among primates (Muller and Emery Thompson 2012). In one extreme is social monogamy and high infant investment, e.g. Azara's night monkey (Rotundo et al. 2005, Aotus azarae), in between are males who occasionally care for unrelated infants, apparently to gain access to the mother, e.g. olive baboons (Smuts and Gubernick 1992, Papio anubis) and in other extreme are polygynous males who provide little or no direct care and compete intensely for access to females, e.g. chimpanzees and gorillas (Muller and Wrangham 2004a, Pan troglodytes; Harcourt and Stewart 2007, Gorilla gorilla).

Still, in comparison to other mammals, the number of primate taxa that provide paternal care is high (Kleiman and Malcolm 1981; Whitten 1987) and the amount of paternal care is particularly high in siamang (Lappan 2008) and in some New World primates, like owl monkeys - genus Aotus and titi monkeys - genus Callicebus (Wright 1984; Huck et al. 2014), and many taxa of the family Callitrichidae (marmosets and tamarins). Callitrichids, 
small-bodied (100-650g) primates, exhibit some unique reproductive traits; production of dizygotic chimeric twin offspring; potential to produce two litters per year; and cooperative breeding, where infant care is extended to other group members, so called non-breeding helpers ${ }^{4}$ (summarized in Garber et al. 2016). Due to (non-breeding) helpers, who usually help at the expense of own reproduction, cooperative breeding systems embody a major puzzle of evolutionary theory "how can altruistic behavior be favored by natural selection?", and they embody an evolutionary conflict, which arises whenever the participants in an interaction cannot achieve their optimum fitness outcome simultaneously. Therefore are cooperative breeding systems an excellent model to investigate behavior ecology and consequences of this evolutionary conflict, including effects on mating, breeding and parental care strategies (Cant 2012). Moreover, callitrichids are an excellent and profoundly complex model. They are the only cooperative breeders among primates and they exhibit flexible reproductive strategies, including monogamy, polygyny, promiscuity, and the prevailing polyandry (Goldizen 1988).

Due to helper's trade-off against own residual reproduction, each helper would prefer the other group member to help more. Therefore, we would expect that breeders, whose help actually trades-off in favor of their own reproduction (Cant 2012), help more than non-breeding helpers. Helping can be described as a form of altruism (Hamilton 1964), but if instead help indeed is based on increasing own fitness (Huck et al. 2004a) we might expect that the mere chance of reproduction, like access to mating and (un)certainty of paternity, results in increased infant care of male helpers. Indeed, in callitrichids males usually are the main helpers in carrying (Savage et al. 1996; Garber 1997; Yamamoto et al. 2009), potentially encouraged by a female polyandrous mating (Huck et al. 2004c)

\footnotetext{
${ }^{4}$ With the term "helpers" we refer to non-breeding individuals who help to rear offspring. In callitrichids all group members, i.e. parents and helpers contribute with infant care (summarized in Garber et al. 2016). However, most of the data on callitrichids does not provide with the parental information, especially about who the father is. Therefore, it is often impossible to make a clear distinction within adult males, in terms of who the father is and who the non-breeding helper is. Thus, whenever the callitrichid parentage status is unclear, we refer to the helping individuals with a more neutral term, i.e. "caretakers".
} 
because copulations provide males with an option of paternity. Another explanation on why male helpers help is a courtship strategy, where infant care performance is a tool to court a female. Courtship strategy is based on female mate choice, and males that perform better in infant care would gain access to (more) mating (Price 1990, cotton-top tamarins, Saguinus oedipus; Smuts and Gubernick 1992, olive baboons, P. anubis) but also see Tardif and Bales (1997, captive common marmosets, Callithrix jacchus, cotton-top tamarins, S. oedipus).

Regardless of what constitutes the initial trigger of caring for infants, carrying is energetically demanding. In callitrichids costs are expressed in loss of body mass (Sánchez et al. 1999, captive cotton-top tamarins, S. oedipus), which implies that physical fatigue should occur and result in a carrying reduction. Loss of body mass mostly affects fathers and to a lesser degree other adults and subadult (Sánchez et al. 1999, captive cotton-top tamarins, S. oedipus). These high costs are due to heavy twin infants, whose body mass at birth corresponds to up to $20 \%$ of mother's body mass. Infants are carried intensively during all group movements until 2-3 months of age, at first both twins often simultaneously by only one adult (Terborgh and Goldizen 1985). In addition to carrying, callitrichid infants are, for many months, regularly fed. Both, carrying and food transfer, are provided unequally and intensively by individual caretakers (Epple 1975; Pryce 1988; Goldizen 1989; Tardif et al. 1992; Huck et al. 2004a).

High energetic demands of infant care and resource availability, limits the number of breeding females in a group (Goldizen et al. 1996, Leontocenus weddelli) ${ }^{5}$. Callitrichids are characterized with only one breeding female per group, but do occasionally exhibit multifemale breeding. Multi-female breeding may result in allonursing (Smith et al. 2001, Saguinus mystax) but also lower infant survival potentially due to infanticide (Tirado Herrera et al. 2000, Leontocebus nigrifrons; Culot et al. 2011, S. mystax). In tamarin species multi-female breeding have been observed in: Saguinus geoffroyi, L. weddelli, $S$. oedipus and S. mystax (detailed review in Garber et al. 2016) and Leontocebus spp. (Goldizen et al. 1996; Tirado Herrera et al. 2000). More infants in the group are likely to raise the costs of infant care, therefore we can assume that helping individuals would

\footnotetext{
${ }^{5}$ In this study we use the current taxa naming of tamarins, following Rylands et al. (2016).
} 
make a choice: which infants to help and to what degree. Furthermore, callitrichids generally produce dizygotic twins which sometimes result in shared paternities of twins (Huck et al. 2005a, wild moustached tamarins, S. mystax; Díaz-Muñoz 2011, S. geoffroyi). Tamarin males are to a considerable degree equal in rank and copulations (Goldizen 1987a), nevertheless, rare paternity data from wild populations suggest that in most groups a single male monopolizes the paternities (Huck et al. 2005a, wild moustached tamarins, S. mystax; Suárez 2007; Díaz-Muñoz 2011, S. geoffroyi). The overall complexity of callitrichid mating systems enhances the research question of this study: how does the individual infant care investment relate to mating and (non-)breeding status, especially in a multi-female breeding situation?

We studied five wild groups of black-fronted tamarins (L. nigrifrons). Within 15 months of observation we had two occurrences of multi-female breeding, one per a group. In this study we examined how differences in their mating system affected patterns of infant care. Particularly, we compared groups with single-female and multiple-female breeding. We predict that we will find multiple paternities and in contrast, also monopolization of paternities within a group. We predict breeders (mother and father) will help in infant care more than non-breeding helpers. Regarding male help, we test three hypotheses: 1) paternity certainty, where we predict that males with a higher level of paternity certainty will help more, 2) physical fatigue, we predict male carrying reduction for the second consecutive litter in the multi-female breeding cases, and 3) pay to copulate, where we predict that males who copulate more help more. In this paper we present wild blackfronted tamarin's (L. nigrifrons) group composition, parentage, mating behavior, infantdirected behavior on individual level and on the study population level, i.e. in relation to age, sex and parentage.

\section{Methods}

\section{Study site and study population}

We carried out this study in primeval Amazonian lowland forest in northeastern Peru, at the Estación Biológica Quebrada Blanco (EBQB), $4^{\circ} 21^{\prime} \mathrm{S}$ and $73^{\circ} 09^{\prime} \mathrm{W}$. For a more detailed description of the study site, see (Heymann 1995). We observed five groups of wild yet 
well-habituated L. nigrifrons. Groups $\mathrm{Gr} 1, \mathrm{Gr} 2, \mathrm{Gr} 3$ were routinely monitored every month by field assistants before the onset of the study, and in groups Gr5 and Gr6 6 we started the processes of habituation in May 2012.

All field work adhered to the "Code of Best Practices for Field Primatology" from the American Society of Primatologists(Riley et al. 2014) and was conducted under authorization from Dirección General Forestal y de Fauna Silvestre of the Peruvian Ministry of Agriculture (authorization no. 268-2012-AG-DGFFS-DGEFFS).

Table 4-1. Composition of study groups

\begin{tabular}{|c|c|c|c|c|c|}
\hline Group & Individual ID' & $\begin{array}{l}\text { Joint } \\
I D^{2}\end{array}$ & Sex & Age class $^{3}$ & Demographic notes $^{4}$ \\
\hline \multirow[t]{10}{*}{ Gr1 } & $1 \mathrm{~m} 1$ & & $\mathrm{~m}$ & adult & \\
\hline & $1 \mathrm{f} 1$ & & $f$ & adult & \\
\hline & $1 \mathrm{f} 2$ & & $f$ & adult & \\
\hline & 1sa1 & & $f$ & $\begin{array}{l}\text { juvenile, } \\
\text { subadult }\end{array}$ & B: 04.03.2011 \\
\hline & $1 \mathrm{sa2}$ & & $f$ & $\begin{array}{l}\text { juvenile, } \\
\text { subadult }\end{array}$ & B: 04.03.2011 \\
\hline & $1 \mathrm{c} 1 / 1 \mathrm{j} 1$ & \multirow[t]{2}{*}{$1 c$} & $m$ & infant, juvenile & B: February 2012 \\
\hline & $1 \mathrm{c} 2 / 1 \mathrm{j} 2$ & & $m$ & infant, juvenile & B: February 2012 \\
\hline & 1cv1 & \multirow[t]{2}{*}{$1 \mathrm{cv}$} & & infant & B: 12.12 .2012 \\
\hline & $1 \mathrm{cv} 2$ & & & infant & $\begin{array}{l}\text { B: } 12.12 .2012 \\
\text { D: } 16.12 .2012-13.01 .2013\end{array}$ \\
\hline & $1 \mathrm{cn}$ & & & infant & B: app. 12.02.2013 \\
\hline \multirow[t]{2}{*}{ Gr2 } & $2 \mathrm{~m} 1$ & & $\mathrm{~m}$ & adult & $\begin{array}{l}\text { B: before 2009, born in } \\
\text { this group }\end{array}$ \\
\hline & $2 \mathrm{~m} 2$ & & $\mathrm{~m}$ & adult & $\begin{array}{l}\text { B: } 21.05 .2009 ?^{5} \\
\text { D: } \quad 29.06 .2013 \\
08.07 .2013\end{array}$ \\
\hline
\end{tabular}

${ }^{6}$ Numbering of groups at EBQB is based on the sympatric moustached tamarins (S. mystax) with which the black-fronted tamarins generally form mixed-species groups (Heymann and Buchanan-Smith 2000). Group $4(\mathrm{Gr} 4)$ which had been named before the onset of this study included only moustached tamarins. 


\begin{tabular}{|c|c|c|c|c|c|}
\hline Group & Individual ID' & $\begin{array}{l}\text { Joint } \\
I D^{2}\end{array}$ & Sex & ${\text { Age } \text { class }^{3}}^{3}$ & Demographic notes ${ }^{4}$ \\
\hline & $2 \mathrm{m3}$ & & $\mathrm{m}$ & adult & $\begin{array}{l}\text { B: } 21.05 .2009 ?^{5} \\
\text { D: } \quad 25.07 .2012 \\
14.08 .2012\end{array}$ \\
\hline & $2 \mathrm{ff}$ & & $f$ & adult & I: before onset of study \\
\hline & $2 \mathrm{f} 2$ & & $f$ & adult & I: February/March 2012 \\
\hline & $2 \mathrm{c} 1 / 2 \mathrm{j} 1$ & $2 c$ & $m$ & infant, juvenile & B: app. 03.04.2012 \\
\hline & $2 \mathrm{c} 2 / 2 \mathrm{j} 2$ & & $m$ & infant, juvenile & B: app. 03.04.2012 \\
\hline & $2 \mathrm{cv} 1$ & $2 \mathrm{cv}$ & & infant & B: 19.02 .2013 \\
\hline & $2 \mathrm{cv} 2$ & & & infant & B: 19.02 .2013 \\
\hline Gr3 & $3 \mathrm{~m} 1$ & & $m$ & adult & $\begin{array}{l}\text { B: } 17.10 .2008 \text { or } \\
21.01 .2010^{6}\end{array}$ \\
\hline & $3 m 2$ & & $\mathrm{~m}$ & adult & $\begin{array}{l}\text { B: } \quad 17.10 .2008 \\
21.01 .2010^{6}\end{array}$ \\
\hline & $3 f 1$ & & $f$ & adult & $\begin{array}{l}\text { B: } 17.10 .2008 \\
21.01 .2010^{6}\end{array}$ \\
\hline & $3 f 2$ & & $f$ & adult & $\begin{array}{l}\text { B: } 17.10 .2008 \text { or } \\
21.01 .2010^{6}\end{array}$ \\
\hline & $3 s a 1$ & & $\mathrm{~m}$ & $\begin{array}{l}\text { juvenile, } \\
\text { subadult }\end{array}$ & B: 10.05 .2011 \\
\hline & $3 s a 2$ & & $f$ & $\begin{array}{l}\text { juvenile, } \\
\text { subadult }\end{array}$ & B: 10.05 .2011 \\
\hline & $3 c 1 / 3 j 1$ & $3 c$ & $f$ & infant, juvenile & B: app. 10.04.2012 \\
\hline & $3 c 2$ & & & infant & $\begin{array}{l}\text { B: app. 10.04.2012 } \\
\text { D: } 20.06 .2012\end{array}$ \\
\hline & $3 c v 1$ & $3 c v$ & & infant & B: 23.01 .2013 \\
\hline & $3 c v 2$ & & & infant & $\begin{array}{l}\text { B: } 23.01 .2013 \\
26.03 .2013\end{array}$ \\
\hline & $3 \mathrm{cn} 1$ & $3 c n$ & & infant & B: 01.05 .2013 \\
\hline & $3 \mathrm{cn} 2$ & & & infant & B: 01.05 .2013 \\
\hline
\end{tabular}




\begin{tabular}{|c|c|c|c|c|c|}
\hline Group & Individual ID' & $\begin{array}{l}\text { Joint } \\
I D^{2}\end{array}$ & Sex & Age class $^{3}$ & Demographic notes $^{4}$ \\
\hline \multirow[t]{8}{*}{ Gr5 } & $5 \mathrm{~m} 1$ & & $m$ & adult & D: 17.04 .2013 \\
\hline & $5 f 1$ & & $f$ & adult & \\
\hline & $5 s a 1$ & & $f$ & subadult & \\
\hline & $5 \mathrm{sa2}$ & & $m$ & subadult & \\
\hline & 5 sa3 & & $f$ & subadult & \\
\hline & $5 c / 5 j 1$ & & $f$ & infant, juvenile & B: March 2012 \\
\hline & $5 \mathrm{cn} 1$ & \multirow[t]{2}{*}{$5 \mathrm{cn}$} & & infant & B: 02.11 .2012 \\
\hline & $5 \mathrm{cn} 2$ & & & infant & B: 02.11 .2012 \\
\hline \multirow[t]{10}{*}{ Gr6 } & $6 \mathrm{~m} 1$ & & $\mathrm{~m}$ & adult & \\
\hline & $6 \mathrm{~m} 2$ & & $m$ & adult & \\
\hline & $6 \mathrm{m3}$ & & $\mathrm{m}$ & adult & \\
\hline & $6 \mathrm{~m} 4$ & & $\mathrm{~m}$ & adult & \\
\hline & $6 f 1$ & & $f$ & adult & \\
\hline & $6 f 2$ & & $f$ & adult & \\
\hline & $6 j 1$ & & $\mathrm{~m}$ & juvenile & \\
\hline & $6 \mathrm{j} 2$ & & $f$ & juvenile & \\
\hline & $6 c 1$ & \multirow[t]{2}{*}{$6 c$} & & infant & $\begin{array}{l}\text { B: } 06.12 .2012 \\
\text { D: } \quad 09.12 .2012 \\
\text { 19.03.2013 }\end{array}$ \\
\hline & $6 c 2$ & & & infant & $\begin{array}{l}\text { B: } 06.12 .2012 \\
\text { D: } \quad 09.12 .2012 \\
\text { 19.03.2013 }\end{array}$ \\
\hline
\end{tabular}

${ }^{1}$ If an individual's name changed during the study period, both names are noted. The names changed due to entering a higher age class; e.g., from infant to juvenile.

${ }^{2}$ Joint ID is used for twin infants, before we could separately identify them.

${ }^{3}$ Age class as it could change throughout the observation time.

${ }^{4} \mathrm{~B}$ : born, I: immigrated, $D$ : disappeared; emigrated or died

${ }^{5}$ One of the males ( $2 \mathrm{~m} 2$ or $2 \mathrm{m3}$ ) was born on that date.

${ }^{6}$ Two individuals were born on each of those dates. 


\section{Births and presence of infants}

We defined the infant carrying period as extensive transport of infants that lasts up to 3 months, whereas food provisioning continued for many months. We have records of eleven births, four of them from before the study period (Fig. 4-1, Table 4-1). The data on infant care were available for nine litters $(1 c v, 1 c n, 2 c, 2 c v, 3 c, 3 c v, 3 c n, 5 c n, 6 c)$. From six litters, we collected data on infant-directed behavior for the entire carrying period (1cv, $1 \mathrm{cn}, 2 \mathrm{cv}, 3 \mathrm{cv}, 3 \mathrm{cn}, 5 \mathrm{cn})$. For two litters $(2 \mathrm{c}, 3 \mathrm{c})$ we collected data for the last two months of the carrying period and for one litter $(6 c)$ we collected only the first 3 days of the carrying period. Gr6 could not be located for almost three months following the birth of infants (6c) on 6 Dec 2012. As the infants had disappeared when Gr6 was relocated in March 2013, we obtained only data for the first 3 days of life. Therefore, we did not use that data for any interpretation (results of infant-directed behaviors of Gr6 are in Fig. A-6. Four litters were born within half a year before the onset of the study. For two of these (litters $2 c, 3 c$ ), the infant carrying period extended into the observation period, and data were collected. In two groups two females gave birth to infants: in both cases we consider a female that gave birth more often to be the main breeder ( $1 \mathrm{f} 1$ and $3 f 1$ ) and the other female to be the secondary breeder ( $1 \mathrm{f} 2$ and $3 \mathrm{f} 2$ ).

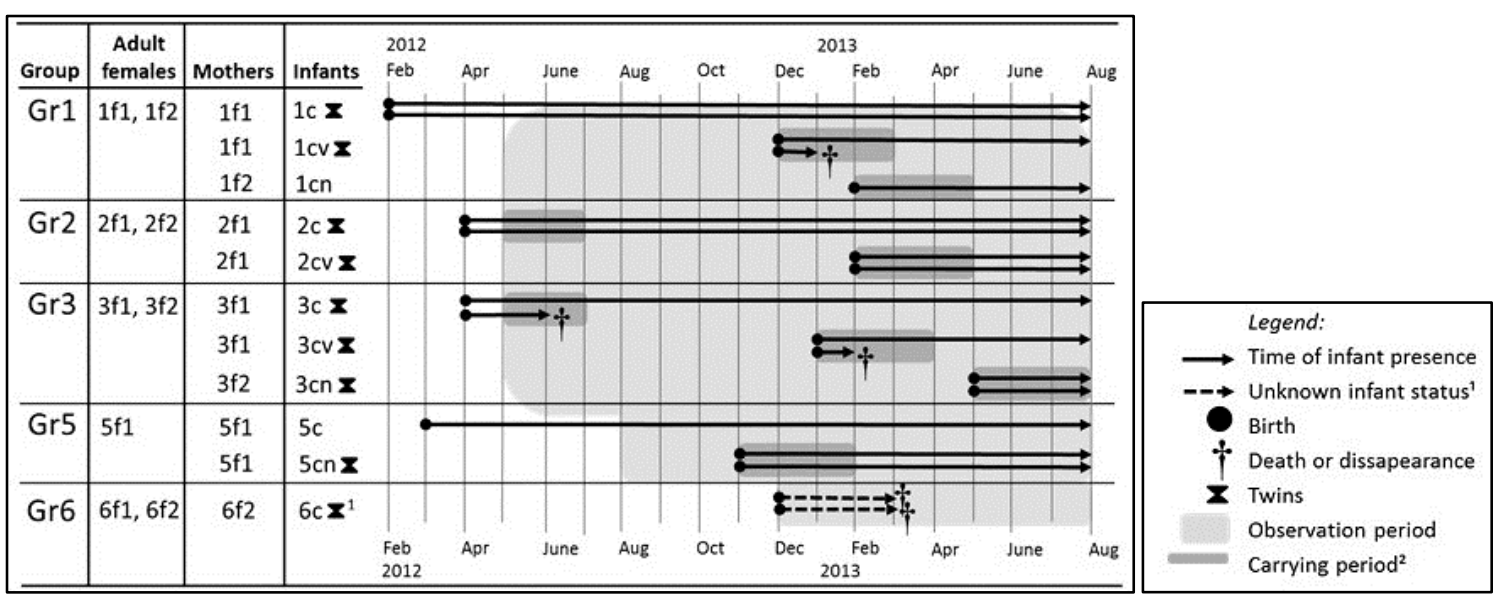

Fig. 4-1: Births and presence of infants in the study population

${ }^{1}$ After the birth of infants the group was observed for 3 consecutive days. The group was not found until the second part of March, when infants were no longer present, meaning they disappeared between 9.12.2012 - 19.03.2013.

${ }^{2}$ We define infant carrying as the first three months of infant's life. 


\section{Behavioral data collection and analyses}

Data collection started in May 2012 (Gr1, Gr2 and Gr3), August 2012 (Gr5) and December 2012 (Gr6) until July 2013. Data were collected by the first author of this paper, four field assistants and two biology students. Our observations were throughout a group's diurnal activity, starting between 5:30 - 8:30 h until 15:00 - 17:00 h. We observed each group for approximately 8.3 hours per day and 7.5 days per month, resulting in a total of 3868.7 observation hours. We identified individuals by their natural markings, e.g., body size, fur patterns, tail shape and genital size and shape. Individuals were assigned to age categories (infant: 0-3 months; juvenile: 4-12 months; subadult: 1-2 years; adult: 2 years and more) according to known birth date or based on size and state of their genital development (Goldizen 1989; Goldizen et al. 1996). Group composition is shown in Table 4-1.

We collected data on mating and all infant-directed behavior, except carrying, using continuous behavior sampling throughout the day. Data on carrying were collected using instantaneous sampling, at five minute intervals, starting when an individual was seen carrying an infant (Martin and Bateson 2007). For all behaviors, we noted which individuals we observed and when. Details are described in Table 4-2. Additionally, we collected data on the activity (food transfer, foraging, resting, locomotion, vigilance, socializing, others) of each visible individual using instantaneous scan sampling (Martin and Bateson 2007) at half-hour intervals for two minutes.

Table 4-2. Description of infant-directed behavior, mating behavior

\begin{tabular}{|c|c|}
\hline $\begin{array}{l}\text { Behavior } \\
\text { (abbreviation) }\end{array}$ & Description \\
\hline \multicolumn{2}{|c|}{ Infant-directed behavior ${ }^{1}$} \\
\hline $\begin{array}{l}\text { Food transfer } \\
\text { (feed) }\end{array}$ & Infant obtains food from a food possessor ${ }^{2}$; does not include lactation. \\
\hline $\begin{array}{l}\text { Infant carrying } \\
\text { (carry) }\end{array}$ & $\begin{array}{l}\text { Infant is carried by an individual: once the carrying started it would be } \\
\text { recorded as a new event on every 5th minute; if a carrier got out of sight } \\
\text { for more than } 5 \text { minutes and would be later again seen carrying an infant, it } \\
\text { would be recorded as a new event. }\end{array}$ \\
\hline
\end{tabular}




\begin{tabular}{|c|c|}
\hline $\begin{array}{l}\text { Behavior } \\
\text { (abbreviation) }\end{array}$ & Description \\
\hline $\begin{array}{l}\text { Infant take } \\
\text { attempt } \\
\text { (take) }\end{array}$ & $\begin{array}{l}\text { Infant transfer attempt, where one animal tries to take the infant from } \\
\text { another, who may or may not be dumping the infant. }\end{array}$ \\
\hline $\begin{array}{l}\text { Rejecting food } \\
\text { transfer } \\
\text { (reject feed) }\end{array}$ & $\begin{array}{l}\text { Infant is refused to be fed: infant's attempt to grab a food item from its } \\
\text { possessor is unsuccessful, because it is physically refused so from the food } \\
\text { owner. }^{2}\end{array}$ \\
\hline $\begin{array}{l}\text { Rejecting to } \\
\text { carry infant } \\
\text { (reject carry) }\end{array}$ & $\begin{array}{l}\text { Infant is refused to be carried: infant who was not carried before is trying } \\
\text { to climb on an individual, who would push it away; infant has been carried, } \\
\text { but is pushed down by the carrier. }\end{array}$ \\
\hline \multicolumn{2}{|c|}{ Mating behavior } \\
\hline $\begin{array}{l}\text { Copulation } \\
\text { (cop) }\end{array}$ & Mounting with pelvic thrusting. \\
\hline
\end{tabular}

${ }^{1}$ Adjusted after (Vogt 1978; Coates and Poole 1983; Huck et al. 2004a).

${ }^{2}$ Infant transfer equals the definition of food "stealing" from (Heymann 1990b), since food was always taken yet never freely given from the food possessor. A more precise description would be that food was allowed to be stolen. As in other callitrichids (Heymann $1990 b$, S. mystax), the event was usually accompanied with the infant's squeal vocalization directed towards the food possessor. This already partly overlaps with "food beg" definition of Cleveland and Snowdon (1984), which includes following, calling and grabbing at food possessor / food item. As a result, if an infant's attempt of grabbing the food item from the possessor was successful we would define it as "infant transfer" and as "rejecting to feed infant" if unsuccessful.

We calculated the percentage of infant-directed behaviors on a study population level, i.e. in relation to age, sex and parentage, and due to multi-female breeding, also on an individual level. We analyzed infant-directed behavior in terms of each individual's contribution to the behavior, see formula below (adopted from Huck et al. 2004a). We did not distinguish between the twins but we treated them as one litter. When applied to the two infants, we considered infant-directed behaviors (e.g. carrying, carry rejection, take attempt) to be two occurrences. We corrected the data for individual visibility which is the relative proportion of instantaneous scan sample points on which an individual could be observed. We incorporated a visibility correction in a calculation of the expected frequencies $(E)$ : 


$$
E=\text { behavior }(\text { total }) * \text { scans }(\text { individual) / scans }(\text { total })
$$

where behavior (total) = frequency at which the behavior was seen in all individuals; scans (individual) $=$ number of sightings of a respective individual in scans; scans (total) = number of sightings of all individuals in scans. Following calculations of percentages were done by this formula:

$$
\% \text { behavior of individual } X=\frac{O_{X} / E_{X} * 100}{\sum_{\text {group }} O / E}
$$

where $O=$ observed frequency of the behavior.

For an individual level, we calculated the percentage of infant-directed behaviors for each set of infants separately for the entire carrying period together (Fig. 4-4-Fig. 4-7) and for each carrying month separately. Finally we calculated the carrying contribution of males in the groups with multi-female breeding (Fig. 4-12, Fig. 4-13) and for all infant-directed behaviors for all carriers in a study population, i.e. in relation to age, sex and parentage (Table A-1). If an individual carried or fed the infant more often it may also have more opportunities for rejection. Therefore we calculated "the index of rejections in carrying and food transfer" which is the number of rejections per carrying or food transfer time (Table 4-9). Calculations were based on the entire infant carrying period for each litter separately. We define this index of rejection as

$$
\text { Index of rejection }=0 \text { of rejection } / \% \text { behavior }
$$

where $O=$ observed frequency of the behavior; carry reject (if the infant was carried before by the same individual) or feed reject; \% = of carry or feed.

Within the study population level, we calculated the percentage of infant-directed behaviors in relation to age class and parentage information of adults (mothers, other females, fathers, other males, subadults, juveniles) (Fig. 4-3, Fig. 4-8 - Fig. 4-11). For each class we calculated medium, minimum and maximum values, upper and lower quartile. We present the results in a box plot. The calculations are based on infant-directed behaviors towards litters within the complete observation period ( 6 litters: $1 \mathrm{cv}, 1 \mathrm{cn}, 2 \mathrm{cv}$, $3 \mathrm{cv}, 3 \mathrm{cn}, 5 \mathrm{cn}$ ). Rates of infant-directed behaviors in litter $1 \mathrm{cn}$ (infant carrying, infant reject 
carrying, infant take attempt), were extreme: very high in the mother and very low in one male and another female. These extreme values could strongly bias the overall average. Therefore, we additionally calculated the percentage of these infant-directed behaviors with the exclusion of litter $1 \mathrm{cn}$.

\section{Genetic sample collection and analyses}

We collected fecal samples non-invasively. From each individual in our study groups we tried to obtain at least three fecal samples. We placed each sample on a filter paper in a twist-off PE tube with silica gel. We sealed the tubes with Parafilm and labelled them (collector, date, time, record number, individual, degree of certainty of individual's identification; A - certain, when we were sure of an animal's identification, B - less certain, when we were almost sure of an animal's identification, but not entirely). We kept samples at ambient temperature of the camp (e.g. $20-30^{\circ} \mathrm{C}$ ) up to three weeks, brought them to town where we placed them in a refrigerator $\left(\right.$ e.g. $\left.5^{\circ} \mathrm{C}\right)$ until exportation to Germany. The collective and storing methods follow (Huck et al. 2005a).

With exception of twin infants, which we could not distinguish in their first months, we analyzed only fecal samples with a clear identification of the individual; label A. We extracted nuclear DNA from the fecal samples using the First-DNA-all tissue kit (GEN-IAL). We used Nanodrop to concentrate DNA and perform purity measurements. We set UV light absorbance on a 260/280 wave length. For the amplification of the microsatellite loci we tested 12 primer pairs that were already used for S. mystax by Huck et al. (2005a), but were previously designed for S. bicolor, S. oedipus and C. jacchus (Nievergelt et al. 1998; Huck et al. 2005a; Böhle et al. unpublished data). For the purpose of our analyses we excluded three primers: two primers were not variable since they showed only one allele (SB_2, SO_258) and one primer failed to show any alleles (SB_7). Finally, we amplified each sample with the remaining 9 primer pairs (Table 4-3). We started the procedure of microsatellite loci amplification with the dilution of concentrated DNA extract on roughly $10 \mathrm{ng} / \mu \mathrm{l}$ with high performance liquid chromatography (HPLC) water. Then we created DNA multiplex: we added $1 \mu \mathrm{l}$ of the DNA extract to the mastermix for DNA multiplex (Table 4-4), which was the same for all primer pairs. We put the created DNA multiplex in a Thermal Cycler (2720, Applied Biosystems), with the aim of amplification of the 
microsatellite loci with hot start PCR technique (Table 4-5). We created a mastermix for DNA singleplex (Table 4-6) to which we added 1-4 $\mu$ l of multiplex (depending on what has previously proven to be better for each primer pair) and again put it in the Thermocycler for the hot start PCR, optimized for the each primer pair (Table 4-7). For DNA fragment analysis of DNA singleplex we used Genetic Analyzer (3130, Applied Biosystems). We used 1-4 $\mu$ l of DNA singleplex, depending on the previous result. We assigned genotypes manually, using the Peak Scanner 1.0 software (Applied Biosystems). Summary statistics of microsatellite loci we analyzed with Genepop 4.2 (Rousset 2008) (Hardy - Weinberg equilibrium test $\left(H W \chi^{2}\right)$ ), and Cervus 3.0.7. (Kalinowski et al. 2007) (null allele, expected heterozygosity (He), observed heterozygosity (Ho) (Table 4-3).

Table 4-3: Summary statistics of used microsatellite loci ${ }^{1}$

\begin{tabular}{|l|l|l|l|l|l|l|}
\hline Locus & $\begin{array}{l}\text { Number } \\
\text { of alleles }\end{array}$ & $\begin{array}{l}\text { Size range (bp) } \\
\text { in L. nigrifrons }\end{array}$ & HE & HO & $\begin{array}{l}\text { HW } \\
\boldsymbol{x}^{2} \text { - test }\end{array}$ & $\begin{array}{l}\text { Null } \\
\text { allele }\end{array}$ \\
\hline SB $8^{2}$ & 7 & $221-237$ & 0.799 & 0.556 & s. & 0.174 \\
\hline SB 192 & 13 & $197-255$ & 0.897 & 0.818 & s. & 0.005 \\
\hline SB 24 & 7 & $137-149$ & 0.827 & 0.806 & n.s. & 0.036 \\
\hline SB 30 & 10 & $91-121$ & 0.835 & 0.763 & s. & 0.003 \\
\hline SB 38 & 7 & $126-150$ & 0.766 & 0.667 & s. & 0.038 \\
\hline SO 2513 & 11 & $126-150$ & 0.884 & 0.706 & s. & 0.052 \\
\hline SO 252 & 6 & $117-133$ & 0.79 & 0.722 & s. & 0.108 \\
\hline SO 284 & 6 & $168-180$ & 0.774 & 0.656 & n.s. & 0.038 \\
\hline CJ $12^{4}$ & 5 & $138-146$ & 0.789 & 0.767 & n.s. & 0.077 \\
\hline mean & 8 & & 0.818 & 0.718 & & \\
\hline
\end{tabular}

${ }^{1} \mathrm{He}=$ expected heterozygosity; Ho = observed heterozygosity; HW = Hardy - Weinberg equilibrium: estimation of exact $P$-Values by the Markov chain method; $b p=$ base pairs; n.s. = not significant; $s .=$ significant

${ }^{2}$ Origin: Saguinus bicolor, Böhle and Zischler (2002)

${ }^{3}$ Origin: S. oedipus, Böhle et al. unpublished data

${ }^{4}$ Origin: C. jacchus, Nievergelt et al. 
Table 4-4: Mastermix for DNA multiplex ${ }^{1}$

\begin{tabular}{|l|l|l|}
\hline \multicolumn{3}{|c|}{ Mastermix for DNA multiplex } \\
\hline Ingredients & Additional information on ingredients & Amount \\
\hline $\mathbf{H}_{\mathbf{2}} \mathbf{0}$ & HPLC quality & $16.4 \mu \mathrm{l}$ \\
\hline $\mathbf{1 0 x}$ reaction buffer & Company GeneCraft & $3.0 \mu \mathrm{l}$ \\
\hline BT & $\mathrm{BSA}^{2}(10 \mathrm{mg} / \mathrm{ml})+0.7 \%$ Triton & $4 \mu \mathrm{l}$ \\
\hline $\mathbf{M g C l}_{\mathbf{2}}$ & $15 \mathrm{mM}$ & $2.0 \mu \mathrm{l}$ \\
\hline $\mathbf{d}^{\prime} \mathbf{N T P}$ & $25 \mathrm{mM}$ & $0.5 \mu \mathrm{l}$ \\
\hline taq-Polymera & Company GeneCraft 1unit & $0.3 \mu \mathrm{l}$ \\
\hline Mix off all 9 primers “forward" & $100 p m o l / \mu l$, unlabeled & $0.9 \mu \mathrm{l}$ \\
\hline Mix off all 9 primers “reverse" & $100 p m o l / \mu l$, unlabeled & $0.9 \mu \mathrm{l}$ \\
\hline
\end{tabular}

${ }^{1}$ Is the same for all primer pairs, calculations are applicable for 1 DNA extract.

${ }^{2} B S A=$ Bovine serum albumin

Table 4-5: PCR protocol for DNA multiplex

\begin{tabular}{|l|l|l|l|}
\hline \multicolumn{4}{|c|}{ PCR protocol for DNA multiplex } \\
\hline Steps & Degrees & Time & Rounds \\
\hline Initialization (with hot start) & $92^{\circ} \mathrm{C}$ & $10 \mathrm{~min}$ & $1 \mathrm{x}$ \\
\hline Denaturation & $92^{\circ} \mathrm{C}$ & $30 \mathrm{~s}$ & $20 \mathrm{x}$ \\
\hline Annealing & $45^{\circ} \mathrm{C}$ & $30 \mathrm{~s}$ & $20 \mathrm{x}$ \\
\hline Extension = elongation & $72^{\circ} \mathrm{C}$ & $30 \mathrm{~s}$ & $20 \mathrm{x}$ \\
\hline Final elongation & $72^{\circ} \mathrm{C}$ & $10 \mathrm{~min}$ & $1 \mathrm{x}$ \\
\hline Final hold & $8^{\circ} \mathrm{C}$ & $\infty$ & \\
\hline
\end{tabular}


Table 4-6: Mastermix for DNA singleplex

\begin{tabular}{|l|l|l|}
\hline \multicolumn{3}{|c|}{ Mastermix for DNA primers } \\
\hline Ingredients & Additional information on ingredients & Amount \\
\hline $\mathbf{H}_{\mathbf{2}} \mathbf{O}$ & HPLC quality & $21.4 \mu \mathrm{l}$ \\
\hline $\mathbf{1 0 x}$ reaction buffer & Company GeneCraft & $3.0 \mu \mathrm{l}$ \\
\hline BT & $10 \mathrm{mg} / \mathrm{ml} \mathrm{BSA}^{2}+0.7 \%$ Triton & $4 \mu \mathrm{l}$ \\
\hline d'NTP & $25 \mathrm{mM}$ & $0.2 \mu \mathrm{l}$ \\
\hline taq-Polymera & Company GeneCraft 1unit & $0.2 \mu \mathrm{l}$ \\
\hline Primer X “forward" & $100 \mathrm{pmol} / \mu \mathrm{l}$, labeled & $0.1 \mu \mathrm{l}$ \\
\hline Primer X “reverse" & $100 \mathrm{pmol} / \mu \mathrm{l}$, unlabeled & $0.1 \mu \mathrm{l}$ \\
\hline
\end{tabular}

${ }^{1}$ Is different for each primer, calculations are applicable for 1 DNA multiplex.

${ }^{2} B S A=$ Bovine serum albumin

Table 4-7: PCR protocol of DNA singleplex

\begin{tabular}{|c|c|c|c|c|c|c|}
\hline \multicolumn{7}{|c|}{ PCR protocol for singleplex } \\
\hline \multirow{3}{*}{ Steps } & \multicolumn{6}{|c|}{ Primers } \\
\hline & \multicolumn{3}{|c|}{ SB_8, SB_38, SO_252 } & \multicolumn{3}{|c|}{$\begin{array}{l}C l \_12, S B \_19, S B \_24, S B \_30, \\
\text { SO_251, SO_284 }\end{array}$} \\
\hline & Degrees & Time & Rounds & Degrees & Time & Rounds \\
\hline $\begin{array}{l}\text { Initialization (with hot } \\
\text { start) }\end{array}$ & $92^{\circ} \mathrm{C}$ & $10 \mathrm{~min}$ & $1 x$ & $92^{\circ} \mathrm{C}$ & $10 \mathrm{~min}$ & $1 x$ \\
\hline Denaturation & $92^{\circ} \mathrm{C}$ & $30 \mathrm{~s}$ & $30 x$ & $92^{\circ} \mathrm{C}$ & $30 \mathrm{~s}$ & $30 x$ \\
\hline Annealing & $45^{\circ} \mathrm{C}$ & $30 \mathrm{~s}$ & $30 x$ & $50^{\circ} \mathrm{C}$ & $30 \mathrm{~s}$ & $30 x$ \\
\hline Extension = elongation & $72^{\circ} \mathrm{C}$ & $30 \mathrm{~s}$ & $30 x$ & $72^{\circ} \mathrm{C}$ & $30 \mathrm{~s}$ & $30 x$ \\
\hline Final elongation & $72^{\circ} \mathrm{C}$ & $10 \mathrm{~min}$ & $1 x$ & $72^{\circ} \mathrm{C}$ & $10 \mathrm{~min}$ & $1 x$ \\
\hline Final hold & $8^{\circ} \mathrm{C}$ & $\infty$ & & $8^{\circ} \mathrm{C}$ & $\infty$ & \\
\hline
\end{tabular}

\section{Parentage analyses}

We performed parental analysis with software Colony 2.0.5.9. (Jones and Wang 2010). We looked for parents of all infants, juveniles and subadults. We considered all adult males as potential fathers as well as all adult females for mothers. Although, if it was already clear from the field study who the true mother was, we applied it as such. When 
using the program, we did not discriminate between the groups. According to program recommendations we implemented the following parameters: male and female polygamy, without inbreeding and clone inference, diploid and dioecious species, scale for full sibship yet weak sibship priority, full likelihood [probability] method, medium precision, unknown allele population frequency, 1 medium long run, codominant marker, genotyping rate: 0.009 and null allele as they were calculated by Cervus software (Table 4-3). Additionally we assumed that we sampled up to $80 \%$ of mothers and fathers. Where possible, Colony software assigned first and second most likely parentage. Here we report parentage probabilities as high (1.0-0.80) or intermediate $(<0.80-0.70)$ (Table 4-8). If high and intermediate probabilities were assigned, it is only for the first most likely parentage. If a second most likely parentage was assigned, it had a lower probability range (0.003 to 0.173). In addition to parentage probability, the program provided full and half-sibling probabilities of offspring. Often when the Colony software was provided with sibling dyads we could combine this information with information on parentage. This gave us additional information about plausible parentage, so called "hints from sibling dyads". An example of a hint: twin infants $2 \mathrm{c}$ had the same mother $(2 \mathrm{f} 1)$ and no assigned candidate father, but according to candidate full-sibling offspring dyads, they were full-siblings. Thus, a combination of this information suggests, that they had the same known mother $(2 \mathrm{f} 1)$ and the same unknown father $(\diamond)$.

\section{Testing the predictions}

To test predictions on mating systems and paternities, we looked into individual mating behavior (Table 4-10, Fig. 4-14) and paternity results (Table 4-8). To test the prediction that breeders contribute in infant care more that non-breeders, we compared infantdirected behaviors on a population level (Fig. 4-3, Fig. 4-8 - Fig. 4-11) with parentage information (Table 4-8). To test the hypothesis paternity certainty, with the prediction that males who have a higher level of paternity certainty help more, we compared adult male individual contributions of infant-directed behaviors (Fig. 4-4 - Fig. 4-7, Fig. 4-12, and Fig. 4-13), individual mating behaviors (Table 4-10) and paternity results (Table 4-8). To test the hypothesis physical fatigue, with the prediction that males lower their carrying contribution for the second consecutive litter in multi-female breeding cases, we 
compared adult male individual carrying contributions between the consecutive litters (Fig. 4-12, Fig. 4-13). To test the hypothesis pay to copulate, with the prediction that males invest more in infant carrying if they mate more with the mother, we calculated the "Spearman correlation between number of copulations and infant carrying percentages" (Table 4-11). We calculated the correlation for the entire study period and for specific periods: infant carrying period, six months before birth and any other time. The period of six months before birth was to include the 5 month gestation in saddleback tamarins (Heistermannn and Hodges 1995) and the potential consorting time (Terborgh and Goldizen 1985, wild saddleback tamarin, L. weddelli; Baker et al. 1993, wild golden lion tamarin, Leontopithecus rosalia; Huck et al. 2004c, wild moustached tamarin, S. mystax; Lledo-Ferrer et al. 2010, wild black-fronted tamarin, L. nigrifrons). 


\section{Results}

Our study presents findings on parentage of five wild groups of L. nigrifrons, their infant care effort for 8 litters $(1 \mathrm{cv}, 1 \mathrm{cn}, 2 \mathrm{c}, 2 \mathrm{cv}, 3 \mathrm{c}, 3 \mathrm{cv}, 3 \mathrm{cn}, 5 \mathrm{cn})$, their mating behavior and offspring survival. Two litters ( $2 \mathrm{c}$ and $3 \mathrm{c}$ ) were not observed in their first month, therefore are not strictly comparable to infant carrying periods of other litters and whenever we present or discuss the results, we state which litters were included. Furthermore, we examine in more detail carrying efforts of adult males in the two cases of two multi-female breeding.

\section{Parentage}

Parentage data with full and half-sibling dyads and hints from sibling dyads are presented in Table 4-8 whereas the parentage dyads alone are presented in Fig. 4-2. We identified the mothers of most of the offspring (infants, juveniles and subadults). Maternities of the youngest infants were known through observations of lactation (Fig. A-7). In cases of allonursing (litters $2 \mathrm{cv}$ and $3 \mathrm{cv}$ ) and nursing only by a non-mother (litter $3 \mathrm{cn}$ ) we based our conclusions on which female showed the strongest interest in infants during the first month of life, especially the first days, as measured through the rates of infant take attempt behavior (Table A-1). Finally, the five month gestation (Heistermannn and Hodges 1995) excludes a female as mother of one set of twins if they were born within four months of another litter (litter 3cn) (Table 4-1). We classified groups Gr2, Gr5 and Gr6 as single-female breeding, and groups Gr1 and Gr3 as multiple-female breeding. Both multifemale breeding groups had two resident adult females, both of them breeding ( $1 \mathrm{f} 1$ and $1 \mathrm{f} 2,3 \mathrm{f} 1$ and $3 \mathrm{f} 2)$. In Gr3, a female from Gr6 (6f2) was identified as the mother of a subadult (3sa2), but as she belonged to Gr6, we did not consider her to be an additional breeding female of Gr3. In Gr5 we did not assign a mother to the three older offspring, but "hints from sibling offspring dyads" indicated that the only adult female (5f1) in the group was likely to be a mother of one of the older offspring (5sa2). 
Table 4-8. Most likely maternity, paternity, full-and half-sibling offspring dyads

\begin{tabular}{|c|c|c|c|c|c|c|}
\hline Group & Offspring $^{1}$ & $\begin{array}{l}\text { Candidate } \\
\text { mother }^{2,3}\end{array}$ & $\begin{array}{l}\text { Candidate } \\
\text { father }^{3}\end{array}$ & $\begin{array}{l}\text { Candidate } \\
\text { full-sibling } \\
\text { offspring } \\
\text { dyads }^{3,4}\end{array}$ & $\begin{array}{l}\text { Candidate } \\
\text { half-sibling } \\
\text { offspring } \\
\text { dyads }^{3,4}\end{array}$ & $\begin{array}{l}\text { Hints from } \\
\text { sibling } \\
\text { offspring } \\
\text { dyads }{ }^{5} \\
\text { (candidate } \\
\text { father, } \\
\text { mother) }\end{array}$ \\
\hline \multirow[t]{7}{*}{ Gr1 } & 1sa1 & $1 \mathrm{f} 1^{* *}$ & $1 \mathrm{~m} 1^{* *}$ & $\mathrm{~A}^{* *}$ & $d^{*}$ & \\
\hline & 1 sa2 & $1 \mathrm{f} 2 * *$ & & & $a^{* *}, e^{* *}, f^{*}$ & Father: $\bullet$ \\
\hline & $1 \mathrm{c} / 1 \mathrm{j} 1$ & $1 \mathrm{f} 1^{* *}$ & $1 \mathrm{~m} 1^{* *}$ & $A^{* *}$ & $c^{*}$ & \\
\hline & $1 \mathrm{c} / 1 \mathrm{j} 2$ & $1 \mathrm{f} 1^{* *}$ & $1 \mathrm{~m} 1^{* *}$ & $\mathrm{~A}^{* *}$ & & \\
\hline & $1 \mathrm{cv} 1$ & $\overline{1 \mathrm{f1}} * *$ & $1 \mathrm{~m} 1^{* *}$ & $A^{* *}$ & $b^{*}$ & \\
\hline & $1 \mathrm{cv} 2^{6}$ & $1 \mathrm{f} 1 * *$ & N/A & $\mathrm{N} / \mathrm{A}$ & N/A & N/A \\
\hline & $1 \mathrm{cn}$ & $1 \mathrm{f} 2^{* *}$ & & & $a^{* *}$ & Father: $\square$ \\
\hline \multirow[t]{4}{*}{ Gr2 } & $2 c / 2 j 1$ & $\overline{2 \mathrm{f} 1} * *$ & & $\mathrm{~B}^{* *}$ & $\mathrm{~g}^{* *}$ & Father: $\diamond$ \\
\hline & $2 c / 2 j 2$ & $2 \mathrm{ff} 1^{* *}$ & & $\mathrm{~B}^{* *}$ & $\mathrm{~h}^{* *}$ & Father: $\diamond$ \\
\hline & 2cv1 & $\underline{\mathrm{ff}}^{* *}$ & & & $\mathrm{~g}^{* *}, \mathrm{~h}^{* *}$ & Father: $\varnothing$ \\
\hline & $2 \mathrm{cv} 2^{6}$ & $2 \mathrm{ff} 1^{* *}$ & N/A & N/A & $\mathrm{N} / \mathrm{A}$ & $\mathrm{N} / \mathrm{A}$ \\
\hline \multirow[t]{8}{*}{ Gr3 } & 3sa1 & & $6 m 4^{* *}$ & & & \\
\hline & 3sa2 & $6 f 2 * *$ & & & $\mathrm{I}^{* *}, \mathrm{~m}^{* *}$ & Father: $\ddagger$ \\
\hline & $3 \mathrm{c} 1 / 3 \mathrm{j} 1$ & $3 \mathrm{f1} \mathbf{1}^{* *}$ & $3 \mathrm{~m} 1 * *$ & & $\mathrm{i}^{*}, \mathrm{j}^{* *}$ & \\
\hline & $3 c 2^{6}$ & $\overline{3 \mathrm{f1}} * *$ & N/A & $\mathrm{N} / \mathrm{A}$ & N/A & $\mathrm{N} / \mathrm{A}$ \\
\hline & $3 \mathrm{cv} 1$ & $3 \mathrm{f1}{ }^{* *}$ & & & $\mathrm{e}^{* *}, \mathrm{j}^{* *}, \mathrm{k}^{*}$ & Father: • \\
\hline & $3 c v 2^{6}$ & $3 \mathrm{f1} * *$ & $\mathrm{~N} / \mathrm{A}$ & $\mathrm{N} / \mathrm{A}$ & N/A & $\mathrm{N} / \mathrm{A}$ \\
\hline & $3 \mathrm{cn} 1$ & $3 \mathrm{f2} * *$ & $3 \mathrm{~m} 1 *$ & & $i^{*}$ & \\
\hline & $3 \operatorname{cn} 2^{6}$ & $3 \mathrm{f} 2 * *$ & $\mathrm{~N} / \mathrm{A}$ & $\mathrm{N} / \mathrm{A}$ & N/A & $\mathrm{N} / \mathrm{A}$ \\
\hline \multirow[t]{6}{*}{ Gr5 } & $5 s a 1$ & & & & $r^{*}$ & \\
\hline & $5 s a 2$ & & & & $p^{*}, r^{*}$ & $\begin{array}{l}\text { Father: } 5 \mathrm{~m} 1 \text { or } \\
\text { mother: } 5 \mathrm{f} 1\end{array}$ \\
\hline & $5 s a 3$ & & & & & \\
\hline & $5 c / 5 j 1$ & $\underline{5 f 1 * *}$ & & & $\mathrm{o}^{* *}$ & Father: $\boldsymbol{\ell}$ \\
\hline & $5 \mathrm{cn} 1$ & $\overline{\text { sf1 }^{* *}}$ & & & $\begin{array}{l}f^{*}, k^{*}, n^{* *}, \\
\text { o** }^{* *}\end{array}$ & Father: • \\
\hline & $5 \mathrm{cn} 2$ & $5 f 1 * *$ & $5 m 1^{* *}$ & & $\mathrm{n}^{* *}, \mathrm{p}^{*}$ & \\
\hline \multirow[t]{4}{*}{ Gr6 } & $6 \mathrm{j} 1$ & $6 f 2 * *$ & $1 \mathrm{~m} 1^{*}$ & & $\begin{array}{l}b^{*}, c^{*}, d^{*}, \\
l^{* *}, s^{* *}\end{array}$ & \\
\hline & $6 \mathrm{j} 2$ & $6 f 2 * *$ & $6 m 1^{* *}$ & & $\mathrm{~m}^{* *}, \mathrm{~s}^{* *}$ & \\
\hline & $6 c 1^{6}$ & $6 f 2 * *$ & N/A & $\mathrm{N} / \mathrm{A}$ & $\mathrm{N} / \mathrm{A}$ & $\mathrm{N} / \mathrm{A}$ \\
\hline & $6 c 2^{6}$ & $6 \mathrm{f2} * *$ & $\mathrm{~N} / \mathrm{A}$ & $\mathrm{N} / \mathrm{A}$ & N/A & $\mathrm{N} / \mathrm{A}$ \\
\hline
\end{tabular}

${ }^{1}$ If an individual's name changed during the study period, both names are noted.

2 Underlined females: known mothers.

${ }^{3}$ High probability: **: 1.00-0.80, intermediate probability: ${ }^{*}:<0.80-0.70$.

${ }^{4}$ The same letters denote candidate (full/half) sibling relationship: $A-B, a-s$.

${ }^{5}$ The same symbols denote the same unidentified candidate father: $\bullet, \square, \diamond, \varnothing, \neq$, e. Detailed explanation on hints is in section Parentage analyses (p. 35).

${ }^{6}$ Offspring not analyzed due to lack of fecal samples or insufficient number of amplifying alleles: 1cv2, 2cv2, 3c2, 3cv2, 3cn2, 6c1, 6c2.

Light blue and dark green color are used to designate the known twins. 
We could assign fathers to roughly one third of the offspring. Paternity assignments revealed a complex picture. Only in one group (Gr1) were all offspring of a female (1f1) sired by the same male $(1 \mathrm{~m} 1)$. In other group, there was a case where paternity for a set of twins was shared between a group and an extra-group male (offspring 6j1 and 6j2, fathers $1 \mathrm{~m} 1,6 \mathrm{~m} 1$ ) or where there were indicated different fathers for different sets of twins of the same female $(1 f 2,3 f 1,5 f 1)$.

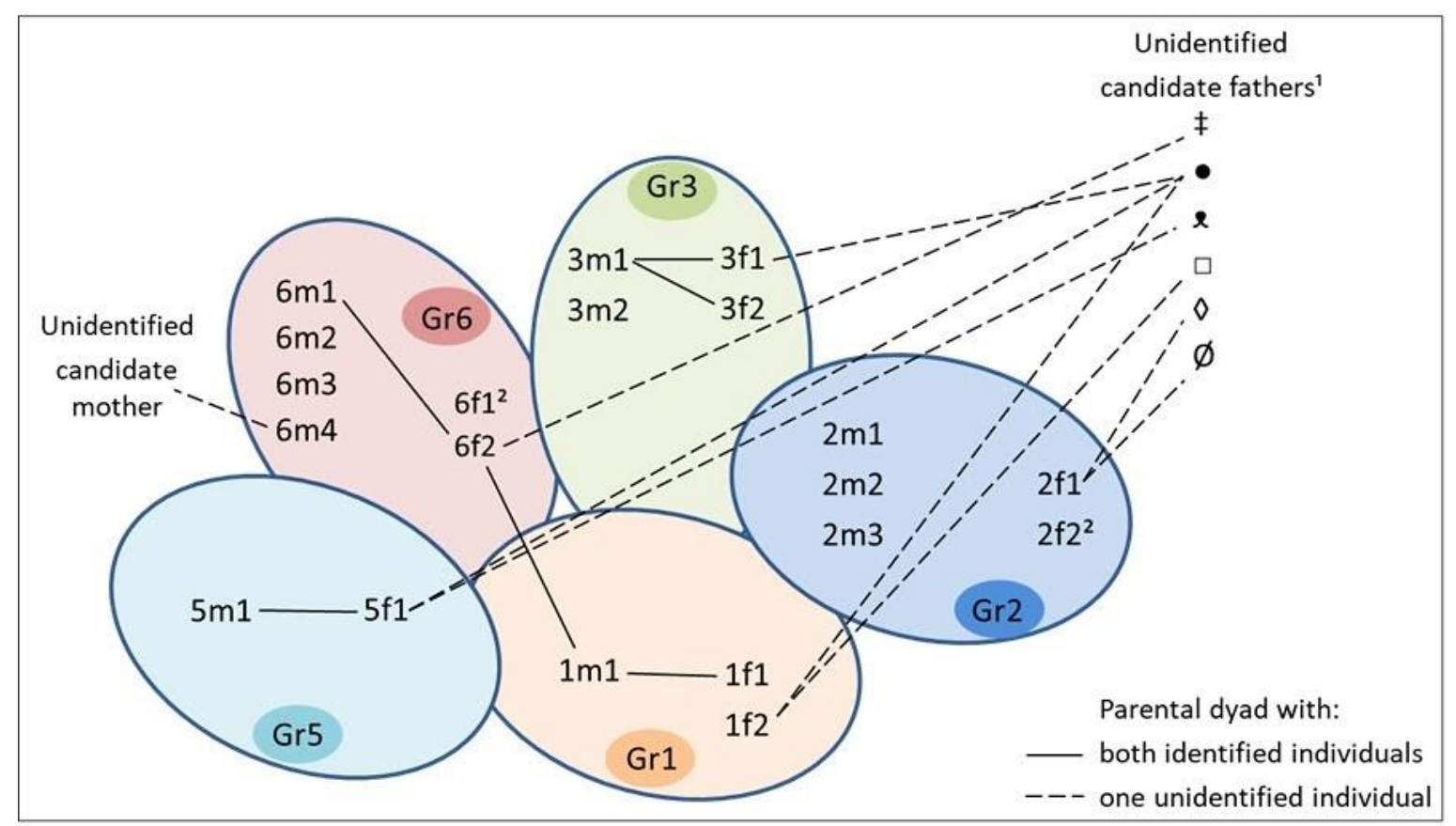

Fig. 4-2: Genetic parental dyads, including: identified individuals with high and intermediate parentage probability, unidentified candidate mother and unidentified candidate fathers. Groups are positioned roughly according to the position of their home ranges (Slana, unpublished data). The lines drawn to unidentified candidate fathers do not imply spatial relationships. The lines drawn to unidentified candidate fathers do not imply spatial relationships.

1 Unidentified candidate fathers $(\ddagger, \bullet, \ell, \square, \oslash, \varnothing)$ derive from "hints from sibling dyads", noted in Table 4-8. Detailed explanation on hints is in section Parentage analyses (p. 35)

${ }^{2}$ Non-breeding females, although it is likely that $2 f 2$ was pregnant, because she was allonursing a litter of $2 f 1$ (Fig. A-7).

\section{Infant survival}

We have a record of 11 litters with totally 20 infants, five of which died (Table 4-1, Fig. 4-1). Surviving offspring had a minimum age of three and a maximum age of 18 months at the end of our study. All infants were born within 18 months, starting three months before data collection. Two litters might have been born as singletons, the other nine litters were born as twins. All five infants that died, did so within the first three months. 
These infants were all born as twins; in three cases one of the twins died and in one case it was both of them. All infants from the secondary breeding females (Gr1, female 1f2; $\mathrm{Gr}$, female 3f2) survived. In contrast, both primary females (Gr1, female 1f1; Gr3, female 3f1) lost one infant twin prior to the secondary females giving birth.

\section{Infant-directed behaviors}

Infant-directed behavior on the study population level, i.e. in relation to age, sex and parentage is depicted in Fig. 4-3, Fig. 4-8 - Fig. 4-11, based on 6 or 5 litters, and in Fig. A-1

- Fig. A-5, based on all 8 litters (see section Behavioral data collection and analyses (p. 29) for explanation). The behavior on the individual level, of all of 8 litters, during carrying period, is depicted in Table 4-9, Fig. 4-4 - Fig. 4-7, and for each month separately in Fig. 4-12, Fig. 4-13 and in Table A-1. In Appendix A we also present information on lactation and on female's (mothers, allo-mothers) refusing to lactate and the behavior towards litter $6 c$, from the first three days after birth (Fig. A-6, Fig. A-7).

\subsection{Carrying}

Main infant carriers are mothers and adult males, regardless of paternity (Fig. 4-3). On an individual level, within the four litters $(1 \mathrm{cn}, 2 \mathrm{c}, 3 \mathrm{c}, 5 \mathrm{cn})$ three of the four main carrying females were mothers (Fig. 4 - Fig. 7). Within the other four litters (1cv, 2cv, 3cv, 3cn) only one of the four main carrying adult males was the father. On average, the main carriers contribute between $40-50 \%$ of carrying, with low values of around $20 \%$ (adult male $3 \mathrm{~m} 2$, litter $3 \mathrm{cn}$ ) and high values above $80 \%$ (mother $1 \mathrm{f} 2$, litter $1 \mathrm{cn}$ ). Secondary carriers are also mostly adults: adult males in 4 litters; one of which was the father (litters $2 c v, 3 c, 3 c v$, $3 \mathrm{cn})$, mothers in 3 litters $(1 \mathrm{cv}, 2 \mathrm{c}, 2 \mathrm{cv})$ and a subadult in 1 litter (litter $5 \mathrm{cn})$. Secondary carriers contribute roughly $20 \%$ of carrying with high values of $40 \%$ (mother, litter $1 \mathrm{cv}$ ). Other carriers that contribute roughly between $10-20 \%$ are again mostly adults: fathers, mothers and subadult females (each in 3 litters), adult male (in 2 litter), adult female and subadult male (each in 1 litter). Individuals that carry up to $5 \%$ are subadults and juveniles, with exception of one adult male (litter $2 c)$. Some individuals did not carry at all: a juvenile (in 3 litters: $2 \mathrm{cv}, 3 \mathrm{cv}, 5 \mathrm{cn}$ ) and an adult female (in 2 litters: $1 \mathrm{cv}, 1 \mathrm{cn}$ ). 


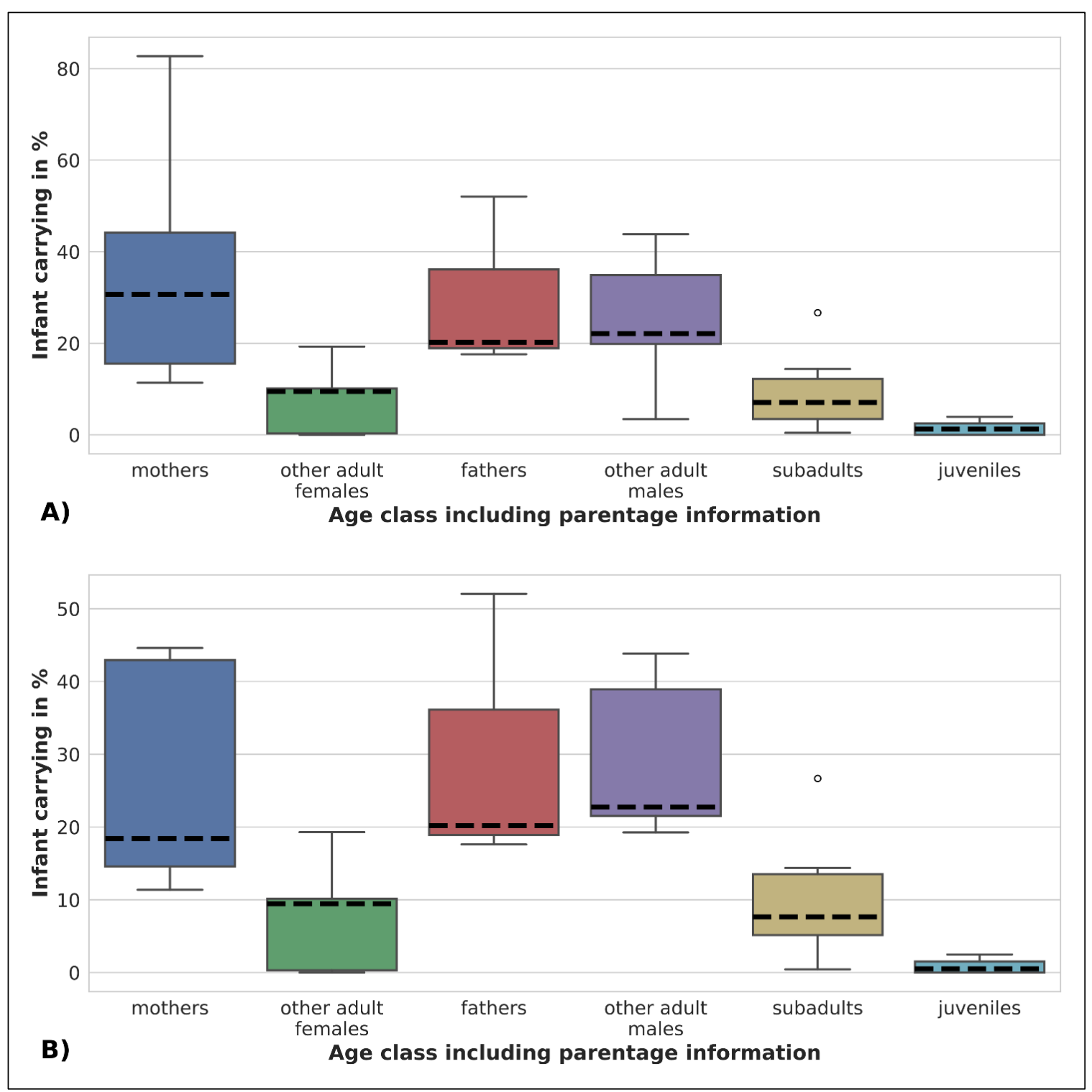

Fig. 4-3: Tukey box plot of contribution of different classes of individuals, combining age class with parentage information, related to infant carrying, based on A) six litters with complete observation periods (0-3 months) B) five litters with complete observation periods (0-3 months), but without litter $1 \mathrm{cn}$ of mother 1f2, whose contribution was extremely high. Boxes extend from first quartile to third quartile. The horizontal line within the box represents the median. Whiskers below (above) the box extend to the lowest (highest) data point which is still within 1.5 times the interquartile range (IQR) of the first (third) quartile, where IQR is the difference between third and first quartile. Open circles (O) indicate data points outside the range encompassed by whiskers. 


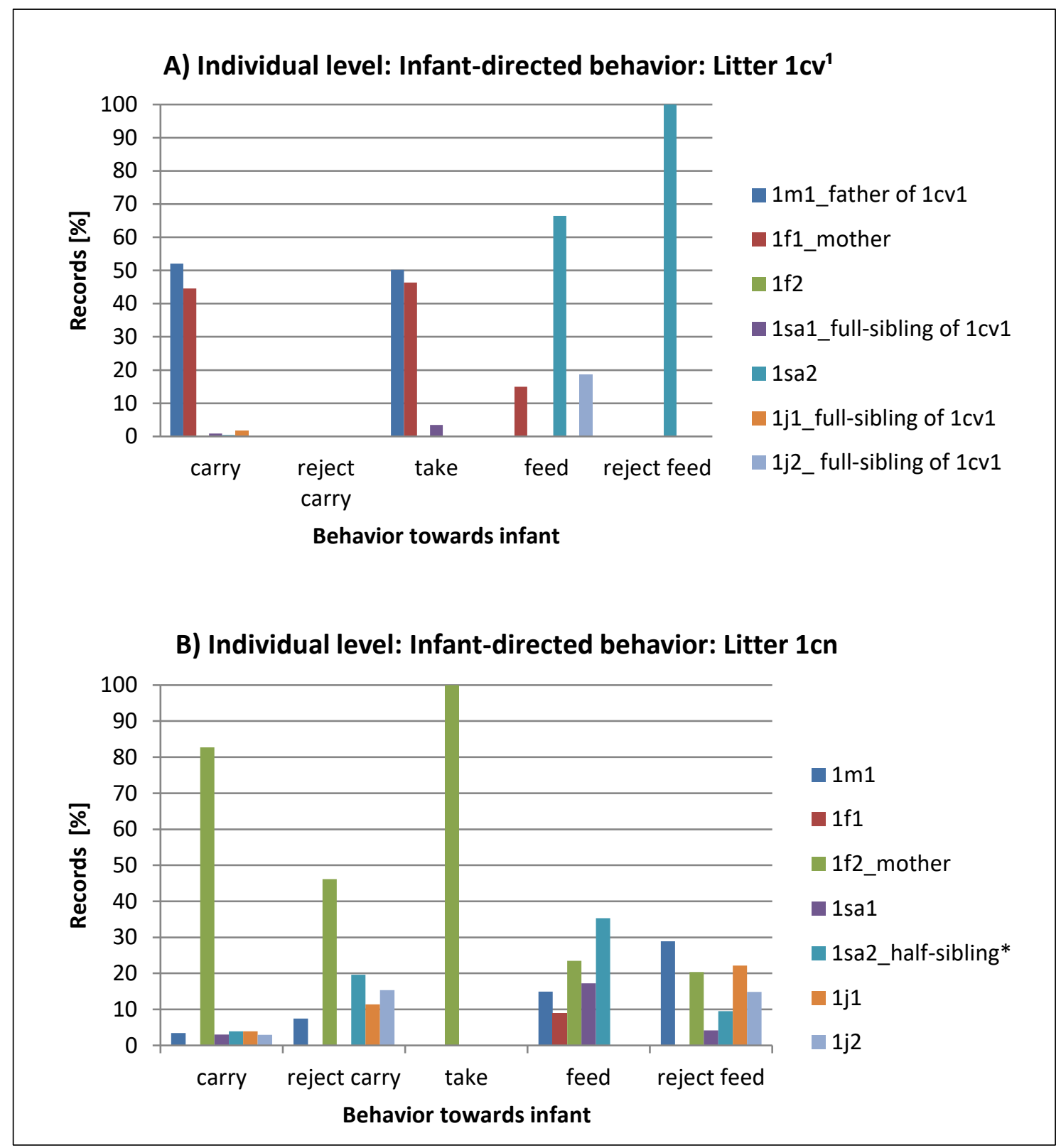

Fig. 4-4: Contribution of infant-directed behavior in Gr1, towards A) litter 1cv B) litter 1cn. The behavior is summed up from the entire infant carrying period, 3 months.

${ }^{1}$ Litter $1 \mathrm{cv}$ represents twins: $1 \mathrm{cv} 1$ \& $1 \mathrm{cv}$.

* Sibling on mother's side. 
Table 4-9: Index of rejections of carrying and food transfer for litters of A) Gr1 B) Gr2 C) Gr3 and D) Gr5.

* Index of rejection could not be calculated because the individual had no record of carrying or food transfer.

\begin{tabular}{|c|c|c|c|c|c|c|c|c|c|}
\hline \multicolumn{10}{|c|}{ A) Index of rejection: Gr1 } \\
\hline $\begin{array}{c}\text { Infant-directed } \\
\text { behavior }\end{array}$ & Litter & \multicolumn{7}{|c|}{ Care takers } \\
\cline { 2 - 11 } & & $1 \mathrm{m1}$ & $1 f 1$ & $1 f 2$ & 1 sa1 & 1 sa2 & $1 j 1$ & $1 j 2$ & All \\
\hline \multirow{2}{*}{ Carrying } & $1 c v$ & 0.0 & 0.0 & 0.0 & 0.0 & 0.0 & 0.0 & $*$ & 0.0 \\
\cline { 2 - 11 } & $1 c n$ & 0.3 & $*$ & 0.1 & 0.0 & 0.8 & 0.8 & 1.0 & 0.2 \\
\hline Food transfer & $1 c v$ & $*$ & 0.0 & $*$ & $*$ & 0.0 & $*$ & 0.0 & 0.0 \\
\cline { 2 - 11 } & $1 c n$ & 0.5 & 0.0 & 0.2 & 0.1 & 0.1 & $*$ & $*$ & 0.3 \\
\hline
\end{tabular}

\begin{tabular}{|c|l|l|l|l|l|l|l|l|l|}
\hline \multicolumn{10}{|c|}{ B) Index of rejection: Gr2 } \\
\hline $\begin{array}{c}\text { Infant-directed } \\
\text { behavior }\end{array}$ & Litter & \multicolumn{7}{|c|}{ Care takers } \\
\cline { 2 - 11 } & & $\mathbf{2 m 1}$ & $\mathbf{2 m 2}$ & $\mathbf{2 m 3}$ & $\mathbf{2 f 1}$ & $\mathbf{2 f 2}$ & $\mathbf{2 j 1}$ & $\mathbf{2 j 2}$ & All \\
\hline \multirow{2}{*}{ Carrying } & $\mathbf{2 c}$ & 0.0 & 0.0 & 0.0 & 0.0 & 0.0 & NA & NA & 0.0 \\
\cline { 2 - 11 } & $\mathbf{2 c v}$ & 0.1 & 0.3 & NA & 0.3 & 1.6 & 0.0 & 0.0 & 0.2 \\
\hline Food transfer & $\mathbf{2 c}$ & 0.5 & 0.2 & 0.1 & 0.1 & 0 & NA & NA & 0.1 \\
\cline { 2 - 11 } & $\mathbf{2 c v}$ & 0.1 & 0.1 & NA & 0.1 & 0.1 & 0.1 & 0.0 & 0.1 \\
\hline
\end{tabular}

\begin{tabular}{|c|l|l|l|l|l|l|l|l|l|}
\hline \multicolumn{10}{|c|}{ Index of rejection: Gr3 } \\
\hline $\begin{array}{c}\text { Infant-directed } \\
\text { behavior }\end{array}$ & Litter & \multicolumn{7}{|c|}{ Care takers } \\
\cline { 2 - 11 } & & $3 m 1$ & $3 m 2$ & $3 f 1$ & $3 f 2$ & $3 s a 1$ & $3 s a 2$ & $3 j 1$ & All \\
\hline \multirow{4}{*}{ Carrying } & $3 c$ & 0.0 & 0.1 & 0.1 & 0.0 & 0.0 & NA & 0.0 & 0.1 \\
\cline { 2 - 11 } & $3 c v$ & 0.1 & 0.0 & 0.0 & 0.0 & 0.0 & $*$ & 0.0 & 0.0 \\
\cline { 2 - 11 } & $3 c n$ & 0.0 & 0.7 & 1.1 & 0.3 & 0.5 & 3.1 & 0.5 & 0.4 \\
\hline \multirow{4}{*}{ Food transfer } & $3 c$ & 0.1 & 0.2 & 0.2 & 0.0 & 0.0 & NA & 0.1 & 0.1 \\
\cline { 2 - 10 } & $3 c v$ & 0.0 & 0.4 & 0.2 & $*$ & 0.0 & 0.0 & 0.1 & 0.0 \\
\cline { 2 - 10 } & $3 c n$ & 0.0 & 0.1 & 0.0 & 0.0 & 0.1 & 0.1 & 0.0 & 0.0 \\
\hline
\end{tabular}




\begin{tabular}{|c|c|c|c|c|c|c|c|c|}
\hline \multicolumn{7}{|c|}{ D) Index of rejection: Gr5 } \\
\hline $\begin{array}{c}\text { Infant-directed } \\
\text { behavior }\end{array}$ & Litter & \multicolumn{7}{|c|}{ Care takers } \\
\cline { 2 - 9 } & & $\mathbf{5 m 1}$ & $\mathbf{5 f 1}$ & $\mathbf{5 s a 1}$ & $\mathbf{5 s a 2}$ & $\mathbf{5 s a 3}$ & $\mathbf{5 j 1}$ & All \\
\hline Carrying & $\mathbf{5 c n}$ & 0.0 & 0.0 & 0.0 & 0.0 & 0.0 & $*$ & 0.0 \\
\hline Food transfer & $\mathbf{5 c n}$ & 0.0 & 0.1 & 0.0 & 0.1 & 0.0 & $*$ & 0.0 \\
\hline
\end{tabular}

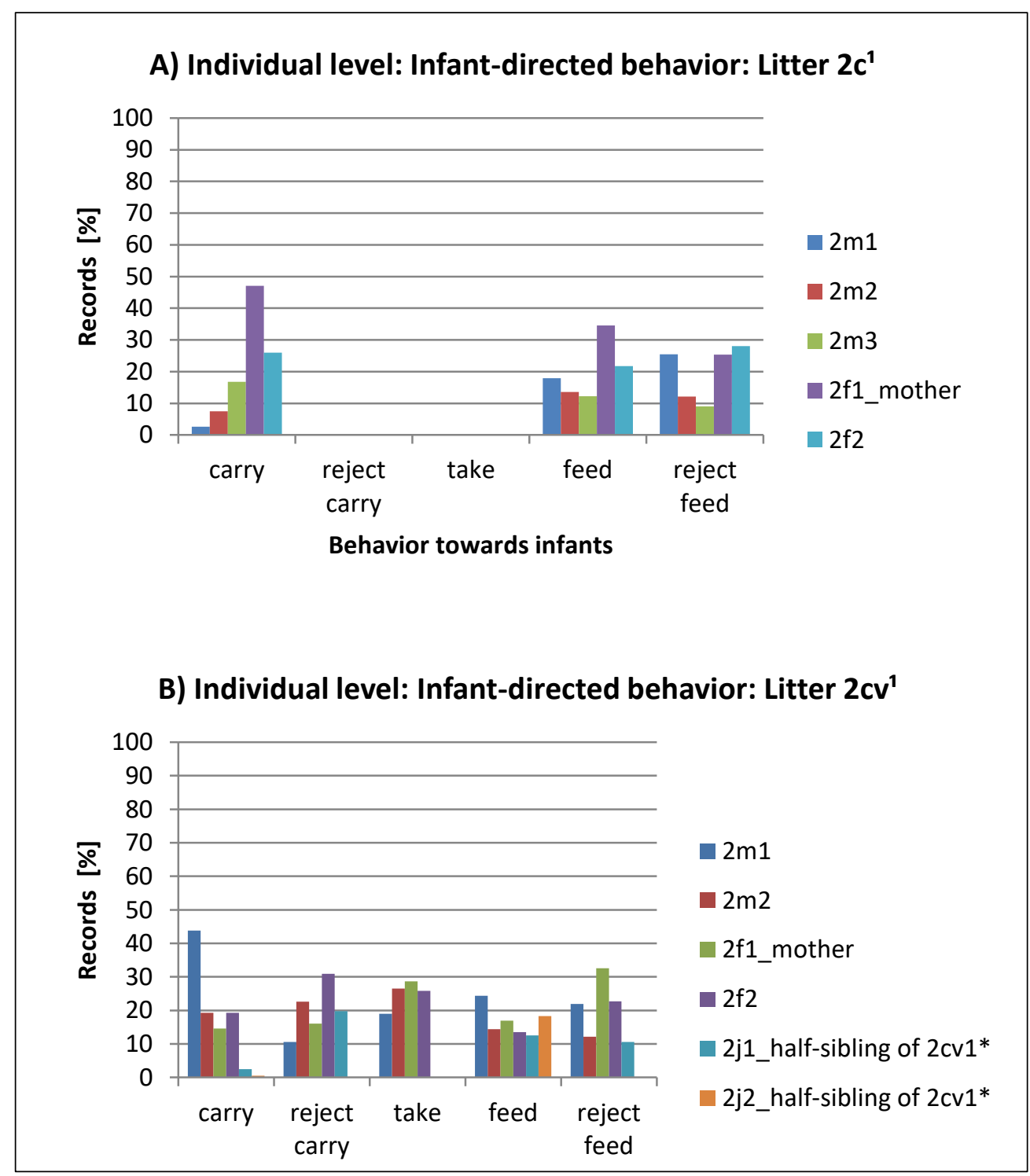

Fig. 4-5: Contribution of infant-directed behavior in Gr2, towards A) litter 2c, B) litter 2cv. The behavior is summed up from the entire infant carrying period: 2 months for litter $2 c$ (without the first month of infant's life) and 3 months for litter $2 \mathrm{cv}$.

${ }^{1}$ Litter $2 c$ represents twins: $2 c 1$ \& $2 c 2$. Litter $2 c v$ represents twins: $2 c v 1 \& 2 c v 2$.

* Maternal sibling 


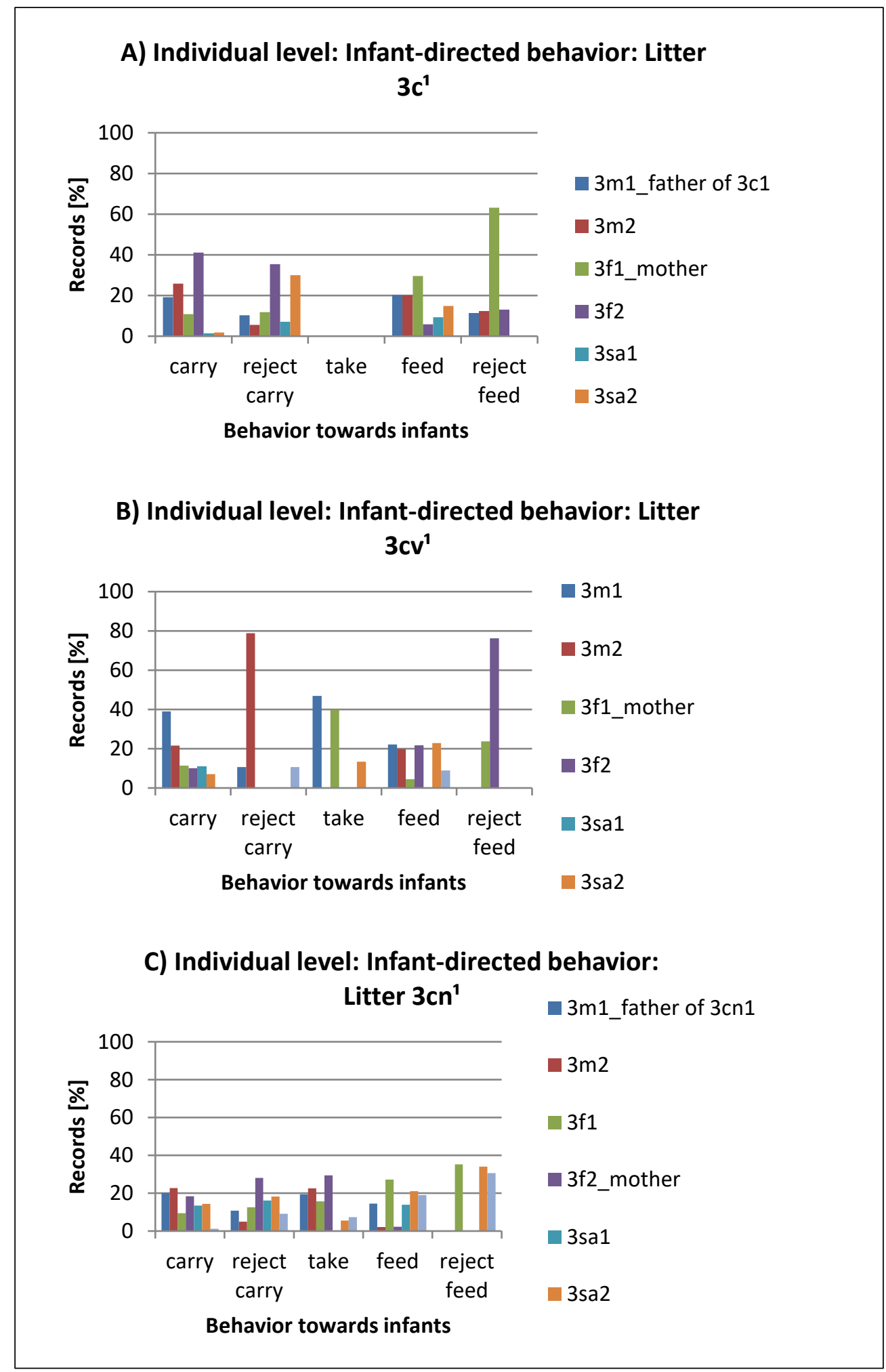

Fig. 4-6: Contribution of infant-directed behavior in Gr3, towards A) litter 3c B) litter 3cv C) litter $3 \mathrm{cn}$. This behavior is summed from the entire infant carrying period: 2 months for litter $3 \mathrm{c}$ (without the first month of infant's life) and 3 months for litter $3 \mathrm{cv}$ and $3 \mathrm{cn}$.

${ }^{1}$ Litter $3 c$ represents twins: $3 c 1$ \& 3c2. Litter 3cv represents twins: $3 c v 1$ \& 3cv2. Litter $3 c n$ represents twins: $3 c n 1 \& 3 c n 2$.

* Maternal sibling

** Paternal sibling 


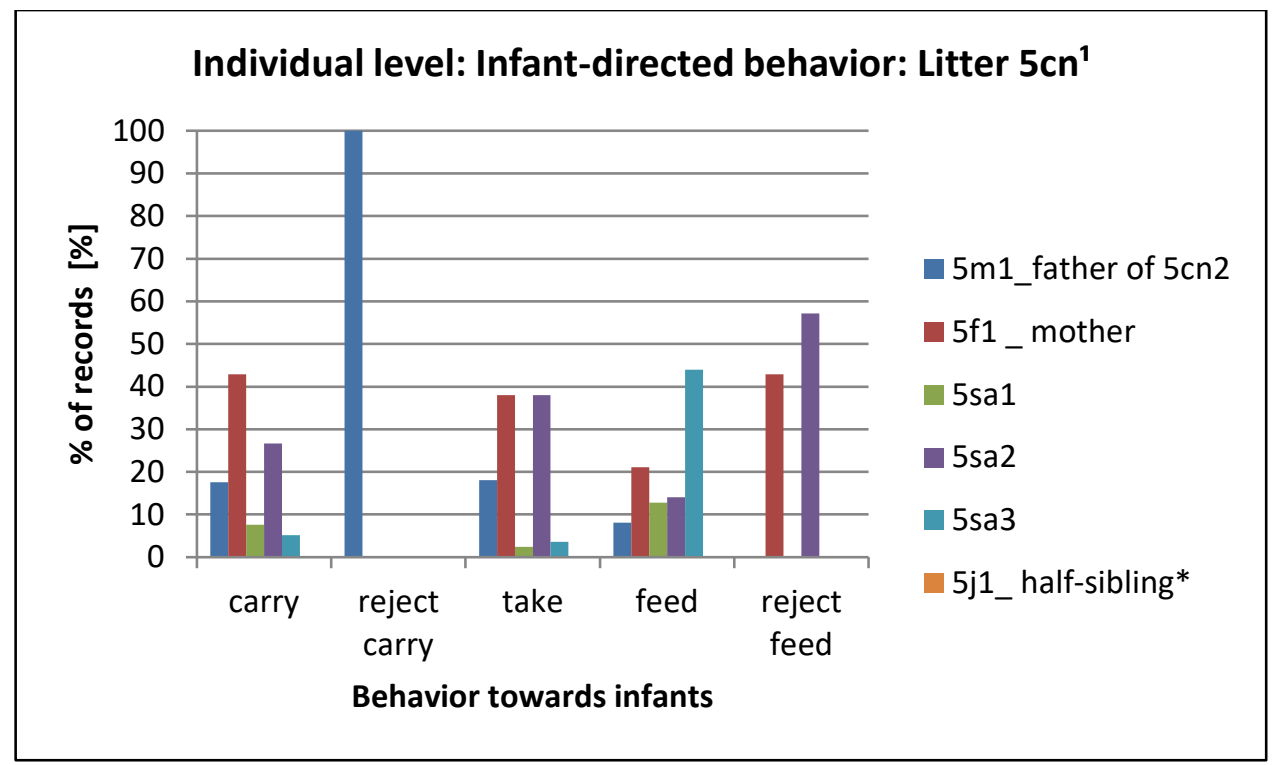

Fig. 4-7: Contribution of infant-directed behavior in Gr5, towards litter $5 \mathrm{cn}$. The behavior is summed up from the entire infant carrying period: 3 months.

${ }^{1}$ Litter $5 c$ represents twins: $5 \mathrm{cn} 1$ \& $5 \mathrm{cn} 2$.

* Maternal sibling

\subsection{Reject carrying}

Rejection of carrying infant litters varied in frequency and from which individuals. Overall, fathers rejected to carry the most (Fig. 4-8). Some litters were never rejected ( $1 \mathrm{cv}$ and $2 \mathrm{c}$ ), rejected by only one individual $(5 \mathrm{cn})$, rejected by less than half of the individuals $(3 \mathrm{cv})$, or by most or all individuals (1cn, 2cv, 3c, 3cn) (Fig. 4-4 - Fig. 4-7, Table 4-9). Individuals that rejected the most ( $1 \mathrm{f} 2$ in litter $1 \mathrm{cn}, 3 \mathrm{f} 2$ in litter $3 c, 3 \mathrm{~m} 2$ in litter $3 c v, 5 \mathrm{~m} 1$ in litter $5 \mathrm{cn}$ ), between 40-100\%, have a low carrying rejection index (0.0-0.1), meaning that proportionally they also carry a lot. The highest index of rejections (0.8-3.1) were by some juveniles, yet they rejected less than $10 \%$. In half of the litters $(1 \mathrm{cn}, 2 \mathrm{cv}, 3 \mathrm{c}, 3 \mathrm{cn})$ mothers who rejected to carry the infants, had a low index of rejection (0.0-0.1). The exception is the female $3 \mathfrak{f} 2$, whose rejection index is 1.1 , yet had the highest carrying rejection percentages in the group (30\%). All adult males participated in carry rejection behaviors in all litters concerned $(1 \mathrm{cn}, 2 \mathrm{cv}, 3 \mathrm{cv}, 3 \mathrm{c}, 3 \mathrm{cn}, 5 \mathrm{cn})$ and resulted in 0.0-0.4 index of rejections. When we considered the whole group as one individual the index of rejections was low, 0.0-0.2, for all but one litter $(3 \mathrm{cn})$, where it was 0.5 . 


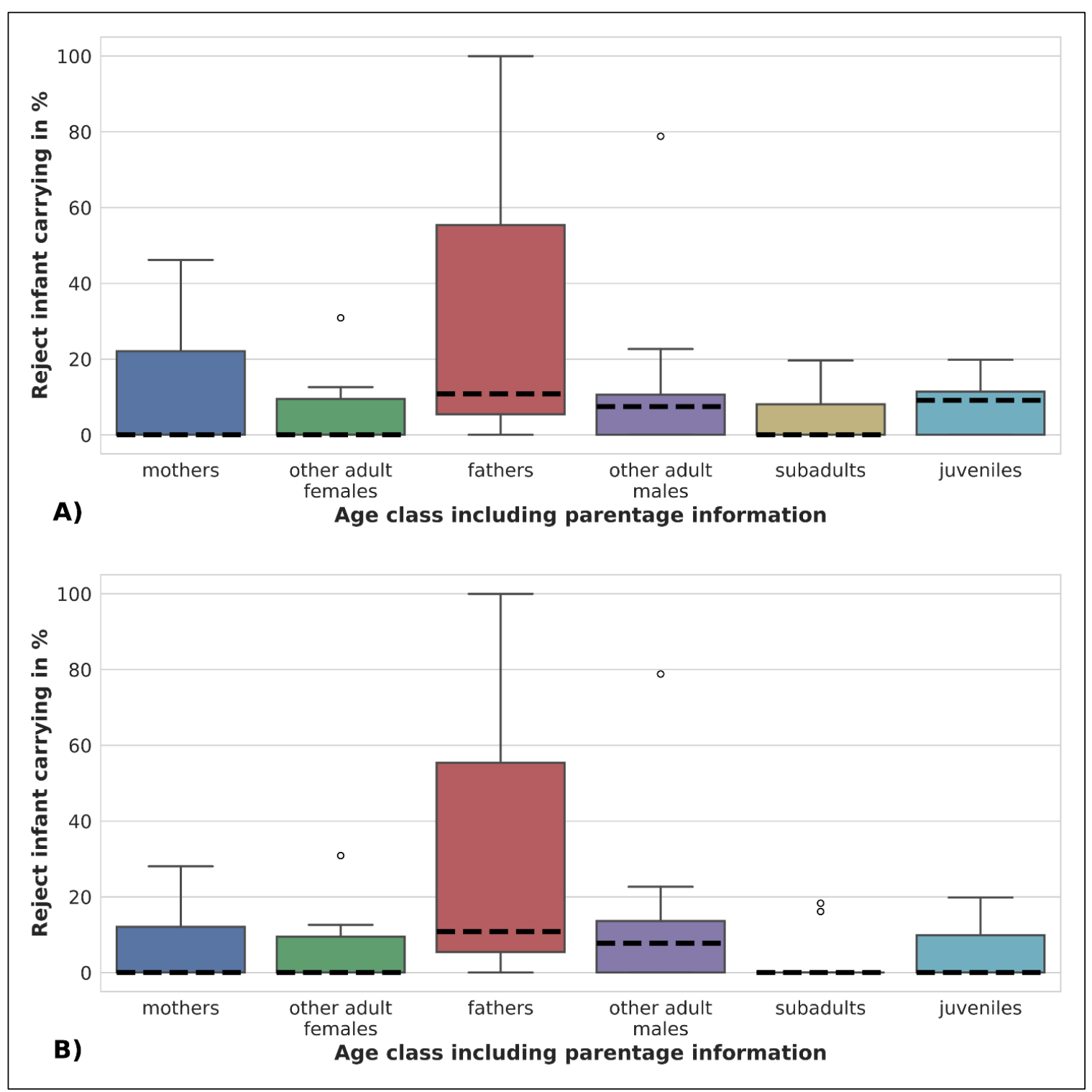

Fig. 4-8: Tukey box plot of contribution of different classes of individuals, combining age class with parentage information, related to carrying rejection, based on A) six litters with complete observation periods (0-3 months) B) five litters with complete observation periods (0-3 months), but without litter $1 \mathrm{cn}$ of mother 1f2, whose contribution was extremely high. See Fig. 4-3 for details.

\subsection{Infant take attempt}

We have records of infant take attempt behavior from 6 out of 8 litters $(1 \mathrm{cv}, 1 \mathrm{cn}, 2 \mathrm{cv}, 3 \mathrm{cv}$, $3 c n, 5 c n$ ) (Fig. 4-4 - Fig. 4-7, Table 4-9). The other two litters (2c, 3c) were not observed in their first month, when the take behavior is the most pronounced (Table A-1). Overall, mothers try to take infants the most. However this includes both extreme values - from not trying to take the infant at all, to being the only individual in the group who attempts to take the litter (mother 1f2) (Fig. 4-9). Among adult males, fathers show the overall 
greater interest in taking the infants although their extreme values do not differ. In most litters $(1 \mathrm{cn}, 2 \mathrm{cv}, 3 \mathrm{cn}, 5 \mathrm{cn})$ mothers were the main individuals who tried to take infants (30-100\%). In other two litters adult males take infants most often (50\%), followed by a mother $(40 \%$, litter $3 \mathrm{cv})$ or they tried to take infants almost equally (litter $1 \mathrm{cv})$. Subadults also participated, yet only in one litter $(5 \mathrm{cn}$ ) with a notable contribution (ca $40 \%$ ).

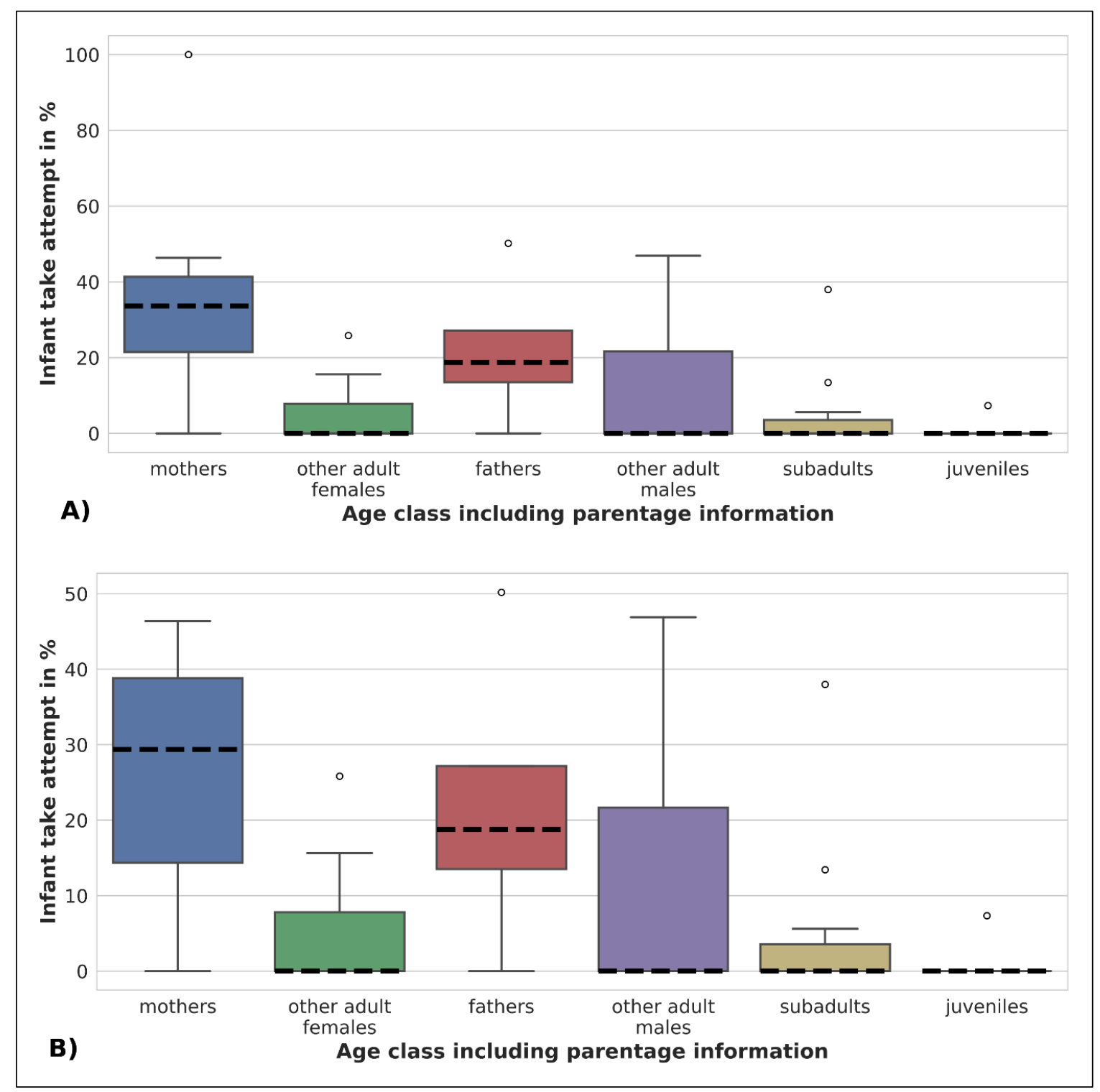

Fig. 4-9: Tukey box plot of contribution of different classes of individuals, combining age class with parentage information, related to infant take attempt, based on A) six litters with complete observation periods (0-3 months) B) five litters with complete observation periods (0-3 months), but without litter $1 \mathrm{cn}$ of mother 1f2, whose contribution was extremely high. Boxes extend from first quartile to third quartile. See Fig. 4-3 for details. 


\subsection{Infant food transfer}

Food transfer was the most equally divided infant-directed behavior. Overall, all age classes contributed substantially with subadults contributing the most (Fig. 4-10). Still, subadults included both extreme values, from not transferring the food at all, to the most. In all but one litter (1cv) infants are fed by all or most of group members (Fig. 4-4 - Fig. 4-7, Table 4-9). In most litters ( $1 \mathrm{cv}, 1 \mathrm{cn}, 3 \mathrm{cv}, 5 \mathrm{cn}$ ) subadults are the main food providers. Other main providers are mothers (litters $2 c, 3 c$ ), adult males (litters $2 \mathrm{cv}, 3 \mathrm{cv}$ ) and adult females (litters $3 \mathrm{cn}, 3 \mathrm{cv}$ ). In litters where food transfer was distributed among all or most individuals $(1 \mathrm{cn}, 2 \mathrm{c}, 2 \mathrm{cv}, 3 \mathrm{c}, 3 \mathrm{cv}, 3 \mathrm{cn}, 5 \mathrm{cn})$ main providers contributed $20-45 \%$ and in the remaining litter $(1 \mathrm{cv})$ even close to $70 \%$. Mothers fed their own litters, but their contribution varied. Among the group members, mothers were the most frequent food providers (approx. 35\% for litters 2c and 3c) or the intermediate (approx. 20\% for litters $1 \mathrm{cn}, 2 \mathrm{cv}, 5 \mathrm{cn}$ ) or the least frequent (approx. 15\% for litter $1 \mathrm{cv}$ and below 5\% for litters $3 \mathrm{cn}, 3 \mathrm{cv})$. All adult males fed all but one litter (1cv). Fathers did not differ from other males in their contribution, which was about $10-20 \%$.

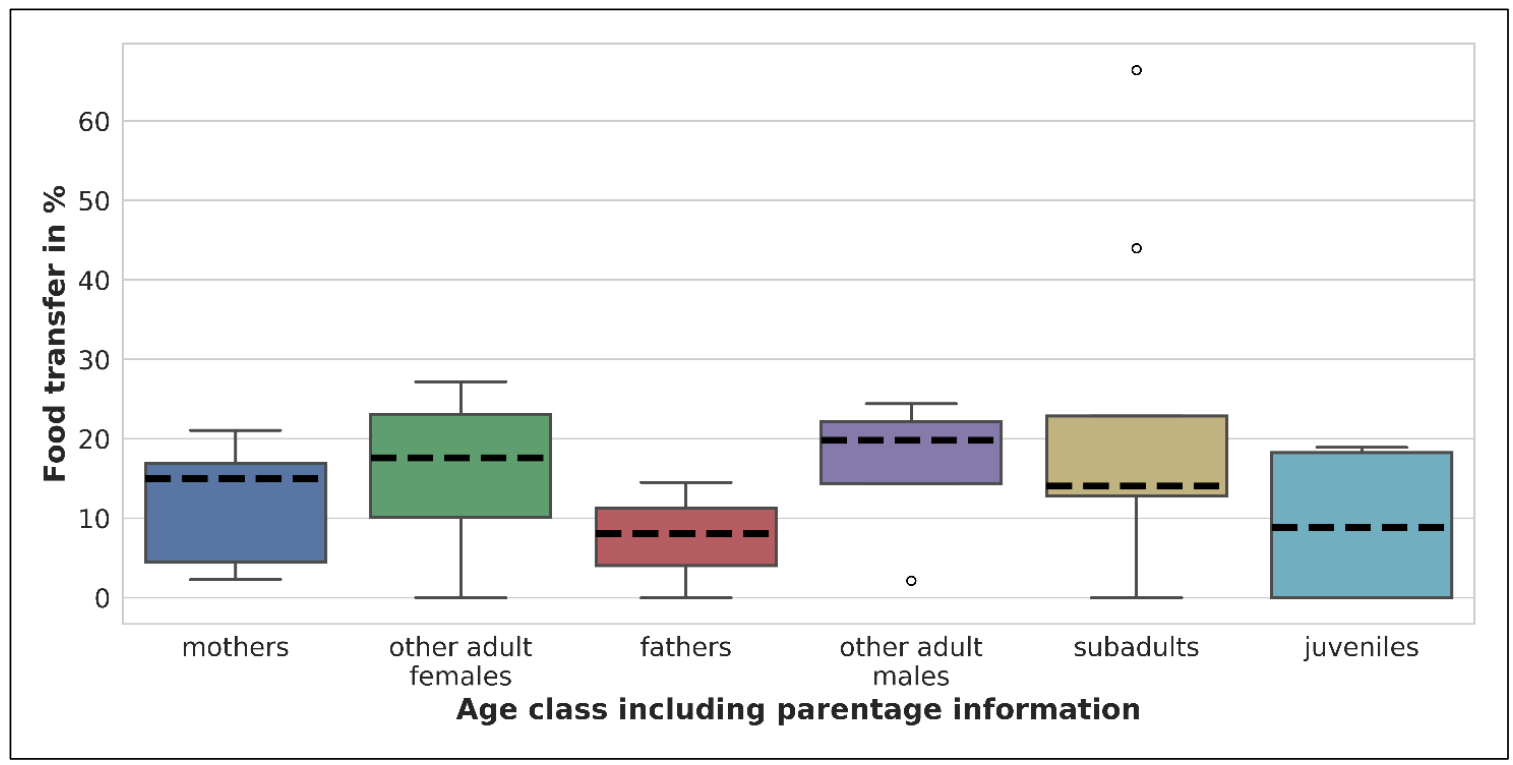

Fig. 4-10: Tukey box plot of contribution of different classes of individuals, combining age class with parentage information, related to infant food transfer, based on six litters with complete observation periods (0-3 months). See Fig. 4-3 for details. 


\subsection{Reject food transfer}

Infants were occasionally rejected to be fed by all age/relative groups, except by the fathers (Fig. 4-11). Overall adult females rejected more than other age/relative groups. Considering each litter separately, in all eight litters infants were sometimes refused to be fed (Fig. 4-4 - Fig. 4-7, Table 4-9). Half of the litters (1cn, 2c, 2cv, 3c) were refused by most or all group members, three litters $(3 c v, 3 c n, 5 c n)$ were refused by less than half, whereas one litter (1cv) was refused by a single individual (1sa2). This subadult female (1sa2) also had the highest food transfer percentage off all study individuals (roughly 65\%, litter 1cv), but a low index of rejection, 0.0-0.1. Indeed, with exception to one litter ( $1 \mathrm{cn})$, individuals that rejected the most also fed a lot, thus had low index of rejections 0.0-0.2. The highest rejection index was 0.4 and 0.5 , by two adult males (litter $1 \mathrm{cn}, 2 \mathrm{c}$ ) and a mother (litter $3 \mathrm{cv}$ ). Other mothers (litters $1 \mathrm{cn}, 2 \mathrm{c}, 2 \mathrm{cv}, 3 \mathrm{c}, 5 \mathrm{cn}$ ) had index of $0.1-0.2$, although their food transfer contribution was between $20-60 \%$. Only in two litters $(1 \mathrm{cv}, 3 \mathrm{cn})$ mothers never refused to feed. Adult males sometimes refused to feed infants in half of the litters $(1 \mathrm{cn}$, $2 c, 2 c v, 3 c)$ : mostly with low feed refusal (10-20\%) and low refusal index, $0.1(2 c, 2 c v, 3 c)$ or higher feed refusal (25-30\%) and higher refusal index, 0.5 (1cn, 2c). When we considered the whole group as one individual the index of rejections was low (0.0-0.1) for all but one litter $(1 \mathrm{cn})$, where it was 0.3 .

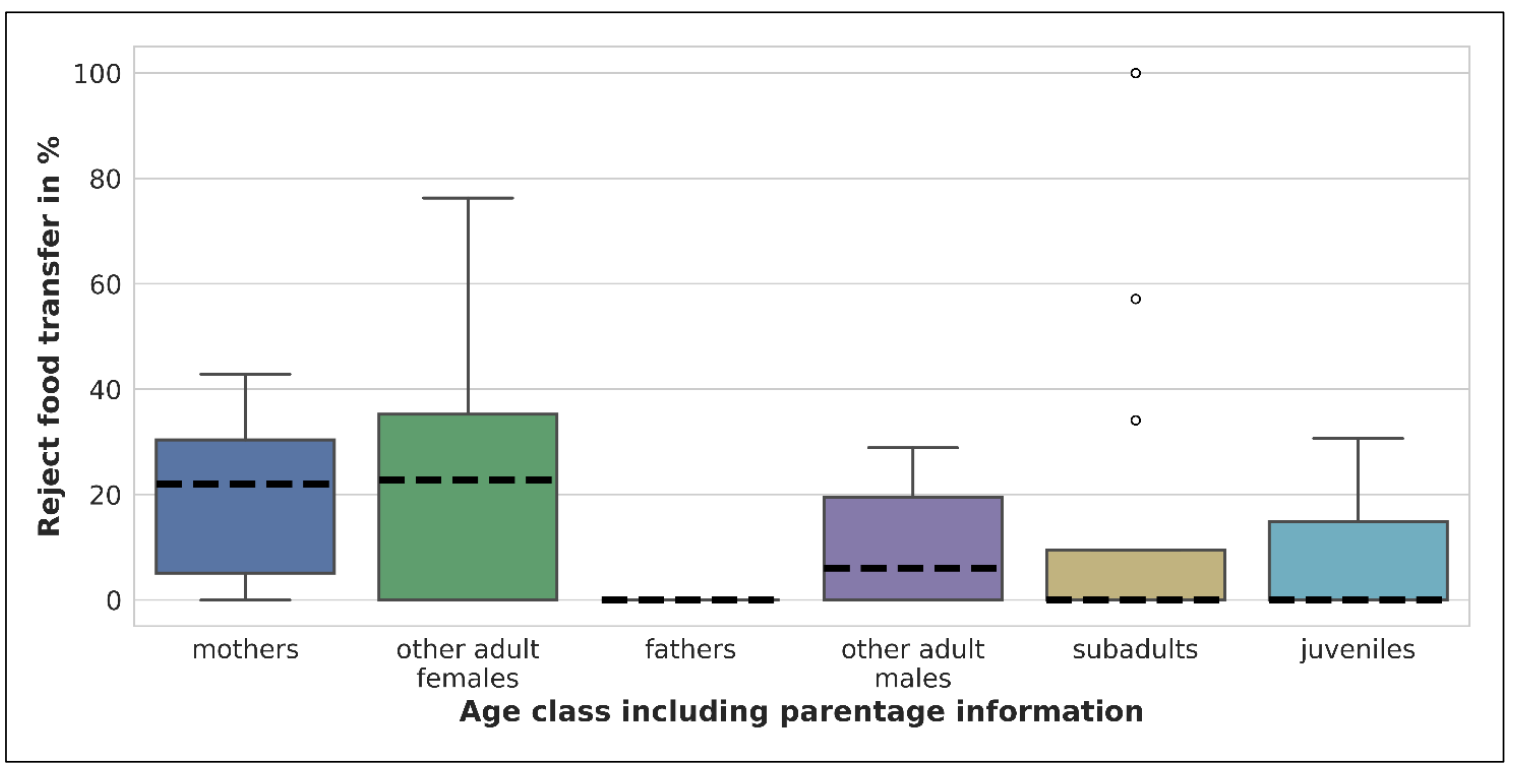

Fig. 4-11: Tukey box plot of contribution of different classes of individuals, combining age class with parentage information, related to infant reject food transfer, based on six litters with complete observation periods (0-3 months). See Fig. 4-3 for details. 


\section{The case of multi-breeding female groups}

We have records of multi-female breeding from two groups (Gr1, Gr3) (Fig. 4-1, Table 4-1 and Table 4-8). Within 2 years and 5 months maternity in both groups was shared among both adult females. In Gr1 the primary breeding female (1f1) gave birth three times (litters $1 \mathrm{sa} 2,1 \mathrm{c}, 1 \mathrm{cv}$ ) and the secondary breeding female (1f2) gave birth twice (litters 1sa1, 1cn). In Gr3 the primary breeding female (3f1) gave birth twice (litters 3c, 3cv) and the secondary breeding female ( $3 f 2$ ) gave birth once (litter $3 \mathrm{cn}$ ). To the best of our knowledge, we present the first data on infant-directed behaviors in multi-female breeding in callitrichids. We present records of carrying periods from the last 15 months, which include five of these litters $(1 \mathrm{cv}, 1 \mathrm{cn}, 3 \mathrm{c}, 3 \mathrm{cv}, 3 \mathrm{cn})$. As already stated, we lack records of the first month of a carrying period of litter 3c, therefore we focused more on other four litters. In Gr1 the secondary breeding female (1f2, litter $1 \mathrm{cn})$ gave birth two months after the primary female (1f1, litter $1 \mathrm{cv})$, therefore it was still within the carrying period of the previous litter. In $\mathrm{Gr} 3$ the secondary breeding female (3f2, litter $3 \mathrm{cn}$ ) gave birth four months after the primary breeding female $(3 f 1,3 c n)$, therefore one month after the end of the carrying period of a previous litter. Contribution of infant-directed behaviors by different individuals for the litters of the primary and secondary breeding females are presented in Fig. 4-4, Fig. 4-6, Fig. 4-12, Fig. 4-13 and Table 4-9.

\subsection{Group 1: carrying, reject carrying, take attempt}

The litter of the primary breeding female $(1 \mathrm{cv})$ was mainly carried or attempted to be taken by its parents, in both cases roughly $50 \%$ by the father $(1 \mathrm{~m} 1)$ and above $40 \%$ by the mother (1f1) (Fig. 4-4). Group members never rejected carrying the litter, thus resulting in the lowest possible index of rejections, 0.0 (Table 4-9). In contrast, the litter of a secondary female $(1 \mathrm{cn})$ was mainly carried only by the mother (1f2), above $80 \%$. Likewise, she was the only individual who took her infant from others to carry it. She also rejected carrying the litter the most frequently (above 40\%), but with a low index of rejection, 0.1. This female represents the extreme case of high carrying, high reject carrying and high take attempt (Fig. 4-3, Fig. 4-8, Fig. 4-9). In contrast, 1sa2 and 1j1 carried little (below 5\%) yet proportionally rejected a lot and resulted in the highest index of rejection within the 
group, 0.8. Mothers did not carry infants of another mother. In both litters subadults and juveniles contribute little to carrying or not at all.

\subsection{Group 1: adult male}

Carrying contribution of the only adult male in the group (1m1) had two extremes: for the litter that he sired $(1 \mathrm{cv})$ he was one of the main carriers (roughly $50 \%$ ) and for the litter of the secondary breeding female (1cn) his carrying contribution was less than 5\% (Fig. 4-4). He carried in four consecutive months: in the first two months, in December and January, only one litter was present $(1 \mathrm{cv})$ and in the next two months, in February and March, both were present (1cv, 1cn) (Fig. 4-12). His overall carrying contribution was the highest in the first consecutive month, in December, around 60\%, and uneven over the next three months (Fig. 4-12A). In the third consecutive month, in February, he had a choice between his old litter (1cv) and a new litter (1cn). He continued to carry the old litter (1cv), above $90 \%$ (Fig. $4-12$ C). His carrying contribution of the new litter (1cn) was the highest $(80 \%)$ in March, in the last consecutive carrying month (Fig. 4-12B), although, he carried both litters roughly equally (Fig. 4-12C). Male's index of carrying rejections differed for the two litters: it was the lowest possible for the litter of the primary female $(1 \mathrm{cv}), 0.0$, because he would never reject to carry it, and higher for the litter of the secondary female $(1 \mathrm{cn}), 0.3$ (Table 4-9). 


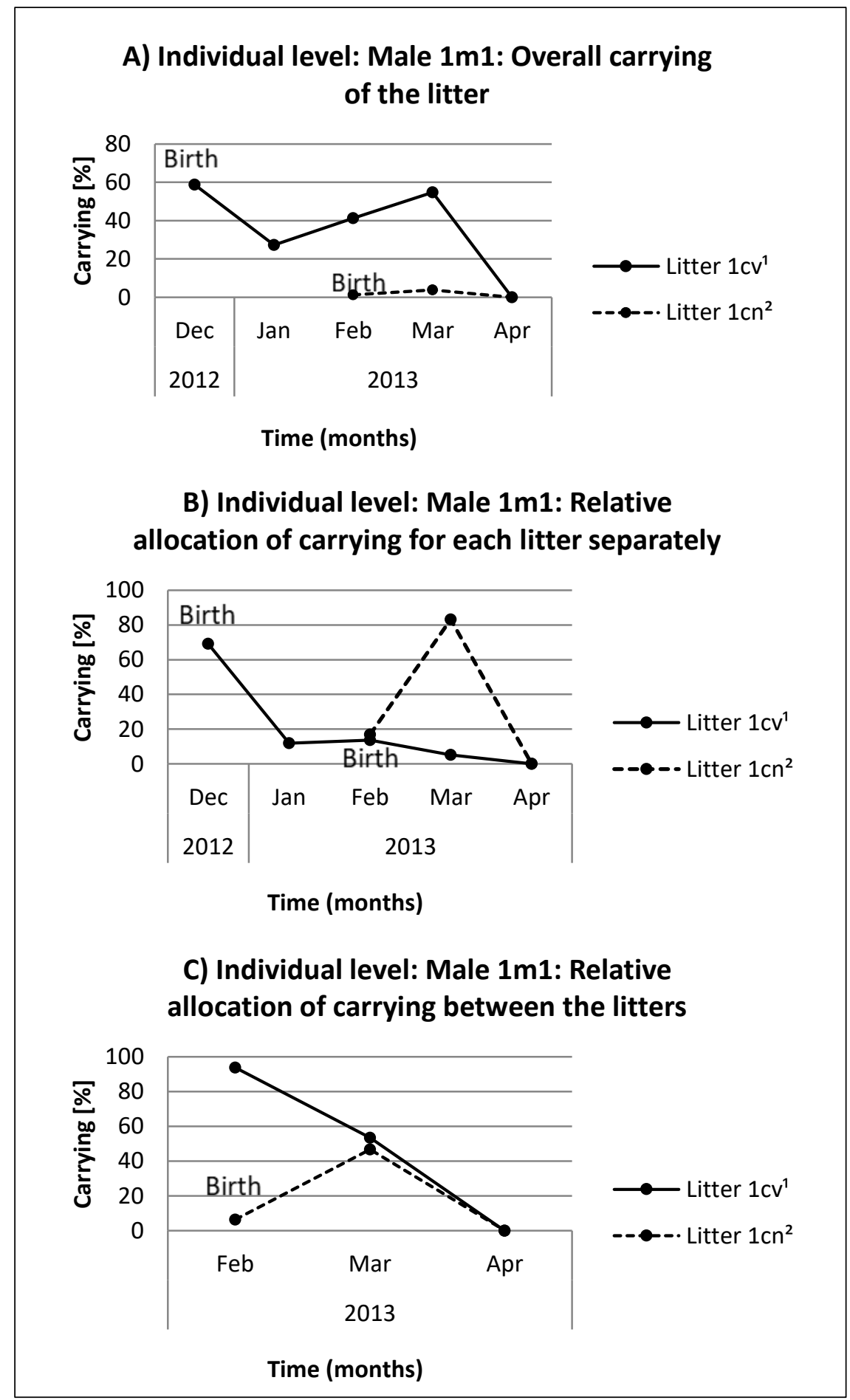

Fig. 4-12: Carrying contribution of male $1 \mathrm{~m} 1$ of the litters from mothers $1 \mathrm{f} 1$ and $1 \mathrm{f} 2$ over time. A) Male's overall carrying of the litter in the group. B) Male's relative allocation of carrying for each litter separately. C) Male's relative allocation of carrying between the litters.

${ }^{1}$ Parents of litter $1 \mathrm{cv}$ are male $1 \mathrm{~m} 1$ and female $1 \mathrm{f} 1$. Litter $1 \mathrm{cv}$ represents twins: $1 \mathrm{cv} 1$ \& $1 c v 2$.

${ }^{2}$ Mother of litter $1 \mathrm{cn}$ is female $1 \mathrm{f} 2$. 


\subsection{Group 1: food transfer}

Infant feeing contribution from group members differed for the two litters (Fig. 4-4, Table 4-9). The most important food provider for the litter of the primary female $(1 \mathrm{cv})$ was a subadult female (1sa2), with roughly $65 \%$ of the contribution. Also, she was the only individual that rejected to feed but still resulted with the lowest possible rejection index, 0.0. For the litter of the secondary female $(1 \mathrm{cn})$ two behaviors, food transfer and the rejection of food transfer, were distributed among majority individuals. The main food provider was with $35 \%$ again with the same subadult female (1sa2), a half-sibling to the litter, and again with low index of rejections, 0.1. The primary breeding female (1f1) was transferring the food to both infants, roughly $10 \%$ and never rejected any. The secondary breeding female (1f2) was transferring food only to her own infant $(1 \mathrm{cn})$ but also rejected to do so, with a low rejection index of 0.2. The adult male $(1 \mathrm{~m} 1)$ did not feed or reject to feed the litter of a primary female (1cv). In contrast, he fed the other litter $(1 \mathrm{cn}), 15 \%$, but he rejected to feed it more than others, roughly $30 \%$ and had the highest index of rejections, 0.5 .

\subsection{Group 3: carrying, reject carrying, take attempt}

All adults and subadults carry all three litters $(1 \mathrm{c}, 1 \mathrm{cv}, 1 \mathrm{cn})$, with adults contributing the most: in litter $3 \mathrm{c}$ close to $100 \%$, in litters $3 \mathrm{cv}$ and $3 \mathrm{cn}$ roughly $80 \%$ (Fig. 4-6). The litter from the secondary female $(3 \mathrm{cn})$ received carrying rejections by all individuals, mostly the mother (3f2), whose rejection index was the second highest in this group, 1.1 (Table 4-9). First litter of the primary female (3c) received most rejections by the secondary female (3f2) and a subadult female (3sa2), each contributed roughly $30 \%$, with a low index of rejections of 0.1 and 0.0 , respectively. The second litter of the primary female (3cv) was rejected to be carried by only the two adult males, mainly by $3 \mathrm{~m} 2$ (almost $80 \%$ ), yet they both had a low index of rejection 0.0-0.1. The first litter of the primary breeder (3c) had no record of take behavior, likely due to no data observations in the first month of carrying period. 


\subsection{Group 3: adult males}

The second litter of the primary female $(3 \mathrm{cv})$ and the litter of the secondary female $(3 \mathrm{cn})$ were born only four months apart, therefore these two litters were a subject of our more detailed comparison (Table 4-1, Fig. 4-1). The most important difference of these two litters was a decrease in carrying effort by one adult male $(3 \mathrm{~m} 1)$ in the consecutive litters $(3 c v, 3 c n$, respectively) (Fig. 4-6). In relation to other group members the male (3m1) decreased his carrying effort from $40 \%$ to $20 \%$. The missing $20 \%$ in the next litter $(3 \mathrm{cn}$ ) was compensated by the group members, mostly by the mother (3f2). Indeed, the difference in her carrying effort between the two consecutive litters was close to $20 \%$. The other adult male $(3 \mathrm{~m} 2)$ contributed $20 \%$ of carrying in both litters. Once the first consecutive litter (3cv) was born in January, both males carried less than in the next two months, in February and March (Fig. 4-13). In the month after the carrying period (April) only one male (3m2) still continued carrying (Fig. 4-13A), although with his lowest investment (Fig. 4-13B). Once the new litter (3cn) was born in May, both males only carried the new litter, with similar investment. Thus, male $3 \mathrm{~m} 2$ participated in carrying for 7 consecutive months, whereas male $3 \mathrm{~m} 1$, paused his carrying effort for one month: April, the fourth consecutive carrying month. Considering infant take attempt behavior, $3 \mathrm{~m} 1$ attempted to take the litter of the primary breeder (3cv) the most frequently (roughly $40 \%)$, whereas for the litter of the second breeder $(3 \mathrm{cn})$ he again halves this respective behavior. $3 \mathrm{~m} 2 \mathrm{had}$ no record of take for litter $1 \mathrm{cv}$ and roughly $20 \%$ for $3 \mathrm{cn}$. 


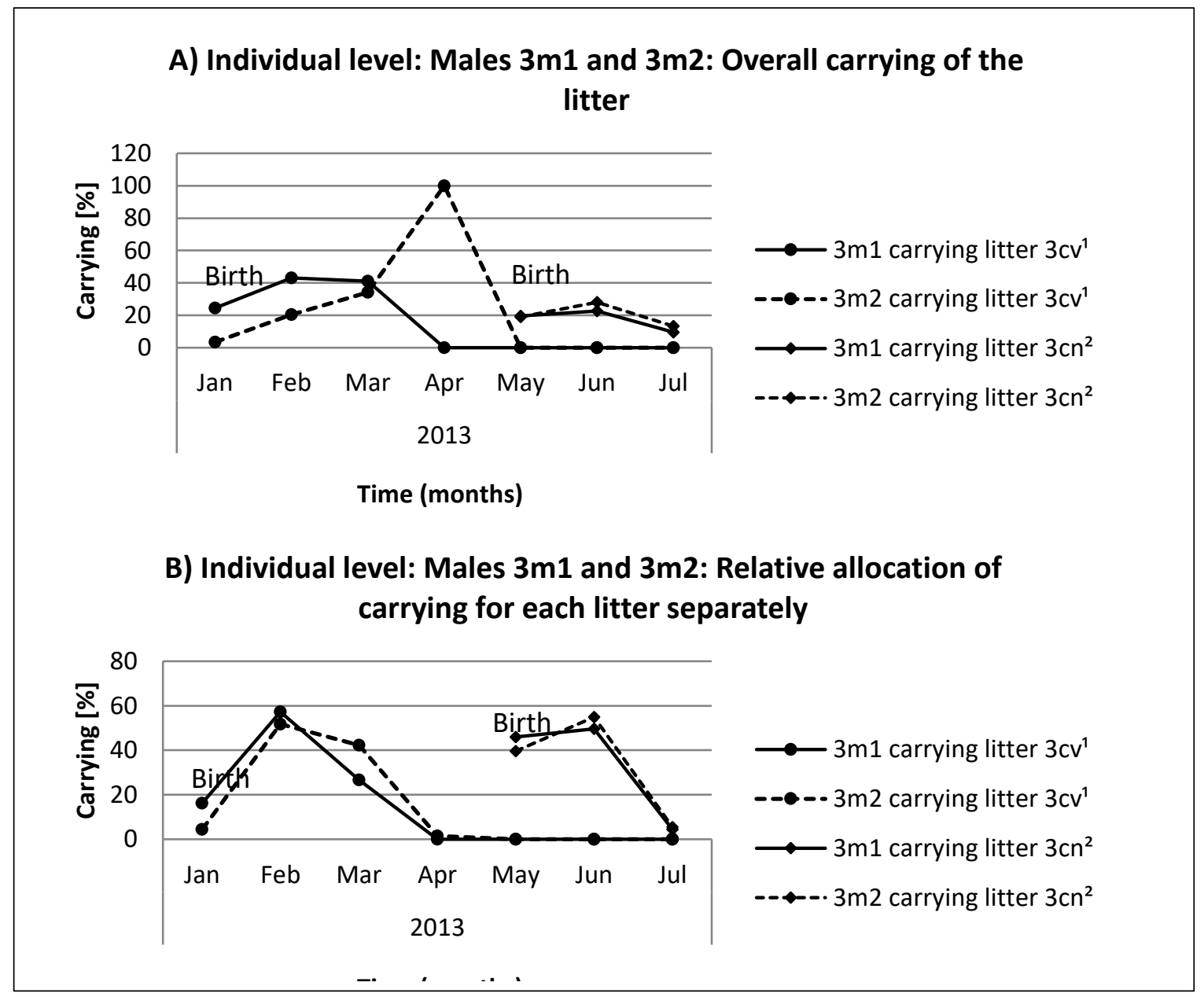

Fig. 4-13: Carrying contribution of males $3 m 1$ and $3 m 2$ for the litter from mothers $3 f 1$ and $3 f 2$ over time. A) Male's overall carrying of the litter in the group. B) Male's relative allocation of carrying for each litter separately.

${ }^{1}$ Mother of litter $3 \mathrm{cv}$ is $3 f 1$, father is of one twin infant is $3 \mathrm{~m} 1$. Litter $3 \mathrm{cv}$ represents twins: $3 c v 1 \& 3 c v 2$.

${ }^{2}$ Mother of litter $3 c n$ is $3 f 2$. Litter $3 c n$ represents twins: $3 c n 1 \& 3 c n 2$.

\subsection{Group 3: food transfer}

Food transfer contribution was in two litters $(3 c, 3 c n)$ shared among all individuals and in one litter (3cv) among all but a subadult male (3sa1) (Fig. 4-6, Table 4-9). Most individuals contributed $10-20 \%$ and had a low index of feed rejections, $0.0-0.2$. The two adult males had parallels in their contributions and rejections: in litter 3c they fed with $20 \%$ and rejected $10 \%$, in litter $3 \mathrm{cv}$ they again fed with $20 \%$ but never rejected to feed, likewise they never rejected to feed the next litter $(3 \mathrm{cn})$, but lowered their food transfer contribution (male $3 \mathrm{~m} 1$ approx. $10 \%$ and male $3 \mathrm{~m} 2$ below $5 \%$ ). Food transfer contribution from mothers had two extremes: the primary breeding female $(3 f 1)$ was the main food provider (30\%) for her first litter (1c) and roughly $5 \%$ the least important provider for her 
next litter (3cv). The secondary breeding female (3f2) was roughly $5 \%$ the least important food provider for her litter ( $3 \mathrm{cn}$ ). Mothers did not provide any food within the first two months (litters $3 \mathrm{cv}$ and $3 \mathrm{cn}$ ) (Table A-1). The breeding females shared lactation of the second primary breeding's litter (3cv) (Table 4-5), with the mother lactating more. Moreover, in the next consecutive litter $(3 \mathrm{cn})$ only the primary breeding female (3f1) lactated, not the mother ( $3 f 2)$. Besides lactation the primary breeding female $(3 f 1)$ was also the main food provider for the litter of the secondary female $(3 \mathrm{cn})$, close to $30 \%$, with a low rejection rate, 0.1 . In contrast, the secondary female $(3 f 2)$ never refused to feed her own litter $(3 \mathrm{cn})$, but did refuse the litters of the primary female, especially the litter parallel to her gestation time (1cv), close to $80 \%$, with the highest index of food transfer rejection within the group, 0.4 .

\section{Mating behavior}

Copulation patterns varied within groups (Table 4-10, Fig. 4-14). All adult females but not all adult males copulated, as well as some subadults and we have a record of an extragroup copulation. All copulations in Gr1 occurred between the primary breeding female (1f1) and the only male in the group (1m1). These copulations were roughly equally distributed throughout the observing time, with exception of a few months where there were none. In Gr2 copulations were shared among two of the three group males ( $2 \mathrm{~m} 1$, $2 \mathrm{~m} 2$ ). Both males copulated more with the breeding female (2f1), male $2 \mathrm{~m} 2$ even more so. Copulations were not evenly distributed over time, but clustered: in July 2012, June and July 2013 for the breeding female and August - September for female $2 f 2$. One cluster of each female mostly overlaps with consorting time of male $2 \mathrm{~m} 2$ (2f1, July 2012; $2 \mathrm{f} 2$, August 2012), and specifically at that time, he was the only male to copulate with consorted females. In Gr3 copulations were shared among all adult individuals. Male 3m1 copulated more than the other male and more equally with both females, whereas $3 \mathrm{~m} 2$ copulated substantially more with the secondary female $3 \mathrm{f} 2$. Both males copulated mostly between June - September 2012, coinciding with carrying period, potential consorting and first months of gestation of a primary breeding females. In Gr5 we noted only a few copulations among the only adult pair $(5 \mathrm{~m} 1,5 f 1)$ and between two subadults. Gr6 provided an extra-group copulation: among an adult male $(6 \mathrm{~m} 3)$ and a subadult female 
from Gr3 (3sa2). Copulations and male carrying effort were not significantly correlated (Table 4-11).

Table 4-10: Mating behavior of all sexually active individuals.

\begin{tabular}{|c|c|c|c|c|c|c|c|c|c|c|c|c|}
\hline \multicolumn{13}{|c|}{ Mating behavior ${ }^{1}$} \\
\hline $\begin{array}{c}\text { Individuals } \\
\text { (copulation } \\
\text { records) }\end{array}$ & $1 f 1$ & $1 f 2$ & $2 f 1$ & $2 f 2$ & $3 f 1$ & $3 f 2$ & $3 s a 2$ & $5 f 1$ & $5 s a 1$ & $6 f 1$ & $6 f 2$ & $\begin{array}{c}\text { Social } \\
\text { mating } \\
\text { systems }^{2}\end{array}$ \\
\hline $1 \mathrm{~m} 1$ & 16 & 0 & & & & & & & & & & $\begin{array}{l}\text { Mono- } \\
\text { gamy }\end{array}$ \\
\hline $2 \mathrm{~m} 1$ & & & 7 & 2 & & & & & & & & \multirow{3}{*}{$\begin{array}{l}\text { Promis- } \\
\text { cuity }\end{array}$} \\
\hline $2 \mathrm{~m} 2$ & & & 12 & 10 & & & & & & & & \\
\hline $2 m 3$ & & & 0 & 0 & & & & & & & & \\
\hline $3 \mathrm{m1}$ & & & & & 14 & 13 & 0 & & & & & \multirow[b]{2}{*}{$\begin{array}{l}\text { Promis- } \\
\text { cuity }\end{array}$} \\
\hline $3 m 2$ & & & & & 3 & 11 & 0 & & & & & \\
\hline $5 \mathrm{~m} 1$ & & & & & & & & 2 & 0 & & & \multirow{2}{*}{$\begin{array}{l}\text { Mono- } \\
\text { gamy }\end{array}$} \\
\hline $5 s a 2$ & & & & & & & & 0 & 2 & & & \\
\hline $6 \mathrm{~m} 1$ & & & & & & & & & & 0 & 0 & \multirow{4}{*}{$?$} \\
\hline $6 \mathrm{~m} 2$ & & & & & & & & & & 0 & 0 & \\
\hline $6 \mathrm{m3}$ & & & & & & & 1 & & & 0 & 0 & \\
\hline $6 \mathrm{~m} 4$ & & & & & & & & & & 0 & 0 & \\
\hline
\end{tabular}

${ }^{1}$ The figures represent the number of observed copulations.

${ }^{2}$ Mating systems; we considered only the copulations among adults and within the groups. Light blue entries indicate within group copulation, dark violet entries extra-group copulation 


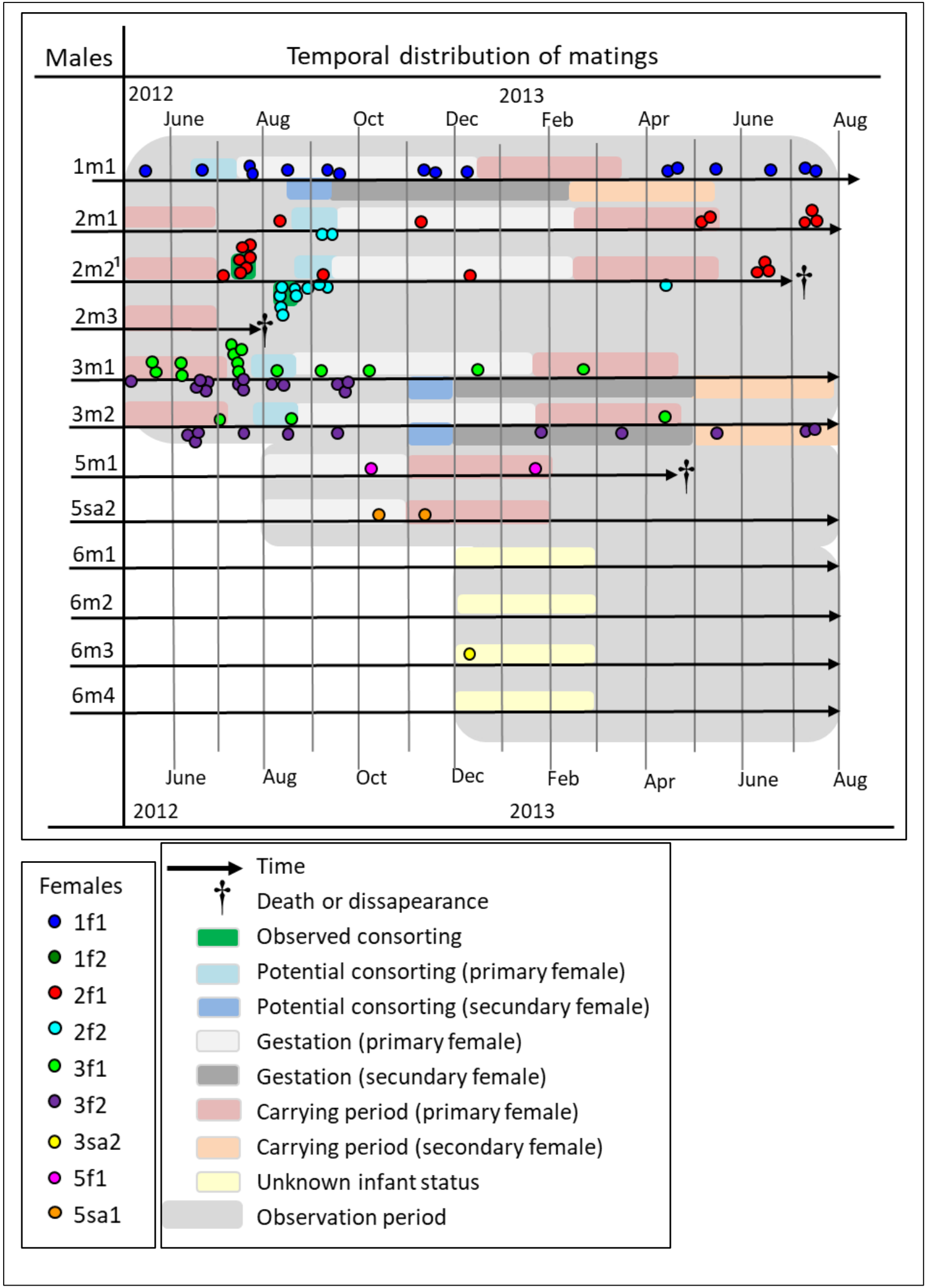

Fig. 4-14: Temporal distribution of matings: among all adults and sexually active subadults.

${ }^{1}$ We observed a male (2m2) consorting twice. Once he consorted the female $2 f 1$, between 19-22.07.2012, and within that time they copulated six times. A second time he consorted the female 2f2, between 14-21.08.2012, and within that time they also copulated six times. 
Table 4-11: Spearman correlation between carrying and copulation

\begin{tabular}{|l|l|l|l|l|}
\hline \multicolumn{5}{|c|}{ Correlation between carrying \& copulation $^{1}$} \\
\hline & $\begin{array}{l}\text { Entire observational } \\
\text { period }^{2}\end{array}$ & $\begin{array}{l}\text { Six months before } \\
\text { birth }^{3}\end{array}$ & $\begin{array}{l}\text { Infant carrying } \\
\text { period }^{4}\end{array}$ & Any other time $^{5}$ \\
\hline r & 0.6 & 0.6 & 0.3 & 0.3 \\
\hline p & n.s. & n.s. & n.s. & n.s. \\
\hline
\end{tabular}

${ }^{1}$ For carrying we used percentages of records, for copulations we used numbers of counts. Sample size includes: 6 adult males $(1 m 1,2 m 1,2 m 2,3 m 1,3 m 2,5 m 1), 6$ adults females mothers (1f1, 1f2, 2ff , 3f1, 3f2, 5f1) and 6 litters (1cv, 1cn, 2cv, 3cv, 3cn, 5cn). This resulted in 9 combinations (data points) of different males copulating with mothers (mother-male combination). We correlated numbers of copulations of a mother-male combination and male's percentages of carrying that mother's litter.

2 Includes all the copulations of a mother-male combination within the entire observational period.

${ }^{3}$ Includes only copulations of a mother-male combination that happened within six months before birth of her litter.

${ }^{4}$ Includes only copulations of a mother-male combination that happened within carrying period of her infant.

${ }^{5}$ Includes only copulations of a mother-male combination that did not happen within six months before birth of her litter and did not happen within carrying period of her infant.

\section{Discussion}

The aim of this study was to identify the social and genetic mating systems of L. nigrifrons, measure their infant care effort and explain why some males help more than others. While the unexpected occurrence of multi-female breeding in two groups created high inter-group variation and thus hampered comparability of patterns of care behavior, it also provided the opportunity to address additional questions, namely on decisions on which litter to invest more when more than one were present.

\section{Mating systems}

In accordance with previous callitrichid research, our study confirms the diversity and complexity of the mating systems of black-fronted tamarins (L. nigrifrons). When we suggest a mating system, then we suggest a social mating system for the group, and a genetic mating system from the individual perspective (Table 4-12, Table 4-10). Mating system definitions are generally based on group and not on individual patterns (Goss- 
Custard et al. 1972; Rowell 1993; Kappeler and van Schaik 2002). Due to our incomplete parentage results and because parentage was not limited to group members, we cannot ascribe a genetic system that would adequately describe the complex situation in a group (Table 4-8). Thus, within this study, we always refer to a genetic system from an individual perspective and to a social system within a group.

Table 4-12: Suggested genetic systems, including: identified individuals with high and intermediate parentage probability, unidentified candidate mother and unidentified candidate fathers $(\ddagger, \bullet, \ell, \square, \diamond, \varnothing)^{1}$.

\begin{tabular}{|c|c|c|c|}
\hline \multicolumn{4}{|c|}{ Suggested genetic systems ${ }^{2}$ from an individual perspective } \\
\hline Group & Individuals & Within a resident group ${ }^{3}$ & $\begin{array}{c}\text { Within a study population } \\
\text { (only if it differs from within a } \\
\text { resident group) }\end{array}$ \\
\hline \multirow[t]{3}{*}{ Gr1 } & $1 \mathrm{~m} 1$ & Monogamy (1f1) & Polygyny $(1 \mathrm{f} 1,6 \mathrm{f2})$ \\
\hline & $1 \mathrm{f1}$ & Monogamy (1m1) & / \\
\hline & $1 \mathrm{f2}$ & / & Polyandry $(\bullet, \square)$ \\
\hline \multirow[t]{5}{*}{ Gr2 } & $2 m 1$ & / & / \\
\hline & $2 m 2$ & / & / \\
\hline & $2 \mathrm{m3}$ & / & / \\
\hline & $2 \mathrm{ff1}$ & / & Polyandry $(\diamond, \varnothing)$ \\
\hline & $2 f 2$ & / & / \\
\hline \multirow[t]{4}{*}{ Gr3 } & $3 m 1$ & Polygyny ( 3f1, 3f2) & / \\
\hline & $3 m 2$ & / & / \\
\hline & $3 f 1$ & Monogamy (3m1) & Polyandry $(3 \mathrm{~m} 1, \bullet)$ \\
\hline & $3 f 2$ & Monogamy (3m1) & / \\
\hline \multirow[t]{2}{*}{ Gr5 } & $5 \mathrm{~m} 1$ & Monogamy (5f1) & / \\
\hline & $5 f 1$ & Monogamy (5m1) & Polyandry $(5 \mathrm{~m} 1, \bullet, \iota)$ \\
\hline \multirow[t]{6}{*}{ Gr6 } & $6 \mathrm{m1}$ & Monogamy (6f2) & / \\
\hline & $6 \mathrm{~m} 2$ & / & / \\
\hline & $6 \mathrm{m3}$ & / & / \\
\hline & $6 \mathrm{~m} 4$ & / & $\begin{array}{l}\text { Monogamy } \\
\text { (unidentified candidate mother) }\end{array}$ \\
\hline & $6 f 1$ & / & / \\
\hline & $6 f 2$ & Monogamy (6m1) & Polyandry $(6 \mathrm{~m} 1,1 \mathrm{~m} 1, \ddagger)$ \\
\hline
\end{tabular}

${ }^{1}$ Unidentified candidate fathers $(\ddagger, \bullet, \ell, \square, \diamond, \varnothing)$ derive from "hints from sibling dyads", noted in Table 4-8. Detailed explanation on hints is in the section Parentage analyses section (p. 35) 
${ }^{2}$ Verification of a breeding system would require genetic data on parentage over several breeding periods. Since breeding females may have up to two litters per year (summarized by Garber et al. 2016; this study), we considered that with 15 months of data we did not sample enough breeding periods, and due to incomplete parentage information of a study population, we speak only of suggested breeding systems.

${ }^{3}$ Genetic system of an individual based on parental dyads limited to a resident group.

${ }^{4}$ Genetic system of an individual based on parental dyads unlimited to a resident group.

In primate groups, social and genetic mating systems within a group may be a incongruent (Kappeler and van Schaik 2002). Polyandry, social and genetic, are considered the prevailing mating systems in callitrichids (summarized in Garber et al. 2016). In our study, we found no evidence for social polyandry (see also Digby 1999, common marmosets, $C$. jacchus; Nievergelt et al. 2000), but we suggest a genetic polyandry for one female (6f2): her litter was sired by one resident and one non-resident male. Hints of unidentified fathers from sibling dyads suggest a genetic polyandry for four more females $(1 f 2,2 f 1$, $3 f 1,5 f 1)$. We suggest social yet no genetic promiscuity (Gr2, Gr3), no social yet genetic polygyny of two males $(3 \mathrm{~m} 1,1 \mathrm{~m} 1$ ) (but see Garber et al. 1993, moustached tamarins, $S$. mystax; Digby 1999, common marmosets, C. jacchus), and both social and genetic monogamy, the latter within a resident group of two males and two females (Gr1, $1 \mathrm{f} 1$ and $1 \mathrm{~m} 1, \mathrm{Gr} 5,5 f 1,5 \mathrm{~m} 1)$.

We suggest that mating systems partly depend on the number of adults. One of our study groups consisted of only one adult of each sex, therefore offers no other option but social monogamy (Gr5) (Table 4-10, Table 4-12). In contrast, the other group with social monogamy consisted of three adults (Gr1). The parentage analyses for these two groups suggest genetic monogamy, polygyny and polyandry, where the latter two systems include extra-group adults (including unidentified males) (Table 4-12). Genetic monogamy within the study population is shown for these five individuals (1f1, 3f2, 5m1, 6f2, 6m4), although due to lack of parentage information we cannot confirm it, except for one female (1f1). To confirm genetic monogamy for wild groups we would require the parentage to belong to only one male and one female over several breeding periods (Garber et al. 2016) and so far genetic monogamy has been documented only in one wild callitrichid species (Huck et al. 2005a). We have records of three consecutive litters of one female (1f1) sired by the same male $(1 \mathrm{~m} 1)$ and therefore we consider that the most likely genetic system of 
that couple within a resident group is monogamous. But as already stated, since this male sired infants of a female in another group, we suggest a genetic polygyny $(1 \mathrm{~m} 1,1 \mathrm{f} 1,6 \mathrm{f} 2)$.

In wild primates, monogamy is common in species that form "nuclear family" groups (male - female pair and their immature offspring) or "extended family" groups (male female pair, their immature and mature offspring). Some callitrichid groups might be best described as the latter (Suárez 2007, Saguinus labiatus; Garber et al. 2016), therefore it is likely that with more genetic data from wild populations more cases of monogamy will be confirmed. Still, many callitrichid traits such as breeding by multiple males and females per group, non-breeding adult females, and frequent migration, disagree with social and genetic monogamy as the modal pattern (Garber et al. 2016). In this study we report on most of the above traits: multi-female breeding ( $G r 1,1 \mathrm{f} 1$ and $1 \mathrm{f} 2 ; \mathrm{Gr} 3,3 \mathrm{f1}$ and 3f2), nonbreeding adult female (Gr2, 2f2; Gr6, 6f1), female immigrations (Gr2, $2 f 1$ and $2 f 2$ ) and potential male emigrations ( $\mathrm{Gr} 2,2 \mathrm{~m} 2,2 \mathrm{~m} 3 ; \mathrm{Gr} 5,5 \mathrm{~m} 1$ ) (Table 4-1).

\section{Mating and paternity}

We did not find evidence of monopolization of paternities within wild L. nigrifrons groups (Table 4-8). Group living often leads to a clear dominance hierarchy, with higher mating and reproductive opportunities skewed to higher ranking males (Altmann 1962, rhesus monkeys, Macaca mulatta; Preston et al. 2001, soay sheep, Ovis aries; Kutsukake and Nunn 2006, primates), or can even lead to monopolization of paternities within a group (Ochi 1993, mouthbrooding cichlid, Ctenochromis horei). Agonistic interactions between males that often determine a male's position in a group (Nishida 1983, chimpanzees, $P$. troglodytes schweinfurthii) are rare in wild callitrichids (Goldizen 1989; Caine 1993; Heymann 1996; Huck et al. 2004c). Therefore, callitrichids are not characterized by a clear dominance hierarchy (Knox 1989; Caine 1993; Huck et al. 2004c), but they are often characterized with polyandry (summarized in Garber et al. 2016). Thus, it seems less conceivable for one male to have a monopoly over paternities but scant genetic data on wild callitrichids shows evidence of monopolization of paternities (Huck et al. 2005a, wild moustached tamarins, S. mystax; Suárez 2007, red-bellied tamarins, S. labiatus; DíazMuñoz 2011, wild Geoffroy's tamarin, S. geoffroyi). Due to our incomplete parentage results we can neither confirm nor exclude monopolization of paternities over different 
sets of twins in the groups. Nevertheless, monopolization of paternities over different sets of twins in the groups seems rather unlikely, because either we have no matching copulations and parentage between a breeding female and male (Gr1, female $1 \mathrm{f} 2$ and male $1 \mathrm{~m} 1$ ), or hints point to one or more other sires (Gr1, Gr2, Gr3, Gr5), or we already determined more than one sire in a group $(\mathrm{Gr} 3, \mathrm{Gr} 6)$.

Instead, we found evidence of monopolization of paternities for a single set of twins (Gr1, litter $1 \mathrm{c}$, father $1 \mathrm{~m} 1$ ), but also shared paternities of twins, between a group and an extragroup male $(\mathrm{Gr} 6$, litter $6 \mathrm{j}$, fathers $6 \mathrm{~m} 1,1 \mathrm{~m} 1)$. Considering the latter two outcomes are callitrichid consorting males, who function as mate-guards (Thornhill and Alcock 1983; Huck et al. 2004c, S. mystax; Lledo-Ferrer et al. 2010, L. nigrifrons), not entirely successful in mate guarding. We have two records of male consorting (Fig. 4-14), which most likely happened during the peak of the female's fertility (Löttker et al. 2004b, S. mystax). Mate guarding is usually physical (Alberts et al. 1996, wild baboons, Papio cynocephalus), but in some mammals, including callitrichids, it can also be chemical, like male over-marking a female's scent (Roberts and Dunbar 2000, klipspringer antelope, Oreotragus oreotragus; Huck et al. 2004c, S. mystax; Ferkin and Pierce 2007, other mammals, review; Lledo-Ferrer et al. 2010, L. nigrifrons). Callitrichid female scent marks may be the chemical equivalent of sexual swellings in some Old World primate taxa (review in Nunn 1999; Huck et al. 2004c) and the chemical compounds may provide a graded signal about a fertile phase (Ziegler et al. 1993; Converse et al. 1995; Washabaugh and Snowdon 1998). This may result in a consorting male not guarding during the entire female fertile period and, in callitrichids, who mate all year long, (Goldizen 1988), a female may mate with other males outside the consorting time, but still within her fertile period (Nunn 1999; Huck et al. 2004c, S. mystax). However, in some cooperative breeders, e.g. meerkats (Young et al. 2007), copulations may not be restricted to between the individuals of the same group and extra-group copulations may be an alternative reproductive tactic.

We also propose that in callitrichids, extra-group copulations are an important breeding strategy. Extra-group copulations may occur during intergroup encounters (Lledo-Ferrer et al. 2011, wild L. nigrifrons) or in a time of occasional separation of some individuals from the resident group. The latter extends for some hours or days (Slana, personal observation, L. nigrifrons) and is potentially equivalent to "extraterritorial forays" of 
subordinate male meerkats (Young et al. 2007). For males, especially those less successful at mating with breeding females, extra-group copulations that result in conceptions might represent an alternative, low-cost strategy to reproduce. For a breeding female extragroup copulations might present a greater mate choice (Birkhead and Parker 1997), especially if her mating opportunities in the group are restricted. This seemed to be the case for one secondary female breeder (1f2), as she did not mate within a group, yet gave birth to two litters, whose paternity was indicated to be from extra-group males (Table 4-8). We have a record of one extra-group copulation ( $6 \mathrm{~m} 3$ and 3sa2) (Table 4-10), however we identified two extra-group paternities (offspring 3sa1 and 6j1) and hints from siblings' dyads indicated a few more. This suggests that extra-group copulations are an important strategy for males and some females to ensure breeding.

\section{Offspring survival}

Our data suggests that a critical period for offspring survival are an offspring's first few months: five out of eight animals that disappeared were infants and the rest were adult males (Table 4-1, Fig. 4-1) (see also Löttker et al. 2004a, S. mystax). Infant mortality may be a result of a predator attack, infanticide, falling from carriers, getting trapped in tree holes etc. (Digby 1995; Tirado Herrera et al. 2000; Oversluijs Vasquez and Heymann 2001; Smith et al. 2001). Another critical factor for offspring survival may be group composition, like number of adults in callitrichids, especially males and breeding females (Koenig 1995, wild C. jacchus; Culot et al. 2011, wild S. mystax; summary by Garber et al. 2016; but see Heymann and Soini 1999, wild Cebuella pygmaea). In our study, a larger number of adults does not always guarantee infant survival: Gr6 included six adults, but both twins disappeared. On the other hand, in Gr5 all offspring survived, although only two adults (male and female) were present. The latter case is the second report of such a case from wild tamarins (see Windfelder 2000, wild emperor tamarin, Saguinus imperator).

In our study, also the number of breeding females in a group did not guarantee infant survival: in both, in groups with one and two breeding females offspring survived and disappeared. Although in both cases of multi-female breeding, the primary female lost one of the twins before the consecutive litter from the secondary female was born, and all litters from the secondary female survived. Under similar circumstances, Tirado 
Herrera and co-workers (2000) observed infanticide, and suggested a parental manipulation based on the infant's low chances of survival or a stress-related infanticide due to simultaneous pregnancy of another female (see also Hrdy 1979). Reasons for the disappearance of the two infants are unclear, yet the influence of another female's pregnancy is a plausible explanation (Digby and Saltzman 2009; Yamamoto et al. 2009). Multi-female breeding or just simultaneous pregnancies may also result in allonursing or nursing by only a non-mother (Digby 1995, wild C. jacchus; Smith et al. 2001, wild S. mystax; Shahuano Tello et al. 2002, wild S. mystax). Thus, it can also be beneficial for offspring survival and for a mother herself, in terms of lower energy demand for milk production and shared maternal care. We have records of allonursing from two groups, one group with multi-female breeding (Gr3) and one with a single-female breeding (Gr2) (Fig. A-7). Based on allonursing in the latter group, it is likely that this was an additional third case of a multi-female pregnancy, but without resulting in a litter to care for.

\section{General patterns of infant-directed behavior}

Our study on L. nigrifrons confirms a general pattern of infant care in callitrichids (Savage et al. 1996; summarized by Garber 1997; Yamamoto et al. 2009): adults are the most important infant caretakers, more so for carrying than food transfer, whereas for food transfer subadults are also important (Fig. 4-3, Fig. 4-10). Among all infant-directed behaviors food transfer is similarly divided among caretakers, even by juveniles (Fig. 4-3, Fig. 4-8 - Fig. 4-11), which implies food transfer to be energetically less demanding than carrying. Also, everybody has to eat, thus everybody had more or less the same chance to be targeted by an infant. Costs of infant care in cooperative breeders, e.g. meerkats and callitrichids (Sánchez et al. 1999; Clutton-Brock et al. 2000; Achenbach and Snowdon 2002) are important to an animal on an individual level (making a decision whether to help, how to help, how often and to which infant). Adult females can base their decision on their contribution to infant care on whether offspring are their own or not. In our study, along with adult males mothers are the principle carriers, whereas other adult females usually carry less or not at all (Fig. 4-3). Adult males, on the contrary, cannot be sure of their paternity, even in case they have copulated, and are certainly not fathers if they have not copulated, which may influence their contribution. In our study, both fathers and non- 
fathers contributed substantially to carrying (see also Huck et al. 2004a, S. mystax). Reasons why adult males help to carry are discussed in greater detail in section Why do adult males help? (p. 68).

Our data from the two cases of multi-female breeding demonstrate that a mother's contribution depends on an adult male's contribution: it is mostly the mother who compensated for the lack of carrying from the adult male (see also, Lappan 2008). In Gr1 the only group male $(1 \mathrm{~m} 1)$ shared the main carrying position with the mother $(1 \mathrm{f} 1)$ for their litter (1cv) (Fig. 4-4, Table 4-9). The mothers' carrying contribution was 45\%, a bit lower than the male's contribution of $51 \%$. In contrast, he barely helped the other mother (1f2, litter $3 \mathrm{cn})$ and contributed only $3 \%$, which resulted in her being extremely burdened with carrying, close to $83 \%$. Other carriers, subadults and juveniles, carried both litters $(1 \mathrm{cv}, 1 \mathrm{cn})$ less, but their carrying contribution for a second litter $(3 \mathrm{cn})$ increased from $3 \%$ to $14 \%$. Although less extreme, data from $\mathrm{Gr} 3$ show a similar pattern. One male $(3 \mathrm{~m} 1)$ reduced his carrying contribution to half, from almost $40 \%$ to $20 \%$, for the second consecutive litter ( $3 \mathrm{cn})$ and again carrying was compensated by subadults and juveniles, $10 \%$, and next $10 \%$ by the litter's mother alone (3f2) (Fig. 4-6, Table 4-9). Despite her compensation of the male's lack of carrying, her carrying contribution for own litter (3cn) was not very high (close to $20 \%$ ), because both adult males together $(3 \mathrm{~m} 1,3 \mathrm{~m} 2)$ still contributed above $40 \%$. These results show not only the importance for the mother to have adult male helper(s), but also suggests that more helpers help balance the carrying burden among the adults (see also Schradin and Anzenberger 2001b, Goeldi's monkey, Callimico goeldii). But to unburden a mother, more than how many carriers, it is important the cumulative carrying effort of adult males.

\section{Why do adult males help?}

\subsection{Paternity certainty}

On the basis of our two multi-female breeding cases we propose that in male callitrichid helping behavior the level of paternity certainty plays a role. Social monogamy is expected to increase the level of paternity certainty (Trivers 1972), whereas promiscuity is expected to reduce it (Smuts and Gubernick 1992, baboons and macaques). High levels of paternity 
certainty are often associated with high male infant care (Wright 1984, owl monkeys, Aotus spp., titi monkeys, Callicebus spp.; Mendoza and Mason 1986) but also relatively low (Bradley et al. 2005; Harcourt and Stewart 2007). Due to female polyandrous mating in callitrichids it is suggested, that male may help to increase their chance for own reproduction (Huck et al. 2004c). This indicates that a level of paternity certainty plays a role.

In our study, in one multi-female breeding case we suggest that the male's high level of paternity certainty influenced his infant care behavior ( $\mathrm{Gr} 1$, male $1 \mathrm{~m} 1$, litter $1 \mathrm{cv}$ ). Within a group, the only group male (1m1) and a primary breeder (1f1) mated exclusively, and he sired all of her litters (1sa, 1c, 1cv). Of her latest litter (1cv), the only litter with complete carrying period data, he was the main carrier, main seeker to carry (behavior: infant take attempt), he never rejected to carry and had the lowest possible index of carrying and food transfer rejections (Fig. 4-4, Table 4-8, Table 4-9, Table 4-10). On the other hand, the infant-directed behavior of the same male ( $\mathrm{Gr} 1$, male $1 \mathrm{~m} 1$ ) towards the litter of the secondary female $(1 \mathrm{f} 2$, litter $1 \mathrm{cn})$ suggests that a male behaves in accordance with low or zero paternity certainty. We have no records of copulations between the two, he was not the sire of her two litters, he carried her latest litter $(1 \mathrm{cn})$ very few times and was not seeking to carry it (behavior: infant take attempt), rather he often rejected to carry and feed.

In the other group with multi-female breeding (Gr3), promiscuous mating between the adult males and females resulted in intermediate levels of paternity certainty. Consequently, both males were the main carriers for the litters of both females (litters $3 c$, $3 \mathrm{cv}, 3 \mathrm{cn}$ ) and fed them with little or without refusal (Fig. 4-6). Additional evidence comes from the temporal patterning of males' carrying of the litters from the secondary females (litters $1 \mathrm{cn}, 3 \mathrm{cn}$ ) in multi-female breeding groups. (Fig. 4-12, Fig. 4-13). In both cases the litter of the secondary female was born while the litter of a primary breeding female (litters 1cv, 3cv) was still carried (Table 4-1, Fig. 4-1). Hence, males and group members could choose which litter to help: older and thus heavier and presumably costlier $(1 \mathrm{cv}$, $3 \mathrm{cv}$ ) or, younger and thus lighter and presumably less costly litter $(1 \mathrm{cn}, 3 \mathrm{cn})$. In the case associated with high paternity certainty ( $\mathrm{Gr} 1$, male $1 \mathrm{~m} 1$, litter $1 \mathrm{cv}$ ) and low to zero paternity certainty ( $\mathrm{Gr} 1$, male $1 \mathrm{~m} 1$, litter $1 \mathrm{cn}$ ), a male continues to mostly carry his litter, 
older and heavier (1cv). In the case associated with medium paternity certainty (Gr3, males $3 \mathrm{~m} 1,3 \mathrm{~m} 2$, litter $3 \mathrm{cv}, 3 \mathrm{cn}$ ), both males changed to carry only the younger but lighter litter (3cn).

We argue that male's level of paternity certainty is based on a social mating system: on whether or not he copulates with a female, and whether or not copulations are shared with other males. The multi-female breeding cases $(\mathrm{Gr} 1, \mathrm{Gr} 3)$ provide evidence, but the same pattern is indicated also in single-female breeding groups (Gr2, Gr5). Therefore, social monogamy increases the paternity certainty and males are likely to help extensively (Gr1, 1m1 and 1f1), social promiscuity lowers the level of paternity certainty, but because of a chance of paternity males help their mating partners (Gr3, 3m1, 3m2 and $3 f 1,3 f 2$; Gr2, $2 m 1,2 m 2$ and $2 f 1$ ), and when there is no sexual relationship, this diminishes the chance of paternity and males invest the least ( $\mathrm{Gr} 1,1 \mathrm{~m} 1$ and $1 \mathrm{f} 2)$. One group with observed social monogamy (Gr5) does not seem to follow this logic, because the male (5m1) helped very little (Fig. 4-7). Although, social monogamy reflects only a mating pattern inside a group, and additionally a male shares a paternity with an unknown extragroup male $(\bullet)$ (Table 4-8). This suggests that males may adopt their strategy to the level of paternity certainty. In the case of male $5 \mathrm{~m} 1$ this would be in relation to low level paternity certainty, i.e. he should help, but less than under a high level of paternity certainty. Furthermore, this imposes a question, whether a male has information about extra-group copulations of his mate or, about infant's parentage.

In terms of fitness, the role of a breeder is more profitable than the role of a helper (Cant 2012). However, before helping kin, the individual must recognize it as a kin, and, only then can decide whether to discriminate between kin and non-kin (Waldman et al. 1988; Keller 1997; Cant 2012). A kin recognition may be achieved by using learned cues, e.g. in cooperative breeding birds (Komdeur et al. 2008, review), or less likely, using genetic cues (Crozier 1986; Rousset and Roze 2007), including odor (Leclaire et al. 2013, S. suricatta). But a kin-biased helping may not be favored in cooperatively breeding birds, mammals and insects, due to the cost of recognition errors, i.e. helping non-kin or not helping kin, that may lower the fitness benefits (Queller et al. 2000; Griffin and West 2003; Cornwallis et al. 2009, birds and mammals; Leadbeater et al. 2010, paper wasps, Polistes dominulus; Cant 2012). In addition, in cooperative breeding bird and mammal species, higher within- 
group relatedness is associated with lower kin discrimination (Cornwallis et al. 2009). Callitrichids exhibit high within-group relatedness (Huck et al. 2005a, S. mystax; DíazMuñoz 2011, wild Geoffroy's tamarin, S. geoffroyi; Garber et al. 2016), thus low kindiscrimination is expected. Moreover, high levels of relatedness also imply that a kinrecognition may not even be needed: in terms of inclusive fitness benefits, a male helper might benefit even under low or zero paternity certainty. The evolutionary conflict of cooperative breeding helpers: helper's helping effort usually trades-off against helper's own residual reproduction (Cant 2012), is likely to be less pronounced in callitrichids: because helping effort is a likely trade-off in their inclusive fitness benefits. Still, due to a paternity certainty and therefore a chance for a direct fitness benefit, males help more or less.

\subsection{Male's physical fatigue}

The data from the two multi-female breeding cases suggests that in callitrichids, males' contribution to parental care could be influenced by a male's physical fatigue. The first indication is provided by the overall carrying contribution of the males from multi-female breeding cases. In one case (Gr1), the only group male (1m1) carried the first consecutive litter (1cv) over $50 \%$ of the time, but the next one (1cn) only less than $5 \%$ (Fig. $4-4)$. In the second case $(\mathrm{Gr} 3)$, one male $(3 \mathrm{~m} 2)$ contributed to both consecutive litters (3cn, $3 \mathrm{cv}$ ) roughly equally, around $20 \%$, whereas the other male $(3 \mathrm{~m} 1)$ contributed unequally: $40 \%$ for the first consecutive litter ( $3 \mathrm{cv}$ ) and $20 \%$ for the second one (3cn) (Fig. 4-6). Carrying reduction for the second consecutive litter was in line with costs of infant care, especially the body mass loss of carriers (Sánchez et al. 1999, S. oedipus; Achenbach and Snowdon 2002, S. oedipus). These costs imply that physical fatigue should occur. The second indication is provided by the only one multi-female breeding case (Gr3). Right after the second consecutive litter ( $3 \mathrm{cn}$ ) was born, both males chose to only continue carrying this new litter, lighter in comparison to the old litter (3cv) (Fig. 4-13). But as discussed in section Paternity certainty (p. 68), this is also likely due to promiscuous mating and a chance of paternity.

Finally, we suggest, that in a case of high level of paternity certainty, physical fatigue is of lesser importance. This suggestion is based on a behavior of one male in a multi-female 
breeding case $(\mathrm{Gr} 1,1 \mathrm{~m} 1)$. Once a female that he never mated with (1f2) gave birth to a new litter $(1 \mathrm{cn})$, he carried it less than $5 \%$ throughout the whole carrying period and he also rejected to carry (Fig. 4-4, Fig. 4-12, Table A-1). Instead, he never rejected to carry the old and thus heavier litter that he sired $(1 \mathrm{cv})$ and he continued to mostly carry it. This litter was from a female (1f1) with which he had a monogamous social and genetic relationship within a group, which suggests a high level of paternity certainty of this male towards this female's litter. The data suggests that the male's decision which litter to care for is more likely to be based on the level of paternity certainty rather than on physical fatigue.

\subsection{Pay to copulate (carrying as a male courtship strategy)}

We do not find evidence for carrying to be a male courtship strategy, although we suggest a link between male infant care and copulating or not (Fig. 4-14, Table 4-11). Courtship strategy is a female strategy, where female chooses mate. Accordingly, it would pay-off for a female to choose a mate who is competent caretaker and males would adopt strategies to convince females that they would be good caretakers, like investing more in infant care (Price 1990), and therefore using infant care as a payment to copulate with a mother (Huck et al. 2004a). Callitrichid females are predominantly polyandrous (Goldizen 1988), thus the strategy seems plausible for callitrichid males (Price 1990). In addition, mother's infant care investment seems to depend on investment of others, especially males (Goldizen 1987b; this study); the same has been suggested for breeding success (Goldizen 1987b). Nonetheless, in our study males' carrying investment did not correlate with the number of copulations in any of the periods tested, including the entire study period (see also, Lappan 2008). Therefore we cannot confirm the hypothesis that infant carrying represents a courtship strategy (in contrast to Price 1990, captive C. jacchus; in agreement with Tardif and Bales 1997, captive C. jacchus and S. oedipus; Huck et al. 2004a, wild S. mystax). One group in our study (Gr1), however, appears to be an exception: a male (1m1) helps evidently more and with less rejections with a litter of his only mating and breeding partner ( $1 \mathrm{f} 1$, litter $1 \mathrm{cv})$ than to the litter of the other female $(1 \mathrm{f} 2)$, litter $1 \mathrm{cn}$ ) (Fig. 4-4, Table 4-9). But, more than the number of copulations, on relevant factor is 
whether the male copulated (with 1f1) or not (with 1f2): detailed discussion is in sections Mating systems (p. 61) and Paternity certainty (p. 68) 1 and 5.1.

\section{Summary and conclusions}

Mating systems: Our study of L. nigrifrons confirmed the diversity and complexity of callitrichid mating systems. We suggest social monogamy and promiscuity for our study groups. Parentage is not limited to group members, therefore it is impossible to ascribe a genetic system on a group level, but rather on an individual level. We suggest genetic monogamy, polygyny and polyandry of individuals. We suggest that mating systems partly depend on the number of adults in the group.

Mating and paternity: Throughout the data set we found one incidence of shared paternity in one set of twins and one incidence of monopolization of paternity in another set of twins. We find extra-group copulations and paternities, which suggests that these must be incorporated the interpretation of callitrichid mating systems.

Offspring survival: We suggest that offspring's first few months are critical for its survival. We show that group composition, i.e. number of adults, number of breeding females, does not guarantee infant's survival.

General on patterns of infant-directed behavior: Food transfer is the infant-directed behavior over age-classes that is most evenly distributed. The most important caretakers are adults, more so for carrying than food transfer. Adult males and mothers are the main carriers. We suggest that in a case of male's carrying lack, it is mostly the mother who compensates.

Why do adult males help?

Paternity certainty: We suggest that males adjust their helping contribution on a level of paternity certainty, which is based on copulating or not with the female and whether copulations are shared with other males. 
Male's physical fatigue: We suggest that males helping contribution is affected by male's physical fatigue. We suggest that in a case of high paternity certainty, physical fatigue is of a lesser importance.

Pay to copulate (carrying as a male courtship strategy): We find no evidence for carrying to be a male courtship strategy, i.e. number of copulations are not related to the amount of carrying. We suggest that instead of number of copulations, it matters whether the male copulated or not. 


\section{Chapter 5}

\section{Activity budget changes while carrying infants in a co-operatively breeding primate}

Authors: Darja Slana', Judith Jacira Achong Sánchez², Allison Licett Núñez Levy², Holger Sennhenn-Reulen ${ }^{3,4}$, Eckhard W. Heymann ${ }^{1}$

${ }^{1}$ Verhaltensökologie \& Soziobiologie, Deutsches Primatenzentrum - Leibniz-Institut für Primatenforschung, Göttingen, Germany

${ }^{2}$ Facultad de Ciencias Biológicas, Universidad Nacional de la Amazonía Peruana, Iquitos, Peru

${ }^{3}$ Kognitive Ethologie, Deutsches Primatenzentrum - Leibniz-Institut für Primatenforschung, Göttingen, Germany

${ }^{4}$ Leibniz-WissenschaftsCampus, Primatenkognition, Deutsches Primatenzentrum Leibniz-Institut für Primatenforschung, Göttingen, Germany

Author contribution, listed by sections: design of the study by DS and EWH; field data collection by DS, JJAS and ALNL; statistical analyses by DS, HSR; writing the manuscript by DS, EWH and HSR; supervision by EWH. 


\section{Abstract}

In co-operatively breeding animal societies, helpers contribute to rearing offspring through feeding and guarding infants, behaviors that incur costs to helpers. In Neotropical callitrichid primates - tamarins and marmosets - infant care also involves carrying of heavy twins (15-20\% of maternal body mass at birth). Under captive conditions with unrestrained access to food, infant carrying results in loss of body mass in fathers and helpers, mediated through changes in the activity budget. Here we compare the activities of wild black-fronted tamarins, Leontocebus nigrifrons, while carrying or not carrying infants. We show that infant carrying strongly reduces the time spent foraging for prey, reduces the time spent feeding and strongly increases the time spent on vigilance. These changes are possibly related to restricted mobility while carrying infants, which is likely to contribute to behavioral modifications of predator avoidance strategies. Furthermore, these changes are likely to incur fitness costs that must be compensated by both indirect and direct fitness benefits. Our findings also provide further arguments against nonadaptive hypotheses of helping behavior.

Keywords: cooperation; infant care; helping; Callitrichidae

\section{Introduction}

Infant care, e.g. provisioning or carrying offspring, is associated with energetic costs which are usually assumed by one or both parents (Clutton-Brock 1991). In cooperatively breeding animals, non-reproductive adults and subadults help parents to rear offspring (Solomon and French 1997; Koenig and Dickinson 2004), and thus also incur energetic costs that can convert into lower growth rates or loss of body mass (Taborsky 1984; Heinsohn and Cockburn 1994; Clutton-Brock et al. 1998).

Callitrichids are a family of Neotropical primates that exhibit flexible mating systems and show high levels of co-operative infant care (Goldizen 1987a, 1988; Garber 1997). They routinely produce twins that at birth together possess $\sim 15-20 \%$ of the maternal body mass (Tardif 1994) This makes infant carrying energetically so costly that, even under captive 
conditions with unrestricted access to food, fathers and helpers lose body mass (Sánchez et al. 1999; Achenbach and Snowdon 2002).

Infant carrying imposes constraints on the type and speed of locomotion and thus probably also on foraging maneuvers (Schradin and Anzenberger 2001a; Caperos et al. 2012). Also in captivity, carriers spend more time in concealed areas, which suggest an effort to reduce the predation risk (Price 1992). Moreover, carriers are less likely to be vigilant, spend less time in locomotion, socializing, foraging, feeding and have lower energy intake (Price 1992; Sánchez et al. 1999). It is thus conceivable that energetic costs of infant carrying in callitrichids are likely to be mediated through changes in the activity budget. Two studies on wild tamarins report decreased time spent feeding and increased time spent resting while carrying infants (Goldizen 1987b; Huck et al. 2004a). However, both studies were based on very small sample sizes (one or two infant care periods, respectively) and did not distinguish feeding from prey foraging. Prey foraging is a major activity of wild tamarins, and prey represents a substantial component of the diet throughout the year (Soini 1987; Garber 1988; Porter 2001). In addition, the two studies on wild tamarins did not include vigilance (Goldizen 1987b; Huck et al. 2004a), which is an important part of anti-predator strategies (Stojan-Dolar and Heymann 2010, Saguinus mystax).

In this paper, we test the hypothesis that infant carrying causes changes in the activity budget. We compare activity budgets of wild black-fronted tamarins, Leontocebus nigrifrons ${ }^{7}$, while carrying and not carrying infants. Specifically, we predict that infant carrying strongly reduces the time spent foraging for prey and the time spent feeding. Constraints on locomotion imposed by infant carrying also imply a higher predation risk for infant carriers, which could be compensated by increased vigilance. Therefore, we predict that more time is spent being vigilant while carrying infants than when not carrying. We do not predict differences in the time spent with locomotion, as any individual has to keep up with its group while travelling through the home range, whether or not it is carrying infants.

\footnotetext{
${ }^{7}$ In this study we use the current taxa naming of tamarins, following Rylands et al. (2016).
} 


\section{Methods}

\section{Study Site and Study Population}

The study was carried out at the Estación Biológica Quebrada Blanco (EBQB), located at $4^{\circ} 21^{\prime} \mathrm{S} 73^{\circ} 09^{\prime} \mathrm{W}$ in a largely pristine rainforest in lowland Peruvian Amazonia. We observed five groups of well-habituated groups of L. nigrifrons, from May 2012 (Gr1, Gr2, Gr3), August 2012 (Gr5) and December 2012 (Gr6) until July 2013. Each group was observed on average for 7.5 days per month and for $8.3 \mathrm{~h}$ per day, resulting in totally 3868.7 hours of observation. Gr1 was observed for 966.8 hours, including 291.5 hours of the carrying period. Gr2 was observed for 938.9 hours, including 292.7 hours of the carrying period. Gr3 was observed for 870.7 hours, including 525.5 hours of the carrying period. Gr5 was observed for 673.1 hours, including 194.9 hours of the carrying period. Gr6 was observed for 419.3 hours, including 25.2 hours of the carrying period. Individuals were identified through natural markings (e.g., genital size, holes in earlobe, kinked tail). They were assigned to age categories (infant: 0-3 months; juvenile: 4-11 months; subadult: 12-23 months; adult: $\geq 24$ months) based on known birth date or on size and the state of genital development (Goldizen 1989). The genital development was assessed by experienced field assistants. Group composition is shown in Table 5-1. All groups lived in mixed-species associations with moustached tamarins (Heymann and Buchanan-Smith 2000, S. mystax). 
Table 5-1. Composition of study groups (excluding infants)

\begin{tabular}{|l|l|l|l|l|l|l|l|}
\hline \multirow{2}{*}{ Group $^{1}$} & & & \multicolumn{2}{|l|}{$\begin{array}{l}\text { A number of animals in } \\
\text { an age-sex class }\end{array}$} & \multirow{2}{*}{$\begin{array}{l}\text { Total } \\
\text { number }\end{array}$} \\
\cline { 2 - 7 } & $\begin{array}{l}\text { adult } \\
\text { females }\end{array}$ & $\begin{array}{l}\text { adult } \\
\text { males }\end{array}$ & $\begin{array}{l}\text { subadult } \\
\text { females }\end{array}$ & $\begin{array}{l}\text { subadult } \\
\text { males }\end{array}$ & $\begin{array}{l}\text { juvenile } \\
\text { females }\end{array}$ & $\begin{array}{l}\text { juvenile } \\
\text { males }^{2}\end{array}$ & \\
\hline Gr1 & 2 & 1 & 2 & 0 & 0 & 2 & 7 \\
\hline Gr2 & 2 & 3 & 0 & 0 & 0 & 2 & 7 \\
\hline Gr3 & 2 & 2 & 1 & 1 & 1 & 0 & 7 \\
\hline Gr5 & 1 & 1 & 2 & 1 & 1 & 0 & 6 \\
\hline Gr6 & 2 & 4 & 0 & 0 & 1 & 1 & 8 \\
\hline
\end{tabular}

${ }^{1}$ Group enumeration follows the S. mystax groups in the study area. Gr4 is not a mixedspecies group and does not include L. nigrifrons.

${ }^{2}$ Excluded from analyses; because juveniles do not carry a lot of time (Tardif et al. 1992; EWH, personal observations).

${ }^{3}$ Excluded from analyses; due to too short observed carrying period (three days).

Table 5-2. Number of litters, litter size, and length of observation periods for infant carrying

\begin{tabular}{|l|l|l|l|}
\hline Group & $\begin{array}{c}\text { Number } \\
\text { of } \\
\text { litters }\end{array}$ & $\begin{array}{r}\text { Number of infants born } \\
\text { in the litter }\end{array}$ & $\begin{array}{c}\text { Duration of the } \\
\text { observation period for } \\
\text { infant carrying } \\
\text { (in months) }\end{array}$ \\
\hline Gr1 & 2 & Twins, singleton ${ }^{2}$ & 3,3 \\
\hline Gr2 & 2 & Twins, twins & $2^{3}, 3$ \\
\hline Gr3 & 3 & Twins, twins, twins & $2^{3}, 3,3$ \\
\hline Gr5 & 1 & Twins & 3 \\
\hline Gr6 ${ }^{4}$ & 1 & Twins & 3 days \\
\hline
\end{tabular}

${ }^{1}$ Number of litters equals number of infant carrying periods.

${ }^{2}$ We were not present when the litter was born, therefore we cannot exclude that twins were born but one of the twins had died.

${ }^{3}$ The litter was born one month before we started with observations, thus we observed only the second and third month of the carrying period.

${ }^{4} \mathrm{Gr} 6$ is due to too short observed carrying period (three days) excluded from analyses. 


\section{Data Collection}

We used instantaneous scan sampling (Martin and Bateson 2007) at 30-min intervals to record the activity of each individual that became visible within 2 min and that could be individually identified, and whether or not it was carrying infants. Carrying one or two infants does not affect the carriers activity (Goldizen 1987b), therefore regardless of whether an individual carried one or two infants, we consider this as one data point. We considered the following activities:

Resting: sitting or lying, without performing any other activity except for autogrooming. Locomotion: walking, running, climbing or jumping over a distance of $1 \mathrm{~m}$.

Feeding: picking a food item with mouth or hands, chewing.

Foraging: visually searching for prey (looking is directed within the arm's reach), manipulating microhabitats or objects that may include prey (e.g. leaves or bromeliad tanks), reaching into knotholes and crevices.

Socializing: any type of social interaction.

Vigilance: head movements in stationary animals where looking is directed beyond arm's reach (Treves 1998; Stojan-Dolar and Heymann 2010).

All field work was conducted under authorization from the Dirección General Forestal y de Fauna Silvestre of the Peruvian Ministry of Agriculture (authorization no. 268-2012AGDGFFS-DGEFFS) and adhered to the ASAB/ABS Guidelines for the Use of Animals in Research.

\section{Statistical Analyses}

Our analyses are based on eight different litters (see Table 5-2) and data on the activity of 21 adult and subadult tamarins (seven adult males, seven adult females, two subadult males, five subadult females) (see Table 5-1). Juveniles may carry infants, but generally do so for very short periods of time (Tardif et al. 1992; EWH, personal observations) and thus were excluded from the analyses. The statistical comparison of activities while carrying or not carrying infants is based on a Bayesian multinomial (logit-link) mixed-effects regression model (Fahrmeir et al. 2013, chap. 7.5.1, 7.6.2) for levels of activity (1: Feeding; 2: Foraging; 3: Locomotion; 4: Resting; 5: Socializing; 6: Vigilance), with conditioning on 
the binary covariate carrying status (ic: infant carried; inc: infant not carried). The model includes the effect of age class, but not of sex class. The calculation of posterior densities was performed with BayesX (Belitz et al. 2015a). From the resulting posterior samples of activity-specific regression coefficients, the distribution of relative frequency (i.e., a probability denoted with $\mathrm{P})$ to observe activity $k=1, \ldots, 6$, conditional on carrying status $=$ infant carried was calculated as:

$$
\mathrm{P}_{S}(\text { Activity }=k \mid \text { carrying status }=\text { infant carried })=\frac{\exp \left(\hat{\beta}_{i c, k}\right)}{\sum_{j=1}^{6} \exp \left(\hat{\beta}_{i c, j}\right)},
$$

where infant carried is the reference category of the binary covariate, and as:

$$
\mathrm{P}_{s}(\text { Activity }=k \mid \text { carrying status }=\text { infant not carried })=\frac{\exp \left(\hat{\beta}_{i c, k}+\hat{\beta}_{i n c, k}\right)}{\sum_{j=1}^{6} \exp \left(\hat{\beta}_{i c, j}+\hat{\beta}_{i n c, j}\right)},
$$

for carrying status $=$ infant not carried, where coefficient $\hat{\beta}_{I n c, k}$ is the coefficient for changing the covariate from infant carried to infant not carried. Index $s=1, \ldots, S$ denotes the sample from the posterior density. In order to get to an identifiable model, one activity category $k \in\{1, \ldots, 6\}$ has to be selected as reference category (Fahrmeir et al. 2013, chap. 6; Belitz et al. 2015a), for which we used feeding.

For the Bayesian model fitting algorithm, all prior distribution assumptions were kept unchanged with respect to the BayesX default: diffuse (i.e., non-informative) priors are considered for fixed effects hyper-parameters (Belitz et al. 2015b), and an inverse Gamma prior for the unstructured Gaussian i.i.d. random intercepts with hyper-parameters $a=$ $b=0.001$ was included in order to cope with unobserved heterogeneity with respect to the subject grouping variable (sensitivity checks on this prior were performed by using hyper-parameters $a=b \in\{0.0001,0.001,0.01,0.1,1\}$, showing only negligible changes in posterior distribution for coefficients $\beta_{p, k}$ ). Markov chain Monte Carlo (MCMC) sampling from the posterior distribution was performed for 32,000 iterations, with 2000 burn-in iterations and a thinning by each $10^{\text {th }}$ iteration; therefore $S=3000$.

Since relative activity frequencies are most convenient for interpretation, we base the inferential results on $99 \%$ credible intervals (calculated as highest posterior density intervals) for the activity-specific relative frequencies, which were calculated from the posterior samples $\hat{\beta}_{i c, k}$, and $\hat{\beta}_{i n c, k}, k \in\{1, \ldots, 6\}$. In analogy to frequentist comparison of 
confidence intervals, the credibility level in each pairwise comparison of $99 \%$ credible intervals is at most 0.01 (Schenker and Gentleman 2001). We therefore also calculate posterior model probability differences (PMP) to evaluate differences in the relative activity frequencies between carrying and not carrying infants. Whenever the value 0 is not covered by the distribution of

$$
\begin{aligned}
\mathrm{P}_{S}(\text { Activity }= & k \mid \text { carrying status }=\text { infant carried }) \\
& -\mathrm{P}_{S}(\text { Activity }=k \mid \text { carrying status }=\text { infant } \text { not carried }),
\end{aligned}
$$

this provides strong evidence for a true underlying difference in the relative activity frequencies between carrying and not carrying infants.

\section{Results}

In three (feeding, foraging, and vigilance) out of the six activity frequencies, we find strong support for differences while carrying infants or not (Fig. 5-1). While carrying infants, tamarins are much less likely to forage for prey and to feed than when not carrying; posterior mode probability (PMP) of prey foraging decreases from $22.7 \%$ (no carrying) to $2.3 \%$ (carrying), of feeding from $7.4 \%$ (carrying) to $1.2 \%$ (no carrying). The PMP of vigilance increased from $28.0 \%$ (no carrying) to $40.1 \%$ (carrying).

The frequency of locomotion increased from $35.7 \%$ (no carrying) to $45.1 \%$ (carrying), but because of a small overlap of credible intervals, we cannot conclude this change to be statistically significant. The distribution of posterior probability differences of resting overlapped with 0 and that of socializing almost overlapped with 0 . This suggests that these two activities do not differ while carrying or not. PMP of resting while carrying is $6 \%$ and when not carrying is $3 \%$, PMP of socializing when carrying is $0.1 \%$ and $2.6 \%$ while not carrying. 

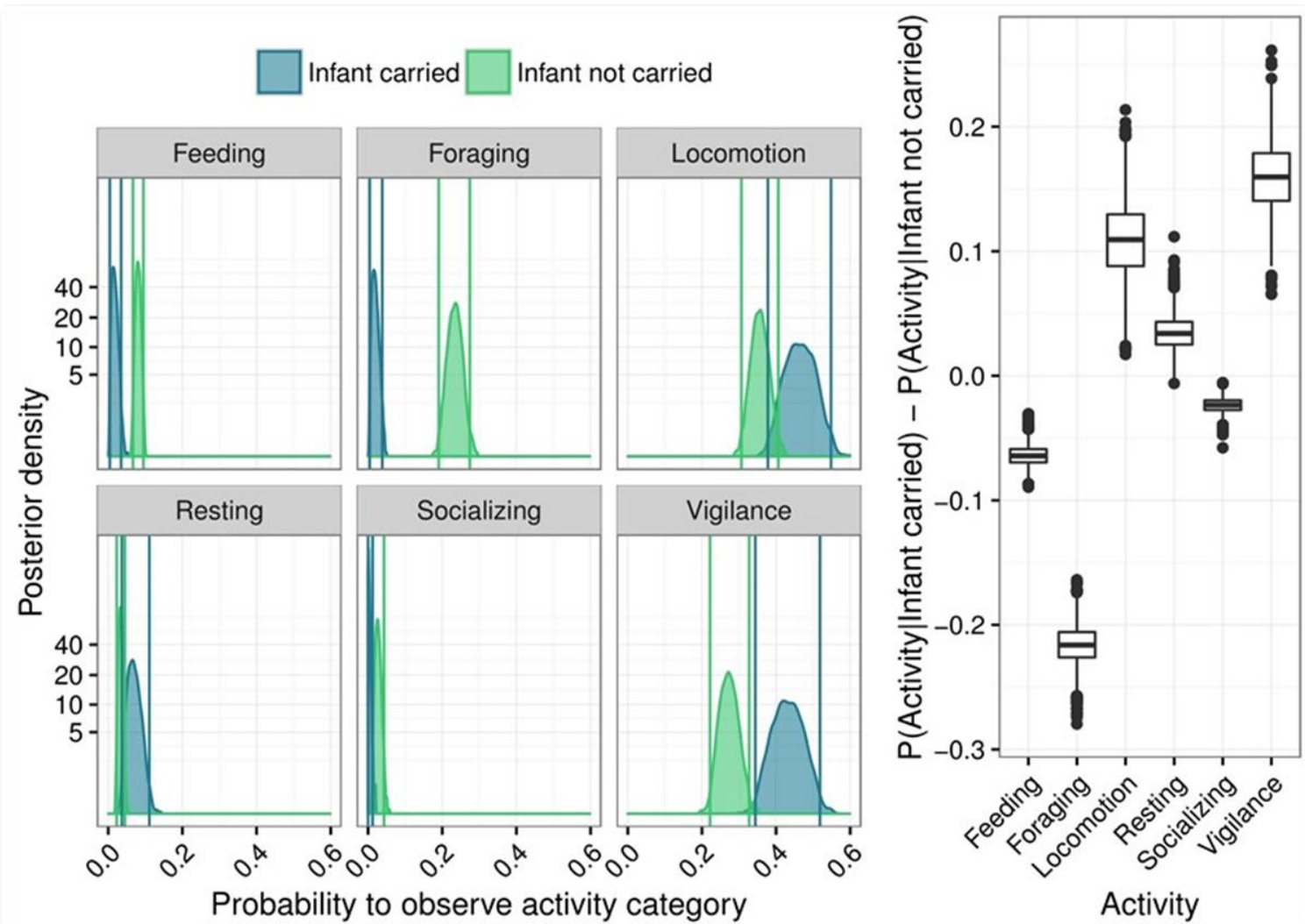

Fig. 5-1. Results of the Bayesian multinomial logit mixed-effects regression model. Left: Posterior densities for frequencies of general activities of adult and sub-adult tamarins conditional on whether infants are carried or not. Vertical lines show limits of activityspecific $99 \%$ credible intervals, conditional on carrying of infant status. $Y$ axis is $\log (1+y)$ transformed for better visualization. When credible intervals of the two conditions (infants carried or not) do not overlap, this represents a difference that is - in classical statistical inference terminology - usually denoted as a statistically significant difference. However, as this graphical conclusion leaves out co-variances of the respective conditions, the inversion of such an argument - overlapping intervals are equivalent to non-significantly different conditions - is not correct. Right: Distribution of posterior differences in activity probabilities ( $P$ in the $y$-axis label is for probability) between carrying and not carrying infants.

\section{Discussion}

Our study shows that tamarins adjust their activity budget while carrying infants and that these shifts are likely to result in energetic costs in carriers, shown in a loss of body mass. Decreased feeding time does not necessarily translate into reduced amounts of ingested food (Zinner 1999) and theoretically could be compensated by increasing ingestion rates. However, saddleback tamarins mainly forage on cryptic prey or prey that is partially or completely concealed within bromeliad tanks and dead leaves, in the leaf litter, and other more or less closed microhabitats (Peres 1993a; Nickle and Heymann 1996; Nadjafzadeh 
and Heymann 2008). Decreased foraging time thus could only be compensated by increasing foraging efficiency, i.e. capture rates; however, it is difficult to conceive a mechanism through which this could be achieved. Given that even under captive conditions with unrestricted access to food, infant carrying results in decreased body mass (Sánchez et al. 1999; Achenbach and Snowdon 2002), it is conceivable that wild tamarins lose body mass, too. Moreover, a decrease in foraging and/or feeding is one of the most frequently recorded change in activity budgets in wild (Goldizen 1987b, Leontocebus weddelli; Huck et al. 2004a, S. mystax) as well as captive carrying callitrichids (Price 1992, Saguinus oedipus; Sánchez et al. 1999, S. oedipus). This makes foraging and feeding decrease also less likely to be due to a seasonal effect. In addition, all our study periods in particular fall completely or mostly in the first half of the year which is usually the period of fruit abundance (E.R. Tirado Herrera \& E.W. Heymann, unpublished data), thus the time when we would not expect it to be low on fruits and prey.

Maneuvers and movements associated with feeding and foraging could increase the risk of infant falling off the back and increase exposure to predators (Goldizen 1987b). Foraging on cryptic and concealed prey requires attention to be strongly focused on foraging substrates and away from the surroundings, thus decreasing the probability of detecting a predator early enough to escape. Even if alarm calls by other members of the mixed-species group provide an early warning, constraints on the type and speed of locomotion during infant carrying, e.g. decreased leaping (Schradin and Anzenberger 2001a; Caperos et al. 2012), would still increase the predation risk. Tamarins are subject to predation by raptors, snakes and probably felids (Emmons 1987; Goldizen 1988; Heymann 1990a; Oversluijs Vasquez and Heymann 2001; Shahuano Tello et al. 2002; Lledo-Ferrer et al. 2009) and show consistently high levels of vigilance (Peres 1993b; Stojan-Dolar and Heymann 2010) even under the predator-free conditions of captivity (Caine 1984, 1986, 1987, Saguinus labiatus).

Also in our study, under both conditions - while carrying and while not carrying - vigilance is the most frequently recorded activity, next to locomotion. The increase in vigilance while carrying is at odds with findings by Price (1992) who reported a decrease of vigilance while carrying infants in captive cotton-top tamarins, S. oedipus. This author suggested that an increase of time infant carriers spent concealed in the upper parts of the enclosure 
is an alternative strategy to vigilance - an active visual search for predators, thus both strategies aiming to reduce a perceived predatory threat. The contrast between our and her findings might be due to wild vs captive conditions, different measures of vigilance or species differences. First, in captive conditions there is no real threat by predators, therefore vigilance might be less pronounced as in the wild. Second, Price (1992) used alarm calls and animals looking up as a measure of vigilance. In contrast, we used visual scanning in all directions (Table 5-2), as predators might come also from side or below. Thus we might have captured more vigilance events. Third, results might be due species specific strategies as already shown for mixed-species groups of Avila-Pires saddleback tamarins (Leontocebus fuscicollis avilapiresi) and red-capped moustached tamarins ( $S$. mystax pileatus), who differ in the frequency of vigilance in directed to above, the same horizon (Peres 1993b). Wild S. oedipus were rarely vigilant during infant carrying, but no detailed comparison between carrying and not carrying has been provided (Savage et al. 1996). Increased vigilance while carrying infants should be expected, because vigilance can fulfill different functions at the same time, e.g. to remain in contact with its group, looking for another animal to transfer the infant and it increases the probability of early detection of predators in a situation where rapid escape is compromised due to constraints on locomotion. Carriers could also hardly employ the extreme response of dropping from trees (Heymann 1990a) as this would impose a high risk of infants getting hurt. Increased rates of alarm calling in the presence of an infant (Heymann 1990a) suggest increased vigilance, but could also be the consequence of increased sensitivity for (potentially) predatory stimuli and/or increased rates of approach and attack by predators.

The social system of callitrichids is unique, as there are no other cooperatively breeding animals who are carrying their offspring. Therefore, our results cannot be directly compared to findings from other cooperative breeders. Nevertheless, there are parallels to findings from cooperatively breeding meerkats, where helpers ("babysitters") guard and feed infants during the first 10-12 weeks after birth (Clutton-Brock et al. 1998, Suricata suricatta). Meerkats significantly increase levels of sentinel behavior in the presence of pups, and when pups are closer to helpers $(<2 \mathrm{~m})$ than when they are further 
away; at the same time, time spent foraging and the amount of food ingested drop significantly (Clutton-Brock et al. 1998; Santema and Clutton-Brock 2013).

In conclusion, our study confirms that infant carrying in a cooperatively breeding primate causes changes to activity budget, in terms of reduced foraging and feeding, and increased vigilance. Considering the latter, to the best of our knowledge, this is the first study that reveals increased vigilance while carrying in callitrichids. These activity budget shifts are likely related to restricted mobility while carrying infants and therefore to modified antipredator behavior. Furthermore, these activity budget shifts are likely to result in energetic costs in carriers. We do not know whether these costs translate into medium and long-term fitness consequences, e.g. lower probability of survival or of own reproduction. To make helping a stable strategy, costs need to be compensated by direct and indirect fitness benefits (Dickinson and Hatchwell 2004). Tamarins show high intragroup genetic relatedness (Huck et al. 2005a; Díaz-Muñoz 2011); thus, costs of infant carrying are likely to be compensated through inclusive fitness gains not only for parents but also for the helpers. In the case of unrelated helpers - which do occur in tamarins (Huck et al. 2005a), costs must be compensated by direct fitness benefits (Clutton-Brock et al. 2001; Dickinson and Hatchwell 2004). Demonstration of costs of infant carrying also argues against non-adaptive hypotheses put forward to explain helping behavior in cooperative breeders (Jamieson and Craig 1987). 


\section{Chapter 6}

\section{Is infant care associated with physiological stress in a cooperatively breeding wild primate?}

Authors: Darja Slana', Judith Jacira Achong Sánchez², Allison Licett Núñez Levy², Holger Sennhenn-Reulen ${ }^{3},{ }^{4}$, Michael Heistermann ${ }^{5}$, Eckhard W. Heymann ${ }^{1}$

${ }^{1}$ Verhaltensökologie \& Soziobiologie, Deutsches Primatenzentrum - Leibniz-Institut für Primatenforschung, Göttingen, Germany

${ }^{2}$ Facultad de Ciencias Biológicas, Universidad Nacional de la Amazonía Peruana, Iquitos, Peru

${ }^{3}$ Kognitive Ethologie, Deutsches Primatenzentrum - Leibniz-Institut für Primatenforschung, Göttingen, Germany

${ }^{4}$ Leibniz-WissenschaftsCampus, Primatenkognition, Deutsches Primatenzentrum Leibniz-Institut für Primatenforschung, Göttingen, Germany

${ }^{5}$ Hormonlabor, Deutsches Primatenzentrum - Leibniz-Institut für Primatenforschung, Göttingen, Germany

Author contribution, listed by sections: design of the study by DS and EWH; field data collection by DS, JJAS and ALNL; statistical analyses by DS and HSR; writing the manuscript by $\mathrm{DS}, \mathrm{HSR}, \mathrm{MH}$ and EWH; supervision by $\mathrm{MH}$ and EWH. 


\section{Abstract}

In cooperatively breeding animal societies, infant care is provided by parents as well as other group members, so-called helpers. In tamarins and marmosets, Neotropical callitrichid primates, infant care consists of carrying and food transfer and is costly to the caretakers. Infant care affects the activity budget of the caretaker, especially in reducing time spent feeding and foraging and decreases the carriers' body mass. Due to these costs, infant care is likely to be stressful, i.e. associated with an increase in stress hormone output. Here we investigate, whether infant care affects fecal cortisol metabolite (FCM) levels, an indicator of the physiological stress response, in wild black-fronted tamarins, Leontocebus nigrifrons. We focus on adult males, the predominant infant care takers, and subadults, who carry less, and compare their FCM levels during periods of carrying and non-carrying and according to their carrying effort. Our study shows that FCM levels of adult males and subadults do not differ between the carrying and non-carrying period. Also, FCM levels did not change in proportion to the carrying effort of adult males nor subadults. FCM levels were higher in adult males than in subadults during the non-carrying period, but did not differ between them during the carrying period. Our data show that infant care is not associated with an increase in stress hormone output and thus imply that infant care is not stressful or that factors not identified in our study attenuate the stress. Due to known infant care costs, the first explanation is less likely than the second. We suggest that infants act as a stress buffer: they balance out the energetic costs that would otherwise lead to a physiological stress response. Furthermore, we suggest that infants can only act as effective stress buffers when caretakers obtain greater maturity and parental or alloparental experience.

Keywords: Callitrichidae; infant care; stress, cortisol

\section{Introduction}

Parental care includes any parental trait that increases offspring fitness, i.e. offspring's survival and eventually the breeding success (Clutton-Brock 1991; Smiseth et al. 2012). Animals show a wide variety of parental traits, starting with gamete provisioning (Williams 1994, birds; Fox and Czesak 2000, arthopods), up to care of mature offspring (Surbeck et 
al. 2011, Pan paniscus). Infant care can be provided by only one parent (monoparental), by both parents (biparental) or can be extended to other group members, nonreproductive adults and subadults or so-called helpers. The latter combines parental and alloparental care, and is in addition to strong ecological constraints on dispersal or independent breeding (Hatchwell 2009) a characteristic of a rare cooperatively breeding system (Solomon and French 1997; Koenig and Dickinson 2004).

Parental care benefits the caregivers but it can also incur costs, often to the parents (Clutton-Brock 1991; Smiseth et al. 2012). The diverse costs include a higher risk of predation, often due to carrying, e.g. in male brood carrying pipefish (Svensson 1988, Nerophis ophidionc) and energetic costs, often expressed in loss of body mass or growth delay, e.g. in great tit (Tinbergen and Verhulst 2000, Parus major). In mammals the costs are particularly high for mothers, due to a specific type of maternal care, lactation (Oftedal 1984; van Noordwijk 2012). Unlike many other mammals, primates exhibit additional costs of parenting, because most primates transport their infants. Primate mothers, who in addition to lactation generally carry their offspring alone, experience major costs of parental care (van Noordwijk 2012). In the Neotropical family Callitrichidae (marmosets and tamarins), the mother receives help from other group members (helpers). This makes these small-bodied (100-650g) marmosets and tamarins unique, as they are the only cooperatively breeding primates. They have a potential to produce two litters per year, usually dizygotic chimeric twins (Garber et al. 2016), and they have high levels of alloparental care, with non-reproductive adults providing extensive offspring carrying and food provisioning. Due to energy demands of heavy infants, infant care is costly. Energetically, costs are expressed in loss of body mass (Sánchez et al. 1999, Saguinus oedipus; Achenbach and Snowdon 2002, S. oedipus; Morcillo et al. 2003, S. oedipus) and changes in almost all daily activities (Price 1992, S. oedipus; Sánchez et al. 1999, S. oedipus; Schradin and Anzenberger 2001a, Callithrix jacchus; Huck et al. 2004a, Saguinus mystax; chapter 5).

Energetic costs may provoke a stress response (Moberg and Mench 2000). In vertebrates, stress is usually detected through increased glucocorticoid output, such as the hormone cortisol (Sapolsky et al. 2000). Cortisol can be measured invasively in blood, as plasma cortisol, or non-invasively in urine and feces (Moberg and Mench 2000). The latter is a 
preferred method in the wild (e.g. Huck et al. 2005b; Bales et al. 2006; Ganswindt et al. 2010). Glucocorticoids are controlled by the hypothalamic-pituitary-adrenocortical (HPA) axis system. Within a few minutes after exposure to a stressor HPX axis releases glucocorticoids into blood (Hennessy et al. 2009, review). In long-term stress, when HPA axis activation is prolonged or repeated, stress may lead to damaging consequences (Moberg and Mench 2000), e.g. in health, reproduction and it may alter behavior. On the other hand, the short-term activation of HPA axis releases an amount of glucocorticoids that are adaptive for coping with short-term stressors (Sapolsky et al. 2000, review). The HPA axis response ensures availability of additional energy by promoting the reallocation of resources from energy consuming systems, like immunity and reproduction (Wingfried and Sapolsky 2003). This short-term activation of an additional energy may help to alleviate detrimental effects of short-term stressors (Willner 1993), such as carrying of heavy infants.

Given that callitrichids extensively carry and feed their heavy twin infants, the question emerges 'Does infant care create stress in callitrichids?' Heavy infants, who's combined body mass of twins corresponds to 16 - $20 \%$ of maternal body mass (Tardif et al. 1993), are carried in all group movements for the first $2-3$ months, and are provided with food for a few months more (Epple 1975; Terborgh and Goldizen 1985; Pryce 1988; Goldizen 1989; Tardif et al. 1992; Huck et al. 2004a). In addition we know that in callitrichids, caring for infants is costly, by imposing behavioral and physiological changes to the carriers, i.e. body mass loss (Sánchez et al. 1999, S. oedipus; Achenbach and Snowdon 2002, S. oedipus) and changes in time distribution of daily activities (Price 1992, S. oedipus; Sánchez et al. 1999, S. oedipus; Schradin and Anzenberger 2001, C. jacchus; Huck et al. 2004, S. mystax; chapter 5). Based on the results mentioned above, we expect carrying to be stressful and therefore reflected in increased cortisol output.

In this study we examine if in callitrichids caring for infants is associated with a physiological stress response reflected in increased glucocorticoid levels. More specifically, we test if in wild black-fronted tamarins (Leontocebus nigrifrons), carrying influences fecal cortisol metabolite (FCM) levels. Our focus is on adult males, as they are frequently reported to be main infant carriers (Savage et al. 1996; Garber 1997; Yamamoto et al. 2009). However since subadults, regardless of sex, can also make a 
significant contribution to infant care (Goldizen 1987b), we have included them in our study, even though they carry less (Huck et al. 2004a). We predict that FCM levels of adult males and subadult helpers increase during periods of infant carrying and that an increase in FCM levels is proportional to the carrying effort. Yet, studies on captive callitrichids indicate no effect of carrying on cortisol levels (da Silva Mota et al. 2006, C. jacchus) or, opposite to expectation, lower cortisol levels in carriers (Nunes et al. 2001, Callithrix kuhlii). Since the natural environment is more complex, less predictable and generally more challenging than a captive environment, increased cortisol levels in response to carrying may be more evident for wild-living animals, like in yellow-bellied marmots (Smith et al. 2012, Marmota flaviventris). For callitrichids, studies on stress hormone output in wild populations indicate no change in cortisol levels in adult males over the course of the year (Huck et al. 2005b, S. mystax) or when compared between the breeding and infant care season (Bales et al. 2006, Leontopithecus rosalia). However, the latter two studies did not focus on or include the carrying effort or infant care in general into their analysis. Diverse arguments suggest that cortisol levels in adult males are likely to be influenced by previous experience in infant care (Nunes et al. 2001; Ziegler et al. 2004; da Silva Mota et al. 2006), interaction with pregnant females (Ziegler et al. 2004; da Silva Mota et al. 2006), and infants themselves (Nunes et al. 2001; da Silva Mota et al. 2006). The link between infant care, stress and cortisol in callitrichids is thus far from being certain, especially considering the apparent lack of information from wild populations. Here we present the first study of wild callitrichids that examines how infant care behavior relates to stress hormone output in the carriers.

\section{Methods}

\section{Study site and study population}

We carried out the study at the Estación Biológica Quebrada Blanco (EBQB), located in primary Amazonian lowland forest in northeastern Peru, $4^{\circ} 21^{\prime} \mathrm{S}$ and $73^{\circ} 09^{\prime} \mathrm{W}$. For a more detailed description of the study site, see Heymann (1995). We studied five groups of well habituated black-fronted saddle-back tamarins (L. nigrifrons). Data collection started in 
May 2012 (groups Gr1, Gr2, Gr3), August 2012 (group Gr5), December 2012 (group Gr6 ${ }^{8}$ ), and lasted until end of July 2013. We observed each group on average for 7.5 days per month and for 8.3 hours per day, resulting in a total of 3868.7 hours of observation. We identified individual animals by natural markings, e.g., fur pattern, tail shape and genital size and shape. Animals were assigned to age categories (infant: 0-3 months; juvenile: 312 months; subadult: 1-2 years; adult: $\geq 2$ years) according to known birth date or based on size and state of their genital development (Goldizen 1989; Goldizen et al. 1996). Group composition, not including infants, is shown in Table 6-1. All groups formed mixed-species associations with moustached tamarins (Heymann and Buchanan-Smith 2000, S. mystax).

Table 6-1. Composition of study groups (excluding the infants)

\begin{tabular}{|c|c|c|c|c|c|c|c|}
\hline \multirow[t]{2}{*}{ Group } & \multicolumn{6}{|c|}{ Number of animals } & \multirow{2}{*}{$\begin{array}{l}\text { Total } \\
\text { number of } \\
\text { animals }\end{array}$} \\
\hline & $\begin{array}{l}\text { Adult } \\
\text { females }\end{array}$ & $\begin{array}{l}\text { Adult } \\
\text { males' }^{1}\end{array}$ & $\begin{array}{l}\text { Subadult } \\
\text { females }^{1}\end{array}$ & $\begin{array}{l}\text { Subadult } \\
\text { males }^{1}\end{array}$ & $\begin{array}{l}\text { Juvenile } \\
\text { females }\end{array}$ & $\begin{array}{l}\text { Juvenile } \\
\text { males }\end{array}$ & \\
\hline Gr1 & 2 & 1 & 2 & 0 & 0 & 2 & 7 \\
\hline Gr2 & 2 & 3 & 0 & 0 & 0 & 2 & 7 \\
\hline Gr3 & 2 & 2 & 1 & 1 & 1 & 0 & 7 \\
\hline Gr5 & 1 & 1 & 2 & 1 & 1 & 0 & 6 \\
\hline Gr6 & 2 & 4 & 0 & 0 & 1 & 1 & 8 \\
\hline Total & 9 & 11 & 5 & 2 & 3 & 5 & 35 \\
\hline
\end{tabular}

${ }^{1}$ Animal groups used for analyses for this study.

\section{Data collection}

\subsection{Behavioral data}

We recorded infant carrying - an individual transport of infant/s on the back - with instantaneous sampling (Martin and Bateson 2007) at 5 minute intervals, starting when an individual was seen carrying an infant. If a carrier was out of sight for more than 5 minutes and was again seen carrying an infant, we recorded it as a new data point (adjusted after Vogt 1978; Huck et al. 2004a). We defined infant carrying (transport)

\footnotetext{
${ }^{8}$ Numbering of groups at EBQB is based on the sympatric moustached tamarins (S. mystax) with which the black-fronted tamarins generally form mixed-species groups (Heymann and Buchanan-Smith 2000). Group 4 (Gr4) which had been named before the onset of this study included only moustached tamarins.
} 
period to the first three months after birth. We collected data on individual visibility with a group scan sampling (Martin and Bateson 2007) performed every half hour for two minutes where we recorded every individual present. We used the latter data for a visibility correction when calculating infant carrying effort (see section Infant carrying effort (p. 96).

All field work adhered to the "Code of Best Practices for Field Primatology" of the American Society of Primatologists (Riley et al. 2014) and conducted under authorization from Dirección General Forestal y de Fauna Silvestre of the Peruvian Ministry of Agriculture (authorization no. 268-2012-AG-DGFFS-DGEFFS).

\subsection{Fecal sampling}

We collected fecal samples throughout the entire study period. We collected feces from clearly identified individuals, and only if the feces (or parts of it up to ca. $0.5 \mathrm{~g}$ ) did not fall into water and were not touched by urine or soil. This rigorous selection process was needed to avoid contamination as well as inaccuracies in determining fecal mass. We collected each sample immediately after defecation in $15 \mathrm{ml}$ conical polypropylene tubes, pre-filled with $4 \mathrm{ml}$ of $80 \%$ ethanol. Prior to placing into the collection tube, we removed any obvious non-fecal material (seeds, stones, undigested matter etc.) and homogenized the sample with a wooden stick. We labelled the tubes with the identity of the monkey and the collector, running number, date, and time.

We extracted the samples within 18 hours of collection using the field extraction method described in Ziegler and Wittwer (2005). In brief, we shook the tubes horizontally by hand for two minutes in order to release the steroid hormones. This was followed by a manually operated centrifuge for two minutes. We pipetted $2 \mathrm{ml}$ of the supernatant into $2.0 \mathrm{ml}$ Eppendorf cups, which were parafilmed to reduce the risk of evaporation. Cups were stored in dark boxes for $1-3$ weeks at ambient temperature $(20-30 \circ \mathrm{C})$ and were subsequently stored refrigerated $\left(5^{\circ} \mathrm{C}\right)$ until transport to the German Primate Centre's endocrinology laboratory for FCM analysis. Fecal samples were then dried to a constant weight to determine fecal dry weight. Three samples were excluded from analysis because their sample tubes partially melted during the drying process. 


\section{Analyses}

\subsection{Study sample}

We based our analyses on infant carrying and FCM levels of adult males and all subadults. The data included 21 months of infant carrying periods of 8 different litters (analyses of infant carrying and FCM levels) and 36 months of infant non-carrying periods (analyses of FCM levels) (Table 6-2). In order to analyze FCM levels we used a minimum of 3 samples per individual for each particular study period. We have excluded from the analyses 1 adult male that provided less than 3 hormonal samples, 1 sample with dubious identification, and 22 samples with dubious data entry or non-reliable dry fecal mass. Specifically for the analyses of "relationship between FCM and infant carrying" (Fig. 6-2), we have also excluded 2 subadults ( 18 samples) that provided less than 3 fecal samples in individual infant carrying periods. Additionally Gr6 was excluded from the analyses, as there were only 3 days where an observation of carrying period was made.

In total, we analyzed 126 fecal samples for FCM. For the purpose of analyzes of "FCM in time periods; infant carrying vs. infant non-carrying" we analyzed 69 fecal samples of 6 adult males and 57 samples of 7 subadults. For the purpose of analyzes of "relationship between FCM and infant carrying" we analyzed 43 fecal samples of 6 adult males and 22 samples of 5 subadults. 
Table 6-2. Number of litters per group, litter size and duration of observational periods

\begin{tabular}{|c|c|c|c|c|c|c|}
\hline \multirow[t]{2}{*}{ Group } & \multirow[t]{2}{*}{$\begin{array}{l}\text { Litter } \\
\text { number }\end{array}$} & \multirow[t]{2}{*}{$\begin{array}{l}\text { Litter } \\
\text { size }\end{array}$} & \multicolumn{2}{|l|}{$\begin{array}{l}\text { Observation periods for } \\
\text { infant carrying (months) }\end{array}$} & \multicolumn{2}{|c|}{$\begin{array}{l}\text { Observation periods for } \\
\text { infant non-carrying (months) }\end{array}$} \\
\hline & & & Specific & All & Specific & All \\
\hline Gr1 & 2 & $\begin{array}{l}\text { twins } \\
\text { singleton }{ }^{1}\end{array}$ & $\begin{array}{l}\text { Dec 2012-Feb } 2013 \text { (3) } \\
\text { Feb-Apr } 2013(3)\end{array}$ & $5^{2}$ & $\begin{array}{l}\text { May-Nov } 2012 \text { (7) } \\
\text { May-July } 2013\end{array}$ & 10 \\
\hline Gr2 & 2 & $\begin{array}{l}\text { twins }^{3} \\
\text { twins }\end{array}$ & $\begin{array}{l}\text { May-Jun } 2012(2) \\
\text { Feb-Apr } 2013 \text { (3) }\end{array}$ & 5 & $\begin{array}{l}\text { Jul 2012-Jan } 2013 \\
\text { (7) } \\
\text { May-July } 2013 \text { (3) }\end{array}$ & 10 \\
\hline Gr3 & 3 & $\begin{array}{l}\text { twins }^{3} \\
\text { twins } \\
\text { twins }\end{array}$ & $\begin{array}{l}\text { May-Jun } 2012 \text { (2) } \\
\text { Jan-Mar } 2013 \text { (3) } \\
\text { May-Jul } 2013 \text { (3) }\end{array}$ & 8 & $\begin{array}{l}\text { Jul-Dec } 2012(6) \\
\text { Apr } 2013(1)\end{array}$ & 7 \\
\hline Gr5 & 1 & twins & Nov 2012 - Jan 2013 (3) & 3 & $\begin{array}{l}\text { Aug-Oct } 2012 \text { (3) } \\
\text { Feb-Jul } 2013 \text { (6) }\end{array}$ & 9 \\
\hline $\mathrm{Gr6}^{4}$ & 1 & twins & Dec 2012 (3 days) & 0 & Mar-Jul2013 (3) & 5 \\
\hline Total & 9 & & & 21 & & 41 \\
\hline
\end{tabular}

${ }^{1}$ We were not present when the litter was born, therefore we do not know if a female actually gave birth to two and not only a single infant.

${ }^{2}$ One month overlap in observation of infant carrying period of the two litters.

${ }^{3}$ Infants born 1 month before the onset of the study.

${ }^{4}$ Excluded from analyses due to short observation period of infant carrying (3 days).

\subsection{Fecal cortisol metabolite (FCM) analysis}

We measured fecal extracts for FCM applying a cortisol microtiterplate enzyme immunoassay previously described by Palme and Möstl (1997). Application of a fecal cortisol assay has been successful for assessing adrenocortical activity in numerous primate species (Cavigelli 1999; Lynch et al. 2002; Heistermann et al. 2006), including several species of callitrichids (Ferreira Raminelli et al. 2001; Ziegler and de Sousa 2002; Huck et al. 2004b; Heistermann et al. 2006). We confirmed the biological validity of our FCM measurement by demonstrating that it reliably detects the pregnancy-related increase in cortisol commonly found in callitrichids and other primate species (e.g. Ziegler et al. 1995; Smith and French 1997; Cavigelli 1999; Brent et al. 2011; Carnegie et al. 2011; Rimbach et al. 2013). Specifically, comparisons of FCM levels measured in fecal samples collected cross-sectionally from non-pregnant and pregnant females revealed a highly significant statistical difference, with FCM levels being on average three times higher in 
the pregnancy samples (pregnancy samples, $n=14$ : $5.24 \pm 4.23 \mu \mathrm{g} / \mathrm{g}$; non-pregnancy samples, $n=16: 1.74 \pm 0.71 \mu \mathrm{g} / \mathrm{g}$; Mann-Whitney U-test: $U=36, p<0.01)$. Accordingly, we are confident that our FCM assay is valid for assessing adrenocortical activity in our study species. The assay was performed as described in Huck et al. (2005b). Cross-reactivity data of the cortisol antibody are reported by Palme and Möstl (1997). Sensitivity of the assay at $90 \%$ binding was $0.6 \mathrm{pg}$. Inter-assay coefficients of variation, assessed by replicate determination of high- and low value quality controls, were $6.4 \%$ (high) and $5.7 \%$ (low), respectively. All hormone concentrations are presented as $\mu \mathrm{g} / \mathrm{g}$ dry mass of feces.

\subsection{Statistical analyses}

\section{a) Infant carrying effort}

We calculated the infant carrying effort as the relative contribution of each individual to total infant carrying with the formula given below (after Huck et al. 2004a). An individual carrying two infants at the same time is counted as two occurrences of infant carrying. We corrected carrying data for individual visibility, which derived from group scan sampling data (Martin and Bateson 2007) We incorporated a visibility correction in the calculation of the expected frequencies $(E)$ :

$$
E=\text { behavior (total) * scans (individual) / scans (total), }
$$

where behavior (total) = frequency at which the behavior was seen in all individuals; scans (individual) $=$ number of sightings of a respective individual in scans; scans (total) = number of sightings of all individuals in scans. Calculations of percentages of carrying behavior were done by the following formula:

$\%$ behavior of individual $X=\frac{o_{X} / E_{X^{*}} 100}{\sum_{\text {group }} O / E}$,

where $O=$ observed frequency of the behavior.

\section{b) Determination of influences on FCM levels}

In the following statistical analyses, a relationship between "FCM levels" and "time periods" or "infant carrying" was investigated using Bayesian multilevel (mixed effects) 
regression model for logarithmic transformed FCM values. We included individuals as random factor, thereby controlling for the repeated measurements from the same individual. A student t distributed response with identity Link was used, leading to robust regression, i.e. less influenced by potential extreme values. The regression analyses were conducted using a Bayesian inference algorithm (Markov chain Monte Carlo, MCMC) as implemented in the Stan (Carpenter et al. 2017) based R add-on package brms (Bürkner 2017). MCMC estimation is a general tool for the estimation of Bayesian regression models that allows quantifying the joint posterior distribution of a model's coefficients with high accuracy, but without calculation of a p-value (Gelman 2006). With the absence of substantial prior knowledge, we used non-informative priors for the regression coefficients included in the different models. Priors for standard deviations of random effects were kept on the weakly informative default implemented in brms. For the MCMC set-up, we used 4 chains per model, with a warm-up of 5000 iterations, a thinning rate of 1 , and 10000 iterations in total for each chain.

\section{c) FCM levels in time periods; infant carrying vs infant non-carrying}

To model the influence of time periods (infant carrying vs infant non-carrying) on the expected value of $\log (\mathrm{FCM})$ concentrations, an interaction term including time periods and age class (both binary) was used. To estimate a potential non-linear relationship between daytime and $\log (\mathrm{FCM})$ levels, we used a non-parametric Bayesian spline approach as implemented by the brms function $\mathrm{s}$, being based on the $\mathrm{R}$ add-on package mgcv (Wood 2004).

\section{d) Relationship between FCM levels and infant carrying}

To model the influence of carrying percentages on $\log (\mathrm{FCM})$ levels, we used an interaction term between infant carrying percentage (numerical) and age classes (binary). Again, to estimate a potential non-linear relationship between daytime and $\log (\mathrm{FCM})$ concentrations, we used a non-parametric Bayesian spline approach as implemented by the brms function s, being based on the R add-on package mgcv (Wood 2004). 


\section{Results}

There was no influence of daytime on FCM levels during the entire study period (Fig. B-1) and within the infant carrying period in specific (Fig. B-2). Our data on the relationship between infant care behavior and FCM levels yielded only one significant result: during non-carrying periods FCM levels are higher in adult males than in subadults (Fig. 6-1D). On the contrary, during carrying periods there is no difference in FCM levels between the two age classes, regardless that absolute FCM levels are higher in adult males (Fig. 6-1C). Furthermore, neither FCM levels of adult males nor of subadults differ between infant carrying and non-carrying periods (Fig. 6-1A, Fig. 6-1B), contrary to our prediction. This is despite that in infant carrying period absolute FCM levels of adult males are lower, and of subadults are higher. 


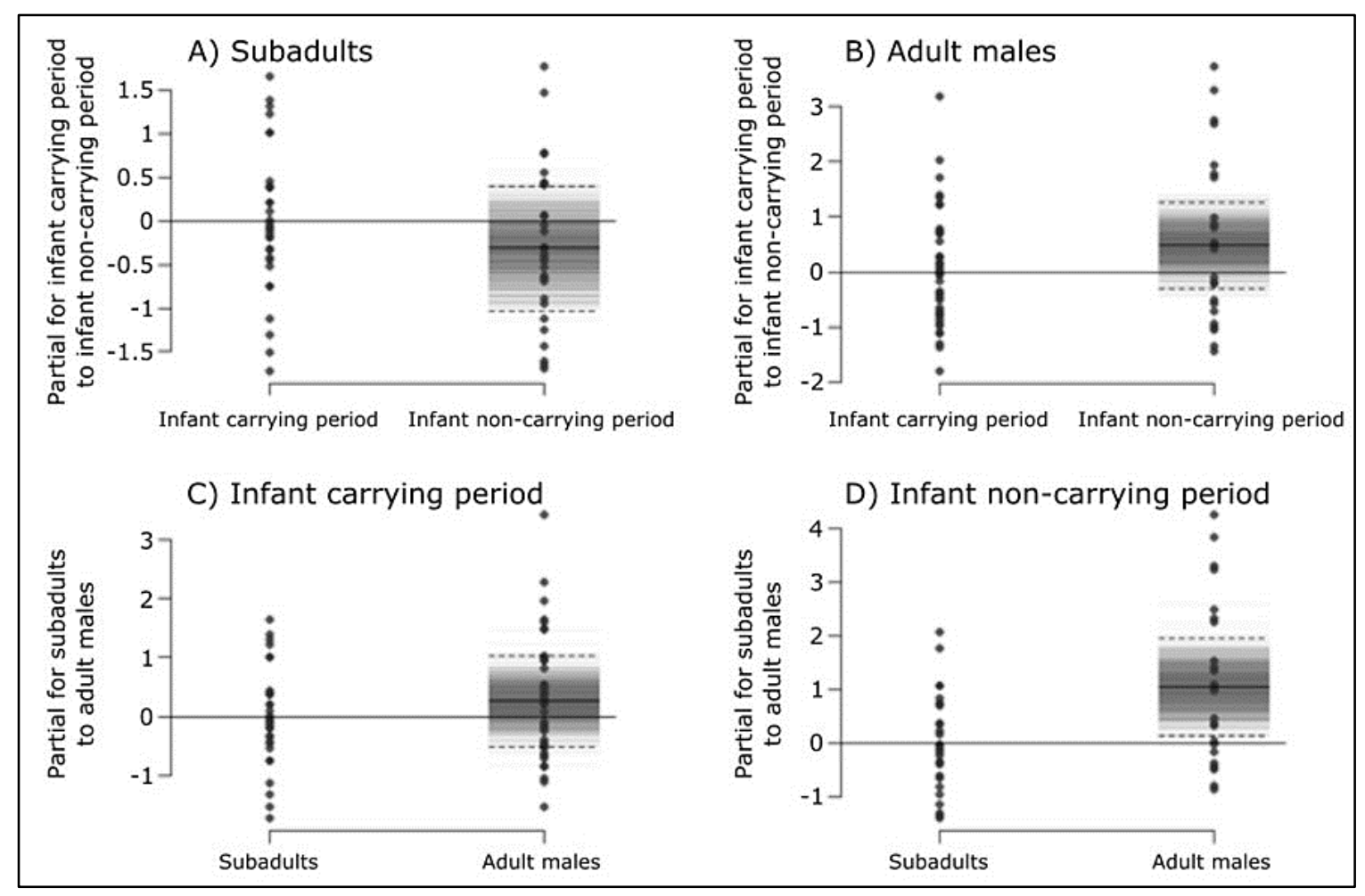

Fig. 6-1. Results of the Bayesian multilevel (mixed effects) regression model shown in the form of partial residual plots (https://en.wikipedia.org/wiki/Partial_residual_plot): logarithmic transformed FCM values of adult males and subadults in time periods (infant carrying and infant non-carrying). We compared FCM values between the infant carrying and the non-carrying period, of $\boldsymbol{A}$ ) subadults $\boldsymbol{B}$ ) adult males. We compared FCM values of subadults and adult males: C) within the infant carrying period, and D) within the infant non-carrying period. Dots (•) represent: partial residuals. Grey shaded lines ( ) represent: partial effects (only for one category per chart as the respective other one is the reference category) given by the original distribution of posterior samples. Bold lines (-) represent: posterior means of coefficients (effects). Dashed lines (----) represent: the boundaries of posterior credible intervals. When a longer bold line is out of dash line boundaries, this represents a statistically significant result.

During infant carrying periods FCM levels do not differ within adult males, regardless of how much they carry infants (Fig. 6-2A, Fig. 6-2B). The same applies to the FCM levels of subadults (Fig. 6-2A, Fig. 6-2C). Furthermore, there is no difference between adult males and subadults, with respect to FCM levels in relation to carrying effort (Fig. 6-2A, Fig. 6-2D). 


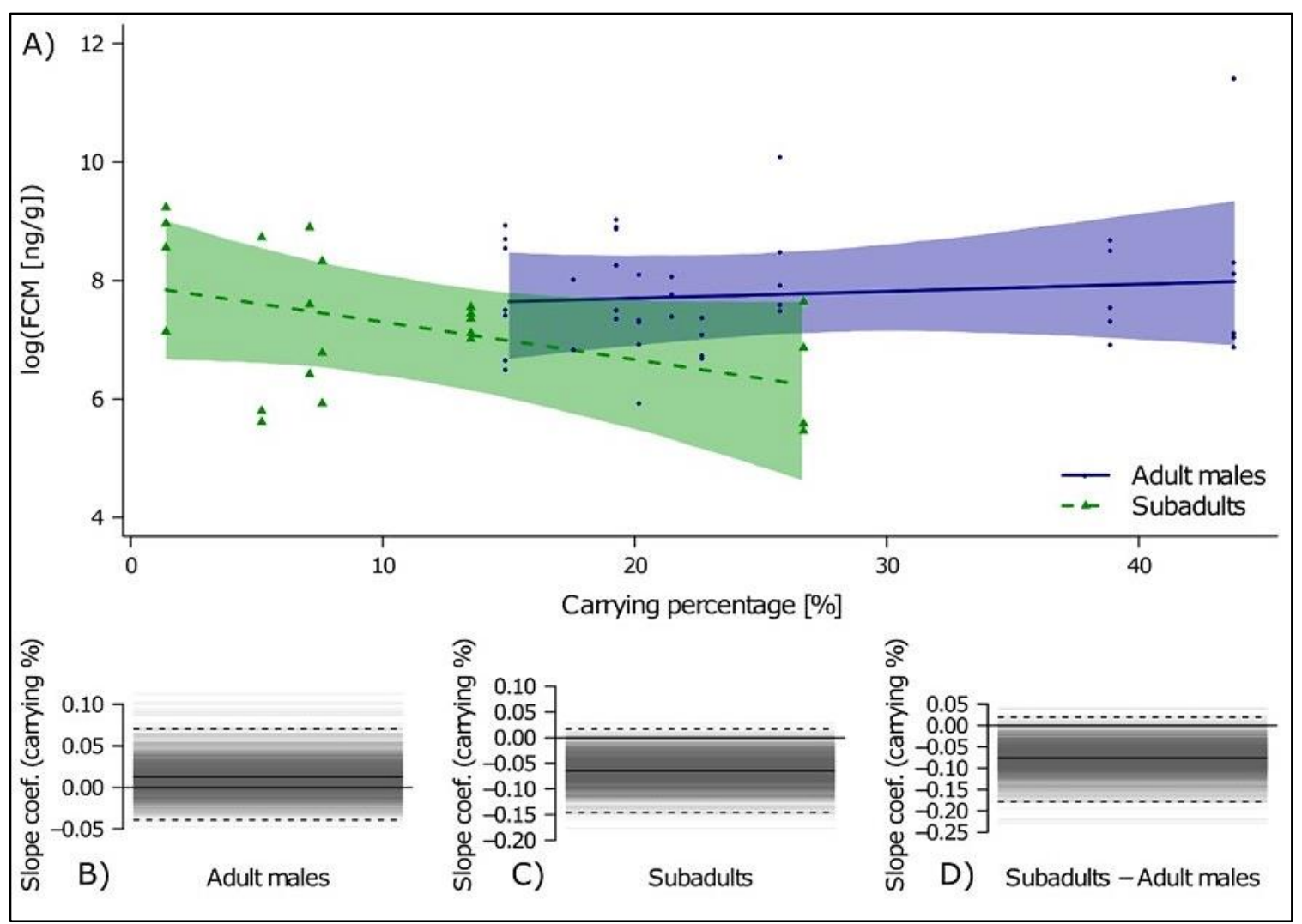

Fig. 6-2. Results of the Bayesian multilevel (mixed effects) regression model: logarithmic transformed FCM values of adult males and subadults, within infant carrying period in relation to individual carrying effort expressed as percentages. Above, A): Posterior distributions of logarithmic transformed FCM values of adult males (blue colored area) and sub-adults (green colored area) conditioned on percentages of the individual carrying contribution. Dots $(\bullet)$ and triangles $(\Delta)$ represent: truly observed values. Dots $(\bullet)$ and triangles $(\Delta)$ with the same score on the $x$-axis represent: repeated measurements, i.e. the same individual with different litters. When an individual carried more than one litter and we could collect at least the minimal amount of hormonal samples required for these specific carrying periods, this combination represents an additional dot or triangle vertical line. Therefore, although we base these analyses on 6 adult males, the vertical lines of dots are represented 9 times. And, for the 5 subadults the vertical lines of triangles are represented 6 times. Below: Slope coefficient of logarithmic transformed FCM values of B) adult males C) subadults D) subadults in relation to adult males, conditioned on percentages of the individual carrying contribution. Grey shaded lines ( ) represent: partial effects given by the original distribution of posterior samples. Bold lines (-) represent: posterior means of coefficients (effects). Dashed lines (----) represent: the boundaries of posterior credible intervals. When a longer bold line is out of dash line boundaries, this represents a statistically significant result.

\section{Discussion}

The aim of our study was to examine whether caring for infants is stressful in wild $L$. nigrifrons, i.e. is associated with increased stress hormone output in caretakers. Our study 
demonstrates that carrying, which represents a major part of infant care and has been shown to result in an energetic burden of the carrier (Sánchez et al. 1999, S. oedipus; Achenbach and Snowdon 2002, S. oedipus), does not influence glucocorticoid levels: FCM values, an indicator of glucocorticoid secretion, do not change according to carrying efforts in adult males nor subadults (Fig. 6-2). This suggests that carrying infants in callitrichids is not stressful in terms of increased glucocorticoid production. However, a link between infant care behavior and glucocorticoids might potentially still exist, but infants may buffer elevations in cortisol of caretakers in response to carrying costs. Our data nevertheless indicate that both adult males and subadults are influenced by the presence of infants, but with opposite effects. Within infant non-carrying periods we detected higher cortisol levels in adult males (Fig. 6-1D). Yet within infant carrying periods no clear difference between adult males and subadults exists (Fig. 6-1C). This implies that a change in cortisol levels in at least one of these two groups occurred. Indeed, we detected indications of changes in cortisol level, i.e. according to absolute FCM levels, during infant carrying period in both, but in opposite direction (Fig. 6-1A, Fig. 6-1B).

In captive S. oedipus carrying heavy infants inflicts costs in terms of loss of body mass especially in larger enclosures (Sánchez et al. 1999; Achenbach and Snowdon 2002; Morcillo et al. 2003). It is therefore conceivable that caretakers in wild callitrichid groups also lose body mass during carrying of infants, perhaps even more so, considering the efforts required for finding and travelling between food resources. Moreover, carrying impacts carriers' activities, particularly reducing time spent feeding and foraging for prey (Price 1992; Schradin and Anzenberger 2001a; Huck et al. 2004a; chapter 5). This creates a challenging and energetically demanding situation for caretakers which we predicted should induce an increase in cortisol output as a mean to compensate the heightened energetic demands. Our finding that FCM levels did not change in response to carrying effort is therefore surprising. We cannot entirely exclude, however, that carrying behavior in callitrichids may be associated to low levels of physiological stress rather than to highimpact stress, and it is not therefore associated with significant or prolonged elevations in cortisol output. If this is the case, assessing FCMs as an integrated measure of cortisol production may just not be sensitive enough to detect any mild and/or short-term cortisol response associated with carrying behavior in our study subjects. 
That said, however, all studies on the relationship between infant carrying and cortisol levels in callitrichids, including ours, agree that carrying is not associated with higher stress hormone output in the caretaker (Nunes et al. 2001, C. kuhlii; da Silva Mota et al. 2006, C. jacchus). Instead, FCM levels of adult males and subadults stay the same (Fig. 6-2) (see also da Silva Mota et al. 2006), or cortisol levels even decrease with more carrying activity by fathers (Nunes et al. 2001). The latter study demonstrates negative correlations between cortisol and carrying across all males. Two previous studies that examined cortisol output in wild adult male callitrichids did not focus directly on carrying behavior. Instead, one study presented FCM levels over the course of a year, including two groups and two new litters (Huck et al. 2005b, S. mystax), whereas the other study looked over the course of three years and included 24 adult males (Bales et al. 2006, L. rosalia). No significant seasonal variations in FCM levels were found despite covering two periods of infant carrying in the first study, and three mating periods compared to two infant care periods in the latter study. These combined findings suggest that the known costs associated with infant carrying, e.g. reduction in feeding time and body mass loss (see above), are not associated with significant elevations in glucocorticoid production and that therefore carrying is not stressful in terms of HPA axis activation. Overall, low cortisol concentrations in caretakers maybe indeed generally beneficial for offspring. There is increasing evidence from laboratory and wild vertebrates showing that small increases of cortisol have a positive effect on parental behavior, whereas large increases in cortisol concentrations in parents may impair parental behavior (Raulo and Dantzer 2018, review).

We suggest that infants may act as a stress buffer for their caretakers in callitrichids. It is known that a positively associated social partner may reduce glucocorticoid responses to stressors, so called "social buffering" (Hennessy et al. 2009, review). According to these authors it is well established that mammalian mothers buffer stress for infants, while the reverse - that infants may buffer the stress of caretakers - has been poorly studied. Rare evidence on infants buffering the stress response of their caretakers comes from guinea pigs (Ritchey and Hennessy 1987, Cavia porcellus) and squirrel monkeys (genus Saimiri, Mendoza et al. 1978; Wiener et al. 1987). Among callitrichids, contact of male C. kuhlii with infants during carrying has been proposed to dampen the physiological stress response of carriers, and to cause a decrease of cortisol levels with increasing carrying 
rates (Nunes et al. 2001). For C. jacchus, these effect of infants on carriers has been suggested for another hormone, prolactin (da Silva Mota and de Sousa 2000; da Silva Mota et al. 2006). Prolactin is broadly associated with parental care behavior in animals (Buntin 1996; Schradin and Anzenberger 1999; Koenig and Dickinson 2004). It is also suspected to counteract the potentially negative effects of high glucocorticoid levels on parental behavior because only when prolactin levels are low, high baseline glucocorticoids result in behavior of parents negative for offspring e.g. nest abandonment in Adelie Penguins (Spée et al. 2010, Pygoscelis adeliae), offspring abandonment (Groscolas and Robin 2001; Groscolas et al. 2008; Spée et al. 2010, 2011). As stated by Raulo and Dantzer (2018, rewiev) "prolactin could maintain the motivational effects of baseline GCs on parental behavior while at the same time reducing the probability that the individual enters an emergency life history stage (i.e., abandoning a nest)". Therefore, in order to retain high levels of parental care, either low cortisol concentrations or high prolactin concentrations should be maintained in a caretaker. Indeed, in common marmosets, in contrast to cortisol, prolactin levels are increased during infant carrying, depending on carrying duration and the number of infants being carried (da Silva Mota and de Sousa 2000; da Silva Mota et al. 2006). The authors argue that physical contact is needed for prolactin to change. Considering cortisol, some evidence show that the extent of infant carrying matters, suggesting that a combination of physical contact with the extent of infant handling is needed for cortisol levels to change (Nunes et al. 2001, male C. kuhlii). In contrast, both our study and the study on C. jacchus (da Silva Mota et al. 2006) demonstrate that cortisol levels do not change according to carrying effort, indicating that a physical contact alone or a mere infant presence is enough to buffer a physiological stress response to carrying.

There are, however, also other factors - previous parental or alloparental experience and male susceptibility to female reproductive condition - that had been suggested to affect the cortisol output in males (Nunes et al. 2001; Ziegler et al. 2004; da Silva Mota et al. 2006). In this study we were unable to "measure" these factors and their influence on cortisol output, but discuss their plausibility when we try to explain the differences and similarities of FCM levels between adult males and subadults in the following. 
One explanation for cortisol changes in captive callitrichids focuses on the period of one month prior to parturition and on parental or alloparental experience. In brief, within older offspring and adult males, only (or more) experienced fathers exhibit an increase in cortisol levels (Ziegler et al. 2004; da Silva Mota et al. 2006), an effect that disappears after parturition (da Silva Mota et al. 2006). Authors argue that the hormonal increase follows the hormonal change in pregnant females and thereby prepares males for their upcoming parenting role or also acts to reinforce affiliation between parents or alloparents. This contrast in cortisol levels between periods before and after parturition additionally speaks in favor of either infants having a role in influencing the cortisol levels in adult males, or the effect of female hormonal influences decreases after birth. Another study from captivity focused only on time after parturition and also noticed that cortisol levels in fathers decreased with parental experience, yet they still carry at a similar rate (Nunes et al. 2001). Experience seems to be the key element for adult males to respond to hormonal changes in females (Ziegler et al. 2004; da Silva Mota et al. 2006) and to reduce the stress response to infant carrying (Nunes et al. 2001). Subadults, however, may not be influenced by the hormonal changes in females, due to physical incapability, i.e. being physically sexually immature, or due to no or less alloparental experience. Therefore, subadults may also not reduce the stress response to infant carrying. Unfortunately, we cannot examine parental or alloparental experience since we lack the necessary information about how many litters each male or subadult had carried before the onset of our study and we have limited hormonal samples for one month before parturition.

However, our data suggest that maturity may play a role in callitrichid stress response, and thus, FCM levels. In comparison to subadults, we found that adult males exhibit higher FCM levels during the non-carrying period (Fig. 6-1D). This result suggests that subadults and adult males are subjected to different stressors or they respond differently to stressors. The first suggestion is less likely, because they both live under the same environmental circumstances. During carrying period, there are no more differences in FCM levels between adult males and subadults (Fig. 6-1C). This suggests that between the carrying and the non-carrying period, a change in FCM levels occurred in at least one of the two groups. According to absolute FCM levels, a change during the carrying periods occurred in both groups, in adult males a decrease and in subadults an increase (Fig. 6-1A, 
Fig. 6-1B). These changes, however, are non-significant. Still it implies that adult males and subadults may respond differently to infants: subadults, who usually carry less and have less caretaking experience (Goldizen 1987b; Huck et al. 2004a) to respond with a slight increase in cortisol output and adult males who generally carry more and are more experienced (Savage et al. 1996; Garber 1997; Yamamoto et al. 2009) to respond with a slight decrease in cortisol output. It seems unlikely that these results can be explained by mere differences in physical strength, because subadults already may have the size and appearance of adults (Yamamoto 1993). Moreover, a link between higher energetic costs and more carrying (Sánchez et al. 1999; Achenbach and Snowdon 2002), usually done by males (Savage et al. 1996; Garber 1997; Yamamoto et al. 2009) do not speak in favor of carrying being less demanding for adult males. Instead, it is more likely that if physical strength plays a role, it is in their investment in carrying.

In conclusion, there seems to be no simple relationship between infant care and glucocorticoid output in caretakers within the callitrichids. We show, that carrying itself does not directly influence cortisol levels of adult males and subadults, regardless of their carrying effort. We suggest that infants act as a "stress buffer" in the way that infant's physical contact or just their presence buffers the energetic costs of carrying that would otherwise lead to activation of the HPA axis and increased glucocorticoid output. Differences between adult males and subadults suggest that they are not exposed to the same stressors or that they respond differently to stressors. We suggest that sexual maturity in combination with parental or alloparental experience plays a role in the relationship between carrying and FCM output. Eventually this may lead adult males to be influenced more by infants. Potentially, infants can only act as effective stress buffers after their caretakers have gained parental or alloparental experience. 



\section{Chapter 7}

\section{General discussion}

The focus of this thesis was to study the mating systems and infant care of wild blackfronted tamarins (Leontocebus nigrifrons), by combining genetic, endocrinological and behavioral data. I aimed to understand why some individuals, especially adult males, contribute more to infant care than others, and how does infant care relate to mating systems. For this reason I tried to identify mating systems, I measured infant-directed behaviors, I tried to explain why some individuals - especially adult males, help more than others (chapter 4), I examined whether carrying incurs changes to activity budget (chapter 5), I investigated whether infant care is physiologically stressful (chapter 6). Due to two unexpected occurrences of multi-female breeding I focused less on examining general patterns of care behavior in chapter 4 and more on those specific circumstances and answered more theoretical questions: "in which litter to invest more and why, if there is a choice of more than one?" In the following, I divide the discussion into specific sections: in the first nine sections, I explain why I looked into specific questions, what the results were and what I suggest (pp 108 - 114), in the next four sections I put my findings into broader context of callitrichids (pp. 115 - 118) and other cooperative breeders (p. 121), and finally I critically evaluate the thesis and give recommendations for future studies ( $p$. 124). The overall focus of this general discussion is to provide plausible answers to the aim of this thesis specified above. 


\section{Major findings and their interpretation}

\section{Mating systems}

In line with the general understanding of callitrichids this thesis confirms the diversity and complexity of the mating systems of black-fronted tamarins. Definitions of mating systems focus on group and not on individual patterns (Goss-Custard et al. 1972; Rowell 1993; Kappeler and van Schaik 2002). Whereas this thesis shows that such definitions are not suitable for describing the mating systems of black-fronted tamarins (chapter 4), and according to general similarities of behavior among callitrichid this may apply to other callitrichid species too. I found that the parental dyads may include resident and nonresident individuals. Therefore, it is impossible to conclude on a genetic mating system within a group that would adequately describe a genetic situation in a group. Thus in this thesis, I refer to a genetic system from an individual perspective. On the contrary, I refer to a social system within a group, because copulations - which define the social system which I observed among adults were only within the group members. Still, because I found extra-group paternities, also extra-group copulations must occur, regardless whether I observed them or not.

Mating systems may reveal insight into species dynamics. In callitrichids, polyandry is considered the prevailing mating system (Goldizen 1988). I found no evidence of social polyandry, instead I found monogamy and promiscuity, within two groups. I found evidence of genetic polyandry for one female and indications (according to hints) for four more females. I suggest two more genetic systems: polygyny and monogamy. Thus I conclude, that in L. nigrifrons polyandry is not the prevailing social system, but it may be the prevailing genetic system. Still, due to incomplete data on parentage, the latter is impossible to confirm. In primate groups, social and genetic mating systems within a group may be incongruent (Kappeler and van Schaik 2002). I suggest the same for $L$. nigrifrons: e.g. social promiscuity in $\mathrm{Gr} 3$, yet genetic monogamy and polygyny within resident individuals, or social and genetic monogamy in Gr1, but one resident female (1f2) is without a social and genetic system within a group, yet she has litters. Furthermore, incongruent may also be the genetic system of individuals within a group and within a study population, e.g.: male $1 \mathrm{~m} 1$ and female $6 \mathrm{f} 2$ are monogamous within their resident 
groups, yet polygamous within the study population. According to hints, two more females $(5 f 1,3 f 1)$ may show the same pattern.

I suggest that mating systems in a group partly depend on the number of resident adults. For example, in this thesis one group consists of only one adult of each sex, therefore offers no other option but social monogamy (Gr5), nonetheless, the female may be genetically polyandrous within a population. The other group with social monogamy consists of one adult male and two breeding females (Gr1). Within this group is the breeding couple $(1 \mathrm{f} 1,1 \mathrm{~m} 1)$ not just mating but also breeding exclusively. Monogamous genetic system has so far been documented only in one wild callitrichid species (Huck et al. 2005a). This is likely due to overall lack of genetic data from the wild callitrichids which would require the parentage to belong to only one male and one female over several breeding periods (Garber et al. 2016). I have records of three consecutive litters of one female (1f1) sired by the same male (1m1) and therefore I consider that the most likely genetic system of that couple within a resident group is monogamous. More detailed descriptions are in the respective section in chapter 4 .

\section{Mating and paternity}

Despite polyandry being the prevailing callitrichid mating system (Goldizen 1988), rare genetic data on wild callitrichids show evidence of monopolization of paternities (Huck et al. 2005a, wild moustached tamarins, Saguinus mystax; Suárez 2007, red-bellied tamarins, Saguinus labiatus; Díaz-Muñoz 2011, wild Geoffroy's tamarin, Saguinus geoffroyi). Due to my incomplete parentage results I can neither confirm nor exclude monopolization of paternities over different sets of twins in the groups. Nevertheless, monopolization of paternities over different sets of twins in the groups seems rather unlikely, because either I found no matching copulations and parentage between a breeding female and male (Gr1, female $1 \mathrm{f} 2$ and male $1 \mathrm{~m} 1$ ), or hints point to one or more other sires (Gr1, Gr2, Gr3, Gr5), or I already determined more than one sire in a group (Gr3, Gr6). Instead, I found monopolization of paternities of one set of twins ( $\mathrm{Gr} 1$, litter 1c, father $1 \mathrm{~m} 1$ ). Callitrichid twins are dizygotic, which theoretically means that twins can be sired by two different males (summarized by Garber et al. 2016). Indeed, I found one twin litter with shared paternities ( $\mathrm{Gr} 6$, twins $6 \mathrm{j} 1$ and $6 \mathrm{j} 2$, fathers $6 \mathrm{~m} 1$ and $1 \mathrm{~m} 1$ ). Callitrichid territories often 
overlap with their neighbor's territories and groups regularly meet (Lledo-Ferrer et al. 2011, wild L. nigrifrons). I found two extra-group paternities (offspring 3 sa1 and 6j1) and indications of a few more, yet only one extra-group copulation (6m3 and 3sa2). More detailed descriptions are in the respective section in chapter 4 . I suggest that in callitrichids extra-group copulations are an important breeding strategy and should be included in interpretation of callitrichid mating systems.

\section{Offspring survival}

Typical twinning does not drastically increase callitrichid populations. In this thesis, five out of eight animals that disappeared were infants and the rest were adult males (see also Löttker et al. 2004a, S. mystax). Thus I suggest that in L. nigrifrons, the first few months are critical for offspring survival. In callitrichid groups, low numbers of adults, i.e. one male and one female, is rare (less than 10\%, 23 cases) and is associated with unsuccessful rearing of offspring (summarized by Garber et al. 2016, but see Windfelder 2000, wild emperor tamarin, S. imperator). I report on a second case from wild tamarins of only two adults successfully rearing offspring. In addition, our groups with higher numbers of adults were both successful and unsuccessful in rearing offspring. Also rare and associated with unsuccessful offspring survival is multi-female breeding (Goldizen et al. 1996; summarized by Garber et al. 2016). In this thesis, I found two out of five groups with multi-female breeding, and offspring survived and disappeared in both, single and multi-female breeding groups. Thus I suggest, that group composition, i.e. number of adults, as well as number of breeding females, does not guarantee L. nigrifrons' infant survival. In both multi-female breeding cases the infant disappearance happened while the secondary female was pregnant. I suggest, that these cases of unsuccessful breeding of young may be related to stress of simultaneous pregnancies (see also Hrdy 1979; Tirado Herrera et al. 2000). On the contrary, I also report on the positive side-effects of the multi-female pregnancies or breeding, i.e. allo-nursing. I have records of allo-nursing in one case of multi-female breeding $(\mathrm{Gr} 3)$, where both females nursed the first consecutive litters but the next consecutive litter was nursed only by its non-mother. The second case of allonursing comes from a single-female breeding group (Gr2), suggesting that a non-breeding 
female was pregnant, but did not result in a litter to care for. More detailed descriptions are in the respective section in chapter 4.

\section{General patterns of infant-directed behavior}

In accordance with general patterns of infant care in callitrichids (Savage et al. 1996; summarized by Garber 1997; Yamamoto et al. 2009), I also confirm that L. nigrifrons adults are the most important infant caretakers, more so for carrying than food transfer whereas for the latter subadults are important too. Food transfer is the most evenly distributed infant-directed behavior over age classes, provided even by juveniles, which implies food transfer to be less energetically demanding than carrying. In callitrichids, the main carriers are often adult males (Savage et al. 1996; summarized by Garber 1997; Yamamoto et al. 2009), which is regardless of paternity also true in this thesis. Adult males contribute up to $50 \%$ of group carrying, although in some cases they carry extremely little, below $5 \%$ (litter $1 \mathrm{cn}$ ). Other principle carriers in this thesis are the mothers, whereas non-mothers usually carry less or not at all. A mother's contribution is usually between $20-40 \%$, with extreme values around $10 \%$ and $80 \%$ (litter $3 \mathrm{cv}$ and litter $1 \mathrm{cn}$, respectively). Based on the two multi-female breeding cases (Gr1, Gr3) I suggest, that it is mostly the mother who compensates for the lack of carrying from adult males (see also Lappan 2008, wild siamang, Symphalangus syndactylus). In short, some males reduced their carrying contribution for the second consecutive litter, and carrying contribution of some other group members was increased, i.e. mostly by the litter's mother and less by subadults and juveniles. The carrying contributions of adult males and the mothers are in multi-female breeding cases more extreme in a group with one adult male (Gr1) than in a group with two adult males (Gr3). More detailed descriptions are in the respective section in chapter 4. These results show the importance for a mother to have adult male caretakers(s) and suggest that more caretakers help balance the carrying burden among the adults (see also Koenig 1995, wild Callithrix jacchus; Schradin and Anzenberger 2001b, Goeldi's monkey, Callimico goeldii). Moreover, to unburden a mother, I suggest that it's more than how many carriers, but also the cumulative carrying effort of adult males. 


\section{Paternity certainty}

High levels of paternity certainty are often associated with willingness of a male to bear costs of infant care (Trivers 1972), like in socially monogamous male owl monkeys (Wright 1984, owl monkeys, Aotus spp., titi monkeys, Callicebus spp.; Mendoza and Mason 1986), but can also be associated with relatively little investment in offspring, like in some singlemale groups (Bradley et al. 2005; Harcourt and Stewart 2007, mountain gorilas, Gorilla gorilla beringei). In contrast, promiscuous mating is expected to reduce paternity certainty, still, in several species of baboons and macaques, males often engage with infants, in terms of carrying, playing, cuddling and protecting (Smuts and Gubernick 1992). In the case of callitrichids it is suggested, that due to female polyandrous mating, male helpers help to increase their chance to reproduce (Huck et al. 2004c), indicating that a level of paternity certainty plays a role. Based on the two multi-female breeding cases in this thesis, I suggest that in L. nigrifrons adult males do adjust their helping contribution on their level of paternity certainty. In the case of one adult male in a group (Gr1) I recorded social monogamy with one female yet no social system with the other female, and therefore suggesting high and (low to) zero paternity certainty, accordingly. Male's help to the female's litter differed: was high (carrying was above 50\%) and low (carrying was below 5\%), accordingly. In the other multi-female breeding case with two adult males (Gr3), I found social promiscuity, suggesting intermedium paternity certainty for litters of both females. The males were the main carriers to the litters of both females, but in comparison to the male in Gr1, these two males from Gr3 helped with intermediate contribution. The same pattern: explained the connection between social systems, paternity certainty and male infant care contribution, is indicated also in one singlefemale breeding group (Gr2). Whereas the other single-female group (Gr5) raises a question, whether a socially monogamous male that is likely to share paternity with an extra-group male, helps less because he has information about extra-group copulations with his mate or he differentiates between whether the infant is his or not, posing a question of kin-recognition. The later seems unlikely - in callitrichids kin-recognition may not be evolutionary favored, due to high within-group relatedness, and thus a helper's inclusive fitness (Huck et al. 2005a, S. mystax; Cornwallis et al. 2009; Díaz-Muñoz 2011, 
wild S. geoffroyi; Garber et al. 2016). More detailed descriptions are in the respective section in chapter 4.

\section{Male's physical fatigue}

Changes in mobility, activity budget - especially lower feeding and foraging time, and body mass induced by infant care (Price 1992; Sánchez et al. 1999; Schradin and Anzenberger 2001a; Achenbach and Snowdon 2002; Huck et al. 2004a; Caperos et al. 2012; chapter 5) indicate that a physical fatigue should occur. Due to the two multi-female breeding cases $(\mathrm{Gr} 1, \mathrm{Gr} 3)$ in this thesis I suggest, that a male's help is based on his physical fatigue, i.e. when comparing male's helping contribution to first $(1 \mathrm{cv}, 3 \mathrm{cv})$ and second consecutive litters $(1 \mathrm{cn}, 3 \mathrm{cn}$ ), the latter litters received less help (from males $1 \mathrm{~m} 1,3 \mathrm{~m} 1$ ) or the same (from male 3m2). Moreover, when the second consecutive litter in Gr3 was born (3cn), both socially promiscuous males, continued carrying only this new, and thus lighter litter. In contrast, the male from Gr1 continued to mostly carry the old and thus heavier litter (1cv): this litter was sired by him, and within the resident group he was socially and genetically monogamous with litter's mother (1f1), which suggests high level of paternity certainty. But, the new, lighter and not his litter $(1 \mathrm{cn})$ from the other female with which he had no social system, he carried little and also often refused to carry. I suggest that in a case of high paternity certainty, like in Gr1, physical fatigue is of lesser importance. More detailed descriptions are in the respective section in chapter 4.

\section{Pay to copulate (carrying as a male courtship strategy)}

According to courtship strategy it would pay-off for a female to choose a mate who is a competent caretaker and males would adopt strategies to convince females they would be good caretakers (Price 1990), i.e. higher carrying effort. Callitrichid flexibility in mating systems, with the prevailing polyandry (Goldizen 1988), implies that males may adopt strategies which would increase their chances of paternity. In this thesis, male carrying investment did not correlate with the amount of copulations in any of the periods tested. Thus I found no evidence of carrying serving as a courtship strategy to gain more copulations (in contrast to Price 1990, captive C. jacchus; in agreement with Tardif and Bales 1997, captive C. jacchus and S. oedipus; Huck et al. 2004a, wild S. mystax). My results 
are similar to socially monogamous and polyandrous groups of wild siamang (Lappan 2008 S. syndacty/us). More detailed descriptions are in the respective section in chapter 4.

\section{Activity budget while carrying or not carrying infants}

Callitrichids are small bodied animals, whose daily activities consist of foraging for prey, feeding, locomotion, vigilance, socializing and resting. Presence of infants does not eliminate these activities, but the energetic costs of infant care (Sánchez et al. 1999; Achenbach and Snowdon 2002; Morcillo et al. 2003) and constraints on carrier's mobility while carrying (Schradin and Anzenberger 2001a; Caperos et al. 2012) imply that a shift in activity budget while carrying should occur. In this thesis I found that while carrying, carriers forage and eat less, but spend more time in vigilance. With less time feeding and foraging carriers are likely to have lower energy input. Although feeding time does not necessarily translate into amounts of ingested food (Zinner 1999) and could theoretically be compensated by increasing ingestion rates, it is hard to imagine a mechanism that would compensate for a decrease in prey foraging time. In callitrichids prey foraging requires good mobility skills, which impede carriers, e.g. decreased leaping (Schradin and Anzenberger 2001a; Caperos et al. 2012). Reduced mobility skills are also likely to results in increased time in vigilance and early detection of a predator may be a compromise to avoid situations where rapid escape would be needed. I suggest the following link: restricted carriers mobility (Schradin and Anzenberger 2001a; Caperos et al. 2012) causes activity budget to shift (Goldizen 1987b, Leontocebus weddelli; Price 1992, S. oedipus; Sánchez et al. 1999, S. oedipus; Huck et al. 2004a, S. mystax; chapter 5) and is likely to result in energetic costs of infant care - loss of body mass (Sánchez et al. 1999; Achenbach and Snowdon 2002; Morcillo et al. 2003). A more detailed interpretation is in chapter 5.

\section{Glucocorticoid response to infant care}

In callitrichids, the induced changes of infant care to their caretakers, e.g. loss of body mass, reduced mobility, shift in daily activities (Price 1992; Sánchez et al. 1999; Schradin and Anzenberger 2001a; Achenbach and Snowdon 2002; Huck et al. 2004a; Caperos et al. 2012; chapter 5) imply that infant care is physiologically stressful. Stress can be detected with a stress indicator, i.e. as in an increase in cortisol metabolite (Moberg and Mench 
2000). Thus I tested and compared fecal cortisol metabolite levels (FMC) in adult males, because they are often the main carriers (Savage et al. 1996; Garber 1997; Yamamoto et al. 2009), and in subadults, who carry less, but carrying can nonetheless be significant (Goldizen 1987b; Huck et al. 2004a). I compared their FMC levels between carrying and non-carrying periods, within the periods, and according to their carrying effort. Only within the non-carrying periods I found higher FMC levels in adult males than in subadult, whereas any other comparison yielded non-significant result. Overall, my data shows that infant care does not result in changes of fecal cortisol metabolite (FCM) levels. This suggests that infant care is not physiologically stressful, potentially due to infants acting as stress buffers. A more detailed interpretation is within the next part of this general discussion (A broader perspective, section 2), but most of all in chapter 6 .

\section{A broader perspective}

\section{Multi-female breeding}

Multi-female breeding is considered rare in callitrichids. Multi-female breeding was found in only 10 out of 288 wild groups of callitrichids, which corresponds to 5 out of 10 callitrichid taxa studied: S. geoffroyi, S. oedipus, S. mystax, L. weddelli and L. nigrifrons (Tirado Herrera et al. 2000; summarized by Garber et al. 2016). This thesis adds two groups $(\mathrm{Gr} 1, \mathrm{Gr} 3)$ to the list of observed multi-female breeding. All these cases include two females - if breeding or lactating or being pregnant. I suggest that a combination of high energetic costs of infant care (Sánchez et al. 1999; Achenbach and Snowdon 2002) and consequential physical fatigue (chapter 4), may be the limiting factor for the number of breeding females in callitrichids. If caring for only one litter can result in physical fatigue of males, and thus less carrying for the second consecutive litter, than a third, or even a fourth consecutive litter, could be helped very little by adult males - probably even under high level of paternity certainty. I showed that a lack of carrying by adult male's is compensated mostly by the mothers (chapter 4). Thus, more breeding females would result in a mother's increase of infant care investment and finally increased energetic costs. 
Another limiting factor to the number of breeding females may be stress related infanticide due to simultaneous pregnancies. In callitrichids, multi-female breeding often results in unsuccessful breeding of young (Goldizen et al. 1996). Offspring death might be due to infanticide by the mother, the primary breeding female (Tirado Herrera et al. 2000, wild L. nigrifrons). Suggested reasons for this infanticide in particular, is a parental manipulation: for an infant who had low chances of survival a mother may have decided to terminate parental investment, or female reproductive competition: stress related infanticide due to a simultaneous pregnancy of another female (Hrdy 1979; Tirado Herrera et al. 2000). This thesis has two parallels to the study of Tirado Herrera and co-workers (2000). First, litters from both secondary females survived (litter $1 \mathrm{cn}, 3 \mathrm{cn}$ ). Second, both primary females $(1 f 1,3 f 1)$ lost one of the twins $(1 \mathrm{cv} 2,3 \mathrm{cv} 3)$, while secondary females were still pregnant. I found no apparent reason why and how the two infants disappeared, yet an influence of another female pregnancy is a plausible explanation. If indeed simultaneous pregnancy imposes stress on mothers (Tirado Herrera et al. 2000) then multi-female breeding may not be favored in callitrichid groups.

Nonetheless, based on this thesis I suggest that multi-female breeding with two breeding females may be more common in wild callitrichids than is currently assumed. Within only 15 study months I confirmed multi-female breeding in two out of five groups. In one case I could confirm a secondary female giving birth twice. Due to observed allonursing, it is likely, that multi-female pregnancy occurred also in group Gr2. Still, allonursing can also result from pseudo-pregnancy, as is overall common in genus Canis and suggested for subordinates of cooperatively breeding Ethiopian wolf (Gobello et al. 2001; Kesteren et al. 2013, Canis simensis). Moreover, such a combination, i.e. allonursing and pseudopregnancy, is suggested to increase non-breeding subordinate inclusive fitness in cooperatively breeding dwarf mongooses, by improving the survial of related offspring (Creel et al. 1991, Halogale parvula). The second group with single-female breeding (Gr6), had two adult females and therefore a potential for two breeding females, but I observed this group for the least time - almost half the time than the other groups. Thus, if multifemale breeding existed, I might have missed it. The third group with single-female breeding (Gr5) consisted of a rare combination of only one adult male and one adult female (summarized by Garber et al. 2016), therefore offered no choice of multi-female 
breeding. Based on maternity and paternity data, this thesis shows that all adult females copulate, even if not within their resident group (females $1 f 2,5 f 2$ ). Taken together, callitrichids may copulate and breed when given a chance, but limiting factors may be the number of adult males needed to help with infant care, male willingness to help and mother's stress due to simultaneous pregnancies.

\section{Infant care and physiological stress}

My findings of fecal cortisol metabolite (FCM) levels suggest that infant care is not physiologically stressful (chapter 6). But, considering carrier's activity budget changes shown in this thesis (chapter 5) and in other studies (Price 1992, S. oedipus; Sánchez et al. 1999, S. oedipus; Schradin and Anzenberger 2001a, C. jacchus; Huck et al. 2004a, Saguinus mystax) as well as the high energetic costs of carrying (Sánchez et al. 1999; Achenbach and Snowdon 2002) this seems like an uncomplete explanation. Based on this thesis and other studies on carrying and/or cortisol in callitrichids - cortisol levels never increased, but stayed the same or decreased (Nunes et al. 2001, Callithrix kuhlii; Huck et al. 2005b, S. mystax; Bales et al. 2006, Leontopithecus rosalia; da Silva Mota et al. 2006, C. jacchus) - I suggest that in callitrichids infants may act as stress buffers. It is known that a positively associated social partner may reduce glucocorticoid responses to stressors, so called "social buffering" (Hennessy et al. 2009, review). Thus infants may balance out the energetic costs that would otherwise lead to a physiological stress response. This explanation agrees with the importance of maintaining low cortisol levels in vertebrate caretakers, because it increases the parental care, whereas high cortisol levels may result in negative behaviors of the parents towards the offspring (Raulo and Dantzer 2018, rewiev), e.g. nest abandonment in Adelie Penguins (Spée et al. 2010, Pygoscelis adeliae), offspring abandonment (Groscolas and Robin 2001; Groscolas et al. 2008; Spée et al. 2010, 2011). Rare evidence on infants buffering the stress response of their caretakers comes from guinea pigs (Ritchey and Hennessy 1987, Cavia porcellus) and squirrel monkeys (genus Saimiri, Mendoza et al. 1978; Wiener et al. 1987). Furthermore, based only on this thesis I cannot explain why there are differences and similarities between FCM levels of adult males and subadults. But taken together with other studies on cortisol and/or infant care in callitrichids (Nunes et al. 2001; Ziegler et al. 2004; da Silva Mota et al. 2006), I 
suggest that infants can only act as effective stress buffers when caretakers mature and gain parental or alloparental experience. In brief, prior to parturition within older offspring and adult males, only more experienced fathers exhibit a change (an increase) in cortisol levels (Ziegler et al. 2004; da Silva Mota et al. 2006), an effect that disappears after parturition (da Silva Mota et al. 2006). This is an indication of the importance of maturity and parental experience. Furthermore, after parturition, cortisol levels in fathers decreased with parental experience, yet they still carry at a similar rate (Nunes et al. 2001). Again, an indication of the importance of parental experience. A more detailed discussion is in chapter 6 .

\section{How do my findings connect?}

The focus of this section is to link my findings and to provide plausible answers to the aim of this thesis: why some individuals, especially adult males, contribute more to infant care than others, and how does infant care relate to mating systems.

What makes a group survive in the long run is the survival of its offspring. Callitrichid offspring are at the greatest risk of disappearance during the first few months of their life (Löttker et al. 2004a, S. mystax; chapter 4). Thus, callitrichid infants must be cared for intensively and they are, although unevenly by all group members (Epple 1975; Pryce 1988; Tardif et al. 1992; Huck et al. 2004a; chapter 4). I show that juveniles are the least important caretakers, subadults contribute more, especially for feeding the infants, and adults contribute the most. Within adults differences also exist: mothers and adult males, the latter regardless of paternity, carry more than non-mothers (chapter 4). The question arises: "Why the differences in infant care contribution?" I suggest that the answer is based on costs and benefits of infant care, which in females relate to whether she is a breeder of not, whereas in adult males to a social mating system of a mother - which influences the level of paternity certainty, and to a physical fatigue. However, the answer is not based on males using carrying as a courtship strategy, or influenced by a physiological stress, i.e. glucocorticoid levels. 
In callitrichids, carrying heavy infants impedes carrier movement, which is likely to affect activity budgets and result in high energetic costs (Price 1992; Sánchez et al. 1999; Schradin and Anzenberger 2001a; Achenbach and Snowdon 2002; Huck et al. 2004a; Caperos et al. 2012; chapter 5). Nonetheless, I show that infant care and carrying itself are not physiologically stressful, likely because infant's act as a stress buffer (chapter 6; see also Hennessy et al. 2009, review). Whether infant social buffering occurs or not, it may only prevent the physiological stress response of energetic costs, i.e. glucocorticoid increase and thus the negative behavior of the parents towards the offspring (see Raulo and Dantzer 2018, review), but not the energetic costs themselves. Thus a decision whether to invest in infant care, how to invest and how much is unlikely to be influenced by a stress factor. Nonetheless the decision is still essential and ultimately leads to differences in infant care contribution.

Due to breeder's direct fitness benefits we might expect breeders to help more than nonbreeding helpers (Cant 2012), which is in this thesis true for females but not for males (chapter 4; see also Huck et al. 2004a, S. mystax). Due to pregnancy and lactation, mothers already exhibit high energetic costs (Oftedal 1984; van Noordwijk 2012). Thus, mothers are likely to adopt strategies that would benefit them in decreasing the cost of infant care. Help from other group members, especially adult males, seems to be essential (chapter 4; see also Schradin and Anzenberger 2001b, C. goeldii): alongside the mothers, adult males are the main carriers and if males carry less, it is mostly the mother who compensates for his lack of carrying. Thus, if a mother is lacking help from an adult male, her energetic costs of infant care are likely to increase (chapter 4; see also Lappan 2008, S. syndactylus). The presence of a larger number of adult males increases females' direct fitness benefits (Koenig 1995, wild C. jacchus), but since one male can contribute more than two males combined (chapter 4), the reasons why adult males contribute to carry are extremely important.

Considering changes in mobility, activity budget and body mass loss induced by infant care (Price 1992; Sánchez et al. 1999; Schradin and Anzenberger 2001a; Achenbach and Snowdon 2002; Huck et al. 2004a; Caperos et al. 2012; chapter 5) and benefits of being a breeder (Cant 2012), it seem reasonable that males might try to obtain information about their paternity and use it to their advantage, i.e. help more if they are likely to be fathers 
(see also Muller and Emery Thompson 2012). Indeed, a social system may give males information about their paternity certainty level and they help accordingly (chapter 4). Moreover, high paternity certainty seems to influence the decision about infant care contribution even more than male's physical fatigue. On the contrary, if having no social system with a mother, indeed is the reason why a male may help less, than in addition to higher tolerance, i.e. less agonistic displays and aggression towards strangers when in small groups without helpers (Schaffner and French 1997, Callithrix kuhli), copulations copulating or not, might be a female strategy to recruit adult male caretakers (chapter 4). For males to help more, I show that the amount of copulations are not important, thus carrying is unlikely to be used as a male courtship strategy (in contrast to Price 1990; in agreement with Tardif and Bales 1997; Huck et al. 2004a).

Copulations may result in producing offspring. Shared paternity of a twin litter between a group and an extra-group male (chapter 4) suggests that consorting males who act as mate guards (Thornhill and Alcock 1983; Huck et al. 2004c, S. mystax; Lledo-Ferrer et al. 2010, L. nigrifrons), may not be entirely successful at restricting a female from copulating with other (group or extra-group) males while she is in her fertile period (see Löttker et al. 2004b, S. mystax). This may be due to males not sensing the exact timing of female fertile period, but rather the probability of ovulation. Thus, a female may mate with other males outside the consorting time, but still within her fertile period (Ziegler et al. 1993; Converse et al. 1995; Washabaugh and Snowdon 1998; Nunn 1999; Huck et al. 2004c, S. mystax). I recorded consorting twice (Gr2) - one male consorted with both group females, but did not sire any offspring. Monopolization of paternities for a single set of twins was found in a group with one male (Gr1), potentially due to lack of female mating opportunities within a group after consorting. Still, in another group with one adult male (Gr5) according to the hints, the litter's paternity is shared between a group and an extragroup male - this is only one of many indications in this thesis, that extra-group copulations are an important breeding strategy in callitrichids (chapter 4).

I found two types of social systems: monogamy and promiscuity. Considering the importance for a mother to have adult male caretakers which are highly involved with infant care, social promiscuity is likely to be more common than monogamy (chapter 4; see also Garber et al. 2016). I suggest that social monogamy may be mostly limited by the 
number of adults in the group, i.e. two, a combination that is rarely found in wild callitrichid groups. Moreover, many callitrichid traits such as multi-male and multi-female breeding per group, but also non-breeding adult females, and frequent migration, disagree with social and genetic monogamy to be a modal pattern (Garber et al. 2016). I found all the traits listed above, although with a slight modification: when there was more than one sire of the group's offspring, then only one sire was from the resident group. I suggest that the observed genetic systems of individuals are a result of these extremely complex relationships within the study population. I also suggest that in cases like this thesis - when a genetic system of an individual within a group may differ from within a population, genetic systems should be based on describing individual genetic patterns.

In conclusion, I suggest that $L$. nigrifrons mating systems and infant care are closely linked (see also Smiseth et al. 2012), and are not affected by a physiological stress of the latter, because there is none (chapter 6 ). Considering changes induced by infant care: in mobility, activity budget, body mass (Price 1992; Sánchez et al. 1999; Schradin and Anzenberger 2001a; Achenbach and Snowdon 2002; Huck et al. 2004a; Caperos et al. 2012; chapter 5) and a male's physical fatigue, but also a mother's need to have adult male caretakers (chapter 4), I suggest that it is in best interest of both, mothers and adult males, to have more caretakers, who can share and balance the infant care investment. This may help to explain overall low agonistic interactions between callitrichid males (Goldizen 1989; Caine 1993; Heymann 1996; Huck et al. 2004c), due to tolerance probably working in favor of recruiting helpers (Schaffner and French 1997). Finally, since mothers benefit more from adult male caretakers with above zero levels of paternity certainty, females would, when possible, prefer to mate with more than one male, resulting in various social and genetic systems.

\section{How do my findings relate to the understanding of cooperative breeders?}

The evolutionary conflict of cooperatively breeding helpers: helper's helping effort usually trades-off against helper's own residual reproduction, represents the greatest challenge in studying cooperative breeders, i.e. "why is altruistic behavior favored by natural selection or, why do non-breeding helpers help?" (Cant 2012). I suggest that in callitrichids 
this conflict may be less pronounced - based on two reasons. First, male helpers may not be sure of their non-breeding status. Females normally copulate with more than one male (Goldizen 1988; Huck et al. 2005a; Garber et al. 2016), thus males are unlikely to know whether they are a father or a non-breeding helper. Indeed, I show that carrying effort of fathers and helpers does not differ (chapter 4). Huck and co-workers (2004a) suggest, that males may help for a chance of their own reproduction - because the offspring they help, might be their own. Second, males may profit regardless of their breeding status. Callitrichids exhibit high within-group relatedness (Huck et al. 2005a, S. mystax; DíazMuñoz 2011, wild S. geoffroyi; Garber et al. 2016; see also Erb and Porter 2017), thus in terms of inclusive fitness benefits, a male helper might benefit even as a non-breeding helper. Nonetheless I show that due to a level of paternity certainty and therefore a chance for a direct fitness benefit, males help more or less (chapter 4). Taken together, I suggest that help from callitrichid caretakers is likely to be more about potential benefits than altruism. I suggest that in cooperative breeders with similar social and genetic structure to callitrichids - polyandrous or promiscuous mating, high within-group relatedness - the conflict of whether an individual helps or not will be less pronounced. Given that the great majority of cooperative breeders exhibit groups of genetic relatives (Cant 2012), e.g. paper wasps, pied kingfishers, Australian bell miners, white fronted beeeaters, dwarf mongooses etc. (summarized by Griffin and West 2003; Cornwallis et al. 2009; Leadbeater et al. 2010), this explanation may be plausible for many of them.

One of the well-studied cooperative breeders that holds many similarities to callitrichids, including my own findings on L. nigrifrons, are mongooses or meerkats (Suricata suricatta). Meerkats are desert-adapted mammals, living in groups of 3 to 25 individuals, typically including a dominant couple and a number of helpers of both sexes. A dominant female is responsible for a vast majority of the breeding attempt, and a dominant male sires most of the groups offspring and helpers (summarized by Clutton-Brock et al. 2000). After birth, two or more helpers "babysit" the infants - helpers stay at the natal burrow for the first three weeks, usually for the whole day and often do not eat, while the rest of the group forage. Thus like in this study of $L$. nigrifrons and in other callitrichids, meerkat caretaker's activity budgets changes - babysitters forage and feed less (Goldizen 1987b, L. weddelli; Price 1992, S. oedipus; Clutton-Brock et al. 1998, S. suricatta; Sánchez et al. 
1999, S. oedipus; Huck et al. 2004a, S. mystax; chapter 5). Additional parallels between callitrichids and meerkats are: energetic costs of caretakers, i.e. loss of body mass up to 11\% (Clutton-Brock et al. 1998; Sánchez et al. 1999; Achenbach and Snowdon 2002), infant care is unequally provided by caretakers and more helpers (caretakers) lower the individual investment (Epple 1975; Pryce 1988; Goldizen 1989; Tardif et al. 1992; CluttonBrock et al. 2000; Huck et al. 2004a; chapter 4). Moreover, more meerkat helpers reduce the maternal care costs: higher maternal body mass at conception of the following litter (Russell et al. 2003, S. suricatta) - this may be equivalent to my findings of the mother's compensation of the lack of carrying by males, for which I suggest that it is likely to result in increased maternal energetic costs. In addition to age and sex, the contribution of meerkat helper's depend on the helper's weight: heavier helpers of both sexes contribute more (Clutton-Brock et al. 2000, S. suricatta). This may be equivalent to my findings of physical fatigue, because I suggest its association with body mass loss and less carrying, and to a similar suggestion in another cooperative breeders - white fronted bee-eater: helper's physical condition may affect its infant care contribution (Emlen and Wrege 1988, Merops bullockoides).

Another callitrichid parallel with meerkats is based on copulations: extra-group copulations may be an important breeding strategy (Young et al. 2007, wild S. suricatta; chapter 4). In meerkats, extra-group copulations may be an alternative reproductive tactics for subordinate males: the majority of subordinate's offspring are due to extragroup paternities. This enables subordinates to breed without dispersal and to reduce their age at first reproduction. Extra-group copulations occur during males subordinate "extraterritorial forays", which occur during peak periods of female fertility and often results in extra-group paternities (Young et al. 2007, wild Suricata suricatta). These forays may be equivalent to occasional separations of L. nigrifrons, two or more animals together, from the resident group, for hours or even days (Slana, personal observation). In addition, callitrichid groups have regular intergroup encounters, they are an opportunity to exchange information via scent. Encounters can be aggressive as males often try to restrain group females from intergroup interactions, still extra-group copulations may occur (Hubrecht 1985, wild C. jacchus; Digby 1999, wild C. jacchus; Huck et al. 2005a, wild S. mystax; Lledo-Ferrer et al. 2011, wild L. nigrifrons). For males, 
especially those less successful at copulating with breeding females, extra-group copulations with conception present an alternative and low-cost strategy to reproduce (Birkhead and Parker 1997). This appears to be similar to subordinate males to copulate more in concealment, whereas the most dominant males mate in the open (Altmann 1962, rhesus monkey Macaca mulatta). For a breeding female extra-group copulations may present a greater mate choice (Birkhead and Parker 1997), especially if her copulating opportunities in the group are restricted. This may be the case for the secondary breeding female (Gr1, female 1f2): she never copulated within the resident group, yet had two litters, whose father is hinted to be an extra-group male.

Similar to this thesis, monopolization of paternities within a group was also not found in cooperatively breeding banded mongooses (Nichols et al. 2010, Mungos mungo). Authors explain, that females of banded mongooses typically synchronize the timing of oestrus, thus it is impossible for one male to mate-guard all group females. Males are divided into guarding and non-guarding males. Although guarding males reproduce more - especially due to older males who guard older and higher quality females, non-guarding males copulate with females when females evade their mate-guards. In contrast to callitrichids, where one male mate-guards one female, and a consorted female does not appear to try to evade her mate-guard (Lledo-Ferrer et al. 2010; Slana, personal observation). Although I also suggest a link between mate-guarding and limited monopolization, I suggest that it may be due to males not knowing the exact timing of breeding period (see explanation in section How do my findings connect?, p. 118).

\section{Strengths and limitations of this thesis, and future recommendations}

A limitation, that then became a strength of this thesis, was having both, single- and multifemale groups (chapter 4). I focused less on examining general patterns of infant care since each group was a representation of different combinations, e.g. number of adults, copulations, parentage and individual infant care investment. Thus most of my conclusions are based on describing individual cases, how they differ from other individual cases, and describing the potential links between the cases. At the same time, this 
embodies the strength of this thesis. Exactly because of the uniqueness of individual cases I could suggest answers, to more theoretical questions based on, in which litter to invest more and why, if there is a choice of more than one. On the contrary, when investigating activity budgets while carrying, the strength of this thesis is the sample size (chapter 5). Other studies from the wild gathered less data - from less groups and individuals, and during less carrying periods (see Goldizen 1987b; Huck et al. 2004a). An additional strength of this thesis is that I included more daily activities - also vigilance, and that I kept the daily activities separate, i.e. not clustering the foraging with feeding (see Goldizen 1987b; Huck et al. 2004a), which enabled me to discuss the specific changes more precisely.

A notable limitation of this thesis is incomplete genetic analyses (chapter 4). Unfortunately I could assign only a few paternities, which limited my possibilities of unveiling genetic systems and other explanations based on the genetic information. Nonetheless, already the limited genetic information revealed that descriptions of $L$. nigrifrons genetic systems cannot be limited to within the group and that there are big differences among the groups. This thesis is already the second study that tried to analyze nuclear DNA of L. nigrifrons using microsatellite primers (see Lledo Ferrer 2010). The analyses in this thesis failed only partly, whereas in the other study the analyses failed completely - at a stage of DNA amplification. In this thesis the problem was noted within the last steps of analyses - assigning the genotypes: DNA peaks were often inconsistent between different samples of the same individual. As stated by Lledo Ferrer (2010) many of the primers, that were already used for S. mystax (see Huck et al. 2005a) could not be adapted for $L$. nigrifrons. One difference between these two callitrichid species is that $L$. nigrifrons eat more gum (Peres 1993a), and certain types of gum have inhibitory effects on PCR amplification (Demeke and Adams 1992). Future studies may consider developing primers specifically for L. nigrifrons or using different types of genetic analyses, like sequencing methods (see Mardis 2008).

This thesis revealed that infant care is not associated with an increase of FCM, and thus I suggest that infant care is not physiologically stressful (chapter 6 ). However, if infant care is associated with low levels of physiological stress, assessing FCMs as an integrated measure of cortisol may not be sensitive enough to detect small and/or short-term 
endocrine changes. Since hormones in feces represent an integrative measure of pooled endocrine activity over several hours or days, measurements are less sensitive in comparison to urine and blood hormone analysis (Heistermann 2010). Thus, if the future studies from wild populations would use urine or blood samples, and would find results similar to ours, this would reinforce my suggestion that infant care does not cause physiological stress. However, an invasive method of taking repeated blood samples in wild group animals, is likely to negate the trust between observers and study animals, increase the momentary stress level of animals, and thus lowering the power of conclusion of what is influencing the glucocorticoid level. There are cases of taking urines samples from wild primates, e.g. chimpanzees (Muller and Wrangham 2004b, a), but it is hard to imagine how this could be achieved with small callitrichids, that are often high in the canopy. However, the three captive studies relevant to the topic of glucocorticoids and infant care in callitrichids, did use blood or urine samples and alike to this thesis, found no cortisol increase (see Nunes et al. 2001; Ziegler et al. 2004; da Silva Mota et al. 2006). Although more sensitive methods for measuring physiological stress (Heistermann 2010) are easily obtained in captivity, captive conditions are generally less challenging and cortisol increases may be less pronounced (Smith et al. 2012, Marmota flaviventris). Furthermore, in captive conditions samples can be taken regularly and in a controlled manner, whereas in wild populations, many fecal samples cannot be found or are contaminated. In wild studies, like this one, this may result in scarce and dispersed hormonal samples (chapter 6), which lowers the ability to "measure" hormonal levels within a potentially desired very narrow time window, e.g. days around parturition (see da Silva Mota et al. 2006). In addition, wild studies, like this one, often have none or only limited information about an individual's past experience, e.g. parental experience, which may be clearly known for captive animals (see Ziegler et al. 2004; da Silva Mota et al. 2006). I suggest that conclusions on the topic of hormones in callitrichids should be based on combining both, the studies from captivity and the wild (detailed discussion in chapter 6).

Last but not least, the overall limitation of a study in the wild is inability to observe and collect data all the time. Due to extra-group paternities I show that in L. nigrifrons extragroup copulations occur more frequently than I actually observed them (chapter 4). 
Ideally, to completely uncover the complex social systems within the population of neighboring callitrichid groups, researchers should document all copulations of each sexually active individuals over a longer period of time. Still, for callitrichid primates that are often difficult to detect for researchers - due to small size, height in canopy, crossing a river over a canopy - it is hard to imagine a better suitable non-invasive method than used in this thesis. 



\section{Chapter 8}

\section{Conclusions}

Activity budget shifts are possibly related to restricted mobility while carrying infants, which is likely to contribute to behavioral modifications of predator avoidance strategies. Furthermore, these activity budget shifts are likely to result in energetic costs in carriers, and must be compensated by both indirect and direct fitness benefits.

Infant care is not physiologically stressful, possible due to infants acting as stress buffers: infants may balance out the energetic costs that would otherwise lead to a physiological stress response. Possibly, infants can only act as effective stress buffers when caretakers are more mature with parental or alloparental experience.

Infant care contribution is possibly based on individual energetic costs and direct or indirect fitness benefits. Adult females are likely to base their contribution on whether they are a breeder or not. Adult males are likely to base their contribution on their physical fatigue, but most of all on a level of paternity certainty, which is likely to depend on the social mating system of the mother - whether she copulates with that male and with other males.

Mother's compensate for a lack of carrying by male's which suggests mother's need to have adult male caretakers. Adult male's physical fatigue due to carrying, also suggests adult male's need to have additional adult male caretakers. Combined, this may relate to females copulating with more than one male, because copulations - not the amount but copulating or not, is likely to affect a male's infant care investment. Whereas in males, this may relate to being tolerant of females copulating with other males. 
Callitrichids may copulate and breed when given a chance, but occurrence of multi-female breeding may be limited by the number of adult males needed to help with infant care, male willingness to help and mother's stress due to simultaneous pregnancies.

Extra-group copulations are likely to be an important breeding strategy, for both, males and females. It is plausible, that female extra-group copulation occur partly because of consorting males cannot sense the exact timing of the female fertile phase. Moreover this may be related to shared paternities of twin litters and to limited monopolization of paternities.

Taken together, there is a link between infant care and mating systems. These complex relations are likely to relate to monogamy not being a modal mating system in callitrichids. Finally, callitrichid mating system definitions cannot be limited to within a group description, but should be based on a description of an individual's mating system or within a population. 


\section{References}

Achenbach GG, Snowdon CT (2002) Cost of caregiving: weight loss in captive adult male cotton-top tamarins following the birth of infants. Int J Primatol 23:179-189

Alberts SC, Altmann J, Wilson ML (1996) Mate guarding constrains foraging activity of male baboons. Anim Behav 51:1269-1277

Altmann SA (1962) A field study of the sociobiology of rhesus monkeys, Macaca mulatta. Ann New York Acad Sci 102:338-435

Baker AJ, Dietz JM, Kleiman DG (1993) Behavioural evidence for monopolization of paternity in multi-male groups of golden lion tamarins. Anim Behav 46:1091-1103

Bales KL, French JA, McWilliams J, et al (2006) Effects of social status, age, and season on androgen and cortisol levels in wild male golden lion tamarins (Leontopithecus rosalia). Horm Behav 49:88-95

Belitz C, Brezger A, Klein N, et al (2015a) BayesX - software for Bayesian inference in structured additive regression models. Version 3.0.2. http://www.bayesx.org

Belitz C, Brezger A, Klein N, et al (2015b) BayesX - software for Bayesian inference in structured additive regression models. Version 3.0.2, methodology manual

Birkhead T, Parker G (1997) Sperm competition and mating systems. In: Krebs J, Davies N (eds) Behavioral ecology: an evolutionary approach, 4th edn. Blackwell Scientific, Oxford, pp 121-148

Böhle UR, Zischler H (2002) Polymorphic microsatellite loci for the mustached tamarin (Saguinus mystax) and their cross-species amplification in other New World monkeys. Mol Ecol Resour 2:1-3 
Bradley B, Robbins M, Williamson E, et al (2005) Mountain gorilla tug-of-war: silverbacks have limited control over reproduction in multimale groups. Proc Natl Acad Sci 102:9418-9423

Brent LJN, Semple S, Dubuc C, et al (2011) Social capital and physiological stress levels in free-ranging adult female rhesus macaques. Physiol Behav 102:76-83

Buntin JD (1996) Neural and hormonal control of parental behavior in birds. Adv Study Behav 25:161-213

Bürkner P-C (2017) brms : an R package for Bayesian multilevel models using Stan. J Stat Softw 80:1-28

Caine NG (1984) Visual scanning by tamarins - a description of the behavior and tests of two derived hypotheses. Folia Primatol 43:59-67

Caine NG (1986) Visual monitoring of threatening objects by captive tamarins (Saguinus labiatus). Am J Primatol 10:1-8

Caine NG (1987) Vigilance, vocalizations, and cryptic behavior at retirement in captive groups of red-bellied tamarins (Saguinus labiatus). Am J Primatol 12:241-250

Caine NG (1993) Flexibility and co-operation as unifying themes in Saguinus social organization and behaviour: the role of predation pressures. In: Rylands $A B$ (ed) Marmosets and tamarins systematics, behaviour, and ecology. Oxford Science Publications, Oxford, pp 200-219

Cant MA (2012) Cooperative breeding systems. In: Royle NJ, Smiseth PT, Koelliker M (eds) The evolution of parental care. Oxford University Press, Oxford, pp 206-225

Caperos JM, Morcillo A, Peláez F, et al (2012) The effect of infant body mass on carrier travel speed in cotton-top tamarins (Saguinus oedipus). Int J Primatol 33:447-459

Carnegie SD, Fedigan LM, Ziegler TE (2011) Social and environmental factors affecting fecal glucocorticoids in wild, female white-faced capuchins (cebus capucinus). Am J Primatol 73:861-869 


\section{References}

Carpenter B, Gelman A, Hoffman M, et al (2017) Stan: a probabilistic programming language. J Stat Softw 76:1-32

Cavigelli SA (1999) Behavioural patterns associated with faecal cortisol levels in freeranging female ring-tailed lemurs, Lemur catta. Anim Behav 57:935-944

Cleveland J, Snowdon CT (1984) Social development during the first twenty weeks in the cotton-top tamarin (Saguinus o. oedipus). Anim Behav 32:432-444

Climate-data.org (2018) Climate graph / weather by month Tamshiyacu. https://en.climate-data.org/south-america/peru/loreto/tamshiyacu295178/\#climate-graph. Accessed 5 Dec 2018

Clutton-Brock TH (1991) The evolution of parental care. Princeton University Press, Princeton

Clutton-Brock TH, Brotherton PNM, O'Riain MJ, et al (2000) Individual contributions to babysitting in a cooperative mongoose, Suricata suricatta. Proc R Soc B 267:301-305

Clutton-Brock TH, Brotherton PNM, O'Riain MJ, et al (2001) Contributions to cooperative rearing in meerkats. Anim Behav 61:705-710

Clutton-Brock TH, Gaynor D, Kansky R, et al (1998) Costs of cooperative behaviour in suricates (Suricata suricatta). Proc R Soc B 265:185-190

Coates A, Poole TB (1983) The behavior of the callitrichid monkey, Saguinus labiatus labiatus, in the laboratory. Int J Primatol 4:339-371

Converse LL, Carlson AA, Ziegler TE, et al (1995) Communication of ovulatory state to mates by female pygmy marmosets, Cebuella pygmaea. Anim Behav 49:615-621

Cornwallis CK, West SA, Griffin AS (2009) Routes to indirect fitness in cooperatively breeding vertebrates: kin discrimination and limited dispersal. J Evol Biol 22:24452457

Creel S, Monfort SL, Wildt DE, et al (1991) Spontaneous lactation is an adaptive result of pseudopregnancy. Nature 351:660-662 
Crozier RH (1986) Genetic clonal recognition abilities in marine invertebrates. Evolution 40:1100-1101

Culot L, Lledo-Ferrer Y, Hoelscher O, et al (2011) Reproductive failure, possible maternal infanticide, and cannibalism in wild moustached tamarins, Saguinus. Primates 52:179-186

da Silva Mota MT, de Sousa MBC (2000) Prolactin levels of fathers and helpers related to alloparental care in common marmosets, Callithrix jacchus. Folia Primatol 71:22-26

da Silva Mota MT, Franci CR, de Sousa MBC (2006) Hormonal changes related to paternal and alloparental care in common marmosets (Callithrix jacchus). Horm Behav 49:293-302

Demeke T, Adams R (1992) The effects of plant polysaccharides and buffer additives on PCR. Biotechniques 12:332-334

Díaz-Muñoz SL (2011) Paternity and relatedness in a polyandrous nonhuman primate: testing adaptive hypotheses of male reproductive cooperation. Anim Behav 82:563571

Dickinson JL, Hatchwell BJ (2004) Fitness consequences of helping. In: Koenig WD, Dickinson JL (eds) Ecology and evolution of cooperative breeding in birds. Cambridge University Press, Cambridge, pp 48-66

Digby L (1995) Infant care, infanticide, and female reproductive strategies in polygynous groups of common marmosets (Callithrix jacchus). Behav Ecol Sociobiol 37:51-61

Digby L, Saltzman W (2009) Balancing cooperation and competition in callitrichid primates: examining the relative risk of infanticide across species. In: Ford SM, Porter LM, Davis LC (eds) The smallest anthropoids: the marmoset/callimico radiation. Springer, New York, pp 135-153

Digby LJ (1999) Sexual behavior and extragroup copulations in a wild population of common marmosets (Callithrix jacchus). Folia Primatol 70:136-145 


\section{References}

Emlen ST, Wrege PH (1988) The role of kinship in helping decisions among white-fronted bee-eaters. Behav Ecol Sociobiol 23:305-315

Emmons LH (1987) Comparative feeding ecology of felids in a neotropical rainforest. Behav Ecol Sociobiol 20:271-283

Epple G (1975) Parental behavior in Saguinus fuscicollis ssp. (Callithricidae). Folia Primatol 24:221-238

Epple G, Katz Y (1980) Social influences on first reproductive success and related behaviors in the saddle-back tamarin (Saguinus fuscicollis, Callitrichidae). Int J Primatol 1:171183

Erb WM, Porter LM (2017) Mother's little helpers: what we know (and don't know) about cooperative infant care in callitrichines. Evol Anthropol Issues, News, Rev 26:25-37

Fahrmeir L, Kneib T, Lang S, et al (2013) Regression: models, methods and applications. Springer, Berlin

Ferkin MH, Pierce AA (2007) Perspectives on over-marking: is it good to be on top? J Ethol 25:107-116

Ferreira Raminelli JL, de Sousa MBC, Sousa Cunha M, et al (2001) Morning and afternoon patterns of fecal cortisol excretion among reproductive and non-reproductive male and female common marmosets, Callithrix jacchus. Biol Rhythm Res 32:159-167

Fox CW, Czesak ME (2000) Evolutionary ecology of progeny size in arthropods. Annu Rev Entomol 45:341-369

Ganswindt A, Muenscher S, Henley M, et al (2010) Endocrine correlates of musth and the impact of ecological and social factors in free-ranging African elephants (Loxodonta africana). Horm Behav 57:506-514

Garber PA (1988) Diet, foraging patterns, and resource defense in a mixed species troop of Saguinus mystax and Saguinus fuscicollis in Amazonian Peru. Behaviour 105:1834 
Garber PA (1991) A comparative study of positional behavior in three species of tamarin monkeys. Primates 32:219-230

Garber PA (1993) Feeding ecology and behavior of the genus Saguinus. In: Rylands AB (ed) Marmosets and tamarins. Systematics, behavior and ecology. Oxford University Press, Oxford, pp 273-295

Garber PA (1997) One for all and breeding for one: cooperation and competition as a tamarin reproductive strategy. Evol Anthropol 5:187-199

Garber PA, Encarnación F, Moya L, et al (1993) Demographic and reproductive patterns in moustached tamarin monkeys (Saguinus mystax): implications for reconstructing platyrrhine mating systems. Am J Primatol 29:235-254

Garber PA, Porter LM, Spross J, et al (2016) Tamarins: insights into monogamous and nonmonogamous single female social and breeding systems. Am J Primatol 78:298-314

Gelman A (2006) Prior distributions for variance parameters in hierarchical models (comment on article by Browne and Draper). Bayesian Anal 1:515-533

Gobello C, de la Sota RL, Goya RG (2001) A review of canine pseudocyesis. Reprod Domest Anim 36:283-288

Goldizen AW (1987a) Tamarins and marmosets: communal care of offspring. In: Smuts BB, Cheney DL, Seyfarth RM, et al. (eds) Primate societies. University of Chicago Press, Chicago, pp 34-43

Goldizen AW (1989) Social relationships in a cooperatively polyandrous group of tamarins (Saguinus fuscicollis). Behav Ecol Sociobiol 24:79-89

Goldizen AW (1987b) Facultative polyandry and the role of infant-carrying in wild saddleback tamarins (Saguinus fuscicollis). Behav Ecol Sociobiol 20:99-109

Goldizen AW (1988) Tamarin and marmoset mating systems: unusual flexibility. Trends Ecol Evol 3:36-40 


\section{References}

Goldizen AW, Mendelson J, van Vlaardingen M, et al (1996) Saddle-back tamarin (Saguinus fuscicollis) reproductive strategies: evidence from a thirteen-year study of a marked population. Am J Primatol 83:57-83

Goldizen AW, Terborgh J (1989) Demography and dispersal patterns of a tamarin population: possible causes of delayed breeding. Am Nat 134:208-224

Goss-Custard JD, Dunbar RI., Aldrich-Blake FPG (1972) Survival, mating and rearing strategies in the evolution of primate social structure. Folia Primatol 17:1-19

Griffin AS, West SA (2003) Kin discrimination and the benefit of helping in cooperatively breeding vertebrates. Science 302:634-636

Groscolas R, Lacroix A, Robin JP (2008) Spontaneous egg or chick abandonment in energydepleted king penguins: a role for corticosterone and prolactin? Horm Behav 53:5160

Groscolas R, Robin J-P (2001) Long-term fasting and re-feeding in penguins. Comp Biochem Physiol A 128:643-653

Hamilton WD (1964) The genetical evolution of social behaviour. II. J Theor Biol 7:17-52

Harcourt AH, Stewart KJ (2007) Gorilla society: conflict, compromise, and cooperation between the sexes. The University of Chicago Press, Chicago

Hatchwell BJ (2009) The evolution of cooperative breeding in birds: kinship, dispersal and life history. Philos Trans R Soc B Biol Sci 364:3217-3227

Heinsohn R, Cockburn A (1994) Helping is costly to young birds in cooperatively breeding white-winged choughs. Proc R Soc B 256:293-298

Heistermann M (2010) Non-invasive monitoring of endocrine status in laboratory primates: methods, guidelines and applications. Adv Sci Res 5:1-9

Heistermann M, Palme R, Ganswindt A (2006) Comparison of different enzymeimmunoassays for assessment of adrenocortical activity in primates based on fecal analysis. Am J Primatol 68:257-273 
Heistermannn M, Hodges JK (1995) Endocrine monitoring of the ovarian cycle and pregnancy in the saddle-back tamarin (Saguinus fuscicollis) by measurement of steroid conjugates in urine. Am J Primatol 35:117-127

Hennessy MB, Kaiser S, Sachser N (2009) Social buffering of the stress response: diversity, mechanisms, and functions. Front Neuroendocrinol 30:470-482

Hershkovitz P (1977) Living New World monkeys (Platyrrhini). With an introduction to primates. The University of Chicago Press, Chicago

Heymann E (1987) A field observation of predation on a moustached tamarin (Saguinus mystax) by an anaconda. Int J Primatol 8:193-195

Heymann EW (1990a) Reactions of wild tamarins, Saguinus mystax and Saguinus fuscicollis to avian predators. Int J Primatol 11:327-337

Heymann EW (2001) Interspecific variation of scent-marking behaviour in wild tamarins, Sanguinus mystax and Sanguinus fuscicollis. Folia Primatol 72:253-267

Heymann EW (1990b) Social behaviour and infant carrying in a group of moustached tamarins, Saguinus mystax (Primates: Platyrrhini: Callitrichidae), on Padre Isla, Peruvian Amazonia. Primates 31:183-196

Heymann EW (1996) Social Behavior of Wild Moustached Tamarins, Saguinus mystax, at the Estación Biológica Quebrada Blanco, Peruvian Amazonia. Am J Primatol 38:101113

Heymann EW (1995) Sleeping habitats of tamarins, Saguinus mystax and Saguinus fuscicollis (Mammalia; Primates; Callitrichidae), in north-eastern Peru. J Zool 237:211-226

Heymann EW, Buchanan-Smith HM (2000) The behavioural ecology of mixed-species troops of callitrichine primates. Biol Rev 75:169-190

Hrdy SB (1979) Infanticide among animals: a review, classification, and examination of the implications for the reproductive strategies of females. Ethol Sociobiol 1:13-40 


\section{References}

Hubrecht RC (1985) Home-range size and use and territorial behavior in the common marmoset, Callithrix jacchus jacchus, at the Tapacura field station, Recife, Brazil. Int J Primatol 6:533-550

Huck M, Fernandez-Duque E, Babb P, et al (2014) Correlates of genetic monogamy in socially monogamous mammals: insights from Azara's owl monkeys. Proc R Soc B 281:20140195

Huck M, Heymann EW, Löttker P (2004a) The many faces of helping: possible costs and benefits of infant carrying and food transfer in wild moustached tamarins (Saguinus mystax). Behaviour 141:915-934

Huck M, Löttker P, Böhle UR, et al (2005a) Paternity and kinship patterns in polyandrous moustached tamarins (Saguinus mystax). Am J Phys Anthropol 127:449-464

Huck M, Löttker P, Heymann EW, et al (2004b) Aspects of the behavioral and endocrine ontogeny of six moustached tamarins, Saguinus mystax (Callitrichinae). Neotrop Primates 12:131-135

Huck M, Löttker P, Heymann EW, et al (2005b) Characterization and social correlates of fecal testosterone and cortisol excretion in wild male Saguinus mystax. Int J Primatol 26:159-179

Huck M, Löttker P, Heymann EW (2004c) Proximate mechanisms of reproductive monopolization in male moustached tamarins (Saguinus mystax). Am J Primatol 64:39-56

Jamieson IG, Craig JL (1987) Critique of helping behavior in birds: a departure from functional explanations. In: Bateson PPG, Klopfer PH (eds) Perspectives in ethology. Springer, Boston, pp 79-98

Jones O, Wang J (2010) COLONY: a program for parentage and sibship inference frommultilocus genotype data. Mol Ecol Resour 10:551-555 
Kalinowski ST, Taper ML, Marshall TC (2007) Revising how the computer program CERVUS accommodates genotyping error increases success in paternity assignment. Mol Ecol 16:1099-1106

Kappeler PM, van Schaik CP (2002) Evolution of primate social systems. Int J Primatol 23:707-740

Keller L (1997) Indiscriminate altruism: Unduly nice parents and siblings. Trends Ecol Evol 12:99-103

Kesteren F, Paris M, Macdonald DW, et al (2013) The physiology of cooperative breeding in a rare social canid; sex, suppression and pseudopregnancy in female Ethiopian wolves. Physiol Behav 122:39-45

Kleiman DG, Malcolm JR (1981) The evolution of male parental investment in mammals. In: Gubernick DJ, Klopfer PH (eds) Parental care in mammals. Plenum Press, New York, pp 347-387

Knogge C, Heymann EW (2003) Seed dispersal by sympatric tamarins, Saguinus mystax and Saguinus fuscicollis: diversity and characteristics of plant species. Folia Primatol 74:33-47

Knox KL (1989) Observations on dominance relations among Saguinus imperator, the emperor tamarin (family: Callitrichidae). PhD thesis, Northwestern University, Evanston

Koenig A (1995) Group size, composition, and reproductive success in wild common marmosets (Callithrix jacchus). Am J Primatol 35:311-317

Koenig W, Dickinson J (eds) (2004) Ecology and evolution of cooperative breeding in birds. Cambridge University Press, Cambridge

Komdeur J, Richardson DS, Hatchwell B (2008) Kin-recognition mechanisms in cooperative breeding systems: ecological causes and behavioral consequences of variation. In: Korb J, Heinze J (eds) Ecology of social evolution. Springer, Berlin, Heidelberg, pp 175-193 


\section{References}

Kullberg C, Angerbjörn A (1992) Social behaviour and cooperative breeding in arctic foxes, Alopex lagopus (L.), in a semi-natural environment. Ethology 90:321-335

Kutsukake N, Nunn CL (2006) Comparative tests of reproductive skew in male primates: the roles of demographic factors and incomplete control. Behav Ecol Sociobiol $60: 695-706$

Lappan S (2008) Male care of infants in a siamang (Symphalangus syndactylus) population including socially monogamous and polyandrous groups. Behav Ecol Sociobiol 62:1307-1317

Leadbeater E, Carruthers JM, Green JP, et al (2010) Unrelated helpers in a primitively eusocial wasp: is helping tailored towards direct fitness? PLoS One 5:e11997

Leclaire S, Nielsen JF, Thavarajah NK, et al (2013) Odour-based kin discrimination in the cooperatively breeding meerkat. Biol Lett 9:

Lledo-Ferrer Y, Hidalgo A, Heymann EW, et al (2009) Field observation of predation of a slate-colored hawk, Leucopternis schistacea, on a juvenile saddle-back tamarin, Saguinus fuscicollis. Neotrop Primates 16:82-84

Lledo-Ferrer Y, Pelaez F, Heymann EW (2010) Can overmarking be considered as a means of chemical mate guarding in a wild callitrichid? Folia Primatol 81:200-206

Lledo-Ferrer Y, Pelaez F, Heymann EW (2011) The equivocal relationship between territoriality and scent marking in wild saddleback tamarins (Saguinus fuscicollis). Int J Primatol 32:974-991

Lledo Ferrer Y (2010) Functions of olfactory communication in wild saddleback tamarins, Saguinus fuscicollis. PhD thesis, Universidad Autónoma de Madrid

Löttker P, Huck M, Heymann EW (2004a) Demographic parameters and events in wild moustached tamarins (Saguinus mystax). Am J Primatol 64:425-449

Löttker P, Huck M, Heymann EW, et al (2004b) Endocrine correlates of reproductive status in breeding and nonbreeding wild female. Int J Primatol 25:919-937 
Lynch JW, Ziegeler TE, Strier KB (2002) Individual and seasonal variation in fecal testosterone and cortisol levels of wild male tufted capuchin monkeys, Cebus apella nigritus. Horm Behav 41:275-287

Mardis ER (2008) Next-generation DNA sequencing methods. Annu Rev Genomics Hum Genet 9:387-402

Martin PR, Bateson PPG (2007) Measuring behaviour: an introductory guide, 3rd edn. Cambridge University Press, New York

Maynard Smith J (1977) Parental investment: a prospective analysis. Anim Behav 25:1-9

Mendoza S, Mason W (1986) Parenting within a monogamous society. In: Else J., Lee PC (eds) Primate ontogeny, cognition and social behaviour. Cambridge University Press, New York, pp 255-266

Mendoza SP, Smotherman WP, Miner MT, et al (1978) Pituitary-adrenal response to separation in mother and infant squirrel monkeys. Dev Psychobiol 11:169-175

Moberg GP, Mench JA (eds) (2000) The biology of animal stress: basic principles and implications for animal. CABI Publishing, Wallingford

Morcillo A, Sánchez S, Fidalgo A, et al (2003) Effects of enclosure size on weight loss after the birth of infants in cotton-top tamarins (Saguinus oedipus). In: Schwibbe M (ed) Primate report 66-1. Deutsches Primatenzentrum, Göttingen, pp 32-33

Moynihan M (1970) Some behavior patterns of platyrrhine monkeys: II. Saguinus geoffroyi and some other tamarins. Smithson Contrib Zool 28:1-77

Muller M, Emery Thompson M (2012) Mating parenting and male reproductive strategies. In: Mitani J, Call J, Kappeler P, et al. (eds) The evolution of primate societies. University of Chicago Press, Chicago, pp 387-411

Muller MN, Wrangham RW (2004a) Dominance, aggression and testosterone in wild chimpanzees: a test of the "challenge hypothesis." Anim Behav 67:113-123 


\section{References}

Muller MN, Wrangham RW (2004b) Dominance, cortisol and stress in wild chimpanzees (Pan troglodytes schweinfurthii). Behav Ecol Sociobiol 55:332-340

Nadjafzadeh MN, Heymann EW (2008) Prey foraging of red titi monkeys, Callicebus cupreus, in comparison to sympatric tamarins, Saguinus mystax and Saguinus fuscicollis. Am J Phys Anthropol 135:56-63

Nichols HJ, Amos W, Cant MA, et al (2010) Top males gain high reproductive success by guarding more successful females in a cooperatively breeding mongoose. Anim Behav 80:649-657

Nickle DA, Heymann EW (1996) Predation on Orthoptera and other orders of insects by tamarin monkeys, Saguinus mystax mystax and Saguinus fuscicollis nigrifrons (Primates: Callitrichidae), in north-eastern Peru. J Zool 239:799-819

Nievergelt CM, Digby $\amalg$, Ramakrishnan U, et al (2000) Genetic analysis of group composition and breeding system in a wild common marmoset (Callithrix jacchus) population. Int J Primatol 21:1-20

Nievergelt CM, Mundy NI, Woodruff DS (1998) Microsatellite primers for genotyping common marmosets (Callithrix jacchus) and other callitrichids. Mol Ecol 7:1432-1434

Nishida T (1983) Alpha status and agonistic alliance in wild chimpanzees (Pan troglodytes schweinfurthii). Primates 24:318-336

Nunes S, Fite JE, Patera KJ, et al (2001) Interactions among paternal behavior, steroid hormones, and parental experience in male marmosets (Callithrix kuhlii). Horm Behav 39:70-82

Nunn CL (1999) The evolution of exaggerated sexual swellings in primates and the gradedsignal hypothesis. Anim Behav 58:229-246

Nyakatura JA, Heymann EW (2010) Effects of support size and orientation on symmetric gaits in free-ranging tamarins of Amazonian Peru: implications for the functional significance of primate gait sequence patterns. J Hum Evol 58:242-251 
Ochi H (1993) Mate monopolization by a dominant male in a multi-male social group of a mouthbrooding cichlid, Ctenochromis horei. Japanese J Ichthyol 40:209-218

Oftedal OT (1984) Milk composition, milk yield, and energy output at peak lactation: a comparative review. Symp Zool Soc London 51:33-85

Orr HA (2009) Fitness and its role in evolutionary genetics. Nat Rev Genet 10:531-539

Oversluijs Vasquez MR, Heymann EW (2001) Crested eagle (Morphnus guianensis) predation on infant tamarins (Saguinus mystax and Saguinus fuscicollis, Callitrichinae). Folia Primatol 72:301-303

Palme R, Möstl E (1997) Measurement of cortisol metabolites in faeces of sheep as a parameter of cortosol concentration in blood. Zeitschrift Für Säugetierkunde Int J Mamm Biol 62, Suppl:192-197

Peres CA (1993a) Diet and feeding ecology of saddle-back (Saguinus fuscicollis) and moustached (S. mystax) tamarins in an Amazonian terra firme forest. J Zool 230:567592

Peres CA (1993b) Anti-predation benefits in a mixed-species group of Amazonian tamarins. Folia Primatol 61:61-76

Porter LM (2001) Dietary differences among sympatric Callitrichinae in northern Bolivia: Callimico goeldii, Saguinus fuscicollis and S. labiatus. Int J Primatol 22:961-992

Preston BT, Stevenson IR, Pemberton JM, et al (2001) Dominant rams lose out by sperm depletion. Nature 409:681-682

Price EC (1992) The costs of infant carrying in captive cotton-top tamarins. Am J Primatol 26:23-33

Price EC (1990) Infant carrying as a courtship strategy of breeding male cotton-top tamarins. Anim Behav 40:1689-1699

Pryce CR (1988) Individual and group effects on early caregiver-infant relationships in redbellied tamarin monkeys. Anim Behav 36:1455-1464 


\section{References}

Queller DC, Zacchi F, Cervo R, et al (2000) Unrelated helpers in a social insect. Nature 405:784-787

Raulo A, Dantzer B (2018) Associations between glucocorticoids and sociality across a continuum of vertebrate social behaviour. Ecol Evol 8:7697-7716

Riley EP, Mackinnon KC, Fernandez-Duque E, et al (2014) Code of best practices for field primatology. International Primatological Society and American Society of Primatologists Steering Committee

Rimbach R, Heymann EW, Link A, et al (2013) Validation of an enzyme immunoassay for assessing adrenocortical activity and evaluation of factors that affect levels of fecal glucocorticoid metabolites in two New World primates. Gen Comp Endocrinol 191:13-23

Ritchey RL, Hennessy MB (1987) Cortisol and behavioral responses to separation in mother and infant guinea pigs. Behav Neural Biol 48:1-12

Roberts SC, Dunbar RIM (2000) Female territoriality and the function of scent-marking in a monogamous antelope (Oreotragus oreotragus). Behav Ecol Sociobiol 47:417-423

Rotundo M, Fernandez-Duque E, Dixson AF (2005) Infant development and parental care in free-ranging Aotus azarai azarai in Argentina. Int J Primatol 26:1459-1473

Rousset F (2008) GENEPOP'007: A complete re-implementation of the GENEPOP software for Windows and Linux. Mol Ecol Resour 8:103-106

Rousset F, Roze D (2007) Constraints on the origin and maintenance of genetic kin recognition. Evolution 61:2320-2330

Rowell TE (1993) Reification of social systems. Evol Anthropol 2:135-137

Russell AF, Brotherton PNM, Mcllrath GM, et al (2003) Breeding success in cooperative meerkats: effects of helper number and maternal state. Behav Ecol 14:486-492

Rylands AB, Heymann EW, Alfaro JL, et al (2016) Taxonomic review of the New World tamarins (Primates: Callitrichidae). Zool J Linn Soc 177:1003-1028 
Sánchez S, Peláez F, Gil-Bürmann C, et al (1999) Costs of infant-carrying in the cotton-top tamarin (Saguinus oedipus). Am J Primatol 48:99-111

Santema P, Clutton-Brock T (2013) Meerkat helpers increase sentinel behaviour and bipedal vigilance in the presence of pups. Anim Behav 85:655-661

Sapolsky RM, Romero LM, Munck AU (2000) How do glucocorticoids influence stress responses? Integrating permissive, suppressive, stimulatory, and preparative actions. Endocr Rev 21:55- 89

Savage A, Snowdon CT, Giraldo LH, et al (1996) Parental care patterns and vigilance in wild cotton-top tamarins (Saguinus oedipus). In: Norconk MA, Rosenberger AL, Garber PA (eds) Adaptive radiations of neotropical primates. Plenum Press, New York, pp 187199

Schaffner CM, French JA (1997) Group size and aggression: "recruitment incentives" in a cooperatively breeding primate. Anim Behav 54:171-180

Schenker N, Gentleman JF (2001) On judging the significance of differences by examining the overlap between confidence intervals. Am Stat 55:182-186

Schradin C, Anzenberger G (2001a) Costs of infant carrying in common marmosets, Callithrix jacchus: an experimental analysis. Anim Behav 62:289-295

Schradin C, Anzenberger G (1999) Prolactin, the hormone of paternity. News Physiol Sci $14: 223-231$

Schradin C, Anzenberger G (2001b) Infant carrying in family groups of Goeldi's monkeys (Callimico goeldii). Am J Primatol 53:57-67

Shahuano Tello N, Huck M, Heymann EW (2002) Boa constrictor attack and group defense in moustached tamarins (Saguinus mystax). Folia Primatol 73:146-148

Smiseth PT, Kölliker M, Royle NJ (2012) What is parental care? In: Royle NJ, Smiseth PT, Kölliker M (eds) The evolution of parental care. Oxford University Press, Oxford, pp $1-17$ 
Smith AC, Tirado Herrera ER, Buchanan-Smith HM, et al (2001) Multiple breeding females and allo-nursing in a wild group of moustached tamarins (Saguinus mystax). Neotrop Primates 9:67-69

Smith JE, Monclús R, Wantuck D, et al (2012) Fecal glucocorticoid metabolites in wild yellow-bellied marmots: experimental validation, individual differences and ecological correlates. Gen Comp Endocrinol 178:417-426

Smith TE, French JA (1997) Social and reproductive conditions modulate urinary cortisol excretion in black tufted-ear marmosets (Callithrix kuhli). Am J Primatol 42:253-267

Smuts B, Gubernick DJ (1992) Male-infant relationships in nonhuman primates: paternal investment or mating effort? In: Hewlett B (ed) Father-child Relations: cultural and biosocial contexts. Aldine de Gruyter, Hawthorne, pp 1-30

Snowdon C, Soini P (1988) The tamarins, genus Saguinus. In: Mittermeier RA, Rylands AB, Coimbra-Filho AF, et al. (eds) Ecology and behavior of neotropical primates, 2 nd edn. World Wildlife Fund, Washington D.C., pp 223-298

Soini P (1987) Ecology of the saddle-back tamarin Saguinus fuscicollis illigeri on the Rio Pacaya, northeastern Peru. Folia Primatol 49:11-32

Solomon NG, French JA (eds) (1997) Cooperative breeding in mammals. Cambridge University Press, Cambridge

Sparkman AM, Adams JR, Steury TD, et al (2010) Direct fitness benefits of delayed dispersal in the cooperatively breeding red wolf Canis rufus. Behav Ecol 22:199-205

Spée M, Beaulieu M, Dervaux A, et al (2010) Should I stay or should I go? Hormonal control of nest abandonment in a long-lived bird, the Adélie penguin. Horm Behav 58:762768

Spée M, Marchal L, Lazin D, et al (2011) Exogenous corticosterone and nest abandonment: a study in a long-lived bird, the Adélie penguin. Horm Behav 60:362-370 
Stojan-Dolar M, Heymann EW (2010) Vigilance in a cooperatively breeding primate. Int J Primatol 31:95-116

Suárez SS (2007) Paternity, relatedness, and socio-reproductive behavior in a population of wild red-bellied tamarins (Saguinus labiatus). PhD thesis, New York University, New York

Surbeck M, Mundry R, Hohmann G (2011) Mothers matter! Maternal support, dominance status and mating success in male bonobos (Pan paniscus). Proc R Soc B 278:590598

Svensson I (1988) Reproductive costs in two sex-role reversed pipefish species (Syngnathidae). J Anim Ecol 57:929-942

Taborsky M (1984) Broodcare helpers in the cichlid fish Lamprologus brichardi: their costs and benefits. Anim Behav 32:1236-1252

Tardif SD (1994) Relative energetic cost of infant care in small-bodied neotropical primates and its relation to infant-care patterns. Am J Primatol 34:133-143

Tardif SD, Bales K (1997) Is infant-carrying a courtship strategy in callitrichid primates? Anim Behav 53:1001-1007

Tardif SD, Carson R, Gangaware B (1992) Infant-care behavior of non-reproductive helpers in a communal-care primate, the cotton-top tamarin (Saguinus oedipus). Ethology 92:155-167

Tardif SD, Harrison ML, Simek MA (1993) Communal infant care in marmosets and tamarins: relation to energetics, ecology, and social organization. In: Rylands $A B$ (ed) Marmosets and tamarins: systematics, behavior and ecology. Oxford University Press, Oxford, pp 220-234

Terborgh J (1983) Five new world primates: a study in comparative ecology. Princeton University Press, Princeton 


\section{References}

Terborgh J, Goldizen AW (1985) On the mating system of the cooperatively breeding saddle-backed tamarin (Saguinus fuscicollis). Behav Ecol Sociobiol 16:293-299

Thornhill R, Alcock J (1983) The evolution of insect mating systems. Harvard University Press, Cambridge

Tinbergen JM, Verhulst S (2000) A fixed energetic ceiling to parental effort in the great tit? J Anim Ecol 69:323-334

Tirado Herrera ER, Knogge C, Heymann EW (2000) Infanticide in a group of wild saddleback tamarins, Saguinus fuscicollis. Am J Primatol 50:153-157

Treves A (1998) The influence of group size and neighbors on vigilance in two species of arboreal monkeys. Behaviour 135:453-481

Trivers RL (1972) Parental investment and sexual selection. In: Campbell B (ed) Sexual selection and the descent of man, 1871 - 1971. Aldine, Chicago, pp 136-179

van Noordwijk MA (2012) From maternal investment to lifetime maternal care. In: Mitani JC, Call J, Kappeler PM, et al. (eds) The evolution of primate societies. The University of Chicago Press, Chicago, pp 321-342

Vogt JL (1978) The social behavior of a marmoset (Saguinus fuscicollis) group II: behavior patterns and social interaction. Primates 19:287-300

Waldman B, Frumhoff PC, Sherman PW (1988) Problems of kin recognition. Trends Ecol Evol 3:8-13

Washabaugh K, Snowdon CT (1998) Chemical communication of reproductive status in female cotton-top tamarins (Saguinus oedipus oedipus). Am J Primatol 4:337-349

Whitten PL (1987) Infants and adult males. In: Smuts BB, Cheney DL, Seyfarth RM, et al. (eds) Primate societies. University of Chicago Press, Chicago, pp 343-357

Wiener SG, Johnson DF, Levine S (1987) Influence of postnatal conditions on the response of squirrel monkey infants to brief perturbations in mother-infant relationships. Physiol Behav 39:21-26 
Williams TD (1994) Intraspecific variation in egg size and egg composition in birds: effects on offspring fitness. Biol Rev 69:35-59

Willner P (1993) Animal models of stress: an overview. In: Stanford SC, Salmon P (eds) Stress: from synapse to syndrome. Academic Press, San Diego, pp 145-166

Windfelder (2000) Observations on the birth and subsequent care of twin offspring by a lone pair of wild emperor tamarins (Saguinus imperator). Am J Primatol 52:107-113

Wingfried JC, Sapolsky RM (2003) Reproduction and resistance to stress: when and how. J Neuroendocrinol 15:711-724

Wood SN (2004) Stable and efficient multiple smoothing parameter estimation for generalized additive models. J Am Stat Assoc 99:673-686

WorldWeatherOnline.com (2018) Tamshiyacu historical weather: yearly averages. https://www.worldweatheronline.com/tamshiyacu-weatherhistory/loreto/pe.aspx. Accessed 5 Dec 2018

Wright PC (1984) Biparental care in Aotus trivirgatus and Callicebus moloch. In: Small MF (ed) Female primates: studies by women primatologists. Alan R. Liss, New York, pp $59-75$

Yamamoto M (1993) From dependence to sexual maturity: the behavioral ontogeny of Callitrichidae. In: Rylands AB (ed) Marmosets and tamarins: systematics, behavior and ecology. Oxford University Press, Oxford, pp 234-254

Yamamoto M, Arruda M, Alencar A, et al (2009) Mating systems and female-female competition in the common marmoset, Callithrix jacchus. In: Ford S, Porter L, Davis L (eds) The smallest anthropoids: the marmoset/callimico radiation. Springer, New York, pp 119-133

Young AJ, Spong G, Clutton-Brock T (2007) Subordinate male meerkats prospect for extragroup paternity: alternative reproductive tactics in a cooperative mammal. Proc $R$ Soc B 274:1603-1609 


\section{References}

Ziegler TE, de Sousa MBC (2002) Parent-daughter relationships and social controls on fertility in female common marmosets, Callithrix jacchus. Horm Behav 42:356-367

Ziegler TE, Epple G, Snowdon CT, et al (1993) Detection of the chemical signals of ovulation in the cotton-top tamarin, Saguinus oedipus. Anim Behav 45:313-322

Ziegler TE, Scheffler G, Snowdon CT (1995) The relationship of cortisol levels to social environment and reproductive functioning in female cotton-top tamarins, Saguinus oedipus. Horm Behav 29:407-424

Ziegler TE, Washabaugh KF, Snowdon CT (2004) Responsiveness of expectant male cottontop tamarins, Saguinus oedipus, to mate's pregnancy. Horm Behav 45:84-92

Ziegler TE, Wittwer DJ (2005) Fecal steroid research in the field and laboratory: improved methods for storage, transport, processing, and analysis. Am J Primatol 67:159-174

Zinner D (1999) Relationship between feeding time and food intake in hamadryas baboons (Papio hamadryas) and the value of feeding time as a predictor of food intake. Zoo Biol 18:495-505 



\section{Appendix A}

\section{Supplementary data for chapter 4}

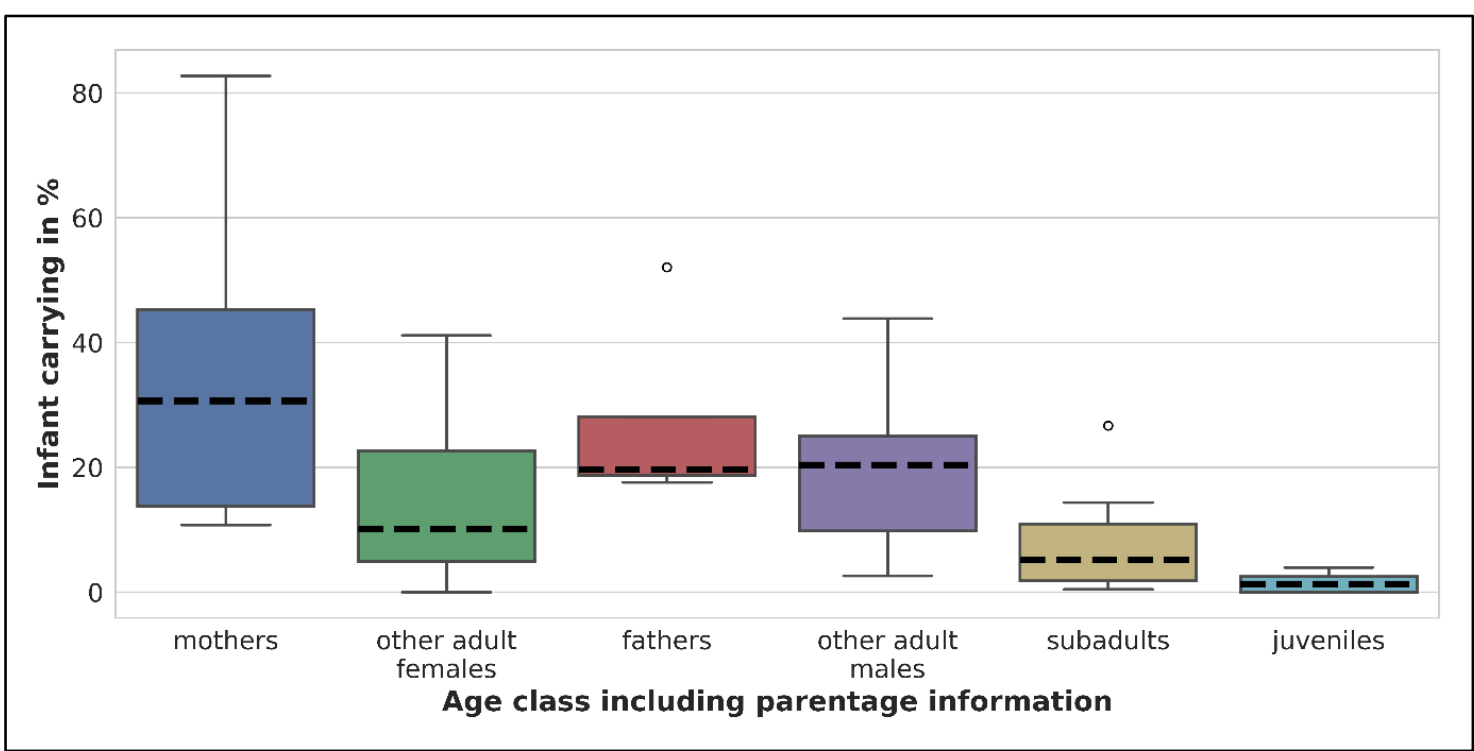

Fig. A-1: Tukey box plot of contribution of different classes of individuals, combining age class with parentage information, related to "infant carrying", based on all eight litters (six litters with complete observation periods (3 months), and two litters with uncomplete observation periods (2 months)). Boxes extend from first quartile to third quartile. The horizontal line within the box represents the median. Whiskers below (above) the box extend to the lowest (highest) data point which is still within 1.5 times the interquartile range (IQR) of the first (third) quartile, where IQR is the difference between third and first quartile. Open circles (O) indicate data points outside the range encompassed by whiskers. 


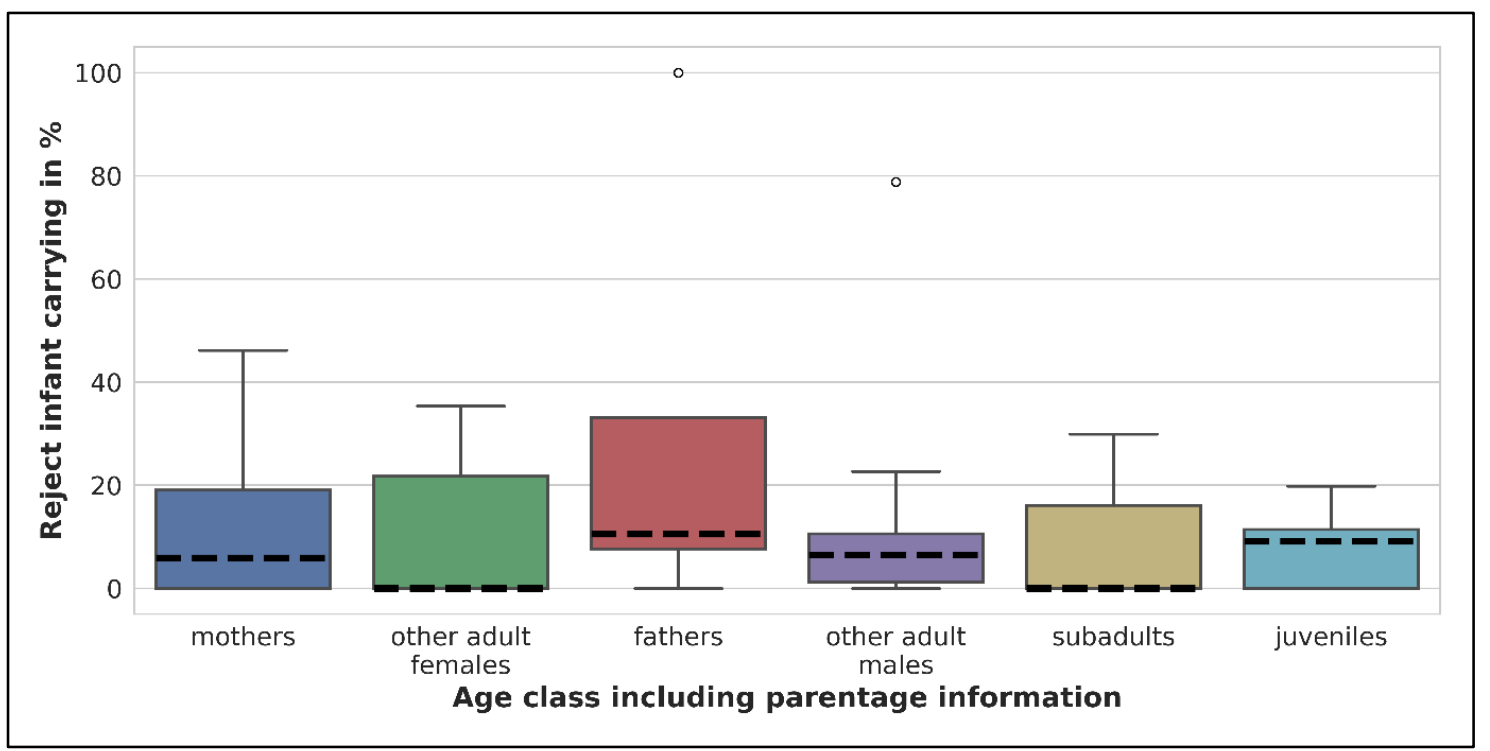

Fig. A-2: Tukey box plot of contribution of different classes of individuals, combining age class with parentage information, related to "reject infant carrying". See Fig. A-1 for further details.

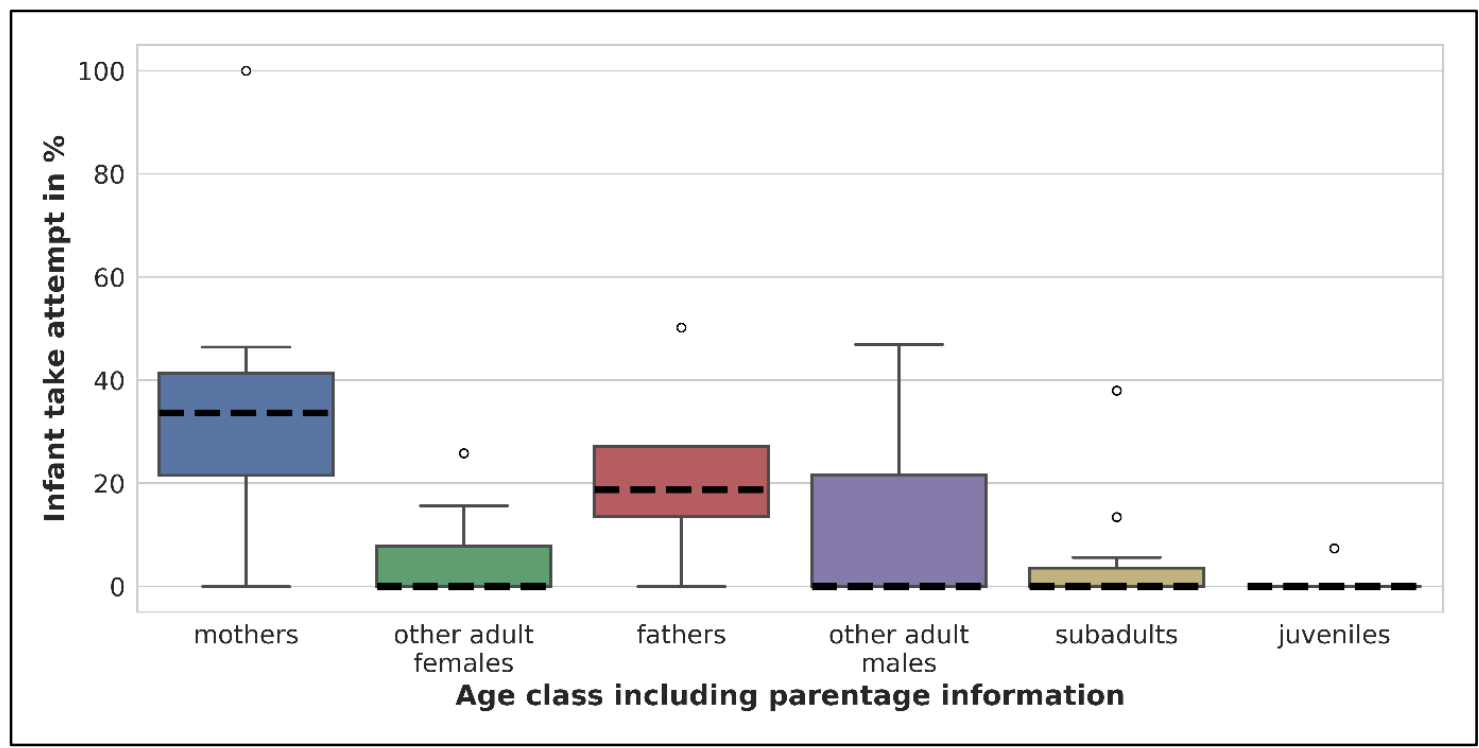

Fig. A-3: Tukey box plot of contribution of different classes of individuals, combining age class with parentage information, related to "infant take attempt". See Fig. A-1 for further details. 


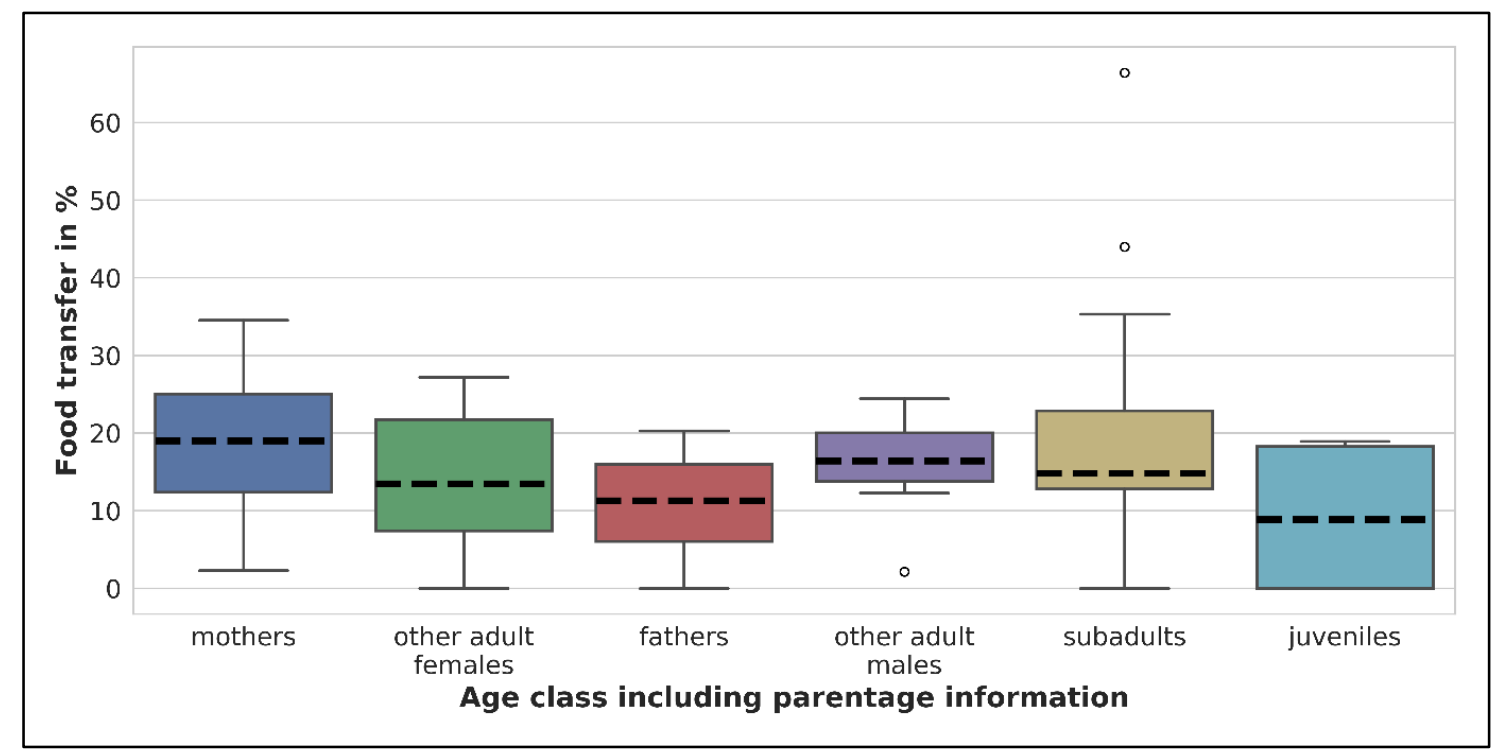

Fig. A-4: Tukey box plot of contribution of different classes of individuals, combining age class with parentage information, related to "food transfer". See Fig. A-1 for further details.

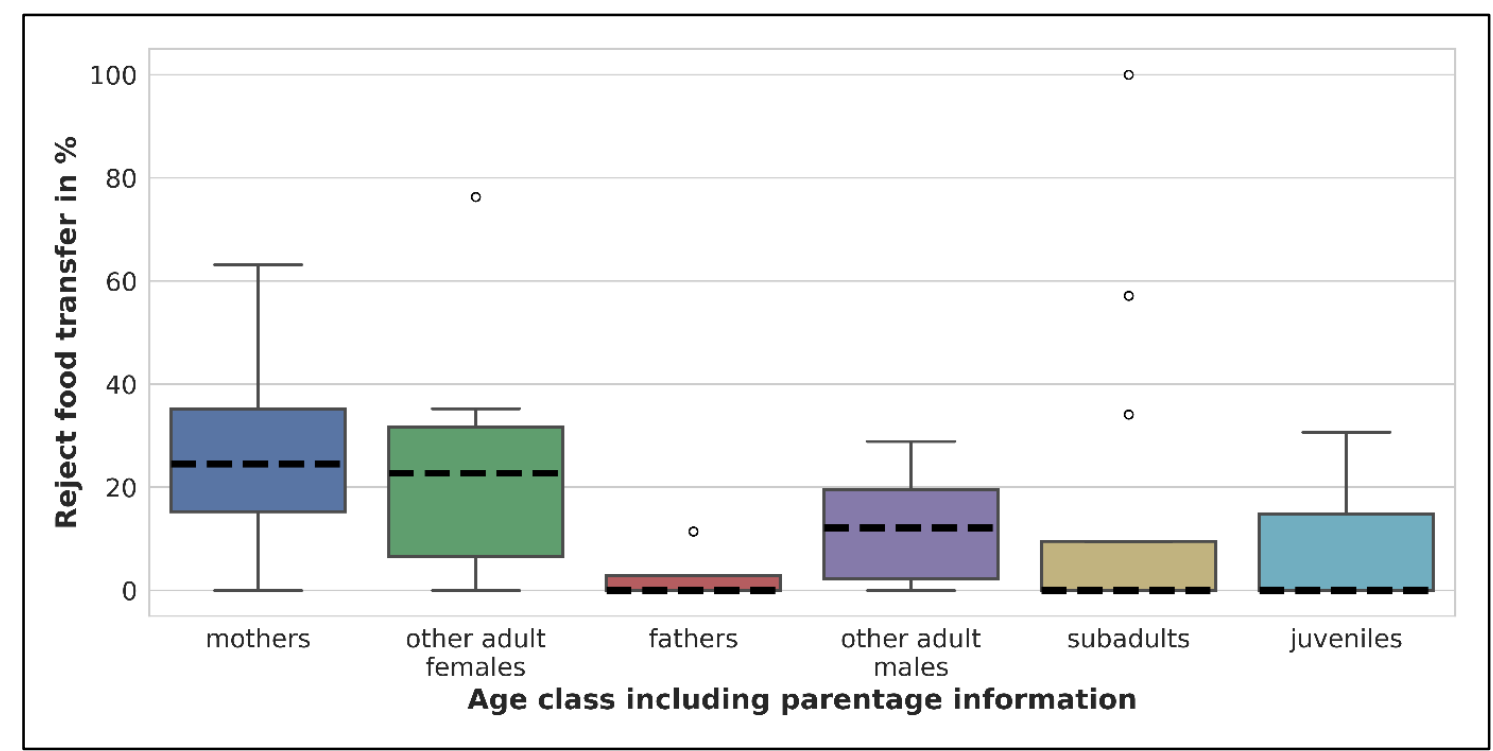

Fig. A-5: Tukey box plot of contribution of different classes of individuals, combining age class with parentage information, related to reject "food transfer". See Fig. A-1 for further details. 
Table A-1: Contribution of infant-directed behavior in A) Gr1 towards litter 1cv and 1cn, B) Gr2 towards litter 2c, C) Gr2 towards litter 2cv, D) Gr3 towards litter 3c, E) Gr3 towards litter $3 \mathrm{cv}$ and $3 \mathrm{cn}, \mathrm{F}) \mathrm{Gr} 5$ towards litter $5 \mathrm{cn}$. The behavior is summed up for each carrying month separately, until the end of the carrying.

\begin{tabular}{|c|c|c|c|c|c|c|c|c|c|c|c|c|c|c|c|}
\hline & A) & & & & & 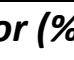 & in & & & & & & & & \\
\hline Care & akers & & & & & 1 & & & & $1 s$ & & & & & \\
\hline & ter & a) & b) & a) & b) & a) & b) & a) & b) & a) & b) & a) & b) & a) & b) \\
\hline Carry & Dec-12 & 59 & NA & 41 & NA & 0 & NA & 0 & NA & 0 & NA & 0 & NA & 0 & NA \\
\hline & Jan-13 & 27 & NA & 60 & NA & 3 & NA & 10 & NA & 0 & NA & 0 & NA & 0 & NA \\
\hline & Feb-13 & 41 & 1 & 46 & 0 & 0 & 86 & 0 & 2 & 3 & 5 & 10 & 6 & 0 & 0 \\
\hline & Mar-13 & 55 & 4 & 24 & 0 & 21 & 85 & 0 & 3 & 0 & 3 & 0 & 1 & 0 & 4 \\
\hline & Apr-13 & 0 & 0 & 0 & 0 & 0 & 36 & 0 & 0 & 100 & 0 & 0 & 0 & 0 & 64 \\
\hline Reject & Dec-12 & 0 & NA & 0 & NA & 0 & NA & 0 & NA & 0 & NA & 0 & NA & 0 & NA \\
\hline carry & Jan-13 & 0 & NA & 0 & NA & 0 & NA & 0 & NA & 0 & NA & 0 & NA & 0 & NA \\
\hline & Feb-13 & 0 & 0 & 0 & 0 & 0 & 15 & 0 & 0 & 0 & 58 & 0 & 27 & 0 & 0 \\
\hline & Mar-13 & 0 & 4 & 65 & 0 & 0 & 67 & 0 & 0 & 0 & 6 & 35 & 0 & 0 & 22 \\
\hline & Apr-13 & 0 & 100 & 0 & 0 & 0 & 0 & 0 & 0 & 100 & 0 & 0 & 0 & 0 & 0 \\
\hline Take & Dec-12 & 54 & NA & 46 & NA & 0 & NA & 0 & NA & 0 & NA & 0 & NA & 0 & NA \\
\hline & Jan-13 & 31 & $\mathrm{NA}$ & 45 & NA & 0 & $\mathrm{NA}$ & 24 & NA & 0 & $\mathrm{NA}$ & 0 & NA & 0 & NA \\
\hline & Feb-13 & 100 & 0 & 0 & 0 & 0 & 100 & 0 & 0 & 0 & 0 & 0 & 0 & 0 & 0 \\
\hline & Mar-13 & 0 & 0 & 0 & 0 & 100 & 0 & 0 & 0 & 0 & 0 & 0 & 0 & 0 & 0 \\
\hline & Apr-13 & 0 & 0 & 0 & 0 & 0 & 0 & 0 & 0 & 0 & 0 & 0 & 0 & 0 & 0 \\
\hline Feed & Dec-12 & 0 & NA & 0 & NA & 0 & NA & 0 & NA & 0 & NA & 0 & NA & 0 & $\mathrm{NA}$ \\
\hline & Jan-13 & 0 & NA & 0 & NA & 0 & NA & 0 & NA & 0 & NA & 0 & NA & 0 & NA \\
\hline & Feb-13 & 0 & 0 & 18 & 0 & 0 & 100 & 0 & 0 & 67 & 0 & 0 & 0 & 15 & 0 \\
\hline & Mar-13 & 8 & 100 & 38 & 0 & 0 & 0 & 18 & 0 & 12 & 0 & 10 & 0 & 14 & 0 \\
\hline & Apr-13 & 0 & 8 & 40 & 9 & 4 & 20 & 11 & 21 & 29 & 41 & 0 & 0 & 15 & 0 \\
\hline Reject & Dec-12 & 0 & NA & 0 & NA & 0 & NA & 0 & NA & 0 & NA & 0 & NA & 0 & $\mathrm{NA}$ \\
\hline & Jan-13 & 0 & NA & 0 & NA & 0 & NA & 0 & NA & 0 & NA & 0 & NA & 0 & NA \\
\hline & Feb-13 & 0 & 0 & 0 & 0 & 0 & 0 & 0 & 0 & 100 & 0 & 0 & 0 & 0 & 0 \\
\hline & Mar-13 & 22 & 100 & 0 & 0 & 34 & 0 & 0 & 0 & 16 & 0 & 28 & 0 & 0 & 0 \\
\hline & Apr-13 & 0 & 22 & 18 & 0 & 20 & 17 & 25 & 4 & 18 & 9 & 19 & 30 & 0 & 18 \\
\hline
\end{tabular}

\section{B) Infant-directed behavior (\%) in Gr2 towards litter 2c}

\begin{tabular}{|c|c|c|c|c|c|c|}
\hline & Caretakers & $\mathbf{2 m 1}$ & $\mathbf{2 m 2}$ & $\mathbf{2 m 3}$ & $\mathbf{2 f 1}$ & $\mathbf{2 f 2}$ \\
\hline \multirow{2}{*}{ Carry } & May-12 & 2 & 6 & 14 & 40 & 36 \\
\cline { 2 - 7 } & Jun-12 & 0 & 0 & 0 & 100 & 0 \\
\hline \multirow{2}{*}{$\begin{array}{c}\text { Reject } \\
\text { carry }\end{array}$} & May-12 & 0 & 0 & 0 & 0 & 0 \\
\cline { 2 - 7 } Take & Jun-12 & 0 & 0 & 0 & 0 & 0 \\
\cline { 2 - 7 } & May-12 & 0 & 0 & 0 & 0 & 0 \\
\hline \multirow{2}{*}{ Feed } & Jun-12 & 0 & 0 & 0 & 0 & 0 \\
\hline \multirow{2}{*}{} & May-12 & 23 & 15 & 21 & 40 & 0 \\
\hline
\end{tabular}




\begin{tabular}{|c|c|c|c|c|c|c|}
\hline \multicolumn{1}{|c|}{ B) Infant-directed behavior (\%) in Gr2 towards litter 2c } \\
\hline & Caretakers & $\mathbf{2 m 1}$ & $\mathbf{2 m 2}$ & $\mathbf{2 m 3}$ & $\mathbf{2 f 1}$ & $\mathbf{2 f 2}$ \\
\hline & Jun-12 & 13 & 13 & 0 & 35 & 39 \\
\hline \multirow{2}{*}{$\begin{array}{c}\text { Reject } \\
\text { feed }\end{array}$} & May-12 & 26 & 6 & 7 & 27 & 34 \\
\cline { 2 - 7 } & Jun-12 & 22 & 23 & 13 & 20 & 22 \\
\hline
\end{tabular}

\begin{tabular}{|c|c|c|c|c|c|c|c|}
\hline \multicolumn{8}{|c|}{ C) Infant-directed behavior (\%) in Gr2 towards litter 2cv } \\
\hline \multicolumn{2}{|c|}{ Caretakers } & $2 m 1$ & $2 m 2$ & $2 \mathrm{f1}$ & $2 f 2$ & $2 \mathrm{j} 1$ & $2 \mathrm{j} 2$ \\
\hline \multirow[t]{4}{*}{ Carry } & Feb-13 & 69 & 6 & 29 & 2 & 0 & 0 \\
\hline & Mar-13 & 29 & 24 & 13 & 39 & 7 & 2 \\
\hline & Apr-13 & 45 & 30 & 9 & 13 & 2 & 0 \\
\hline & May13 & 39 & 0 & 61 & 0 & 0 & 0 \\
\hline \multirow{4}{*}{$\begin{array}{l}\text { Reject } \\
\text { carry }\end{array}$} & Feb-13 & 0 & 0 & 0 & 0 & 0 & 0 \\
\hline & Mar-13 & 0 & 0 & 17 & 62 & 25 & 0 \\
\hline & Apr-13 & 15 & 31 & 17 & 20 & 16 & 0 \\
\hline & May13 & 100 & 0 & 0 & 0 & 0 & 0 \\
\hline \multirow[t]{4}{*}{ Take } & Feb-13 & 20 & 0 & 80 & 0 & 0 & 0 \\
\hline & Mar-13 & 17 & 38 & 17 & 28 & 0 & 0 \\
\hline & Apr-13 & 0 & 0 & 0 & 0 & 0 & 0 \\
\hline & May13 & 0 & 0 & 0 & 0 & 0 & 0 \\
\hline \multirow[t]{4}{*}{ Feed } & Feb-13 & 0 & 0 & 0 & 0 & 0 & 0 \\
\hline & Mar-13 & 0 & 0 & 0 & 0 & 0 & 0 \\
\hline & Apr-13 & 24 & 15 & 16 & 11 & 14 & 20 \\
\hline & May13 & 20 & 11 & 17 & 36 & 9 & 6 \\
\hline \multirow{4}{*}{$\begin{array}{c}\text { Reject } \\
\text { feed }\end{array}$} & Feb-13 & 0 & 0 & 0 & 0 & 0 & 0 \\
\hline & Mar-13 & 0 & 0 & 0 & 100 & 0 & 0 \\
\hline & Apr-13 & 28 & 16 & 41 & 0 & 15 & 0 \\
\hline & May13 & 0 & 0 & 0 & 0 & 0 & 0 \\
\hline
\end{tabular}

\begin{tabular}{|c|c|c|c|c|c|c|c|}
\hline \multicolumn{8}{|c|}{ D) Infant-directed behavior (\%) in Gr3 towards litter 3c } \\
\hline \multicolumn{2}{|c|}{ Caretakers } & $3 \mathrm{~m} 1$ & $3 \mathrm{~m} 2$ & $3 f 1$ & $3 f 2$ & 3sa1 & $3 s a 2$ \\
\hline \multirow[t]{3}{*}{ Carry } & May-12 & 20 & 33 & 12 & 34 & 0 & 1 \\
\hline & Jun-12 & 15 & 14 & 9 & 53 & 6 & 3 \\
\hline & Jul-12 & 16 & 67 & 17 & 0 & 0 & 0 \\
\hline \multirow{3}{*}{$\begin{array}{l}\text { Reject } \\
\text { carry }\end{array}$} & May-12 & 0 & 0 & 6 & 26 & 14 & 53 \\
\hline & Jun-12 & 17 & 9 & 15 & 46 & 0 & 13 \\
\hline & Jul-12 & 0 & 46 & 0 & 54 & 0 & 0 \\
\hline \multirow[t]{3}{*}{ Take } & May-12 & 0 & 0 & 0 & 0 & 0 & 0 \\
\hline & Jun-12 & 0 & 0 & 0 & 0 & 0 & 0 \\
\hline & Jul-12 & 0 & 0 & 0 & 0 & 0 & 0 \\
\hline \multirow[t]{3}{*}{ Feed } & May-12 & 0 & 0 & 85 & 0 & 0 & 15 \\
\hline & Jun-12 & 24 & 22 & 19 & 7 & 12 & 15 \\
\hline & Jul-12 & 30 & 16 & 22 & 19 & 8 & 4 \\
\hline \multirow{3}{*}{$\begin{array}{l}\text { Reject } \\
\text { feed }\end{array}$} & May-12 & 0 & 0 & 0 & 0 & 0 & 0 \\
\hline & Jun-12 & 17 & 12 & 62 & 14 & 0 & 0 \\
\hline & Jul-12 & 24 & 0 & 65 & 0 & 11 & 0 \\
\hline
\end{tabular}




\begin{tabular}{|c|c|c|c|c|c|c|c|c|c|c|c|c|c|c|c|}
\hline \multicolumn{16}{|c|}{ E) Infant-directed behavior (\%) in Gr3 towards litter a) 3cv, b) 3cn } \\
\hline \multirow{2}{*}{\multicolumn{2}{|c|}{$\begin{array}{c}\text { Caretakers } \\
\text { Litter }\end{array}$}} & \multicolumn{2}{|c|}{$3 m 1$} & \multicolumn{2}{|c|}{$3 m 2$} & \multicolumn{2}{|c|}{$3 f 1$} & \multicolumn{2}{|c|}{$3 f 2$} & \multicolumn{2}{|c|}{ 3sa1 } & \multicolumn{2}{|c|}{$3 s a 2$} & \multicolumn{2}{|c|}{$3 \mathbf{j 1}$} \\
\hline & & a) & b) & a) & b) & a) & b) & a) & b) & a) & b) & a) & b) & a) & b) \\
\hline \multirow[t]{7}{*}{ Carry } & Jan-13 & 25 & NA & 4 & NA & 25 & NA & 15 & NA & 22 & NA & 11 & NA & 0 & NA \\
\hline & Feb-13 & 43 & NA & 20 & NA & 12 & NA & 9 & NA & 8 & NA & 8 & NA & 0 & NA \\
\hline & Mar-13 & 41 & $\mathrm{NA}$ & 34 & NA & 2 & NA & 12 & NA & 8 & NA & 2 & NA & 0 & NA \\
\hline & Apr-13 & 0 & NA & 100 & NA & 0 & NA & 0 & NA & 0 & NA & 0 & NA & 0 & NA \\
\hline & May-13 & 0 & 20 & 0 & 19 & 0 & 12 & 0 & 22 & 0 & 14 & 0 & 11 & 0 & 2 \\
\hline & Jun-13 & 0 & 23 & 0 & 28 & 0 & 6 & 0 & 17 & 0 & 11 & 0 & 15 & 0 & 1 \\
\hline & Jul-13 & 0 & 10 & 0 & 13 & 0 & 14 & 0 & 7 & 0 & 27 & 0 & 29 & 0 & 0 \\
\hline \multirow{7}{*}{$\begin{array}{l}\text { Reject } \\
\text { carry }\end{array}$} & Jan-13 & 0 & NA & 0 & NA & 0 & NA & 0 & NA & 0 & NA & 0 & NA & 0 & NA \\
\hline & Feb-13 & 0 & NA & 100 & NA & 0 & NA & 0 & NA & 0 & NA & 0 & NA & 0 & NA \\
\hline & Mar-13 & 21 & NA & 54 & NA & 0 & NA & 0 & NA & 0 & NA & 0 & NA & 25 & NA \\
\hline & Apr-13 & 0 & NA & 46 & NA & 0 & NA & 0 & NA & 54 & NA & 0 & NA & 0 & NA \\
\hline & May-13 & 0 & 17 & 0 & 0 & 0 & 14 & 0 & 38 & 0 & 14 & 0 & 0 & 0 & 18 \\
\hline & Jun-13 & 0 & 7 & 0 & 10 & 0 & 11 & 0 & 29 & 0 & 23 & 0 & 20 & 0 & 0 \\
\hline & Jul-13 & 0 & 9 & 0 & 5 & 0 & 16 & 0 & 17 & 0 & 8 & 0 & 38 & 0 & 7 \\
\hline \multirow[t]{7}{*}{ Take } & Jan-13 & 52 & NA & 0 & NA & 31 & NA & 0 & NA & 0 & NA & 17 & NA & 0 & NA \\
\hline & Feb-13 & 0 & NA & 0 & NA & 0 & NA & 0 & NA & 0 & NA & 0 & NA & 0 & NA \\
\hline & Mar-13 & 0 & NA & 0 & NA & 0 & NA & 0 & NA & 0 & NA & 0 & NA & 0 & NA \\
\hline & Apr-13 & 0 & NA & 0 & NA & 0 & NA & 0 & NA & 0 & NA & 0 & NA & 0 & NA \\
\hline & May-13 & 0 & 17 & 0 & 22 & 0 & 14 & 0 & 35 & 0 & 0 & 0 & 6 & 0 & 6 \\
\hline & Jun-13 & 0 & 0 & 0 & 0 & 0 & 100 & 0 & 0 & 0 & 0 & 0 & 0 & 0 & 0 \\
\hline & Jul-13 & 0 & 0 & 0 & 0 & 0 & 0 & 0 & 0 & 0 & & 0 & 0 & 0 & 0 \\
\hline \multirow[t]{7}{*}{ Feed } & Jan-13 & 0 & NA & 0 & NA & 0 & NA & 0 & NA & 0 & NA & 0 & NA & 0 & NA \\
\hline & Feb-13 & 0 & NA & 0 & NA & 0 & NA & 49 & NA & 0 & NA & 32 & NA & 20 & NA \\
\hline & Mar-13 & 29 & NA & 23 & NA & 5 & NA & 14 & NA & 0 & NA & 22 & NA & 7 & NA \\
\hline & Apr-13 & 0 & NA & 11 & NA & 4 & NA & 47 & NA & 20 & NA & 17 & NA & 0 & NA \\
\hline & May-13 & 15 & 0 & 13 & 10 & 2 & 0 & 31 & 0 & 4 & 0 & 32 & 0 & 4 & 0 \\
\hline & Jun-13 & 11 & 0 & 10 & 0 & 12 & 0 & 45 & 0 & 7 & 0 & 15 & 100 & 0 & 0 \\
\hline & Jul-13 & 9 & 15 & 0 & 0 & 25 & 29 & 35 & 3 & 0 & 15 & 31 & 18 & 0 & 20 \\
\hline \multirow{7}{*}{$\begin{array}{l}\text { Reject } \\
\text { feed }\end{array}$} & Jan-13 & 0 & NA & 0 & NA & 0 & NA & 0 & NA & 0 & NA & 0 & NA & 0 & NA \\
\hline & Feb-13 & 0 & NA & 0 & NA & 0 & NA & 0 & NA & 0 & NA & 0 & NA & 0 & NA \\
\hline & Mar-13 & 0 & NA & 0 & NA & 29 & NA & 73 & NA & 0 & NA & 0 & NA & 0 & NA \\
\hline & Apr-13 & 4 & NA & 20 & NA & 37 & NA & 25 & NA & 0 & NA & 20 & NA & 0 & NA \\
\hline & May-13 & 0 & 0 & 11 & 0 & 10 & 0 & 0 & 0 & 21 & 0 & 21 & 0 & 38 & 0 \\
\hline & Jun-13 & 15 & 0 & 0 & 0 & 11 & 0 & 12 & 0 & 0 & 0 & 62 & 0 & 0 & 0 \\
\hline & Jul-13 & 0 & 0 & 0 & 0 & 100 & 35 & 0 & 0 & 0 & 0 & 0 & 33 & 0 & 31 \\
\hline
\end{tabular}




\begin{tabular}{|c|c|c|c|c|c|c|c|}
\hline \multicolumn{8}{|c|}{ F) Infant-directed behavior (\%) in Gr5 towards litter 5cn } \\
\hline \multicolumn{2}{|c|}{ Caretakers } & $5 \mathrm{~m} 1$ & $5 f 1$ & 5sa1 & $5 s a 2$ & $5 s a 3$ & $5 \mathrm{j1}$ \\
\hline \multirow[t]{4}{*}{ Carry } & Nov-12 & 19 & 46 & 7 & 26 & 1 & 0 \\
\hline & Dec-12 & 14 & 34 & 0 & 28 & 24 & 0 \\
\hline & Jan-13 & 33 & 28 & 32 & 6 & 0 & 0 \\
\hline & Feb-13 & 15 & 54 & 0 & 31 & 0 & 0 \\
\hline \multirow{4}{*}{$\begin{array}{l}\text { Reject } \\
\text { carry }\end{array}$} & Nov-12 & 0 & 0 & 0 & 0 & 0 & 0 \\
\hline & Dec-12 & 0 & 0 & 0 & 0 & 0 & 0 \\
\hline & Jan-13 & 100 & 0 & 0 & 0 & 0 & 0 \\
\hline & Feb-13 & 0 & 100 & 0 & 0 & 0 & 0 \\
\hline \multirow[t]{4}{*}{ Take } & Nov-12 & 18 & 38 & 3 & 36 & 4 & 0 \\
\hline & Dec-12 & 23 & 42 & 0 & 34 & 0 & 0 \\
\hline & Jan-13 & 0 & 0 & 0 & 0 & 0 & 0 \\
\hline & Feb-13 & 0 & 0 & 0 & 0 & 0 & 0 \\
\hline \multirow[t]{4}{*}{ Feed } & Nov-12 & 0 & 0 & 0 & 0 & 0 & 0 \\
\hline & Dec-12 & 0 & 0 & 0 & 0 & 0 & 0 \\
\hline & Jan-13 & 4 & 11 & 9 & 7 & 67 & 0 \\
\hline & Feb-13 & 21 & 79 & 0 & 0 & 0 & 0 \\
\hline \multirow{4}{*}{$\begin{array}{l}\text { Reject } \\
\text { feed }\end{array}$} & Nov-12 & 0 & 0 & 0 & 0 & 0 & 0 \\
\hline & Dec-12 & 0 & 0 & 0 & 0 & 0 & 0 \\
\hline & Jan-13 & 0 & 43 & 0 & 57 & 0 & 0 \\
\hline & Feb-13 & 33 & 0 & 66 & 0 & 0 & 0 \\
\hline
\end{tabular}

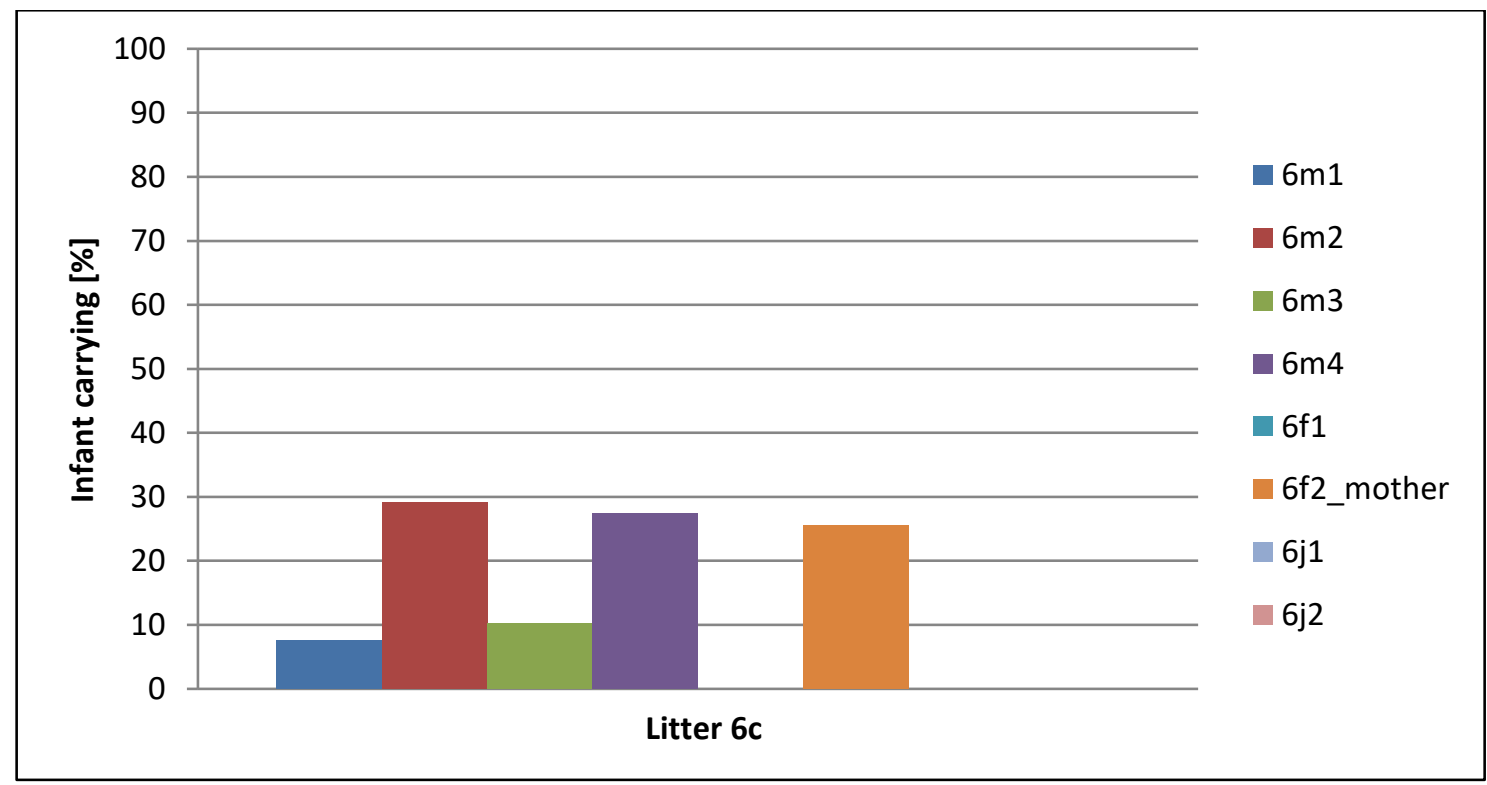

Fig. A-6: Contribution of infant-directed behavior in Gr6, towards litter 6c. Behavior is summed up from the entire infant carrying period of $6 c$ that we could gather: 3 days, starting with the day the litter was born. We observed only one type of infant-directed behavior: "infant carrying". 


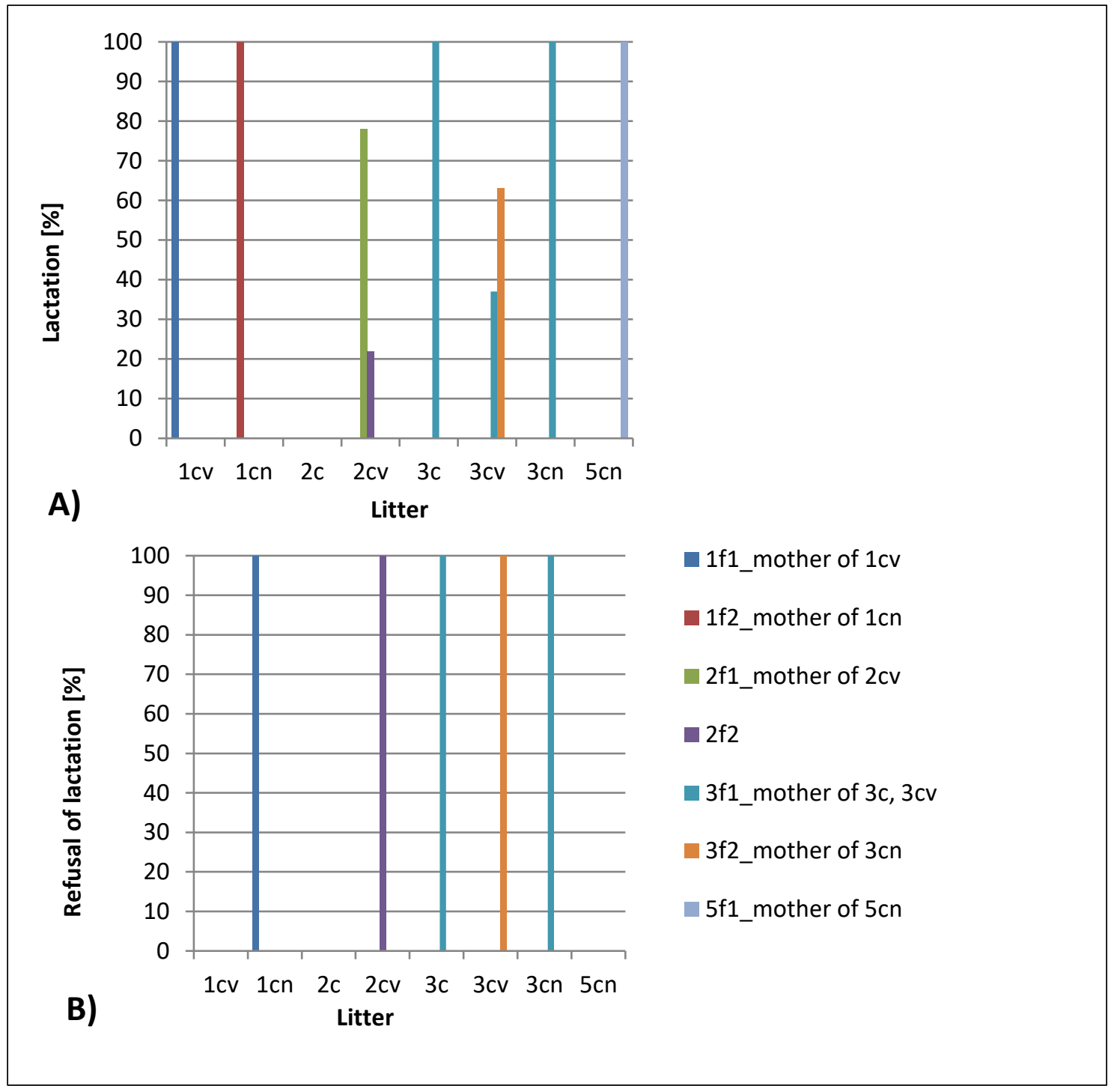

Fig. A-7: Contribution of infant-directed behavior deriving from food transfer: A) lactation $B$ ) refusal of lactation. The behavior is summed up from the entire infant carrying period, 3 months. Percentages calculations are based on all adult females within each group. 


\section{Appendix B}

\section{Supplementary data for chapter 6}

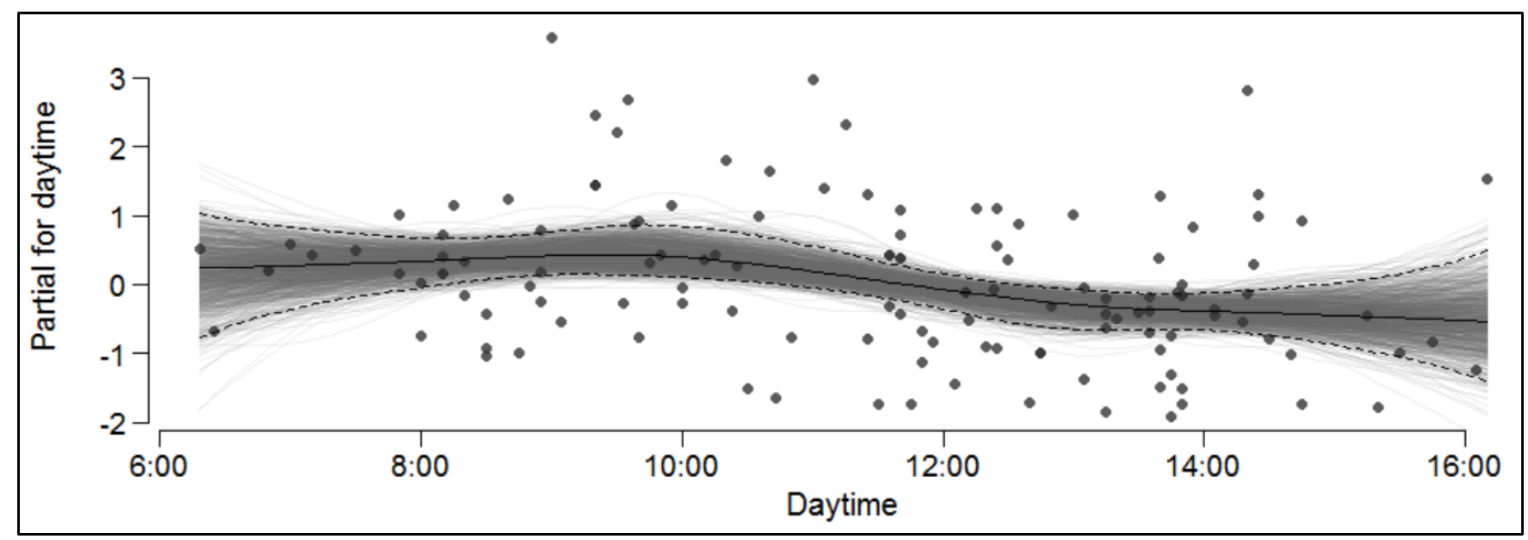

Fig. B-1: Daily fluctuations of cortisol levels of adult males and subadults collected overall the entire study period.

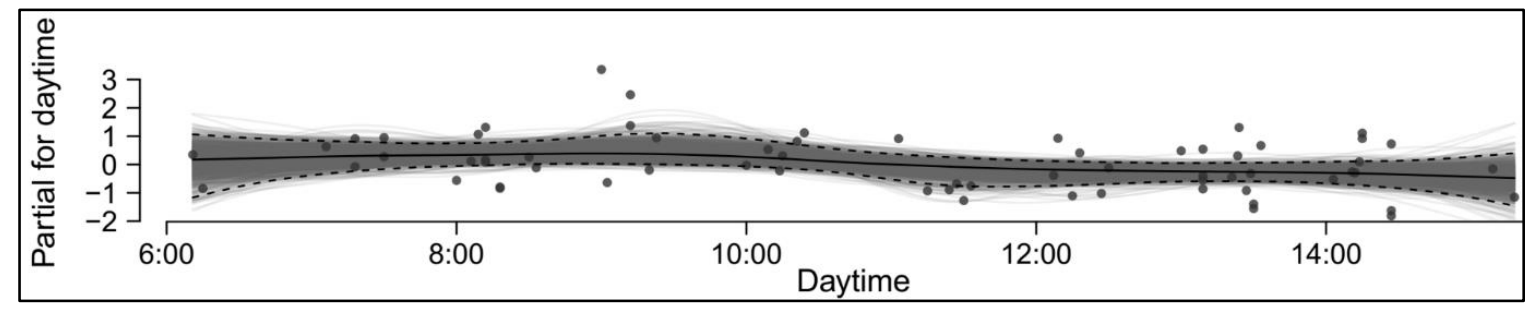

Fig. B-2: Daily fluctuations of cortisol levels of adult males and subadults collected within infant carrying period. 



\section{Acknowledgements}

What a ride! From Europe to South America, from the jungle to the laboratory, from not knowing what a pichico is, to recognizing them individually in the wild. There are numerous people that without their help this project would not be in the current form or would not have happened at all. To start, Mojca Stojan-Dolar, who introduced me into the world of primatology and equipped me with priceless tips. I am deeply grateful to my supervisor Eckhard W. Heymann for giving me the opportunity to conduct this project. Thank you for your guidance and numerous discussions as well as moral support in all stages of this project.

I am thankful to Julia Ostner for being in my thesis committee and for evaluating my thesis. I addition, I am thankful to Julia Fischer for also being in my thesis committee for all these years, as well as I am grateful to Christian Roos, Matthias Waltert and Margarete Boos for agreeing to be part of my examination board. I am grateful to the German Primate Center for the financial and general support over the years, and to Georg-August University School of Science, for accepting me as a doctoral student and for offering me the GAUSS family oriented bridging fund, which was much needed towards the end of the project.

I am grateful to Michael Heistermann, who was supportive from the very beginning of my project, when my knowledge and understanding of hormones was still very limited. Thank you, Andrea Heistermann, for your fast and effective work in the laboratory. I am grateful to Christian Roos for his guidance in matters of genetics and for always being positive, despite the numerous problems with genetic analysis. Thank you, Christiane Schwarz and Christina Glaschke, for helping me analyze the fecal samples from the field and being excellent teachers in the laboratory. I am extremely grateful to Holger Sennhenn-Reulen, for his help with the statistical analysis and for his patience.

I am thankful to all the people from the Sociobiology department. First, Peter Kappeler, who contributed enormously to my project, and to my professional and personal growth. Numerous events, either work to fun related, worked magic in bonding us researchers 
from all over the world. I deeply appreciate the endless conversations and mutual encouragement and moral support of other PhD students who are/were in the same boat. Anna, Hanitra, Thiago, Eva, Omer, Charlotte, Tiziana, Franzi, Klara, Andrea, Flavia, Josue, Andreas and many more. A special thanks to my two special ladies, Hanitra and Anna, who made my office days and life in general full of fun and love. Thank you also Anja and Simon, who made all the bureaucracy look so easy. I am a forever debt to Nicola Campbell, my friend, babysitter, neighbor and ongoing English teacher. Thank you for numerous proof readings of this thesis.

Along this journey I got to meet many wonderful people, who helped shape me into who I am today. A big thank you to all my new friends from various places, but also the old ones that are always there for me. A special thanks to my "Peruvian crew". To Ney and Camilo, who were not just field assistants, but also friends and teachers of the Peruvian culture. To my students, Allison and Jacira, whose dedication to the project undoubtedly improved it in many ways. To Migdonio and Gabriel whose local wisdom never ceased to amaze me. To Carlos, who was happy to share his artistic knowledge. To "cocineras", who's cooking and cleaning made life in the jungle much more pleasant. To the people of Diamante and Chino who open-heartedly invited me to be a part of the local community and to Omer, a companion on this Peruvian adventure.

Most of all, I am grateful to my family, immediate and extended. Mojca, thank you for always recognizing when your big sister needed a listening ear and a push to the right side. Mami and ati, thank you for letting me do things my way, for being patient, for restraining yourselves on numerous occasions, but for always keeping a safety net open. Last but not least, my enormous gratitude goes to my partner Fabian and our little daughter Leila. Fabian, you are my rock in all imaginable ways. Especially thank you for maximizing your paternal care in the last months and keeping me calm. Finally, words cannot express gratefulness of having "moja mala pikica". Leila, you continue to demonstrate what the real costs of parental care are, but also that these are easily overtaken by endless benefits of having you next to me. 
Acknowledgements 



\section{Declaration}

I hereby confirm that this thesis entitled "Mating systems and infant care of cooperatively breeding black-fronted tamarins (Leontocebus nigrifrons)" describes my own work. It was conducted and composed independently, without the use of any utilities other than those indicated in the text.

Göttingen, $25^{\text {th }}$ of February, 2019

Darja Slana 



\section{Curriculum Vitae}

Name:

Darja Slana

Title: Univerzitetna diplomirana biologinja, Profesorica biologije

Date \& Place of Birth:

Nationality:

23. 02. 1983, Ptuj (Slovenia)

Slovene

\section{Finished Education:}

Primary school:

Osnovna Šola Markovci, Markovci, Slovenia (1990 - 1998)

Secondary school:

Gimnazija Ptuj, Ptuj, Slovenia (1998 - 2002)

Diploma study:

Biology, Dept. for Biology, Biotechnical Faculty, University of Ljubljana, Slovenia (2003-2010). Diploma-thesis: "Aspects of hunters and the general towards the possible additional settlement of the Eurasian lynx (Lynx lynx) in Slovenia."

\section{Current Education:}

Doctoral study:

PhD student at the University of Göttingen and the German Primate Center (DPZ) (since 2013). PhD-thesis: "Mating systems and infant care of cooperatively breeding blackfronted tamarins (Leontocebus nigrifrons)."

\section{Past research projects:}

- "Coexistence of species Niphargus timavi and Gammarus fossarum". I was a member of a student research team, studying ecology of amphipod crustaceans. We did a series of field and laboratory observations. Ljubljana, Slovenia (2008).

- "Performing monitoring for ecological state of watercourse in the year 2007, biological part - benthos invertebrates". I did field sampling and sorting of benthos invertebrates. Ljubljana, Slovenia (2008-2009). 
- "Monitoring bat activity with transect method using bat detectors on Ljubljansko barje". I participated in a field research on bat monitoring. Ljubljana, Slovenia (2008-2009).

- "Trees and bats also inhabit Ljubljana". I participated in a field research on bat distribution on trees. Ljubljana, Slovenia (2009).

- "DinaRis". Within that project I conducted my diploma thesis, which was a combination of biology in sociology (human dimensions) on Eurasian lynx (Lynx lynx). Ljubljana, Slovenia (2008 - 2010).

- "The Status and Ecology of the Golden Monkey". Volunteer work on habituation and behavior research project of golden monkeys (Cercopithecus mitis kandi). Mgahinga Gorilla National Park, Uganda (2010 - 2011).

\section{Current research project:}

- "Mating systems and infant care of cooperatively breeding black-fronted tamarins (Leontocebus nigrifrons)." A research project for my PhD-thesis.

\section{Publications:}

- Bavec H., Simona G., Mitja K., Bojan M., Tratar D., Slana D., Kovačec Ž. 2007. Barve plodov: biokemične podobnosti. Collectanea studentium physiologiae plantarum, 2, 2: $9-12$

- Slana, D., 2010. Aspects of hunters and the general public towards the possible additional settlement of the Eurasian Iynx (Lynx lynx) in Slovenia. University of Ljubljana, Biotechnical faculty, Graduation thesis

\section{Other work experience:}

- Museum guide on two exhibitions. National museum of Slovenia, Ljubljana, Slovenia (2010).

- Workshop leader: animal presentations. ZOO Ljubljana, Ljubljana, Slovenia (2010 - 2011).

\section{Personal interests:}

Animal social behavior, nature conservation, travel, sports, family. 